Printed December 1989

\title{
Draft Forecast of the Final Report for the Comparison to 40 CFR Part 191, Subpart B for the Waste Isolation Pilot Plant
}

Sharla G. Bertram-Howery, Melvin G. Marietta, D. R. (Rip) Anderson, Kenneth F. Brinster, Leo S. Gomez, Robert V. Guzowski, Robert P. Rechard

Prepared by

Sandia National Laboratories

Albuquerque, New Mexico 87185 and Livermore, California 94550

for the United States Department of Energy

under Contract DE-AC04-76DP00789

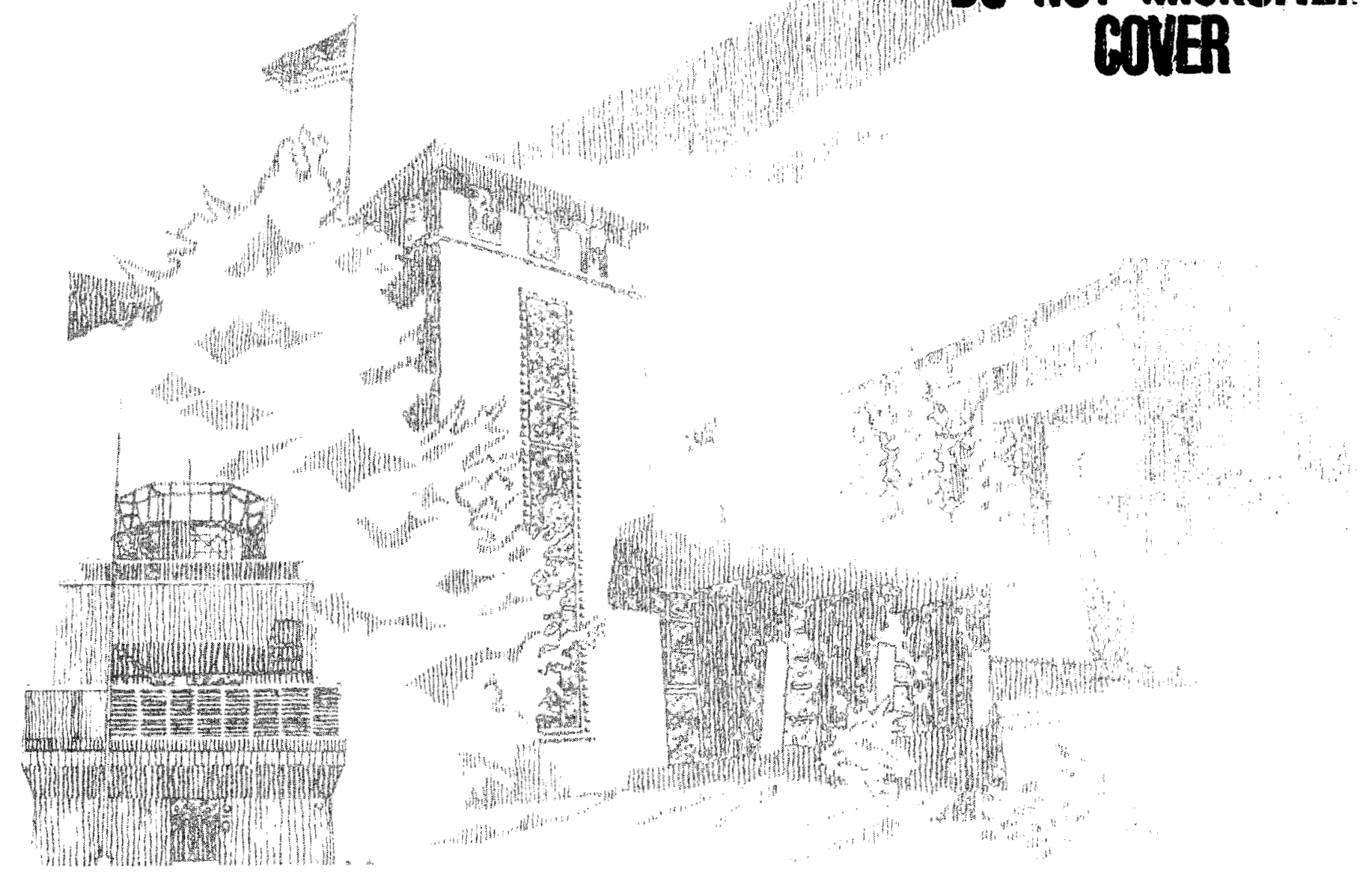




\section{DISCLAIMER}

This report was prepared as an account of work sponsored by an agency of the United States Government. Neither the United States Government nor any agency Thereof, nor any of their employees, makes any warranty, express or implied, or assumes any legal liability or responsibility for the accuracy, completeness, or usefulness of any information, apparatus, product, or process disclosed, or represents that its use would not infringe privately owned rights. Reference herein to any specific commercial product, process, or service by trade name, trademark, manufacturer, or otherwise does not necessarily constitute or imply its endorsement, recommendation, or favoring by the United States Government or any agency thereof. The views and opinions of authors expressed herein do not necessarily state or reflect those of the United States Government or any agency thereof. 


\section{DISCLAIMER}

Portions of this document may be illegible in electronic image products. Images are produced from the best available original document. 
Issued by Sandia National Laboratories, operated for the United States Department of Energy by Sandia Corporation.

NOTICE: This report was prepared as an account of work sponsored by an agency of the United States Government. Neither the United States Government nor any agency thereof, nor any of their employees, nor any of their contractors, subcontractors, or their employees, makes any warranty, express or implied, or assumes any legal liability or responsibility for the accuracy, completeness, or usefulness of any information, apparatus, product, or process disclosed, or represents that its use would not infringe privately owned rights. Reference herein to any specific commercial product, process, or service by trade name, trademark, manufacturer, or otherwise, does not necessarily constitute or imply its endorsement, recommendation, or favoring by the United States Government, any agency thereof or any of their contractors or subcontractors. The views and opinions expressed herein do not necessarily state or reflect those of the United States Government, any agency thereof or any of their contractors.

Printed in the United States of America. This report has been reproduced directly from the best available copy.

Available to DOE and DOE contractors from

Office of Scientific and Technical Information

PO Box 62

Oak Ridge, TN 37831

Prices available from (615) 576-8401, FTS 626-8401

Available to the public from

National Technical Information Service

US Department of Commerce

5285 Port Royal Rd

Springfield, VA 22161

NTIS price codes

Printed copy: A10

Microfiche copy: A01 


\title{
DRAFT FORECAST OF THE FINAL REPORT FOR THE COMPARISON TO 40 CFR PART 191, SUBPART B, FOR THE WASTE ISOLATION PILOT PLANT
}

\author{
Sharla G. Bertram-Howery \\ Melvin G. Marietta \\ D. R. (Rip) Anderson, Kenneth F. Brinster*, \\ Leo S. Gomez, Robert V. Guzowski*, \\ and Robert P. Rechard \\ Sandia National Laboratories \\ Albuquerque, NM 87185
}

\begin{abstract}
The United States Department of Energy (DOE) is planning to dispose of transuranic wastes, which have been generated by defense programs, at the Waste Isolation Pilot Plant (WIPP) near Carlsbad, New Mexico. The WIPP Project will assess compliance with the requirements of the United States Environmental Protection Agency's Standard, Environmental Radiation Protection Standards for the Management and Disposal of Spent Nuclear Fue1, High-Level and Transuranic Radioactive Wastes (40 CFR Part 191). Assessing compliance with the long-term performance criteria of Subpart B of the Standard is a cornerstone of successful implementation of a DOE TRU-waste disposal system.

This report forecasts the planned 1992 document, Comparison to 40 CFR, Part 191, Subpart B, for the Waste Isolation Pilot Plant (WIPP). It has the same format, with the same table of contents. The text is, where available, a preview for 1992. Where not yet available, the text is either preliminary or incomplete. DOE, as the implementing agency for the WIPP under the Standard, is responsible for determining whether the WIPP complies with the four requirements of Subpart B. The 1992 document, which will describe the compliance evaluation process and compare the WIPP's performance with Subpart $B$ of the Standard, will be the quantitative basis for DOE's determination. That report will evolve from this Forecast.
\end{abstract}

* Science Applications International Corporation 


\section{ACKNOWLEDGEMENTS}

The authors wish to acknowledge the research and development work of the scientists and engineers of the Waste Management Technology Department of Sandia National Laboratories who have conducted studies of the Waste Isolation Pilot Plant (WIPP) for over ten years. Their work is fundamental to the assessment of compliance with the EPA Standard, 40 CFR Part 191 Subpart B. Much of the work was conducted prior to the 1985 promulgation of the Standard. Our colleagues have successfully anticipated many of the data and modeling needs for performance assessment. The WIPP performance assessment activity at Sandia was initiated at the beginning of fiscal 1987 by the Department of Energy. As a result, we have found the work completed and ongoing by our colleagues to be invaluable. Because they planned and conducted much of their work in the absence of a Standard, some additional data and models have been defined as necessary to complete the performance assessment. The additional work has been incorporated into their activities and is described in Preliminary Plan for Disposal-System Characterization and Long-Term Performance Evaluation of the Waste Isolation Pilot Plant (Sandia National Laboratories SAND89-0178, April 1989, Bertram-Howery and Hunter, Editors). We are indebted to them for their contributions to our efforts to date, and recognize that the completion of the final performance assessment will depend in large part on their work.

We thank those whose review of earlier drafts provided insight and guidance for this version:

Performance Assessment Peer Review Pane1

G. R. Heath, University of Washington

R. J. Budnitz, Future Resources Associates, Inc.

T. A. Cotton, J. K. Associates

P. A. Domenico, Texas A \& M University

C. J. Mann, University of Illinois

T. H. Pigford, University of California at Berkeley

Sandia National Laboratories

J. E. Campbe11, 6416

R. G. Klett, 6342

The schedule for preparation and production of this Draft Forecast was demanding. We could not have met it without the support of Tech. Reps., Inc. personnel Debra Medina and John Stikar for editing; Darcy Pulliam, Chris Northrop and the Illustration Department for illustration and coordination; Debbie Rivard, Ona Bailey, Theresa Allen and Dolores Miera for word processing, and Debbie Marchand, Debbie Salgado, and the Production Department, all directed by Bob Jones, of the Energy and Waste Management Department. 


\section{PREFACE}

The United States Department of Energy (DOE) is planning to dispose of transuranic (TRU) wastes generated by defense programs at the Waste Isolation Pilot Plant (WIPP) near Carlsbad, New Mexico. The WIPP Project will assess compliance with the requirements of the United States Environmental Protection Agency's (EPA) Standard, Environmental Radiation Protection Standards for the Management and Disposal of Spent Nuclear Fuel, High-Level and Transuranic: Radioactive Wastes (40 CFR Part 191; U.S. EPA, 1985). Assessing compliarce with the long-term performance criteria of Subpart $B$ of the Standard is $a$. cornerstone of successful implementation of a DOE TRU-waste disposal system.

\section{PURPOSE OF THE FORECAST}

This report (to be referred to as the Forecast) forecasts the planned 1992 document, Comparison to 40 CFR Part 191, Subpart B for the WIPP (referred to as the Comparison). It has the same format and the same table of contents. Where results are available, the text is a preview of that for 1992. Where results are not yet available, the text is either preliminary or incomplete. DOE, as the implementing agency for the WIPP under the Standard, is responsible for determining whether the WIPP complies with the four requirements of Subpart B. The 1992 document, which will describe the compliance evaluation process and compare the WIPP's performance with Subpart $B$ of the Standard, will be the quantitative basis for DOE's determination. That report will evolve from this Forecast.

The 1992 Comparison will be without precedent. Therefore, careful planning will be required to assure that the Comparison can be prepared and accepted on time and that it will be adequate to support the determination of compliance and to withstand external challenges. Coordination between the performance assessment team at Sandia National Laboratories; the DOE WIPP Project Office, Albuquerque Operations Office, and Headquarters; the WIPP Panel of the 
National Research Council's Board on Radioactive Waste Management; the New Mexico Environmental Evaluation Group; and the EPA will be necessary if the format and scope are to be agreed upon prior to final preparation of the Comparison, which will start about October 1991. This Forecast is being used as the basis for those interactions.

The Comparison will be reviewed prior to publication by all of the above groups. Responding to comments and revising the report will be necessary before the report can be published. The review may conceivably necessitate additional analyses and incorporation of new data into the Comparison. The review and publication cycle is scheduled to be completed between september 1992 and July 1993; the schedule is too tight to allow rescoping and reformatting the Comparison at that late date. Therefore, this Forecast is published initially as a draft to afford all the review groups the opportunity to assist in establishing the format and scope of the Comparison. 


\section{NOMENCLATURE}

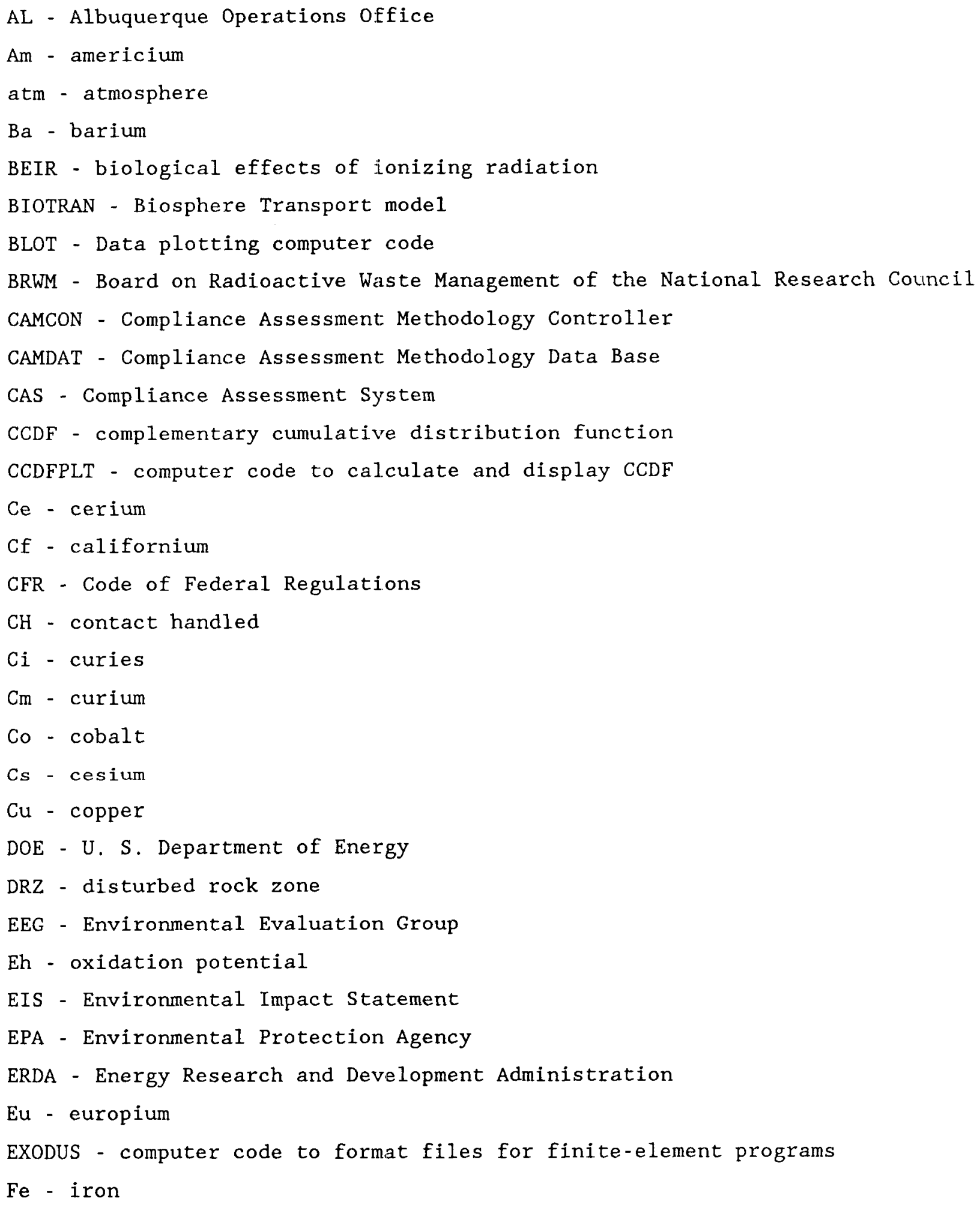


FEIS - Final Environmental Impact Statement

FRP - fiberglass-reinforced plywood

FSAR - Final Safety Analysis Report

$f t$ - foot

gal - gallon

GENESIS - computer code to format files for finite-element programs

GI - gastrointestinal

g - gram

HEPA - high efficiency particulate air (filter)

ICRP - International Commission on Radiological Protection

$\mathrm{kg}$ - kilogram

$\mathrm{km}$ - kilometer

$\ell$ - liter

LHS - Latin hypercube sampling

MB139 - Marker Bed 139

$\mathrm{mg} / \ell$ - milligrams per liter

Mn - manganese

$\mathrm{MPa}$ - megapascal

mrem - millirem

NAS - National Academy of Sciences

nCi - nanocuries

NEA - Nuclear Energy Agency

NEFTRAN - computer model for groundwater flow and radionuclide transport

$\mathrm{Ni}$ - nickel

NM - New Mexico

Np - neptunium

NRC - Nuclear Regulatory Commission

$\mathrm{Pa}$ - Pasca1

$\mathrm{Pb}$ - lead

pdf - probability distribution function

$\mathrm{pH}$ - the negative logarithm of the activity of hydrogen ion

$\operatorname{Pr}$ - praseodymium

$\mathrm{Pu}$ - plutonium

QA - quality assurance

$\mathrm{Ra}$ - radium

Rem - roentgen equivalent man

vi 


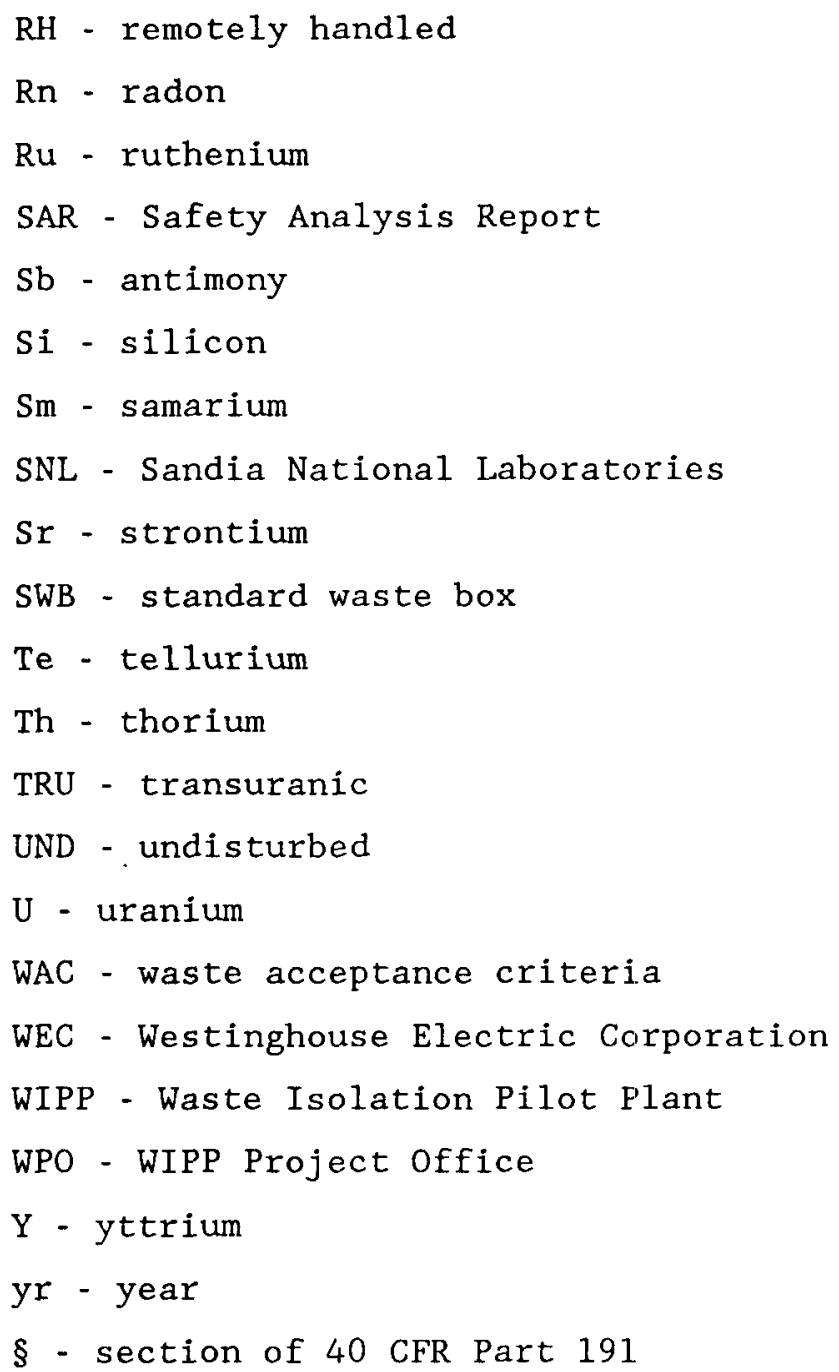




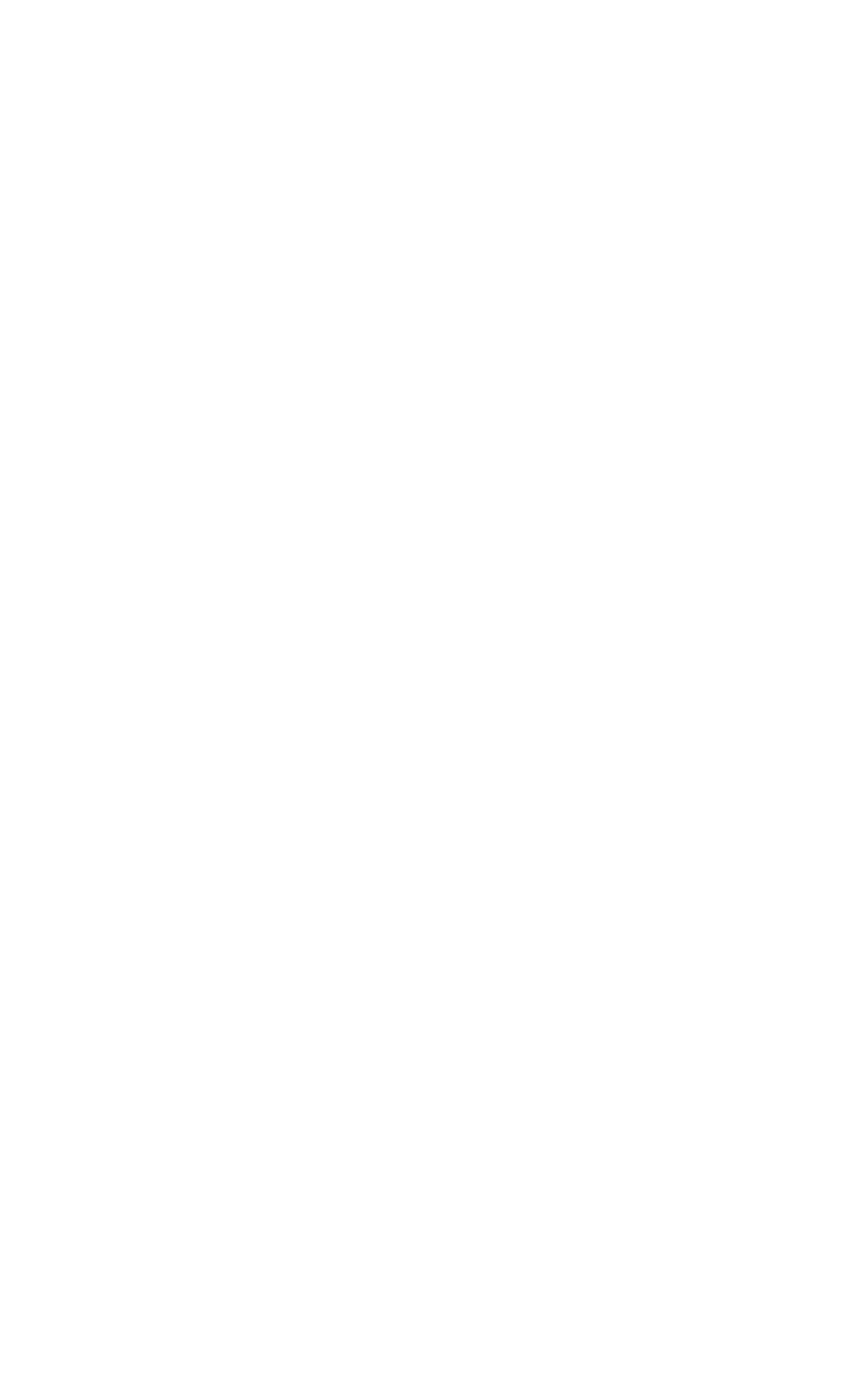
. 


\section{CONTENTS}

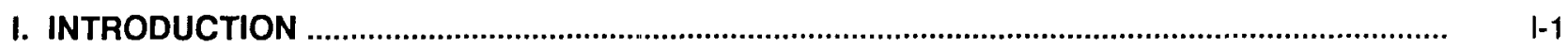

Purpose and Organization of the Comparison.....................................................................

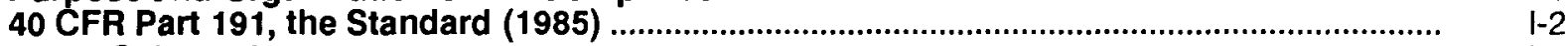

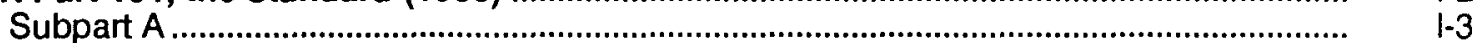

Subpart B …................................................................................................................

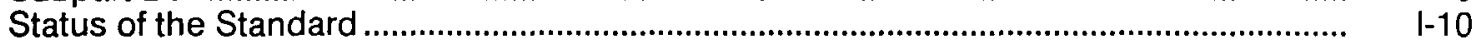

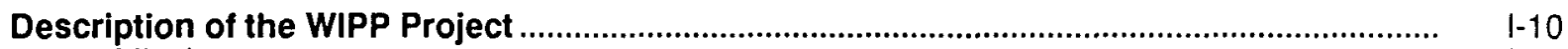

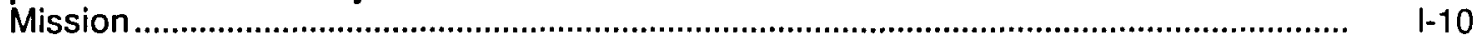

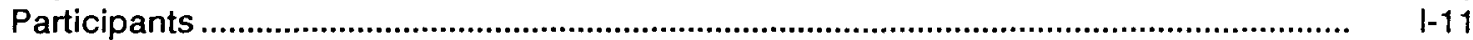

Site: Area of Proposed Land Withdrawal ....................................................................

Repository/Shaft System ........................................................................................................

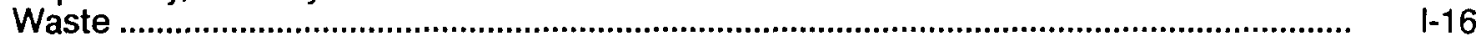

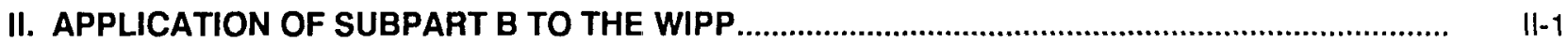

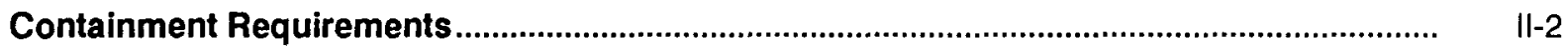

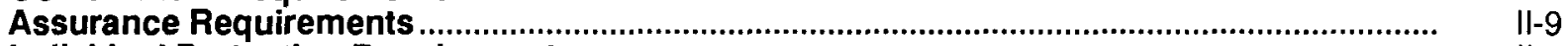

Individual Protection Requirements ....................................................................................

Ground water Protection Requirements.................................................................................

Special Sources of Groundwater.................................................................................

Requirement Does Not Apply to the WIPP …............................................................ $\quad \| 12$

III. COMPLIANCE ASSESSMENT PHILOSOPHY AND METHODOLOGY OVERVIEW .................... III-1

Philosophy.

The Containment Requirements

The Individual Protection Requirements ......................................................................

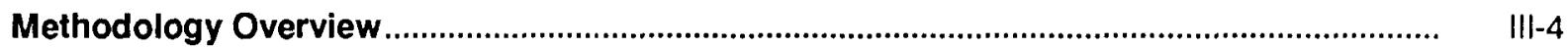

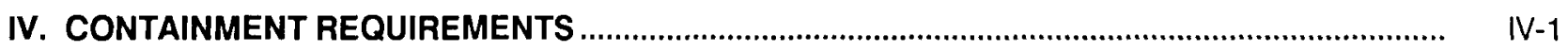

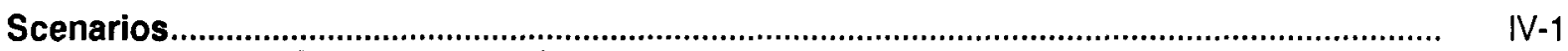

Events and Processes Retained............................................................................. IV 2

Events and Processes Screening ........................................................................... IV

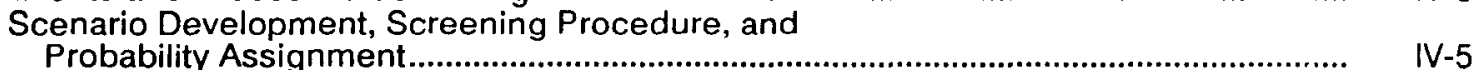

Application of Scenario Development and Screening to the WIPP ................................. IV-10

Compliance Assessment System ...................................................................................... IV-14

A Summary of the Hydrogeology of the Northern Delaware Basin ............................... IV-15

Hydrogeology of the Bell Canyon Formation....................................................... IV 15

Hydrogeology of the Castile and Salado Formations .......................................... IV

Hydrogeology of the Rustler Formation .............................................................. IV -25

Hydrogeology of the Rustler Aquitards .................................................................. IV

Rustler-Salado Residuum Hydrostratigraphic Unit.............................................. IV

The Culebra Dolomite Hydrostratigraphic Unit................................................... IV -34

Hydrologic Properties of the Culebra Dolomite Hydrostratigraphic
Unit.

Hydrogeology of the Magenta Dolomite Hydrostratigraphic Unit ........................ I'V-42

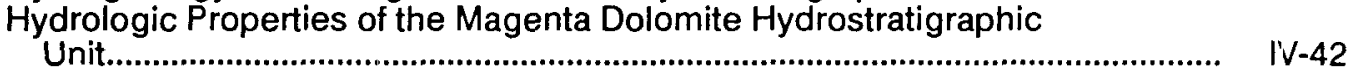

Hydrogeology of the Supra-Rustler Rocks...................................................... IV IV-46 
Surface Water.

IV -48

Summary

Calibration of Groundwater Models

IV -50

Repository/Shaft System Overview

Room Model

Panel-Seal Modeling

Seal-Material-Consolidation Modeling

Brine-Inflow Modeling

Disturbed Rock Zone Modeling

Flow and Transport Modeling.

Panel Seal and Room Assemblage

Drift Modeling

Shaft Seal System.

Seal-Material-Consolidation Modeling

Brine-Inflow Modeling

Disturbed Rock Zone Modeling

Flow and Transport Modeling...

Shaft-Seal System in RESYSM

Radionuclide Transport

Regional-Scale Contaminant Transport Calculations in the Culebra Dolomite Member.

Transport Models.

CAMCON: Controller for Compliance Assessment System

Primary Data Base

Secondary Data Base.

Computational Data Base

Code-Linkage and Data-Flow Controller.....................

Parameter Uncertainty and Sensitivity Analyses.

IV-51

IV-53

IV-60

IV-60

IV-62

IV-62

IV-63

IV-64

IV-64

IV-65

IV-65

IV-67

IV-67

IV-68

IV-68

IV-69

IV-69

IV-70

IV-71

IV-72

IV-73

IV-73

IV-74

IV-74

IV-76

V. INDIVIDUAL PROTECTION REQUIREMENTS

$\mathrm{V}-1$

Compliance Assessment Approach

$V-1$

Undisturbed Performance.

Release at a Livestock Pond

Conceptual Model of the System to be Analyzed.

Compliance Assessment System

Exposure Pathways Identification

Computer Models and Data....

VI. ASSURANCE REQUIREMENTS PLAN

Active Institutional Controls

Multiple Barriers .

Natural Resources

VI-2

VI-2

Waste Removal

VI-3

VII. RESULTS

VII-1

Containment (Performance Assessment)

VII-1

Scenario Release Analyses.

Complementary Cumulative Distribution Function (CCDF)

VII-1

VII-1

Individual Protection

VII-1

Releases

VII-1

Doses

VII-2 


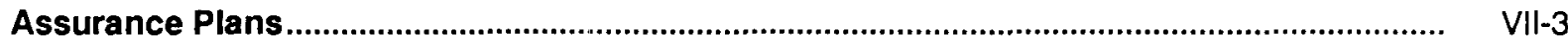

VIII. COMPARISON TO THE STANDARD..................................................................................... VIII-1

Containment Requirements ................................................................................................ VIII-1

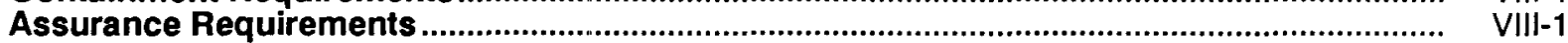

Individual Protection Requirements .......................................................................................... VIII-1

Groundwater Protection Requirements.................................................................................... VIII-1

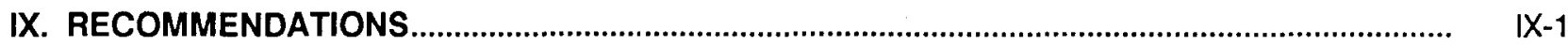

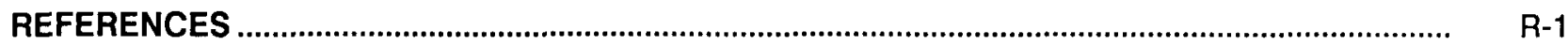

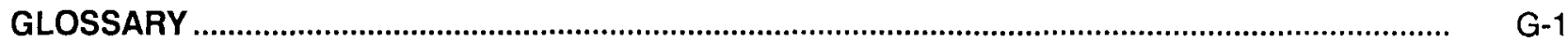

APPENDIX A: Title 40, Code of Federal Regulations, Subchapter F, Part 191........................ A-1

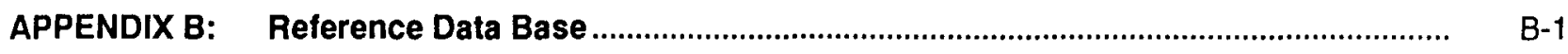

APPENDIX C: Response to Review Cornments....................................................................... C-1 


\section{FIGURES}

Figure

Page

1-1 Map Showing Selected Features Around the WIPP ........................................................... I-4

1-2 Artist's Concept Showing the Two Components of the WIPP Disposal

System: Controlled Area and Repository/Shaft System ............................................ $\quad$ 1-7

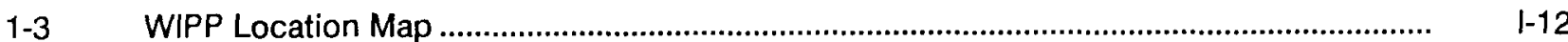

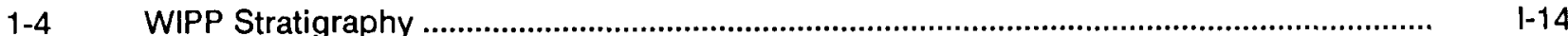

1-5 Proposed WIPP Repository, Showing Both TRU-Waste Disposal Areas and Experimental Areas

$1-16$

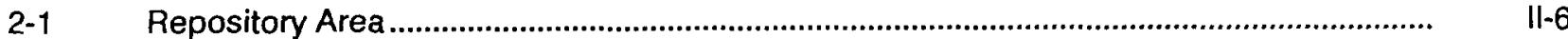

2-2 Hypothetical CCDF Illustrating Compliance with the Containment

Requirements

2-3 Illustration of Certain Definitions .........................................................................................

3-1 Compliance Assessment Methodology Structure ........................................................... III-6

3-2 A Sequence of Codes for Consequence Modeling …........................................................

4-1 Example of a Logic Diagram with Two Release $(R)$ and Three Transport (T) Phenomena for the Construction of Scenarios

IV-7

4-2 Potential Scenarios for the WIPP Disposal System ........................................................... IV-9

4-3 Preliminary Set of Scenarios for the WIPP Disposal System............................................ IV-13

4-4 Map of the Los Medaños Study Area Showing the Boundaries of the Los Medaños Model, the Local Model, the Proposed Land Withdrawal and the Observation Well Network

4-5 Generalized Stratigraphic Column of the Delaware Mountain Group and Younger Sedimentary Rocks of and near the WIPP Disposal System

4-6 Map Showing the Orientation of the Upper Bell Canyon

Sandstone Stringers in the Vicinity of the WIPP

4-7 Map Showing the Outline of the Delaware Basin and the Generalized Locations of the Castile and Salado Formations.

4-8 Geologic Cross-Section Across the WIPP Disposal System Residuum of the Rustler Formation in the Los Medaños Area in the Los Medaños Area 
4-12 Rustler Formation Halite and Culebra Dolomite Transmissivity around the WIPP

4-13 Negative-Log Hydraulic Conductivities of the Culebra Dolomite Member of the Rustler Formation in the Los Medaños Area.

4-14 Adjusted Potentiometric Surface of the Culebra Dolomite Member of the Rustler Formation in the Los Medaños Area.

4-15 Brine Densities of Water from the Culebra Dolomite Member of the Rustler Formation in the Los Medaños Area.

4-16 Negative Log Hydraulic Conductivities of the Magenta Dolomite Member of the Rustler Formation in the Los Medaños Area.

4-17 Adjusted Potentiometric Surface of the Magenta Dolomite Member of the Rustler Formation in the Los Medaños Area

4-18 Brine Densities of Water from the Magenta Dolomite Member of the Rustler Formation in the Los Medar̃os Area

4-19 Isopach Map of the Supra-Rustler Rocks in the Los Medaños Area.

4-20 Plan View of Storage Horizon Showing Shatt, Drift and Panel Seal Locations

4-21 Conceptual Model Used in Simulating Undisturbed Performance.

4-22 Schematic Design of a WIPP Panel Seal

4-23 Schematic Design of a WIPP Lower Shaft-Seal System .

4-24 Coupling Through a Computational Data Base using a "Neutral File"

4-25 Algorithm for Logical Data Flow During Compliance Assessment

4-26 Intervals Used with a Latin Hypercube Sample of Size $n=5$ in

Terms of the Density Function and Cumulative Distribution Function for a Normal Random Variable. 


\section{TABLES}

Table

Page

1-1 Approved CH-TRU Waste Containers for Transportation and

Emplacement at the WIPP Facility ................................................................................ $\quad 1-17$

1-2 Estimated Quantities of TRU Mixed Waste by Waste Form................................................ I-20

1-3 Representative Radionuclide Content of $\mathrm{CH}$-TRU Waste................................................ I-22

1-4 Representative Radionuclide Content of RH-TRU Waste.................................................. I-23

2-1 Techniques for Assessing and Reducing Uncertainty in the WIPP Performance Assessment ...................................................................................

4-1 Events and Processes Retained for Scenario Development ........................................... IV-3

4-2 Events and Processes Dismissed from Further Analysis ................................................. IV-4

4-3 Factors Potentially Important for Modeling the Room .................................................... IV-55

4-4 Factors to be Considered in the Panel-Seal Component of RESYSM ............................. IV-56

4-5 Factors to be Considered in the Drift/MB139 Component of RESYSM ............................ IV-58

4-6 Factors to be Considered for the Shaft/Seal Component of RESYSM.............................. IV-59 


\section{INTRODUCTION}

\section{PURPOSE AND ORGANIZATION OF THE COMPARISON}

The Department of Energy (DOE) must comply with the United States

Environmental Protection Agency's (EPA) Environmental Radiation Protection

Standards for Management and Disposal of Spent Nuclear Fuel, High-Level and Transuranic Radioactive Wastes (40 CFR Part 191; U.S. EPA, 1985), referred to herein as the Standard. Comparison of the long-term performance of the W.CPP disposal system to the requirements of the Standard will contribute to the determination of whether the disposal system will provide safe disposal of radioactive wastes. The Comparison, when completed, will be the final report of the performance assessment of the WIPP disposal system.

The organization of the Comparison, which is forecast in this report, is based on the requirements of the Standard. Within the format of the requirements, it is organized according to the methodology developed by the performance assessment team to implement the guidance found in Appendix B to the Standard. This level of organization reflects the program elements described in the DOE management plan for the test phase (U.S. DOE, 1989a; also see Bertram-Howery and Hunter, 1989a).

Because this report is a preview of the final report, many sections are preliminary or incomplete. Brief descriptions of the Standard and the WIPP Project will be provided in this chapter. Chapter II will discuss application of Subpart B of the Standard to the WIPP disposal system. Chapter III will describe the compliance-assessment philosophy of the WIPP Project and will. provide an overview of the methodology. Chapter IV will describe the methodology for assessing compliance with the Containment Requirements ( $\$ 191.13$ ) of the Standard. Chapter $V$ will describe the methodology for assessing compliance with the Individual Protection Requirements ( $\$ 191.15$ ) of the Standard. Chapter VI will describe plans for implementation of the Assurance Requirements ( $\S$ 191.14) of the Standard. Chapter VII will present 
the results of the assessment and Chapter VIII will compare the results to the requirements. Chapter IX will contain the recommendations of the WIPP Project relative to determination of compliance. Appendix A contains the full text of the Standard, as promulgated by the EPA in 1985. Appendix B will contain the reference data base for the compliance assessment.

There are no guidelines in the Standard for the preparation and review of compliance assessment reports. The Comparison will be reviewed extensively within the DOE and by the WIPP Panel of the National Research Council's Board on Radioactive Waste Management (BRWM); the State of New Mexico, including the Environmental Evaluation Group (EEG); and the EPA. Therefore, the planned organization of the final version of the document includes Appendix $C$, which will present the official review comments and responses to those comments, analogous to the comment-response section typically provided in decision-basis documents.

The Comparison focuses on Subpart B of 40 CFR Part 191. Compliance with other regulatory requirements and analyses for other purposes, such as safety assessments, are discussed in separate documents.

\section{CFR PART 191, THE STANDARD (1985)}

The Standard promulgated in 1985 by the EPA is divided into two subparts. Subpart A applies to a disposal facility prior to closure and limits annual radiation doses from waste management and storage operations to members of the public outside the site. Subpart $B$ applies after closure and limits cumulative releases of radioactive materials to the accessible environment for 10,000 years. Subpart $B$ also limits both radiation doses to members of the public in the accessible environment and radioactive contamination of certain sources of groundwater within or near the controlled area for 1,000 years after disposal. Appendix A of the Standard specifies how to determine release limits, and Appendix $B$ of the Standard provides non-mandatory guidance for implementation of Subpart B. Application of the Standard to the WIPP is described in the Compliance Strategy (U.S. DOE, 1989b), which discusses the WIPP interpretation of various terms and definitions contained in the Standard. 
The concept of "sites" is integral to limits established by Subparts A and B for releases of waste from the repository, both during operation and after closure. "Site" is used differently in the two Subparts; the meaning of "site" at the WIPP for each Subpart is discussed and defined below in the: appropriate section. The definitions of "controlled area" and "accessible environment," which are also important in assessing compliance with the Standard, depend on the definition of "site." "Site" has also been used generically for many years by the waste-management community (e.g., in the phrases "site characterization" or "site specific"); few uses of the worcl correspond to either of the EPA's usages (Bertram-Howery and Hunter, 1989 b).

\section{SUBPART A}

Subpart A limits the radiation doses that may be received by members of the public in the general environment as a result of management and storage of TRU wastes at DOE disposal facilities not regulated by the NRC. Subpart A requires that "the combined annual dose equivalent to any member of the public in the general environment resulting from discharges of radioactive material and direct radiation from such management and storage shal1 not exceed 25 millirems to the whole body or 75 millirems to any critical organ" ( $\S 191.03(\mathrm{~b})$ ). The general environment is the "total terrestrial, atmospheric, and aquatic environments outside sites within which any activity, operation, or process associated with the management and storage of...radioactive waste is conducted" ( $\$ 191.02(0)$ ).

"Site" for the purposes of Subpart $A$ is the secured-area boundary shown in Figure 1-1. This area will be under the effective control of the security force at the WIPP, and only authorized persons will be allowed within the boundary (U.S. DOE, 1989b). This means that unauthorized visitors to the site vicinity can be assumed to be no closer than the secured-area boundary. In addition, the DOE will gain control over the sixteen-section area within the land-withdrawal boundary; this boundary is referred to in the agreement with New Mexico and in the WIPP Final Safety Analysis Report (FSAR, U.S. DOE, 1989c) as the "WIPP site boundary." This control will prohibit habitation within the boundary. Consequently, for the purposes of operational dose assessment to nearby residents, the assumption can be made that no one lives closer than the latter boundary (Bertram-Howery and Hunter, 1989b). 


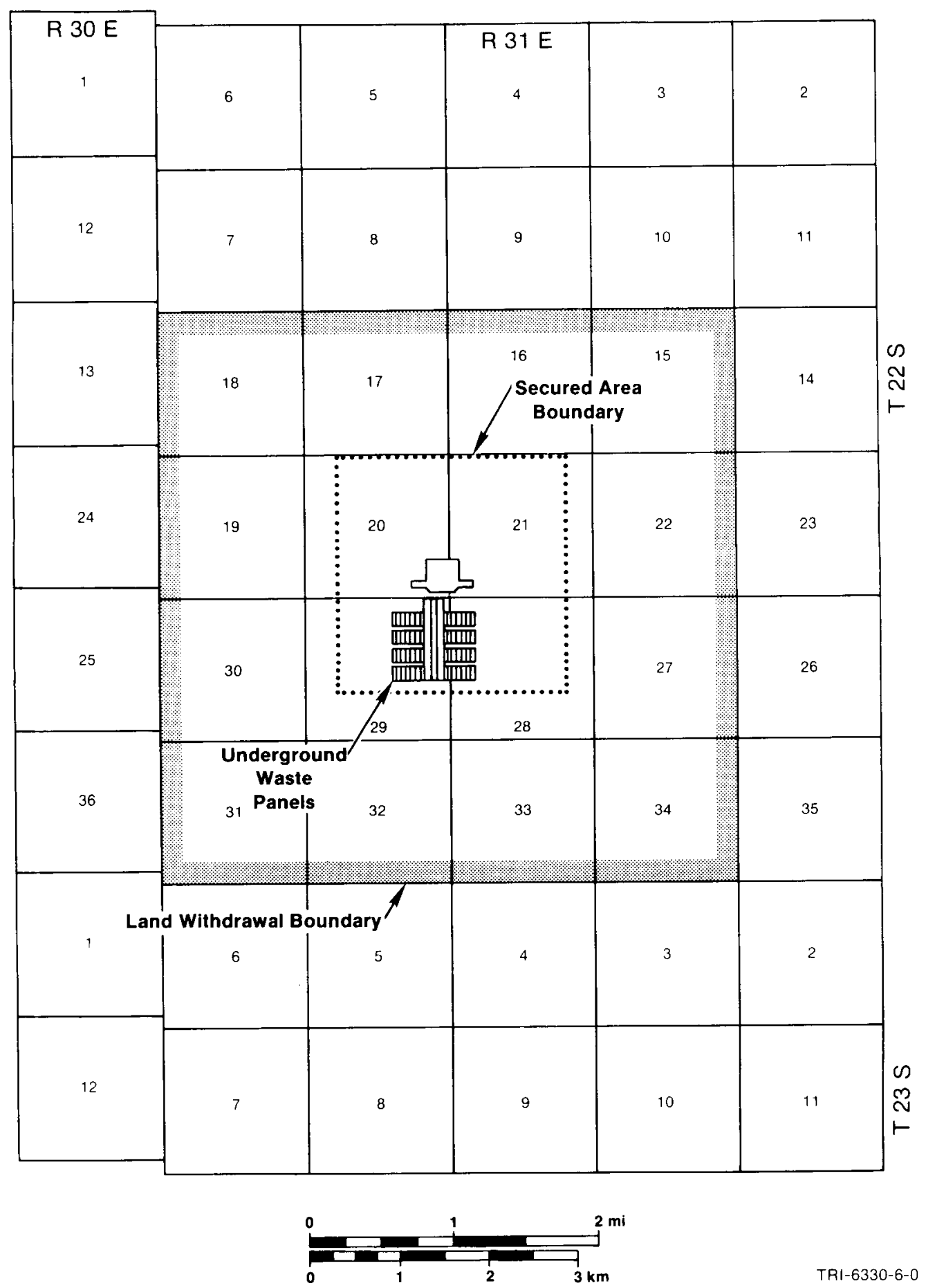

Figure 1-1. Map Showing Selected Features around the WIPP (U.S. DOE, 1989b). 
Subpart A requires that the DOE control emissions along all pathways, so that the dose limits are not exceeded. The actual mechanics of controlling emissions are inherent in the design and operation of the WIPP. The design and operation are described in the FSAR, as are projections of potential releases to the general environment from normal operations. These projections indicate that the WIPP, as designed, will comply with Subpart A. In the Second Modification to the Consultation and Cooperation Agreement (U.S. DOE and State of New Mexico, 1981), DOE agreed to begin compliance with Subpart A with the first receipt of waste at WIPP. A pre-operational monitoring plan is in place. Emissions monitoring-and-sampling systems and environmental radiation monitoring programs will be implemented during operations (BertramHowery and Hunter, 1989b).

A description of the Subpart A compliance approach is contained in the WIPP Compliance Strategy (U.S. DOE, 1989b; cf. Bertram-Howery and Hunter, 1989b and U.S. DOE, 1989c). Compliance with Subpart B is the topic of this report; therefore, Subpart A will not be discussed further.

\section{SUBPART B}

In evaluating compliance with Subpart B, the WIPP Project intends to follow to the extent possible the guidance found in Appendix B of the Standard (U.S. DOE, 1989b). The application of subpart B to the WIPP is discussed in detail in Chapter II. The Containment Requirements ( $\$ 191.13$ ) and Individual Protection Requirements ( $\$ 191.15$ ) necessitate predictions of releases for 10,000 years and of doses for 1,000 years. The Assurance Requirements (§ 191.14) complement the Containment Requirements. The Groundwater Protection Requirements ( $\S 191.16$ ) protect "special sources of ground water" from contamination at concentrations greater than certain limits and is the only requirement in the Standard that limits radionuclide concentrations.

The term "disposal site" is used frequently in Subpart B and in Appendix B of the Standard. For the purposes of the WIPP strategy for compliance with Subpart B, the disposal site and the controlled area are the same. The "site" for the purposes of Subpart A and the "disposal site" for the purposes of 
Subpart B are not the same. The controlled area for Subpart B includes the secured area and additional surrounding areas to be determined (U.S. DOE, 1989b). The Standard defines "disposal system" to mean any combination of engineered and natural barriers that isolate the radioactive waste after disposal. For the WIPP, the disposal system is the combination of the repository/shaft system and the geologic and hydrologic systems of the controlled area (Figure 1-2). The repository/shaft system, as defined, includes the WIPP underground workings and all emplaced materials and the altered zones within the Salado Formation and overlying units resulting from construction of the underground workings. The controlled area defined by the EPA is limited to the lithosphere and the surface within $5 \mathrm{~km}(3 \mathrm{mi})$ of the outer boundary of the WIPP waste-emplacement panels. The boundary of this maximum-allowable controlled area does not coincide with the proposed boundary for the WIPP land withdrawal. The extent of the WIPP controlled area will be defined during the performance assessment, but will not be less than the withdrawn area (Bertram-Howery and Hunter, 1989a).

The EPA recognized that Subpart B must be implemented in the design phase because active surveillance cannot be relied upon over the very long time frames of interest. The EPA also recognized that the Standard "must accommodate large uncertainties, including uncertainties in our current knowledge about disposal system behavior and the inherent uncertainties regarding the distant future" (U.S. EPA, 1985, p. 38070).

Both the Containment Requirements and the Individual Protection Requirements require a "reasonable expectation" that their various quantitative tests can be met. This test of judgment is meant by the EPA to "acknowledge the unique considerations likely to be encountered upon implementation of these disposal standards" (U.S. EPA, 1985, p. 38071). The Standard "clearly indicates that comprehensive performance assessments, including estimates of the probabilities of various potential releases whenever meaningful estimates are practicable, are needed to determine compliance with the containment requirements" (U.S. EPA, 1985, p. 38076). These requirements "emphasize that unequivocal proof of compliance is neither expected nor required because of the substantial uncertainties inherent in such long-term projections. 
Not to Scale

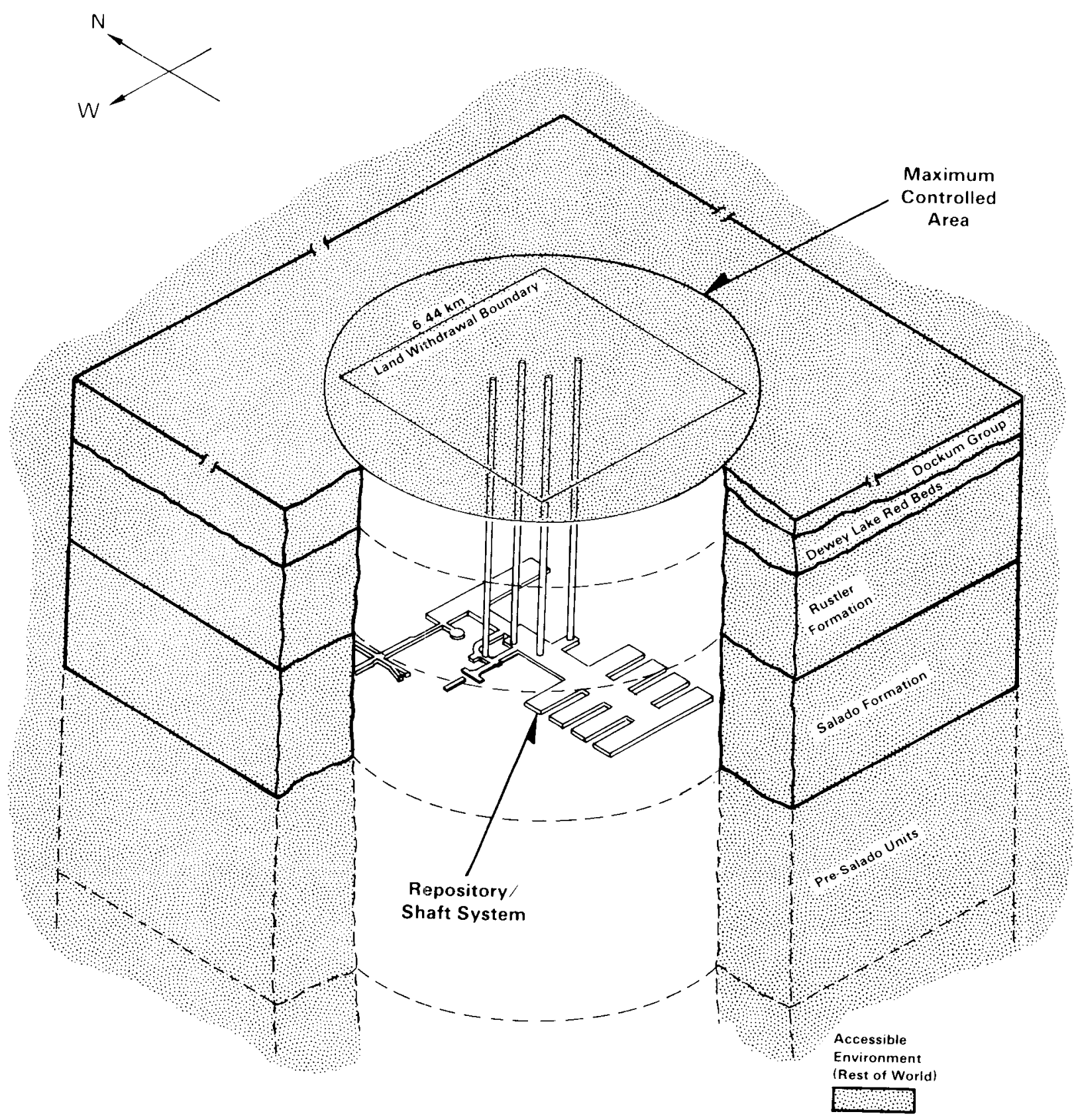

TRI-6330-7-0

Figure 1-2. Artist's Concept Showing the Two Components of the WIPP Dispasal System: Controlled Area and Repository/Shaft System. The repository/shaft system scale is exaggerated. The proposed landwithdrawal boundary is shown at the same scale as the maximum extent of the controlled area (Bertram-Howery and Hunter, 1989a). 
Instead, the appropriate test is a reasonable expectation of compliance based upon practically obtainable information and analysis" (ibid.). The EPA states that the Standard requires "very stringent isolation while allowing the [DOE] adequate flexibility to handle specific uncertainties that may be encountered" (ibid.).

The EPA's assumptions regarding performance assessments and uncertainties are incorporated in Appendix B of the Standard, which the EPA intends the implementing agencies to follow. The EPA intended these assumptions to "discourage overly restrictive or inappropriate implementation" of the requirements (U.S. EPA, 1985, p. 38077). The guidance in Appendix B to the Standard indicates that "compliance should be based upon the projections that the [DOE] believes are more realistic....Furthermore,...the quantitative calculations needed may have to be supplemented by reasonable qualitative judgments in order to appropriately determine compliance with the disposal standards" (U.S. EPA, 1985, p. 38076). In particular, Appendix B states:

The [EPA] believes that the [DOE] must determine compliance with $\S \S 191.13,191.15$, and 191.16 of Subpart B by evaluating long-term predictions of disposal system performance. Determining compliance with $\S 191.13$ will also involve predicting the likelihood of events and processes that may disturb the disposal system. In making these various predictions, it will be appropriate for the [DOE] to make use of rather complex computational models, analytical theories, and prevalent expert judgment relevant to the numerical predictions. Substantial uncertainties are likely to be encountered in making these predictions. In fact, sole reliance on these numerical predictions to determine compliance may not be appropriate; the [DOE] may choose to supplement such predictions with qualitative judgments as well.

Portions of the disposal system should not be disregarded, even if projected performance is uncertain, except for portions of the system that make negligible contributions to the overall isolation provided by the disposal system.

The Containment Requirements state, in $\S 191.13(\mathrm{~b})$, that:

Performance assessments need not provide complete assurance that the requirements of 191.13(a) will be met. Because of the long time period involved and the nature of the events and processes of interest, there will inevitably be substantial uncertainties in projecting disposal system performance. Proof of the future performance of a disposal system is not to be had in the ordinary sense of the word in situations that deal with much shorter time frames. Instead, what is required is a reasonable expectation, on the basis of the record before the [DOE], that compliance with 191.13(a) will be achieved. 
The EPA recognized that too many uncertainties exist in projecting the behavior of natural and engineered components for 10,000 years and there are too many opportunities for errors in calculations or judgments for the numerical requirements to be sufficient for determining the acceptability of a disposal system. Qualitative requirements were included in the Standard to ensure that "cautious steps are taken to reduce the problems caused by these uncertainties" (U.S. EPA, 1985, p. 38079). These qualitative Assurance Requirements are an essential complement to the quantitative Containment Requirements. Each qualitative requirement was chosen to compensate for some aspect of the inherent uncertainty in projecting the future performance of a disposal system. The Assurance Requirements begin by declaring that compliance with their provisions will "provide the confidence needed for longterm compliance with the requirements of 191.13."

The determination of compliance with Subpart $B$ depends on the estimated complementary cumulative distribution function (CCDF) and the estimated doses; however, it also depends on the strength of the assurance strategies that will be implemented and on the qualitative judgment of the DOE and its analysts. The preceding discussion clearly demonstrates the EPA's recognition of the difficulties involved in predicting the future and in quantifying the outcomes of future events. It also shows that the EPA expects the DOE to understand the uncertainties in the disposal system's behavior only to the extent practical.

One type of uncertainty that cannot be completely resolved is the validity of various models for predicting disposal system behavior 10,000 years into the future. Although models will be validated to the extent possible, expert judgment must be relied upon where validation is not possible. In the case of competing conceptual models, if a single conceptual model cannot be demonstrated to be the most consistent with available data, multiple conceptual models will be developed and performance assessment calculations will incorporate each model as appropriate.

The Standard (as promulgated in 1985) is reproduced in Appendix A of this report. 
Chapter I: Introduction

Subpart B of the Standard was remanded to the EPA by the United States Court of Appeals for the First Circuit in July 1987. The Court found that the EPA had neither reconciled the Individual Protection Requirements with Part $\mathrm{C}$ of the Safe Drinking Water Act nor explained the divergence between the two sets of criteria; furthermore, the EPA had not explained the basis for the 1,000-year design criterion in the Individual Protection Requirements. The Court also found that the Groundwater Protection Requirements were promulgated without proper notice and comment. The Second Modification to the Consultation and Cooperation Agreement (U.S. DOE and State of New Mexico, 1981) commits the WIPP Project to proceed with the evaluation of compliance with the Standard as first promulgated until such time as a revised Standard becomes available. Therefore, this report discusses the Standard as first promulgated. Compliance plans for the WIPP will be revised as necessary in response to any changes in the Standard resulting from the court's decision.

\section{DESCRIPTION OF THE WIPP PROJECT}

This section presents the WIPP Project mission and identifies the participants in the Project, then briefly describes the repository/shaft system, the site, and the waste.

\section{MISSION}

Congress authorized the WIPP in 1979 by Public Law 96-164 (Public Law 96-164, 1979) as a research and development facility. The WIPP is designed as a fullscale pilot plant to demonstrate the safe management, storage, and disposal of TRU defense waste. The WIPP performance assessment will help the DOE determine whether the WIPP will isolate wastes from the accessible environment sufficiently well to satisfy the disposal requirements in Subpart $B$ of the Standard. Predictions with respect to compliance with Subpart B of the Standard will provide input to the decision on whether WIPP will become a disposal facility. That decision is expected to occur upon completion of the performance assessment. The DOE will apply Subpart A of the Standard to the WIPP beginning with the first receipt of TRU waste (U.S. DOE, 1989b). 
"Disposal," as defined in the Standard, will occur when the mined repository is sealed and decommissioned.

\section{PARTICIPANTS}

The DOE is the implementing agency, as defined in the Standard, for the WIPP Project. The WIPP Project is managed by the DOE Albuquerque Operations Office (DOE/AL) through the DOE WIPP Project Office (DOE/WPO) in Carlsbad, New Mexico. The WPO is assisted by two prime contractors: Westinghouse Electric Corporation (WEC) and Sandia National Laboratories (SNL). The operating contractor will be responsible for operations once the decision is made to permanently emplace waste at the WIPP and is also responsible for compliance with Subpart A and with the Assurance Requirements of Subpart $B$ of the Standard. WEC is the operating contractor during the test phase. SNL provides scientific investigations of salt-bed disposal of TRU waste, site characterization, analysis, engineered-barrier designing, in situ testing, and evaluation of compliance with the long-term performance criteria in Subpart $B$ of the Standard.

The DOE and the State of New Mexico have had an Agreement for Consultation and Cooperation since 1981 (U.S. DOE and State of New Mexico, 1981). This agreement ensures that the State, through the EEG, has an active part in assuring that public safety issues are fully addressed. In addition, external review of the WIPP Project is provided by the BRWM WIPP Panel. Informal review of the compliance evaluation will be provided by the EPA. The WIP? also receives close public scrutiny.

SITE: AREA OF PROPOSED LAND WITHDRAWAL

The characteristics of the WIPP site are described in detail in the WIPP Final Safety Analysis Report (FSAR) (U.S. DOE, 1989c). The WIPP (Figure 1-3) is located in southeastern New Mexico, about $42 \mathrm{~km}$ (26 mi) east of Carlsbad, in the Delaware Basin. The area has a low population density. The nearest population center is the city of Carlsbad (pop. 27,000). Two smaller communities, Loving (pop. 1,500) and Malaga (pop. 150), are located about $33 \mathrm{~km}(20 \mathrm{mi})$ to the southwest. Less than 30 permanent residents live within 


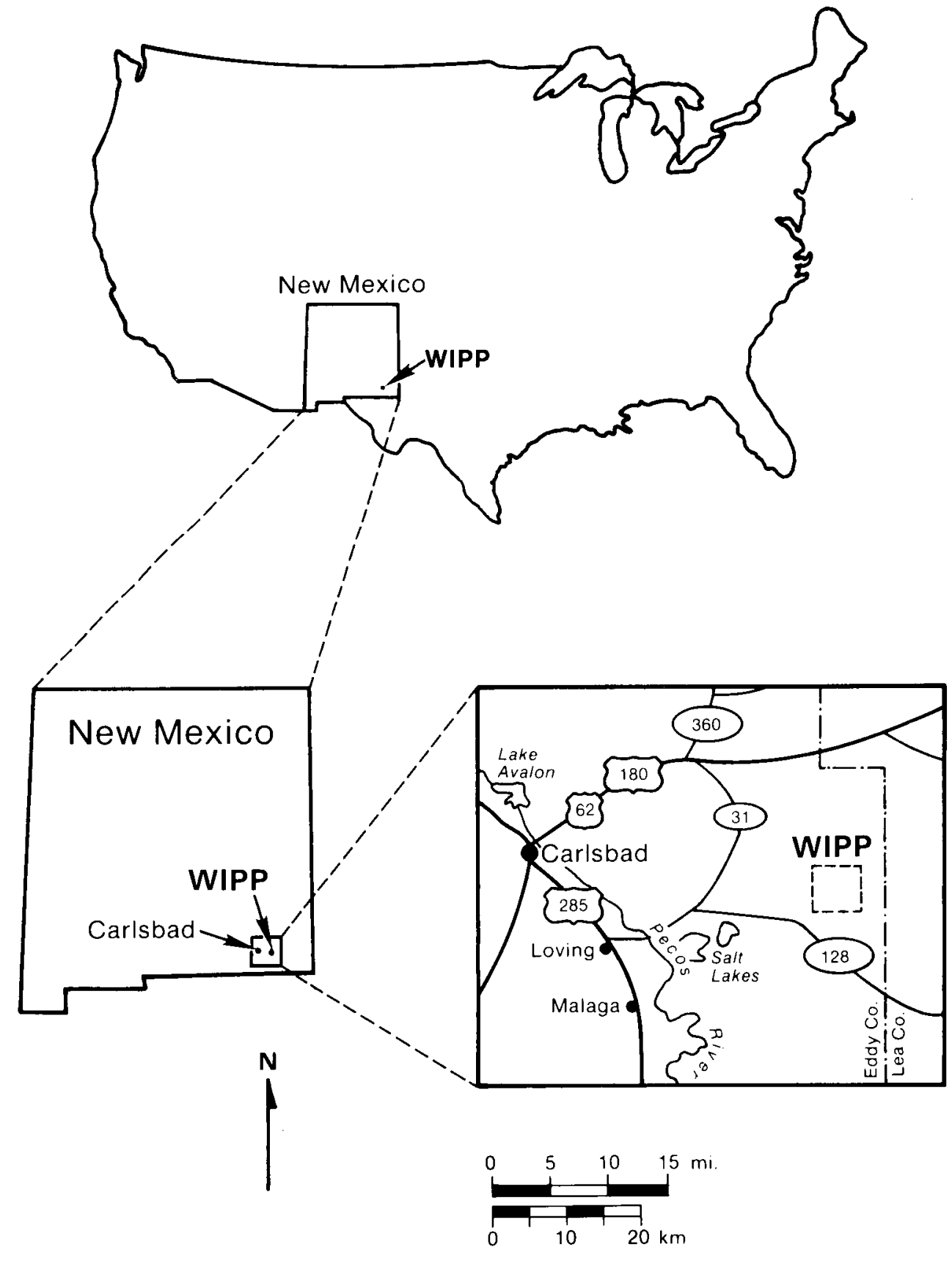

TR1-6342-223-0

Figure 1-3. WIPP Location Map (after Bertram-Howery and Hunter, 1989b). 
1 a $16-\mathrm{km}(10-\mathrm{mi})$ radius. The nearest residents live in a ranch house about

$25.6 \mathrm{~km}$ ( $3.5 \mathrm{mi})$ south of the WIPP surface facility (U.S. DOE, 1989c).

5

6

The surface of the proposed land withdrawal of the WIPP has been leased for cattle grazing. At present, none of the ranches within ten miles use well water for their livestock; the quality of the water is too poor for cattle. Water for people and cattle is supplied by pipeline (U.S. DOE, 1989c).

Potash, oil, and gas are the only known important mineral resources; however, resource extraction is not permitted within the proposed land withdrawal boundaries. The volumes and locations of these resources are estimated in the Final Environmental Impact Statement (FEIS) for the WIPP (U.S. DOE, 1980b). The surrounding area is used primarily for grazing, potash mining, and oil and gas exploration. There are about 56 oil and gas wells within a radius of $16 \mathrm{~km}$ (10 mi); the wells generally tap Pennsylvanian strata, about 4,200 $\mathrm{m}$ $(14,000 \mathrm{ft})$ deep. The nearest well is about $5 \mathrm{~km}(3 \mathrm{mi})$ to the southsouthwest of the surface facility. Three potash mines and two associated chemical processing plants are between 8 and $16 \mathrm{~km}$ ( 5 and $10 \mathrm{mi}$ ) away. Potash mining is anticipated within a radius of 3 to $8 \mathrm{~km}$ (2 to $5 \mathrm{mi}$ ) (U.S. DOE, 1989c). The potash zone is about $137 \mathrm{~m}$ (450 ft) thick and is encountered about $457 \mathrm{~m}(1,500 \mathrm{ft}$ ) below the surface (Figure 1-4).

\section{REPOSITORY/SHAFT SYSTEM}

The WIPP repository is located in the Salado Formation, $655 \mathrm{~m}(2,150 \mathrm{ft})$ below the land surface. The Salado is a $600-\mathrm{m}-(2,000-\mathrm{ft}-)$ thick sequence of 200-million-year-old salt with minor amounts of clay and anhydrite. The nearest perennial stream is the Pecos River, $23 \mathrm{~km}$ (14 mi) away at its closest point. Groundwater circulation in the Salado is extremely limited; waterbearing units of the Rustler Formation overlying the Salado produce only small amounts of water that is too salty for human consumption. The repository will remain dry while it is ventilated, but slow seepage of interstitial brine does occur. Brine under pressure occurs in localities below the Salado in the Castile Formation (Waste Management Technology Department, 1987). 

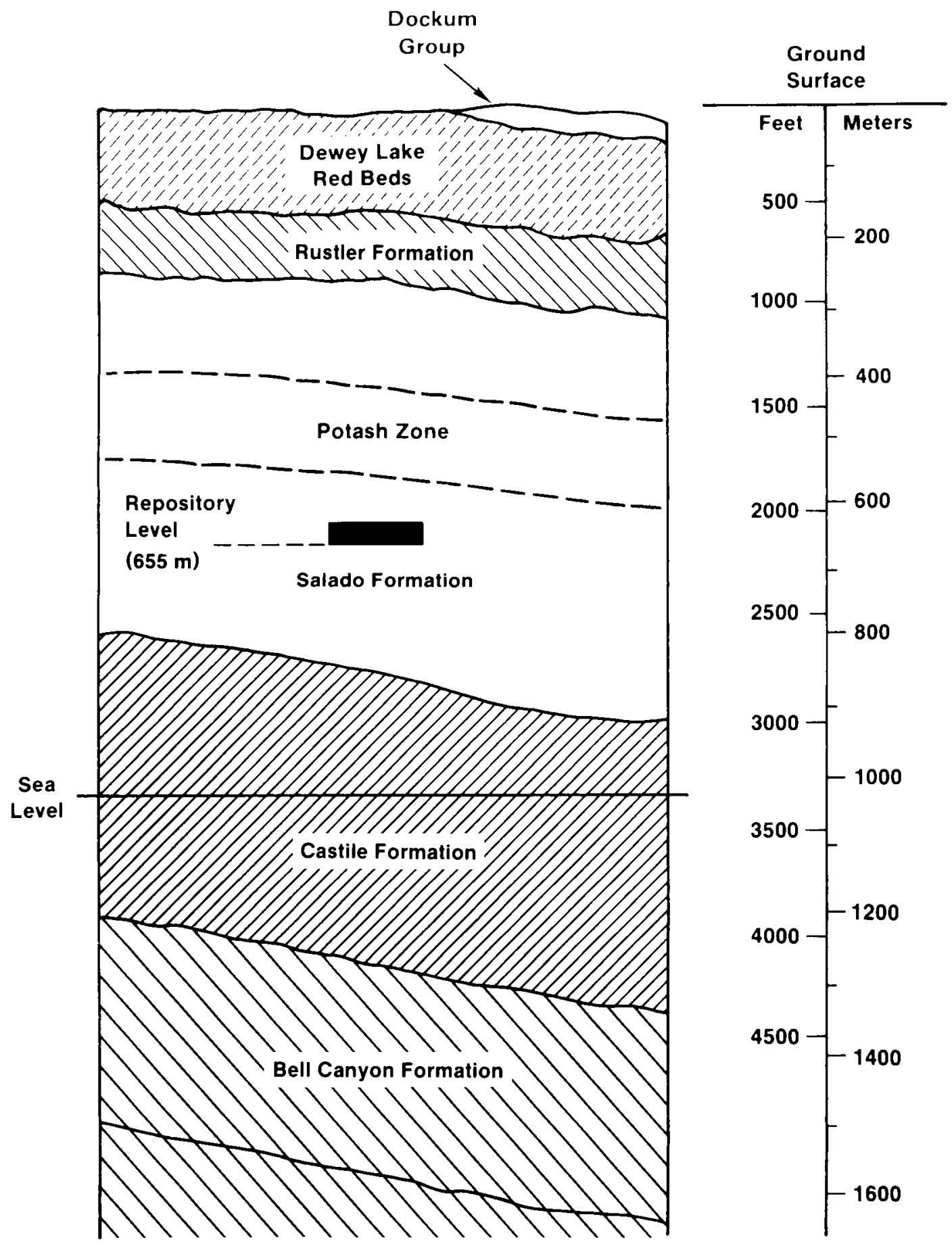

TRI-6330-4-0

Figure 1-4. WIPP Stratigraphy (after Waste Management Technology Dept., 1987). 
If the DOE successfully demonstrates compliance with the Standard, the WIPP is expected to become the nation's first and only large-scale, mined geologia repository for TRU waste (Figure 1-5). Ultimately, eight panels of seven rooms each will be mined. As each panel is filled with waste, the next panel will be mined. Before the repository is closed permanently, each panel will be sealed, waste will be placed in the drifts between the panels, and access ways will be sealed off from the shafts. Because the WIPP is a research and development facility, an extensive experimental area is also in use and under construction north of the waste-disposal area (Bertram-Howery and Hunter, 1989b).

The WIPP underground facility is composed of four shafts connected to a single underground disposal level. All shafts have four principle components: a collar, a lined section penetrating the rock overburden; an unlined section penetrating the salt; and a key at the rock/salt contact about $260 \mathrm{~m}$ ( $850 \mathrm{ft}$ ) below the surface to provide a transition from the lined section to the unlined section. The exhaust shaft is the exhaust air duct for the repository and is $4 \mathrm{~m}$ (14 ft) in diameter from the bottom of the key to the repository level. The construction and salt handling shaft provides the only means for removing mined materials; it also serves as the secondary air supply and is $3 \mathrm{~m}(10 \mathrm{ft})$ in diameter below the key. The air intake shaft serves as the primary air intake opening; it is $5 \mathrm{~m}$ (16 ft) in diameter below the key. The waste shaft, designed to permit the transport of radioactive waste between the surface waste-handling facilities and the underground disposal area, is $6 \mathrm{~m}$ (19 ft) in diameter below the key; it also provides access for personnel, materials, large equipment, and diesel fuel. The shafts will be sealed upon decommissioning of the WIPP (U.S. DOE, 1989c).

Design of the WIPP provided for the access and disposal openings to remain stable and provide minimum clearance for equipment during waste emplacemert; salt creep will eventually close these openings. The 100-acre disposal area contains all of the underground facilities for waste handling, waste disposal, operations, and maintenance. All of the underground horizontal openings are rectangular in cross section. The disposal area drifts, in the southern part of the repository, are $4 \mathrm{~m}$ (13 ft) high by $8 \mathrm{~m}(25 \mathrm{ft}$ ) wide; the disposal rooms are $4 \mathrm{~m}$ (13 ft) high, $10 \mathrm{~m}$ (33 ft) wide, and $91 \mathrm{~m}$ (300 ft) long. Other 


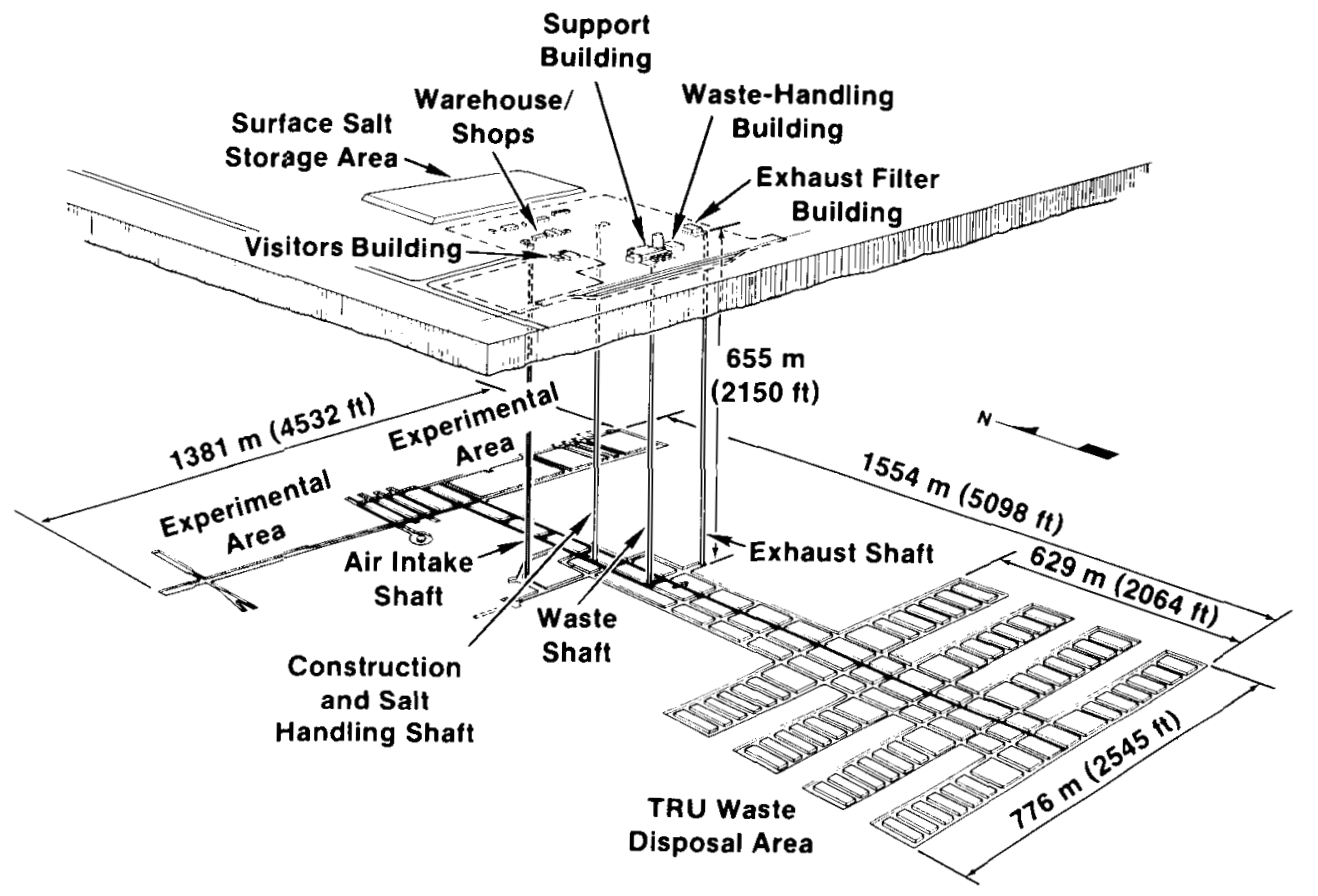

TRI-6330-132-0

Figure 1-5. Proposed WIPP Repository, Showing Both TRU-Waste Disposal Areas and Experimental Areas (after Waste Management Technology Dept., 1987).

drifts range from about 2 to $4 \mathrm{~m}$ ( 8 to $12 \mathrm{ft}$ ) high and 4 to $8 \mathrm{~m}$ (14 to $25 \mathrm{ft}$ ) wide. The width of the pillars between rooms is $30 \mathrm{~m}(100 \mathrm{ft})$. The drift entries to the disposal areas will be sealed to isolate the disposal panels. The conceptual design envisions a multiple-component seal approximately $30 \mathrm{~m}$ (100 ft) long (U.S. DOE, 1989c).

\section{WASTE}

The TRU waste for which WIPP is designed is defense-program waste generated by the United States government. TRU wastes are those radioactive wastes that, without regard to source or form, are contaminated with concentrations greater than $100 \mathrm{nCi} / \mathrm{g}$ of alpha-emitting, transuranic radionuclides with half-lives greater than 20 years. In accordance with DOE Order $5820.2 \mathrm{~A}$ (U.S. DOE, 
46

TABLE 1-1. APPROVED CH-TRU WASTE CONTAINERS FOR TRANSPORTATION AND EMPLACEMENT AT THE WIPP FACILITY (U.S. DOE, 1989C)

\begin{tabular}{|c|c|c|}
\hline $\begin{array}{l}\text { Container } \\
\text { Description }\end{array}$ & $\begin{array}{l}\text { Container } \\
\text { Dimension } \\
\text { (hxwxl) }\end{array}$ & $\begin{array}{l}\text { Nominal } \\
\text { Volume }\end{array}$ \\
\hline $\begin{array}{l}\text { DOT 17C 55- } \\
\text { Gallon Drums }\end{array}$ & $\begin{array}{c}0.3 \times 0.2 \mathrm{~m} \text { dia } \\
(35 \times 24 \mathrm{in})\end{array}$ & $\begin{array}{l}0.2 \mathrm{~m}^{3} \\
\left(7.4 \mathrm{ft}^{3}\right)\end{array}$ \\
\hline Steel Box & $\begin{array}{l}0.3 \times 0.5 \times 0.6 \mathrm{~m} \\
(38 \times 54 \times 68 \mathrm{in})\end{array}$ & $\begin{array}{l}2.3 \mathrm{~m}^{3} \\
\left(82 \mathrm{ft}^{3}\right)\end{array}$ \\
\hline Steel Box & $\begin{array}{c}0.7 \times 0.6 \times 1.0 \mathrm{~m} \\
(77 \times 68 \times 112 \mathrm{in})\end{array}$ & $\begin{array}{c}9.5 \mathrm{~m}^{3} \\
\left(339 \mathrm{ft}^{3}\right)\end{array}$ \\
\hline $\begin{array}{l}\text { Steel Box (FRP } \\
\text { Box Overpacked) }\end{array}$ & $\begin{array}{l}0.5 \times 0.5 \times 0.7 \mathrm{~m} \\
(54 \times 54 \times 88 \mathrm{in})\end{array}$ & $\begin{array}{c}4.1 \mathrm{~m}^{3} \\
\left(148 \mathrm{ft}^{3}\right)\end{array}$ \\
\hline $\begin{array}{l}\text { Seven-Pack of 55- } \\
\text { Gallon Drums }\end{array}$ & & $\begin{array}{c}1.5 \mathrm{~m}^{3} \\
\left(52^{\star} \mathrm{ft}^{3}\right)\end{array}$ \\
\hline Standard Waste Box & $\begin{array}{l}0.3 \times 0.6 \times 0.5 \mathrm{~m} \\
(38 \times 71 \times 55 \mathrm{in})\end{array}$ & $\begin{array}{l}1.8 \mathrm{~m}^{3} \\
\left(64 \mathrm{ft}^{3}\right)\end{array}$ \\
\hline
\end{tabular}

50 
Chapter I: Introduction

1 A small portion of the waste volume must be remotely handled ( $\mathrm{RH}$ ), that is, the surface dose rate exceeds $200 \mathrm{mrem} / \mathrm{h}$ so that the waste canisters must be packaged for handling and transportation in specially shielded casks. The

The WIPP's capacity is equivalent to about 863,000 drums containing about 9,000,000 $\mathrm{Ci}$ of $\mathrm{CH}-\mathrm{TRU}$ waste and no more than 5,100,000 $\mathrm{Ci}$ of RH-TRU waste. The total curies of RH-TRU waste is limited by the First Modification to the Consultation and Cooperation Agreement (U.S. DOE and State of New Mexico, 1981). The complex analyses for the evaluation of compliance with Subpart $B$ of the Standard require knowledge of the waste inventory. Therefore, all analyses will be based on current projections of the final inventory, estimated at 385,000 drums and 19,500 boxes of $\mathrm{CH}$-TRU waste (Lappin et al., 1989) and 4,000 to 5,000 canisters of RH-TRU waste (U.S. DOE, 1989c). 38 Mexico 
these constituents significantly affect the ability of radionuclides to migrate out of the repository.

Cemented and Uncemented Aqueous Waste. This is a wastewater treatment sludge that is precipitated at a $\mathrm{pH}$ of 10 to 12 . It may be either an uncemented, damp solid or cemented with portland cement. Alcohols and halogenated organics in the sludge derive from the cleaning of equipment and glassware and the degreasing of metals. Some aqueous process waste may also contain metals, such as cadmium and lead.

Cemented and Uncemented Organic Waste. Organic waste containing oil and halogenated organic solvents may be an uncemented, damp solid or cemented with Envirostone cernent and an emulsifier. Organic waste consists of lathe coolants and degreasing solvents used in plutonium fabrication.

Solidified Process and Laboratory Solid Waste. This consists of anion and cation resins and incinerator ash that are neutralized and immobilized with portland cement. Solvents in this waste are from plutonium-recovery operations.

Combustible Waste. This includes paper and cloth (dry and damp), various plastics such as polyethylene and polyvinyl chloride, wood, and filters contaminated with trace quantities of halogenated organic solvents. These materials are generated in plutonium-recovery and plutonium-fabrication processes and analytical laboratories.

Metal Waste. Lead, tantalum, stainless steel, and aluminum constitute the majority of these wastes, which include equipment, tools, crucibles, and molds. Residual halogenated organic solvents may also be found in this waste form.

Filter Waste. These wastes are Ful-Flo and high-efficiency particulate air (HEPA) filters and processed filter media with portland cement added to absorb any residual liquid and neutralize residual acids. Exhaust stream filters may be contaminated with volatile organic solvents used in plutonium fabrication and recovery processes. 
Inorganic Solid Waste. Materials such as firebrick, Oil Dri, concrete, and soil are included in this waste form, which may be contaminated with residual halogenated organic solvents. This waste results from decontamination and decommissioning of plutonium recovery areas.

Leaded Rubber Waste. This includes leaded rubber gloves and aprons used throughout plutonium processing areas.

The estimated quantity of each waste form in $\mathrm{CH}-\mathrm{TRU}$ waste from two DOE facilities is given in Table 1-2. Most of the organic solvents are present in

TABLE 1-2. ESTIMATED QUANTITIES OF TRU MIXED WASTE BY WASTE FORM FROM THE ROCKY FLATS PLANT AND THE IDAHO NATIONAL ENGINEERING LABORATORY (U.S. DOE, 1989C)

\section{Cemented and uncemented sludges from aqueous wastewater treatment}

Cemented and uncemented organic sludges

Solidified process and laboratory waste

Combustible waste

Metal waste

Filter waste

Inorganic solid waste

Leaded rubber
Quantity (kg)

$6,121,100$

$1,749,400$

95,300

$2,740,300$

$4,295,600$

$1,258,900$

211,400

244,000

TOTAL

residual quantities from the cleaning of equipment, plastics, glassware, and filters. A major constituent of $\mathrm{CH}$-TRU waste is lead that is present predominantly as shielding, glovebox parts, and lead-lined gloves and aprons (U.S. DOE, 1989c). Lead is used as shielding in most of the RH-TRU waste packages. Trace quantities of mercury, barium, chromium, and nickel have also been reported in some sludges (U.S. DOE, 1989c). The following two RH-TRU waste forms contain hazardous chemical constituents (U.S. DOE, 1989c): 
Solid Waste. This waste contains mixtures of combustibles (e.g., paper, polyvinyl chloride, polypropylene, polyethylene, and neoprene) and noncombustibles (e.g., laboratory equipment, tools, and small electric motors) that were removed from a hot cell facility at oak Ridge National Laboratory. This waste will not contain free liquids ore particulates.

Sludges. Fuel sludges and process sludges will be solidified. This waste will be a solid monolith packaged in lead-shielded canisters.

The inventory of radionuclides contained in the waste upon receipt at the WIPP has been projected over the 25-year operational lifetime of the repository (Tables $1-3$ and 1-4). The radionuclide composition of $\mathrm{CH}-\mathrm{TRU}$ waste varies widely depending upon which DOE facility generated the waste. To simplify radiological analyses, the mean activity of a 55-gallon drum for each generator was weighted based on the estimated number of containers contributed by each facility for disposal in the WIPP. The combined product of this weighted activity with the individual radionuclide distributions in the waste produced by each generator was used to represent the radionuclide content of an average drum shipped to the WIPP (U.S. DOE, 1989c). The Oak Ridge National Laboratory is projected to be the predominant source of RH-TRU waste. The existing RH-TRU waste contains a wide range of radionuclides. The average reference RH-TRU waste for the WIPP consists of a normalized actinide inventory and an assumed distribution of mixed activation and fission products. The concentration of all radionuclides in RH-TRU waste will not exceed $23 \mathrm{Ci} / \ell$ (U.S. DOE, 1989c).

The fissile material content in equivalent grams of plutonium-239 allowed by the WAC is a maximum of $200 \mathrm{~g}$ for a $55-\mathrm{gallon} \mathrm{drum}$ and $5 \mathrm{~g} / \mathrm{cm}^{3}$ up to $350 \mathrm{~g}$ for boxes. The average content is approximately $17 \mathrm{~g}$ for a drum and $90 \mathrm{~g}$ for the most common box (U.S. DOE, 1989c).

Subpart B of the Standard sets release limits in curies for isotopes of americium, carbon, cesium, iodine, neptunium, plutonium, radium, strontium, technetium, thorium, tin, and uranium, as well as certain other radionuclides (Appendix A of this report). Although the initial inventory contains little 
Chapter I: Introduction

1 or none of some of the listed nuclides, they may be produced as a result of

2 radioactive decay and must be accounted for in the compliance evaluation.

3 Moreover, any radionuclides not listed in Subpart B that could contribute to

4 doses must be accounted for.

5

6

TABLE 1-3. REPRESENTATIVE RADIONUCLIDE CONTENT OF CH-TRU WASTE (U.S. DOE, 1989c)

9

10

11

12

13

14

\section{Standard Waste Box (SWB)}

Th-232

U-233

U-235

U-238

Np-237

Pu-238

Pu-239

Pu-240

Pu-241

Pu-242

Am-241

Cm-244

Cf-252

Mass g/container

$6.0 \times 10^{0}$

$1.7 \times 10^{0}$

$4.0 \times 10^{-1}$

$1.0 \times 10^{-1}$

$3.1 \times 10^{-2}$

$6.2 \times 10^{-1}$

$1.4 \times 10^{1}$

$8.5 \times 10^{-1}$

$6.6 \times 10^{-2}$

$7.8 \times 10^{-3}$

$4.9 \times 10^{-1}$

$4.2 \times 10^{-4}$

$1.0 \times 10^{-5}$

$1.2 \times 10^{1}$

$6.7 \times 10^{0}$

$9.6 \times 10^{-1}$

$2.5 \times 10^{1}$

$4.4 \times 10^{-4}$

$4.2 \times 10^{-2}$

$7.9 \times 10^{1}$

$6.5 \times 10^{0}$

$6.7 \times 10^{-1}$

$7.5 \times 10^{-2}$

$2.1 \times 10^{-1}$

$8.6 \times 10^{-5}$

$2.1 \times 10^{-6}$
Activity Ci/container

$6.6 \times 10^{-7}$

$1.7 \times 10^{-2}$

$8.8 \times 10^{-7}$

$3.5 \times 10^{-6}$

$2.2 \times 10^{-5}$

$1.1 \times 10^{1}$

$8.5 \times 10^{-1}$

$1.9 \times 10^{-1}$

$6.8 \times 10^{0}$

$3.1 \times 10^{-5}$

$1.7 \times 10^{0}$

$3.4 \times 10^{-2}$

$5.4 \times 10^{-3}$

TOTAL $\overline{2.1 \times 10^{1}}$

$1.3 \times 10^{-6}$

$6.5 \times 10^{-2}$

$2.1 \times 10^{-6}$

$8.3 \times 10^{-6}$

$3.1 \times 10^{-7}$

$7.2 \times 10^{-1}$

$4.9 \times 10^{0}$

$1.5 \times 10^{0}$

$6.9 \times 10^{1}$

$2.9 \times 10^{-4}$

$7.3 \times 10^{-1}$

$7.0 \times 10^{-3}$

$1.1 \times 10^{-3}$

TOTAL $\overline{7.7 \times 10^{1}}$ 
1

a

4

5

6

7

8

9

10

11

12

13

14

15

16

17

18

19

20

21

22

23

24

89

28

20

TABLE 1-4. REPRESENTATIVE RADIONUCLIDE CONTENT OF RH-TRU WASTE (U.S. DOE, 1989c)

Radionuclide

Co-60

Sr-90

Ru-106

Sb-125

Cs-137

Ce-144

Eu-155

U-233

U-235

U-238

Pu-238

Pu-239

Pu-240

Pu-241

Pu-242

Am-241

Cm-244

Cf-252
Ci/canister

$1.7 \times 10^{-1}$

$5.1 \times 10^{0}$

$3.5 \times 10^{-2}$

$1.1 \times 10^{-3}$

$4.3 \times 10^{0}$

$3.4 \times 10^{-1}$

$1.7 \times 10^{-3}$

$5.5 \times 10^{-3}$

$3.0 \times 10^{-3}$

$1.5 \times 10^{-3}$

$5.7 \times 10^{0}$

$6.8 \times 10^{0}$

$2.2 \times 10^{0}$

$1.2 \times 10^{1}$

$3.8 \times 10^{-4}$

$2.1 \times 10^{-1}$

$1.6 \times 10^{-1}$

$2.8 \times 10^{-1}$

TOTAL
$\mathrm{Ci} / \ell$

$2.0 \times 10^{-4}$

$6.0 \times 10^{-3}$

$4.2 \times 10^{-5}$

$1.2 \times 10^{-6}$

$5.0 \times 10^{-3}$

$4.0 \times 10^{-4}$

$2.0 \times 10^{-6}$

$6.5 \times 10^{-6}$

$3.6 \times 10^{-6}$

$1.7 \times 10^{-6}$

$6.7 \times 10^{-3}$

$8.0 \times 10^{-3}$

$2.5 \times 10^{-3}$

$1.4 \times 10^{-2}$

$4.5 \times 10^{-7}$

$2.5 \times 10^{-4}$

$1.9 \times 10^{-4}$

$3.3 \times 10^{-4}$

$4.3 \times 10^{-2}$ 


\section{APPLICATION OF SUBPART B TO THE WIPP}

Subpart B of the Standard applies at the WIPP to cumulative releases of radioactive materials into the accessible environment ( $\S 191.13$ ) and to annual radiation doses received by members of the public in the accessible environment ( $\S 191.15$ ) as a result of TRU waste disposal. It requires actions and procedures ( $\S 191.14$ ) to increase confidence that the release limits will be met at the WIPP. It would also apply to radioactive contamination of certain sources of groundwater $(\S 191.16)$ in the vicinity of the WIPP disposal system from such TRU wastes, if any of these sources of groundwater were found to be present (U.S. DOE, 1989b). Each of the four requirements of Subpart B and their evaluation by the WIPP Project is discussed below. The full text of the Standard is reproduced as Appendix A of this report.

Appendix B to the Standard is EPA's guidance to the implementing agency (in this case, the DOE). In the preamble to the Standard (U.S. EPA, 1985, p. 38069), the EPA stated that it intends the guidance to be followed:

...Appendix B...describes certain analytical approaches and assumptions through which the [EPA] intends the various long-term numerical standards of Subpart B to be applied. This guidance is particularly important because there are no precedents for the implementation of such long-term environmental standards, which will require consideration of extensive analytical projections of disposal system performance.

The EPA based Appendix $B$ on some of the analytical assumptions it used to develop the technical basis for the numerical disposal standards. Thus, the EPA "believes it is important that the assumptions used by the [DOE] are compatible with those used by the EPA in developing this rule. Otherwise, implementation of the disposal standards may have effects quite different than those anticipated by EPA" (U.S. EPA, 1985, p. 38074). Chapter II documents the assumptions and interpretations of the Standard used in the compliance assessment. 
6

\title{
CONTAINMENT REQUIREMENTS
}

The primary objective of Subpart B is to isolate the waste from the accessible environment by limiting long-term releases. This objective is reflected in $\S 191.13$, the Containment Requirements. Evaluation of compliance is based on a performance assessment, which has specific meaning within the Standard:

\begin{abstract}
"Performance Assessment" means an analysis that: (1) identifies the processes and events that might affect the disposal system; (2) examines the effects of these processes and events on the performance of the disposal system; and (3) estimates the cumulative releases of radionuclides, considering the associated uncertainties, caused by all significant processes and events. These estimates shall be incorporated into an overall probability distribution of cumulative release to the extent practicable ( $\$ 191.12(q))$.
\end{abstract}

The assessment as defined must provide reasonable expectations that all releases resulting from significant processes and events that may affect the disposal system for 10,000 years after disposal have: (1) a likelihood of less than one chance in ten of exceeding quantities specified in Appendix $A$ of the rule; and (2) a likelihood of less than one chance in 1,000 of exceeding ten times the specified quantities. The term "performance assessment" has come to be used to refer to the prediction of all long-term performance, because the performance assessment methodology, with minor modifications, can also be used to assess compliance with the 1,000-year performance. Henceforth, this report will refer to the assessment of compliance with both the Containment Requirements and the Individual Protection Requirements as the "performance assessment".

Appendix A to the Standard establishes release limits for all the regulated radionuclides. Table 1 in that appendix gives the limit for cumulative releases to the accessible environment for 10,000 years after disposal for each radionuclide per unit of waste. Note 1 (e) to Table 1 defines the unit of waste as an amount of TRU waste containing one million curies of alphaemitting transuranic radionuclides with half-lives greater than 20 years. Note 2(b) describes the development of release limits for a TRU waste disposal system: the release limits are the quantities in Table 1 multiplied by the units of waste. Note 6 describes the manner in which release limits are to be used to determine compliance with $\S 191.13$ : for each radionuclide released, 
the ratio of the cumulative release to the total release limit for that radionuclide must be determined; ratios for all radionuclides released are summed for comparison to the requirements of $\S 191.13$. Thus, the quantity of a radionuclide that may be safely released depends on the quantities of all other nuclides projected to be released, but cannot exceed its own release limit. The summed normalized release cannot exceed 1 for probabilities greater than 0.1 and cannot exceed 10 for probabilities greater than $0.00 \mathrm{l}$. Potential releases estimated to have probabilities less than 0.001 are not regulated.

For example, Table 1 in Appendix A to the Standard lists the release limits for plutonium-239 and americium-241 as 100 curies each per waste unit. For a repository with a waste unit of one and a release that contained only those two nuclides, the sum of the two must not be greater than 100 curies unlesis the probability of the release is less than 0.1 and must not be greater than 1,000 curies unless the probability is less than 0.001 . The smallest release limit in the table is 10 curies per waste unit for thorium-230 or -232; the largest release limit is 1,000 curies per waste unit for technetium-99. For the WIPP, the maximum possible waste unit for the stated capacity is about 15; however, all radioactivity in the waste cannot be included in the waste unit because it is not all from "alpha-emitting transuranic radionuclides with half-lives greater than 20 years." The waste unit for the WIPP will likely be about six. Regardless of the waste unit, all regulated radionuclides must be included in release calculations.

For the WIPP performance assessment, the disposal system consists of the underground facility with its engineered barriers and the subsurface geology and hydrology of the disposal site. The engineered barriers are backfill in the rooms; seals in the drifts and panel entries; backfill and seals in the shafts; and plugs in the boreholes (U.S. DOE, 1989b). Engineered modifications to the repository could include making the waste form a barrier.

The most significant event that may affect the disposal system probably will be human intrusion. Typical examples of human intrusion include but are not limited to exploratory or exploitational drilling for any reason, mining, or the construction of other facilities for reasons unrelated to the repository. 
The EPA gives specific guidance in Appendix B of the Standard for possibilities for human intrusion that may be mitigated by design, site selection, and passive institutional controls need be considered. In particular, as long as passive institutional controls "endure and are

6 understood" they can be assumed to deter systematic or persistent exploitation

7 of the disposal site, and furthermore, can reduce the likelihood of

8 inadvertent, intermittent human intrusion to a degree to be determined by the

9 DOE. However, passive institutional controls can never be assumed to eliminate the chance of inadvertent, intermittent human intrusion. EPA suggests that exploratory drilling for resources is the most severe intrusion that must be considered (U.S. EPA, 1985).

Active institutional controls cannot be considered to prevent intrusion for more than 100 years after closure. For the WIPP, the likelihood of inadvertent intrusion is assumed, based on the EPA guidance, to be no greater than 30 boreholes per $\mathrm{km}^{2}\left(0.4 \mathrm{mi}^{2}\right)$ of repository area per 10,000 years (U.S. DOE, 1989b). Effects of the site, design, and passive institutional controls can be used in judging the likelihood and consequences of inadvertent drilling intrusion. The EPA suggests in Appendix B of the Standard that intruders will soon detect or be warned of the incompatibility of their activities with the disposal site by their own exploratory procedures or by passive institutional controls (U.S. EPA, 1985).

Four conclusions may be drawn for the WIPP performance assessment relative to human intrusion:

No human intrusion of the repository will occur during the period of active 
Intrusion of the repository leads to its detection. No mechanism for detection need be advanced. The EPA's use of the word "incompatibility" allows the conclusion that the intruders will plug and abandon their boreholes to avoid the effects of the repository.

The number of exploratory boreholes assumed to be drilled inside the controlled area is to be based on site-specific information and need not exceed 30 boreholes $/ \mathrm{km}^{2}\left(0.4 \mathrm{mi}^{2}\right)$ per 10,000 years. No more severe scenarios for human intrusion inside the controlled area need be considered. While passive institutional controls endure, the drilling rate may be significantly reduced, although the likelihood cannot be eliminated.

The repository area is not defined in the standard but is necessary for evaluating the human intrusion scenarios. For the WIPP, the repository area includes the entirety of the excavated workings at mine level and all unmined or unexcavated salt of any size that lies between any two portions of the excavated workings. Thus the repository area is defined as the smallest convex polygon that will enclose the excavated workings (Figure 2-1) (U.S. DOE, 1989b).

In the Second Modification to the Consultation and Cooperation Agreement, the DOE agreed to prohibit subsurface mining, drilling, slant drilling under the withdrawn area, or resource exploration unrelated to the WIPP Project on the sixteen square miles to be withdrawn under DOE control. The EPA guidance advises that active institutional controls (such as the above prohibition) will be effective for no more than 100 years after the repository is decommissioned. Inadvertent intrusion will be considered possible in the analysis beginning at that time, based on the DOE plan for active institutional controls (see Chapter VI below).

The definition of performance assessment requires the consideration of numerous uncertainties in the projected performance of the disposal system. The WIPP Project will use the interpretation of the EPA requirement for uncertainty analysis developed in previous work at SNL for high-level waste disposal (Cranwell et al., 1982; Pepping et al., 1983; Hunter et al., 1986; Cranwell et al., 1987; Campbell and Cranwe11, 1988; Rechard, 1989). The EPA 


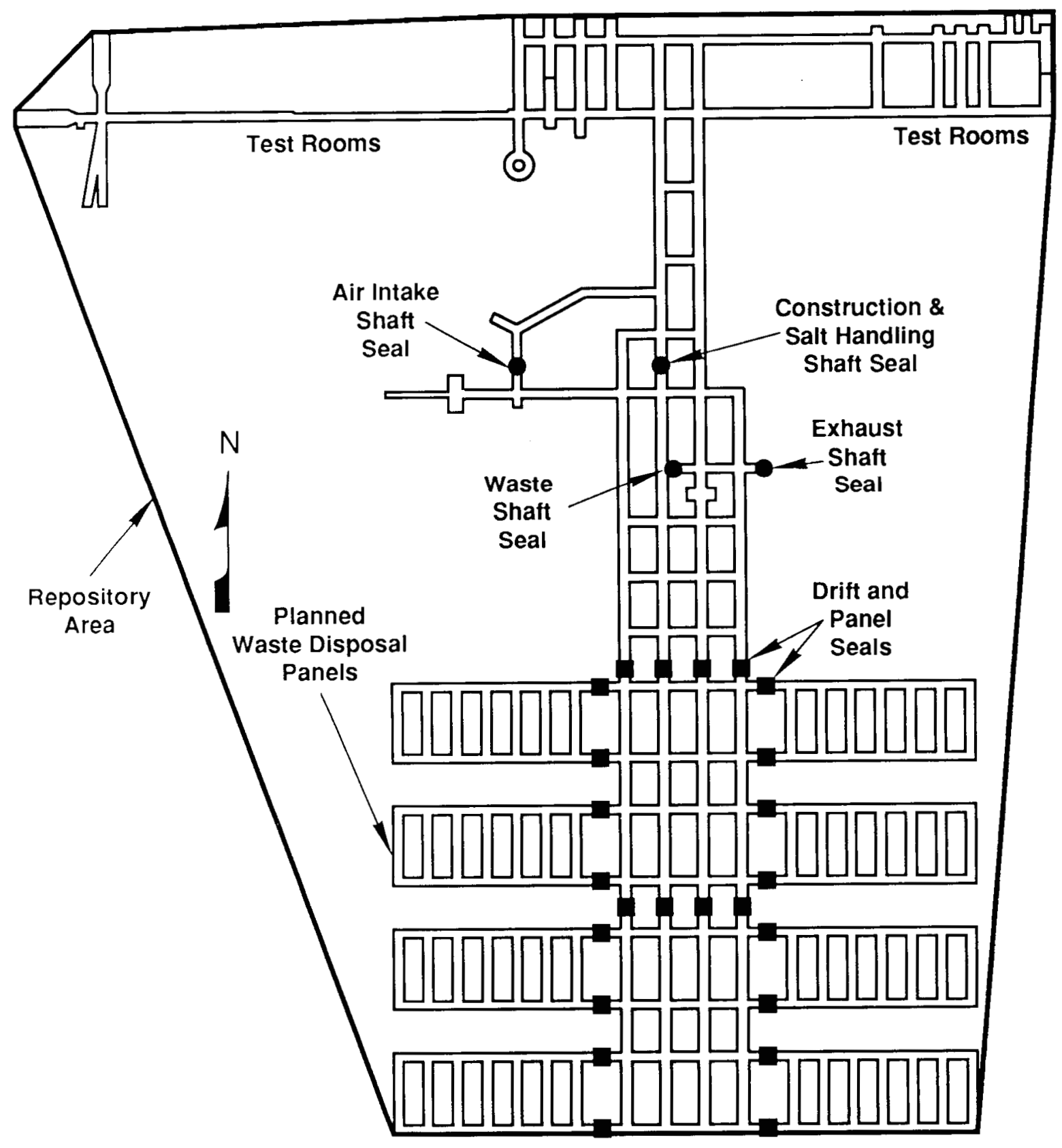

TRI-6342-10-0

Figure 2-1. Repository Area (after U.S. DOE, 1989b). 
has explicitly recognized that performance assessments will contain uncertainties and that many of these uncertainties cannot be eliminated. The WIPP Project will reduce uncertainty to the extent practicable using a variety of techniques (Table 2-1).

TABLE 2-1. TECHNIQUES FOR ASSESSING AND REDUCING UNCERTAINTY IN THE WIPP PERFORMANCE ASSESSIMENT (after Bertram-Howery and Hunter, 1989a)

\begin{tabular}{cl}
$\begin{array}{c}\text { Type of } \\
\text { Uncertainty }\end{array}$ & $\begin{array}{c}\text { Technique for Assessing } \\
\text { or Reducing Uncertainty }\end{array}$ \\
\hline $\begin{array}{c}\text { Scenarios } \\
\text { (Completeness, } \\
\text { Logic, and Probabilities) }\end{array}$ & $\begin{array}{l}\text { Expert Judgment and } \\
\text { Peer Review; } \\
\text { Quality Assurance }\end{array}$ \\
Conceptual Models & Expert Judgment and \\
& Peer Review; \\
& Sensitivity Analysis; \\
& Quality Assurance \\
& Expert Judgment and \\
Computer Models & Peer Review; \\
& Verification and Validation*; \\
& Sensitivity Analysis; \\
& Quality Assurance \\
& Expert Judgment and \\
Parameter Values & Peer Review; \\
and Variability & Data-Collection Programs; \\
& Sampling Techniques; \\
& Sensitivity Analysis; \\
& Uncertainty Analysis; \\
& Quality Assurance
\end{tabular}

*to the extent possible

The Standard requires that the results of the performance assessment be incorporated into an overall probability distribution of cumulative release to the extent practicable. In Appendix B, the EPA suggests that the results be assembled into a single complementary cumulative distribution function (CCDF) that indicates the probability of exceeding various levels of cumulative release (Figure 2-2). The EPA suggests that this single curve can incorporate all parameter and scenario uncertainty, and if this single distribution function meets the requirement of $\S 191.13$, then a disposal system can be considered to be in compliance with the Containment Requirements (BertramHowery and Hunter, 1989b). Thus, EPA states that satisfying the numeric 


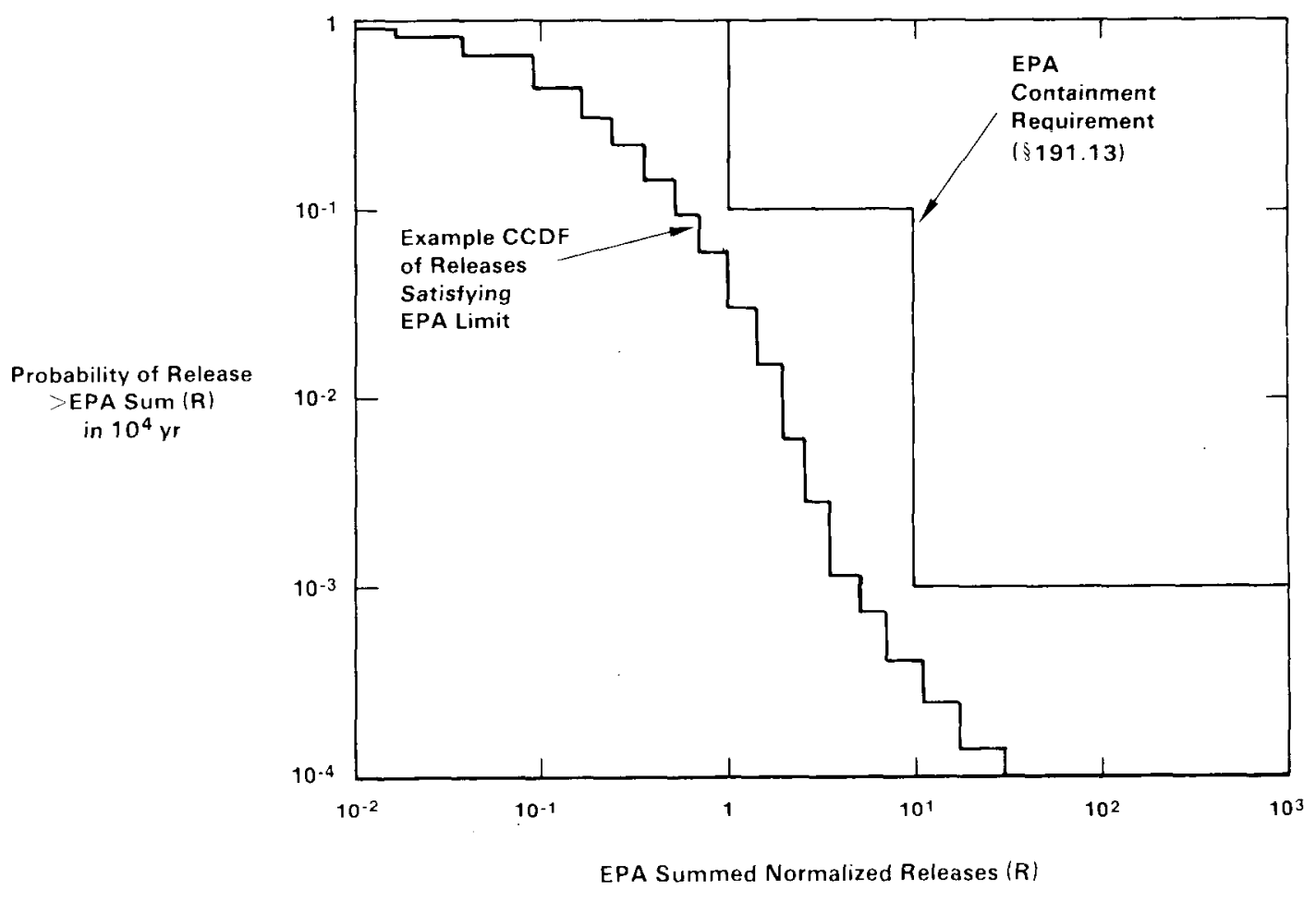

TPI-6342-17-0

Figure 2-2. Hypothetical CCDF Illustrating Compliance with the Containment Requirements (after Rechard, 1989).

requirements is sufficient to demonstrate compliance with $\S 191.13$ but does not say it is absolutely necessary.

The EPA acknowledged that implementation of the Containment Requirements might require modification of those standards in the future. This implementation

...will require collection of a great deal of data during site characterization, resolution of the inevitable uncertainties in such information, and adaptation of this information into probabilistic risk assessments. Although [EPA] is currently confident that this will be successfully accomplished, such projections over thousands of years to determine compliance with an environmental regulation are unprecedented. If--after substantial experience with these analyses is acquired--disposal systems that clearly provide good isolation cannot reasonably be shown to comply with the containment requirements, the [EPA] would consider whether modifications to Subpart B were appropriate... (U.S. EPA, 1985, p. 38074).

This statement implies that there can be a basis for concluding that a system provides good isolation that does not totally depend upon the calculated CCDF. 


\section{ASSURANCE REQUIREMENTS}

6

The EPA has included Assurance Requirements ( $\$ 191.14$ ) in the Standard to provide the confidence needed for long-term compliance with the Containment Requirements for those facilities not regulated by the NRC. The Assurance Requirements include six provisions: active institutional controls; post.. closure monitoring for performance deviations; passive institutional controls; different types of barriers, encompassing both engineered and natural barriers; avoidance of sites where a reasonable expectation of future rescurce exploration exists, unless favorable disposal characteristics compensate; and the possibility of removal of wastes for a reasonable period of time. Some of the activities required to comply with the Assurance Requirements cannot be fully defined until after the performance assessment is well underway, because that assessment will identify parameters needed for certain of the requirements (Bertram-Howery and Hunter, 1989b).

\section{INDIVIDUAL PROTECTION REQUIREMENTS}

The Individual Protection Requirements ( $\$ 191.15$ ) necessitate the prediction of potential doses to man resulting from releases to the accessible environment during the first 1,000 years after closure of the repository, in the event that the PA predicts such releases. Although challenges to this requirement contributed to the remand of Subpart B to the EPA, the WIPP Project cannot assume that the requirement will change when the Standard is repromulgated.

The methodology developed for assessing compliance with the Containment Requirements can be used to predict releases in order to estimate doses as specified by the Individual Protection Requirements. However, the EPA suggests in Appendix B of the Standard that compliance with $\S 191.15$ can be determined based upon "best estimate" predictions rather than a CCDF. Thus, when uncertainties are considered, only the mean or median of the appropriate distributions, whichever is greater, need fall below the limits, according to Appendix B. 
Chapter II: Application of Subpart B to the WIPP

The Individual Protection Requirements limit the annual dose equivalent from the disposal system to any member of the public in the accessible environment to 25 millirems to the whole body or 75 millirems to any critical organ. These requirements apply to undisturbed performance of the disposal system, considering all potential release and dose pathways for 1,000 years after disposal. The Standard requires that modeled individuals be assumed to consume $2 \ell(0.5 \mathrm{gal}) /$ day of drinking water from a significant source of groundwater, which is specifically defined in the standard.

"Undisturbed performance" means predicted behavior of a disposal system, including consideration of the uncertainties in predicted behavior, if the disposal system is not disrupted by human intrusion or the occurrence of unlikely natural events ( $\$ 191.12(\mathrm{p})$ ).

"Significant source of groundwater" as used in this Part, means: (1) An aquifer that: (i) Is saturated with water having less than 10,000 milligrams per liter of total dissolved solids; (ii) is within 2,500 feet of the land surface; (iii) has a transmissivity greater than 200 gallons per day per foot, provided that any formation or part of a formation included within the source of groundwater has a hydraulic conductivity greater than 2 gallons per day per square foot; and (iv) is capable of continuously yielding at least 10,000 gallons per day to a pumped or flowing well for a period of at least a year; or (2) an aquifer that provides the primary source of water for a community water system as of [November 18, 1985].

Human intrusion means any human activities other than those directly related to repository characterization, construction, operation, or monitoring. The effects of intrusion are specifically excluded for the undisturbed performance analysis (U.S. DOE, 1989b).

Unlikely natural events at the WIPP will be those events and processes that have not occurred in the past at a sufficient rate to affect the Salado Formation at the repository horizon within the controlled area in such a way as to have caused the release of radionuclides, had they been present. Only the presence of groundwater has affected the Salado in the vicinity of the WIPP at the repository horizon for the past several million years. Therefore, the WIPP Project will model only groundwater flow and the effects of the repository as the undisturbed performance (U.S. DOE, 1989b).

No water-bearing unit at the WIPP meets the first definition of significant source of groundwater everywhere, because the level of dissolved solids is 
high and transmissivity is low in most places (Mercer, 1983); however, the WIPP Project will assume that any portion of an aquifer that meets the first definition is a significant source of groundwater. Communication between nonqualifying and qualifying portions will be evaluated. No community water system is being supplied by any aquifer near the WIPP, therefore no aquifer meets the second definition of significant source of groundwater (U.S. DOE, $1989 b)$.

The Dewey Lake Red Beds are saturated only in some areas. Neither the Magenta Dolomite Member nor the Culebra Dolomite Member of the Rustler Formation (Figure 1-4) appears to be a significant source of groundwater. Aquifers below the Salado Formation are more than $760 \mathrm{~m}(2,500 \mathrm{ft})$ below the land surface at the WIPP. The nearest aquifer that meets the first definition of a significant source of groundwater over its entire extent is the alluvial and valley-fill aquifer along the Pecos River at Malaga Bend, $26 \mathrm{~km}$ (16 mi) away. Communication between this aquifer and any other aquifers in the vicinity of the WIPP will be evaluated (U.S. DOE, 1989b).

No releases from the repository/shaft system are expected to occur within 1,000 years (Lappin et al., 1989; Marietta et al., 1989); therefore, dose predictions for undisturbed performance may be unnecessary.

\section{GROUNDWATER PROTECTION REQUIREMENTS}

Special sources of groundwater are protected from contamination at levels greater than certain 1imits by the Groundwater Protection Requirements (§ 191.16).

\section{SPECIAL SOURCES OF GROUNDWATER}

Special sources of groundwater are defined as ...those Class I groundwaters identified in accordance with the [EPA's] Ground-Water Protection Strategy published in August 1984 that: (1) Are within the controlled area encompassing a disposal system or are less than five kilometers beyond the controlled area; (2) are supplying drinking water for thousands of persons as of the date the [DOE] 
1 chooses a location within that area for detailed characterization as a

2 potential site for a disposal system...; and (3) are irreplaceable in

3 that no reasonable alternative source of drinking water is available to

4 that population ( $\$ 191.12(0)$ ).

\section{REQUIREMENT DOES NOT APPLY TO THE WIPP}

10

At the time the DOE chose the WIPP location (and indeed at present), no source of water within $5 \mathrm{~km}(3 \mathrm{mi})$ of the maximum allowable extent of the controlled area (Figure 2-3) was supplying drinking water for thousands (or even tens) of persons. Therefore, no special sources of groundwater will be affected by the

14 WIPP project and the requirement to analyze radionuclide concentrations in 15 such groundwater does not apply. 


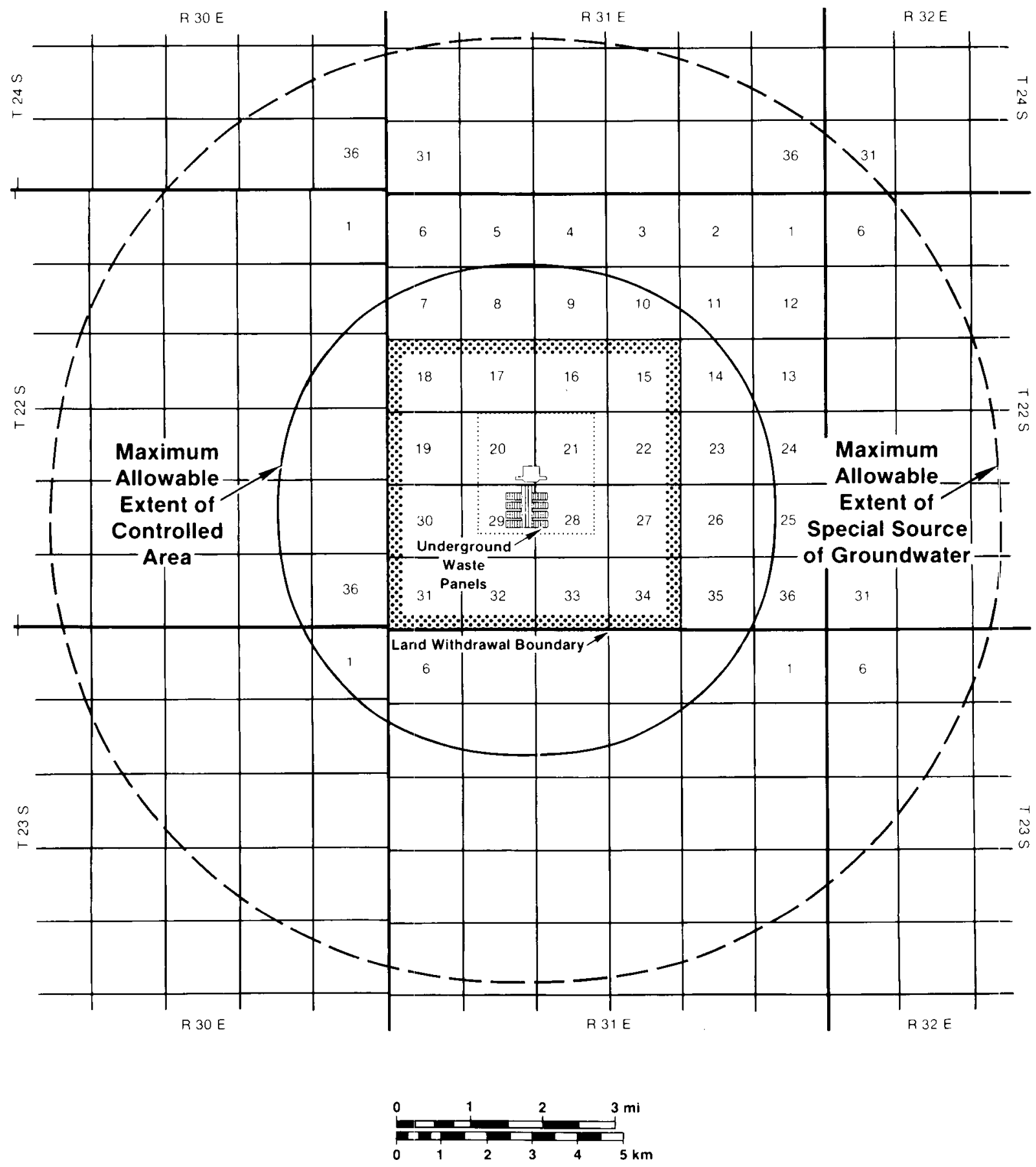

TRI-6342-230-0

Figure 2-3. Illustration of Certain Definitions (after U.S. DOE, 1989b). The dashed line, drawn $5 \mathrm{~km}$ ( $3 \mathrm{mi}$ ) from the maximum allowable extent of the controlled area ( $\$ 191.12(\mathrm{~g})$ ), shows the maximum area in which the occurrence of a special source of groundwater ( $\S 191.12(0)$ ) is of regulatory interest. The performance assessment will help determine the extent of the WIPP controlled area. 


\section{COMPLIANCE ASSESSMENT PHILOSOPHY AND METHODOLOGY OVERVIEW}

The long-term performance requirements of Subpart B of the Standard are the focus of this report. For the WIPP, two requirements must be met. The Containment Requirements ( $\S 191.13$ ) limit cumulative releases of radioactive materials to the accessible environment for 10,000 years. The Individual Protection Requirements ( $\$ 191.15$ ) limit radiation doses to members of the public in the accessible environment for 1,000 years. First, the philosophy for assessing compliance of the WIPP with these requirements is discussed. Second, a methodology for performing this assessment is described.

\section{PHILOSOPHY}

\section{THE CONTAINMENT REQUIREMENTS}

The Standard ( $\$ 191.13(a)$ ) requires that performance assessments be used to determine whether cumulative releases to the accessible environment for 10,000 years after disposal from all significant processes and events that may affect the disposal system will meet specific release limits (U.S. EPA, 1985). Whereas no specific requirements are indicated as to how compliance is to be demonstrated, Appendix B to Subpart B of the Standard describes how compliance can be determined by use of a complementary cumulative distribution function $(\mathrm{CCDF})$.

A performance-assessment methodology consists of the following parts (Hunter et al., 1986; Cranwell et al., 1987; Cranwell et al., 1989): (1) procedures for scenario development, (2) models for use in determining releases to the accessible environment, and (3) a procedure for a compliance assessment with the regulatory standards. Descriptions of the procedure for compliance assessment based on the construction of a CCDF are available (Cranwell et al., 1982; Pepping et al., 1983; Hunter et al., 1986; Cranwell et al., 1987; Campbe11 and Cranwe11, 1988; and Rechard, 1989). 
Scenarios are sets of naturally occurring, human-induced, or waste-induced conditions that represent realistic potential future states of the repository, the geologic systems, and the groundwater flow systems that could affect the migration and transport of radionuclides from the repository to the accessible environment (Cranwell et al., 1989). Whereas the Standard does not mention "scenarios" as such, the need for their development is implied in $\S 191.13$.

Several different techniques have been proposed for the development of scenarios. The basic steps are summarized (Cranwell et al., 1982) as: identifying a comprehensive list of events and processes that may affect the long-term isolation of the radioactive waste, (2) classifying the events and processes to aid in completion arguments, (3) screening the events and processes based on well-defined criteria, (4) forming scenarios by combining the remaining events and processes, and (5) screening the scenarios by welldefined criteria. Appendix B of the Standard indicates that individual events and processes, and by implication their combined form as scenarios, do not have to be considered in performance assessment if their probability of occurrence is less than one chance in 10,000 in 10,000 years, or their omission is not expected to significantly change the probability distribution of cumulative releases. Another screening criterion is the physical reasonableness of the event or process for a specific disposal system and of the combination of events and processes in scenarios.

Scenario development provides a means for analysis of uncertainty in future states of the disposal system. Uncertainty in the events and processes that make up a scenario is represented by assigning a probability of occurrence to each event or process. The probability of occurrence of the scenario is derived from the constituent events and processes. These constituent probabilities are estimated where possible and determined by expert judgment when data is insufficient to support probability estimates.

The goal of the scenario-development procedure is to develop a comprehensive set of mutually exclusive scenarios that could result in the release of radionuclides to the accessible environment. To initiate an analysis, the physical processes being modeled are carefully defined, and multi-dimensional 
conceptual and mathematical models are developed that adequately describe the processes over the range of conditions to be modeled. For these models to be credible, phenomena and parameters that are determined to be important to the performance measure by sensitivity analyses must be included.

Individual scenarios that significantly affect the groundwater-flow regime are usually analyzed separately to identify important parameters and examine the scenario's affect on the conceptual model. These sensitivity analyses may use complex, two- or three-dimensional models of groundwater flow and transport. When the flow behavior and other parameters are better understood, simpley models of flow and transport and other processes that mimic the predicted behavior can be substituted for use in repetitive uncertainty analyses.

An important aspect of model development and application is model verification and validation. Verification ensures that the model correctly performs the operations specified in the numerical procedures. Verification does not assess the physical correctness of the solution, therefore, a model is verified when it numerically solves the specified problem correctly. Model validation is the procedure that addresses physical correctness. Validation usually involves a test of the model output against available data to ensure that the model is a correct representation of natural processes or systems for which it is intended. Such tests evaluate both the mathematical and related conceptual models. Few models that describe environmental systems can ever be fully validated on the space and time scales of interest. Rather, model adequacy for the particular application is a subjective judgment of the analyst based on partial validation exercises.

In principle, models used for performance assessment can be either deterministic or stochastic. Deterministic models do not explicitly account for uncertainties, whereas stochastic models may. The models currently being considered for use in the WIPP performance assessment are all deterministic, because stochastic models incorporating the many processes affecting performance of the WIPP disposal system would be too complex to develop and use effectively. Many stochastic processes are included through deterministic assumptions. Monte Carlo sampling techniques are used to perform stochastic analysis with systems of deterministic models. 
Chapter III: Compliance Assessment Philosophy and Methodology Overview

The physical processes by which radioactive material can be released to the accessible environment are complex. As a result, the models being used for the WIPP performance assessment are generally complex, and the results of the consequence estimates have large uncertainties associated with them. In general, uncertainty in the consequence modeling has two components: model uncertainty and data uncertainty (Cranwell and Helton, 1981). Model uncertainty is partially addressed by verification and validation. There are always unquantifiable uncertainties associated with judging model adequacy. Because validation of environmental models on the time scales of interest is impossible, model uncertainty must ultimately be assessed by subjective judgments based on partial model validation. In WIPP performance assessment, data uncertainties are handled by first selecting ranges and distributions for each parameter and then using a statistical sampling procedure to select parameter values for each deterministic calculation. Many sampled values are used to generate a distribution of consequence values, and the range and distribution of these values reflect data uncertainty.

\section{THE INDIVIDUAL PROTECTION REQUIREMENTS}

The Standard ( $\$ 191.15$ ) requires that whole-body and critical-organ doses be calculated for radionuclide releases to the accessible environment from all pathways assuming undisturbed conditions during the first 1,000 years after disposal. One of the products of scenario development for the Containment Requirements will be a scenario for undisturbed conditions. The techniques for analyzing this scenario will be available through the performance assessment required by the Containment Requirements. If releases to the accessible environment are predicted to occur during the first 1,000 years after closure, compliance with the Standard will be determined using pathway and dosimetry models described below.

\section{METHODOLOGY OVERVIEW}

The WIPP compliance assessment methodology comprises the procedures and tools necessary for implementing the compliance assessment philosophy. Migration of radionuclides from the repository is estimated by applying a collection of techniques and computer codes in the methodology. The methodology consists of 
characterization of the disposal system and the region, techniques for scenario development and probability estimates, computer codes for consequence modeling, statistical techniques for uncertainty and sensitivity analyses, and a procedure that assembles the above results into a CCDF.

The methodology (Figure 3-1) builds on previous work at SNL for high-leve1waste disposal in hypothetical repositories in bedded salt (Cranwell et al., 1987) and basalt (Bonano et al., 1988). It also builds on work done at SNL in collaboration with the International Nuclear Energy Agency of the Organization for Economic and Cooperative Development (NEA, 1988) to analyze empirical data for potential subseabed repositories.

The first step in the analysis is describing the disposal system. Characteristics of the controlled area, the repository/shaft system, and the waste are described. Based on the disposal system description, those events and processes that are most likely to contribute to migration of radionuclides from the repository/shaft system and transport to the accessible environment are identified and screened. Once these events and processes have been developed into scenarios and these scenarios have been screened based on physical reasonableness and probability, a sequence of models is used to estimate the consequence of each remaining scenario (Figure 3-2).

The physical processes simulated in consequence modeling for the Containment Requirements include groundwater flow; repository resaturation from brine inflow; gas generation from corrosion and microbiological activity; room closure from salt creep; radionuclide transport in rooms, drifts, MB139, and shafts; and radionuclide transport in the geosphere. For the Individual Protection Requirements, radionuclide transport to and dispersion in the biosphere (i.e., surface and near-surface) and human intake of radionuclides must also be included.

Groundwater flow is simulated at regional and local scales for computational efficiency. The Los Medaños regional and local models are coupled through boundary conditions that are passed from regional to local models. For calibration, each model can provide boundary conditions to the other. These 

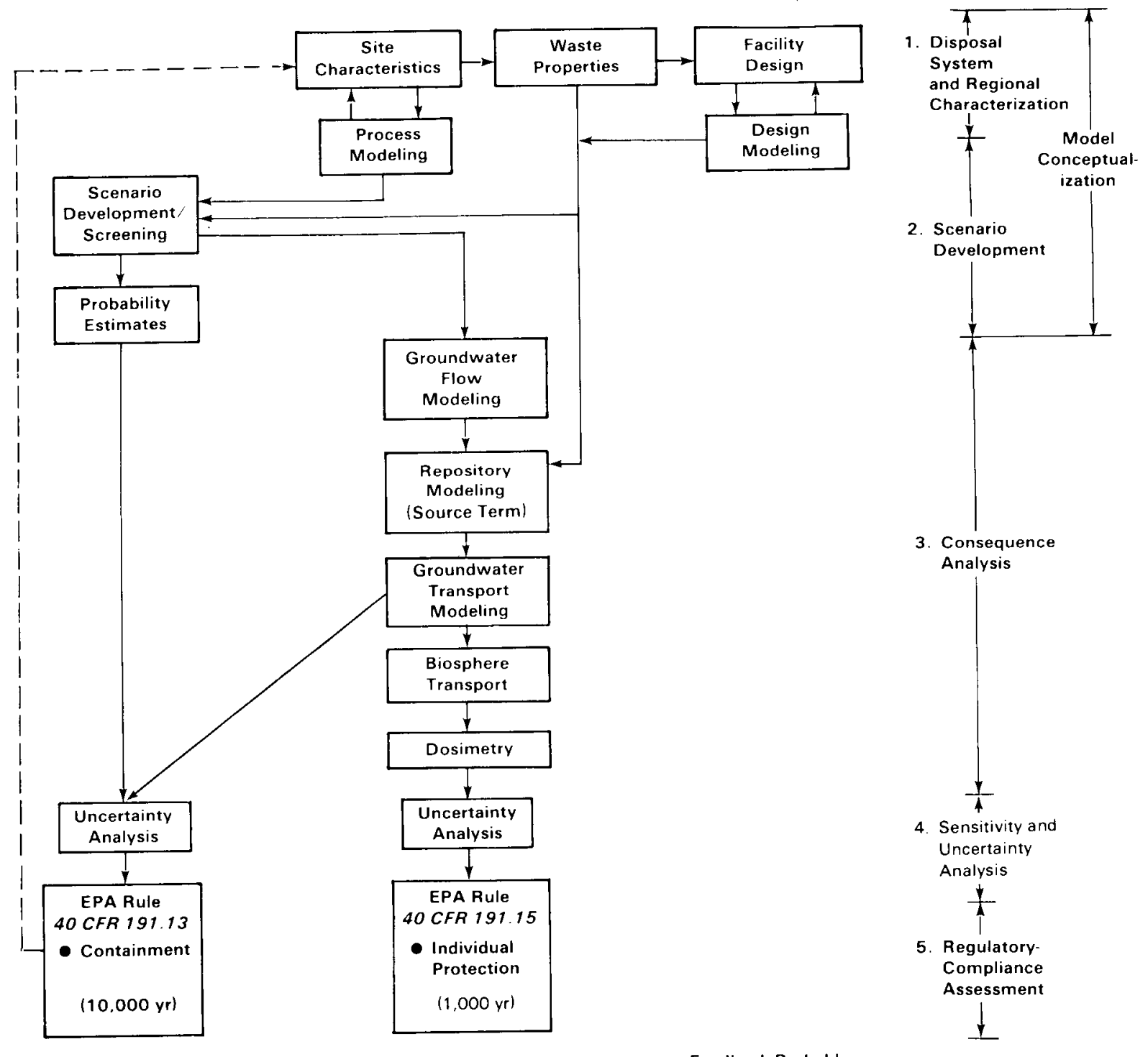

Figure 3-1. Compliance Assessment Methodology Structure (after Rechard, 1989). 
- Hydrologic Parameters

- Geologic Properties

- Hydrologic Parameters

- Geologic Properties

- Facility Design

- Waste Properties

- Material Properties

- Hydrologic Parameters

- Geologic Properties

- Chemical Parameters

- Waste Properties

- Chemical Parameters

- Surface-Water, Air, and Particle Flow Rates

- Waste Properties

- Potential Food Chains

- Ingestion/Inhalation Rates

- Internal/External Dose Rates

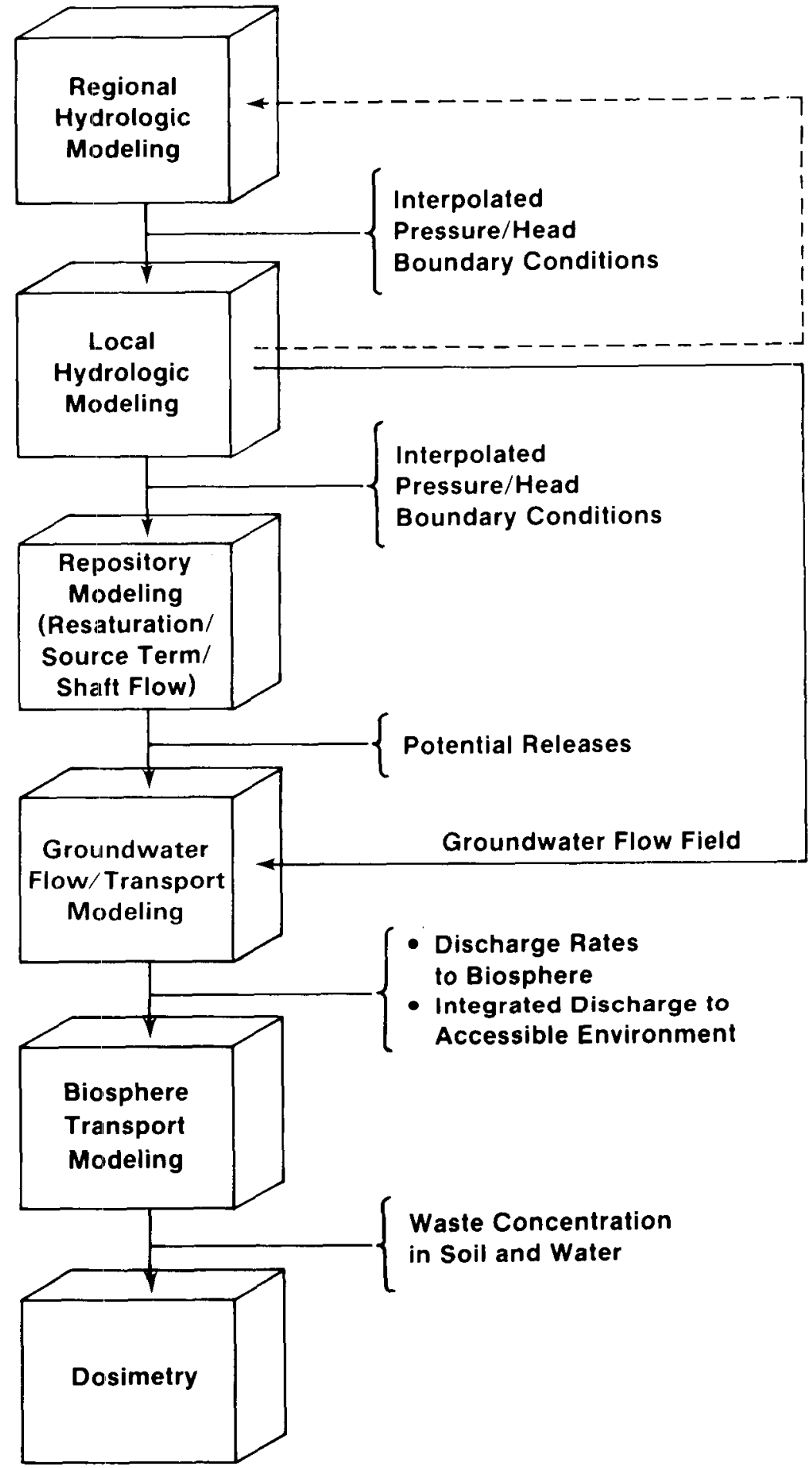

TR1-6334-16-0

Figure 3-2. A Sequence of Codes for Consequence Modeling (Rechard, 1989). 
hydrologic models provide flow fields necessary for calculating radionuclide transport to the accessible environment where the cumulated release of each radionuclide can be obtained by integrating the discharge rate over 10,000 years .

For the Individual Protection Requirements, the biosphere transport code simulates the movement of radionuclides through the surface and near-surface environment and uptake by humans. This information is then used to estimate the whole-body and critical-organ doses.

For the Containment Requirements, comparison with the Standard can be made by a probability vs. consequence curve in the form of a CCDF. The CCDF of a value $\chi$ of consequence $X$ indicates the probability of $X$ having values greater than $\chi$. Because consequence models currently being considered for use in WIPP performance assessment are deterministic models, the uncertainty of input data can be incorporated into the analysis through Monte Carlo sampling of these data. The following is a brief description of an approach to generate a CCDF using a Monte Carlo sampling technique.

Appropriate ranges and distributions for model parameters are chosen for each significant scenario. This establishes a set of variables for characterizing data uncertainties over all scenarios. The distributions are statistically sampled to obtain sets of values (referred to as "input vectors"). For all scenarios, $m$ input vectors are generated. The same $m$ input vectors are used for $m$ consequence calculations for each scenario, but not all parameters may be used in a single scenario analysis. Cumulative release to the accessible environment is the consequence calculated for each input vector, producing a distribution of cumulative releases for each scenario. A single CCDF is then generated by normalizing each consequence by the EPA limits for each significant scenario, ranking these normalized releases from largest to smallest, calculating the probability that a release is larger than some $R_{0}$ from this ranking, weighting this probability by the probability of the associated scenario, summing over all significant scenarios, and plotting the result against $R_{0}$ for each combination of $R_{0}$ and weighted sum of probabilities to obtain a probability versus consequence curve (step function) that is the CCDF (Cranwell et al., 1982; Pepping et al., 1983; Hunter et al., 1986; 
Cranwe11 et al., 1987; Campbell and Cranwe11, 1988; and Rechard, 1989). If all portions of the CCDF (Figure 2-2) lie within the envelope of the EPA's Containment Requirements, compliance is indicated.

The compliance assessment methodology uses a modular system of computer codes controlled by a computerized executive package. This system is referred to as the "Compliance Assessment Methodology CONtroller" (CAMCON). CAMCON contains translators that automatically translate the output of one computer code into the appropriate input format for the next code. In this way, the executive controller can perform a computation for $m$ input vectors through the entire set of modules with little operator intervention.

CAMCON contains three data bases that are strictly controlled for qualityassurance (QA) purposes. The primary data base comprises observational data in a reduced form that are transformed, either objectively/subjectively using interpolations or optimal-estimation routines or totally subjectively by expert judgment, into a secondary data base that can be accessed by the executive controller. Transformation of primary data to secondary data is carefully quality controlled. During the calculation of cumulative release, the executive controller creates a computational data base that is generated anew for each input vector.

An important feature of CAMCON is that QA of calculations, data manipulation, and file management is explicitly included and automatically controlled. This QA process guarantees reproducibility for each computation and minimizes human error. QA for the performance assessment is included in the SNL QA program for the WIPP Project (SNL, 1988). 


\section{CONTAINMENT REQUIREMENTS}

The Containment Requirements ( $\S 191.13$ ) are described in Chapter II (also Appendix A). An overview of a methodology for assessing compliance with this requirement is provided in Chapter III. This chapter applies the methodology to the WIPP. Because research and development work is continuing, required data and understanding for some parts of the system are incomplete (BertrainHowery and Hunter, 1989a). Subsystems where work is nearly complete are well understood and are described in more detail in the following sections. These sections are indicated clearly below. Subsystems that are not well understood are described in less detail and include considerable judgment. Such judgrnent is based on the experience of the research staff, and must be confirmed with data-acquisition programs, design-demonstration tests, and (to the extent possible) model validation. These sections are also indicated clearly below.

\section{SCENARIOS}

Performance assessment for the Containment Requirements consists of a series of analyses that predict the performance of the disposal system for 10,000 years and compare the predicted performance with the Standard. Performance assessment includes scenario development and screening and probability assignment. A scenario is a combination of events and processes representing a possible future state of the disposal system. There are four criteria for using scenarios to construct a CCDF for evaluating whether a disposal system meets the Containment Requirements: (1) the set of scenarios selected for analysis must comprehensively describe all possible future states of the disposal system, (2) scenarios in the set must be mutually exclusive, (3) consequences of each scenario must be estimated, and (4) probability of occurrence of each scenario must be assigned. Analyses of consequences of initial scenarios may suggest areas of further research, which may in turn suggest new scenarios.

The combination of all the events and processes that might affect a disposal system would produce an extremely large number of scenarios, most of which 
would have little or no effect on the performance of the disposal system. Certain criteria established in the standard allow for the elimination from consideration of those events and processes (and by implication scenarios) having low probability of occurrence and/or having little consequence. Both of these criteria are described in Appendix B of the Standard (reproduced in Appendix $A$ to this report). In addition, the standard restricts to 10,000 years the time period over which these events and processes must be considered.

This section identifies events and processes considered for scenario development for the WIPP performance assessment. Barring unexpected results from research programs or consequence analysis, a subset of these events and processes will be selected for the set of scenarios to be used for the final comparison of WIPP's predicted performance to the Containment Requirements (§ 191.13).

\section{EVENTS AND PROCESSES RETAINED}

Several reports have described events and processes that could result in radionuclide releases from the WIPP disposal system (e.g., Claiborne and Gera, 1974; Bingham and Barr, 1979; U.S. DOE, 1980a; Environmental Evaluation Group, 1980; Hunter, 1989) and for releases from real and hypothetical bedded-salt repositories other than WIPP (e.g., Cranwell et al., 1982; Cranwell et al., 1989). New evidence and new regulatory developments combined to make some of the events and processes of earlier workers unimportant (Hunter, 1989). Other evidence necessitates the consideration of events and processes not previously considered. Although these events and processes (Table 4-1) represent a nearly final set, the set will be iteratively revised during consequence analysis and data collection (Hunter, 1989).

Effects of human intrusion, repository construction, and waste emplacement dominate events considered in this section. For the most part, natural events and processes other than groundwater flow and climatic change probably will not contribute to eventual development of a final scenario set. Most natural 
3

TABLE 4-1. EVENTS AND PROCESSES RETAINED FOR SCENARIO DEVELOPMENT (after Hunter, 1989)

Groundwater Flow

Climate Change

Drilling into Repository

Effects of Pressurized Brine Occurrence

Effects of Mining for Resources

Seal Performance

Leaching

Nuclear Criticality

Waste/Rock Interaction

Waste Effects (e.g., gas generation, radiolysis)

events that occur in southeastern New Mexico take place so infrequently, affect such small areas, or change the system so slightly that they cannot contribute to scenarios that are of concern to the performance assessment. Thus, events and processes considered are groundwater flow, climatic change, human intrusion, seal performance, and near-field dissolution. Other phenomena considered include effects of pressurized brine injection, waste/rock interactions, and waste effects.

\section{EVENTS AND PROCESSES SCREENING}

Four screening criteria follow the guidelines in the Standard (e.g., Cranwell et al., 1989; Hunter et al., 1986): physical reasonableness, probability, potential consequences, and regulatory guidelines. A number of events and processes were screened from further consideration (Table 4-2) in the WIPP performance assessment on the basis of one or more of these criteria (Hunter, 1989). For the most part, events and processes that were dismissed have very low probabilities, although some also can be dismissed using one or more of the other criteria.

Four dissolutional processes were dismissed. Dissolution of the repository horizon by fresh water (except for solution mining) was dismissed because it 
5

6

7

8

9

10

11

12

13

15

16

TABLE 4-2. EVENTS AND PROCESSES DISMISSED FROM FURTHER ANALYSIS (after Hunter, 1989)

Dissolution Other Than Leaching

Breccia-Pipe Formation

Migration of Brine Aquifer

Migration of Brine Inclusions

Induced Diapirism

Exhumation, Sedimentation

Faulting

Diffusion
Glaciation

Igneous Intrusion

Meteorite Impact

Sabotage, Warfare

Subsidence

Thermal Effects from Waste

Uplift of Surface

is physically unreasonable. Migration of the Rustler-Salado residuum was dismissed on the basis of negligible consequence. Vertical dissolution would not expose a repository at WIPP for 2 to 3 million years and was dismissed because it is of no consequence on the regulatory time scale. Breccia pipes were dismissed on three premises. First, the occurrence of a breccia pipe at the WIPP is not physically reasonable. Second, granting for the sake of argument that one might occur, the probability of intersecting the repository is less than the cutoff in the Standard. Third, preliminary analysis of consequences (Spiegler, 1982) has shown them to be negligible, or even zero, during the 10,000-year regulatory period (Hunter, 1989).

Induced diapirism in the salt is physically unreasonable and should not be retained for consequence analysis. Similarly, diffusion of significant amounts of waste to the accessible environment is physically unreasonable. Releases resulting from migration of intracrystalline brine inclusions through salt in response to thermal gradients were dismissed on the basis of physical unreasonableness. Glacial loading of the disposal system was also considered to be physically unreasonable, although climatic changes accompanying continental or alpine glaciation were retained (Hunter, 1989).

Neither exhumation by erosional processes nor significant sedimentation are reasonable within 10,000 years. Thermal effects and surface uplift were also dismissed on the basis of negligible consequence. Faulting, igneous 
intrusion, and meteorite impact have low probability. The analysis of release of waste from the WIPP disposal system by sabotage or warfare is unnecessary according to the Standard, and is improbable in any event (Hunter, 1989).

Three kinds of subsidence might occur at and near the WIPP: subsidence of the overlying rock into the repository, subsidence as a result of conventional or solution mining for potash, or regional subsidence as a result of oil and gas extraction. Subsidence could in turn conceivably affect the disposal system in three ways: by increasing the hydraulic conductivity of the country rcck, by creating fractures through the country rock, or by disturbing the surface drainage. Increased hydraulic conductivity and transport through fractures that result from subsidence were dismissed on the basis of negligible consequence. Increased releases as a result of subsidence and disruption of surface drainage was considered to be physically unreasonable (Hunter, 1989). Increased vertical connection that results from subsidence and its effect on recharge is retained, because it may be important in combination with extreme climatic changes.

\section{SCENARIO DEVELOPMENT, SCREENING PROCEDURE, AND PROBABILITY ASSIGNMENT}

Those events and processes that survive screening are combined to form scenarios. For the construction of a CCDF, the scenarios must be comprehensive and mutually exclusive. In the past, events and processes were combined by the use of event trees (Bingham and Barr, 1979; Hunter, 1983; Hunter et al., 1982; Hunter et al., 1983). An event tree is an inductive logic method for identifying possible outcomes of a given initiating event (McCormick, 1981). Once the systems that can be utilized after a failure are identified and enumerated, the failure and success states are identified through bifurcations within the tree. If partial failures are considered, a greater number of branches are needed. The result is an event tree that provides accident sequences associated with an initiating event. Analyses of this type commonly are used to assess potential accidents at nuclear power plants (e.g., U.S. NRC, 1975).

The disadvantages of using event trees to develop scenarios for natural systems are: (1) the imposed temporal relationship of events and processes to 
one another, (2) the apparent arbitrariness of branching within the tree, (3) the inability to assure completeness of the final scenario set, and (4) the inability of the tree to handle feedback loops, whereby development along one branch may change the systems to the point where the branching that resulted in that scenario will be reversed. In addition, parameter values commonly are used to identify separate branches of the tree, thereby implying that the final scenarios are not mutually exclusive and creating confusion with both the application and interpretation of uncertainty analyses.

\section{Logic diagrams may be used to resolve the above concerns (Cranwell et al.,} 1989). Hypothetical release and transport events and processes are combined to form scenarios through the use of a logic diagram (Figure 4-1). Events and processes are phenomena (such as human intrusion events, which occur at a specific time, and surface erosion, which is a process occurring over a time period) that affect radionuclide transport through the disposal system. No temporal relationship between the events and processes is implied by their sequence across the diagram. Parameter values are not used to define the events and processes. At each junction within the diagram a yes/no decision is made as to whether the next event or process is added to the scenario. The logic diagram produces scenarios that are comprehensive, because all possible combinations of events and processes are developed; the scenarios are mutually exclusive, because each scenario is a unique set of events and processes; and possible feedback loops may be incorporated in models of the combination of events and processes. The time of occurrence for an event or process is a variable that can be sampled during the uncertainty analysis. Such a diagram is constructed after the events and processes have been screened (Table 4-1) so that only those events and processes retained for scenario development are used.

After the scenarios are developed, further screening can substantially reduce their number. The criteria for screening are physical reasonableness, probability of occurrence, and consequence. Whereas the events and processes that make up the scenarios are physically reasonable for the disposal system (because physically unreasonable events and processes were eliminated earlier), certain combinations may not be. These so-called "physically 


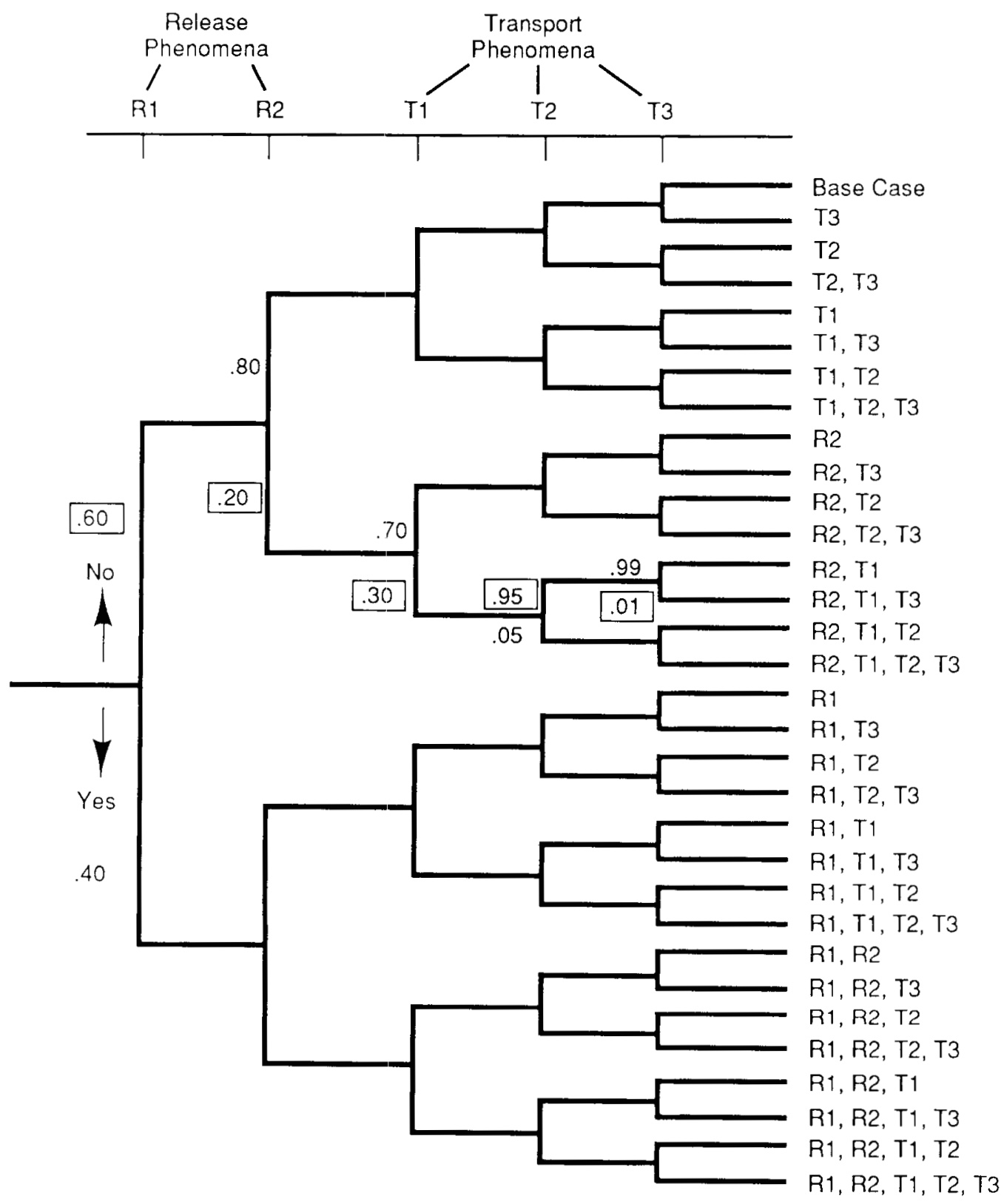

Indicates examples of probability values needed to determine probability of scenario R2T1T3

Probability of R2T1T3 $=(.60)(.20)(.30)(.95)(.01)=3.4 \times 10^{-4}$

TRI-6342-222-0

Figure 4-1. Example of a Logic Diagram with Two Release (R) and Three Transport ( $T$ ) Phenomena for the Construction of Scenarios (after Cranwell et al., 1989), Illustrating Scenario Probability Assignment. 
unreasonable" combinations can also be interpreted as having low probability. If possible, assigning probabilities and screening scenarios on this basis may be the more credible approach. In either case, these combinations may be eliminated from further consideration. As was the case with individual events and processes, each scenario with a probability of occurrence of less than one chance in 10,000 in 10,000 years can be eliminated from consideration. The scenario probability is determined after the probability of an occurrence and of a nonoccurrence of each event and process is estimated for the appropriate "yes" and "no" legs at each junction in the logic diagram (Figure 4-2). Final probability estimates for the events and processes retained in the WIPP scenario development have not been made. Opinions of panels of experts are likely to be used to estimate probabilities of occurrence. The scenario probability is the product of the probabilities of all the "yes" and "no" legs along the pathway to the complete scenario, assuming phenomena are independent.

This mechanical procedure for assigning probabilities to the scenarios uses previously estimated probabilities for individual events and processes. Guidelines for elimination of low-probability scenarios described in Appendix $B$ of the Standard will be rigorously applied to scenario screening.

A final screening criterion is consequence, meaning integrated discharge to the accessible environment for 10,000 years. Based on the guidance in Appendix $B$, scenarios can be eliminated from consideration if their omission would not significantly change the final CCDF. Because the degree to which the CCDF will be affected by omitting such scenarios is difficult to estimate prior to constructing the CCDF, only those scenarios that have no releases will be omitted from consideration. If a scenario results in no discharge within 10,000 years, it can be deleted from inclusion in the CCDF. An additional step is to eliminate duplicate scenarios. Each event and process in a scenario must contribute to the migration or transport of radionuclides. Any event or process that does not contribute is extraneous, and as a result, the scenario is effectively a duplicate of another scenario without the extraneous events or processes. 


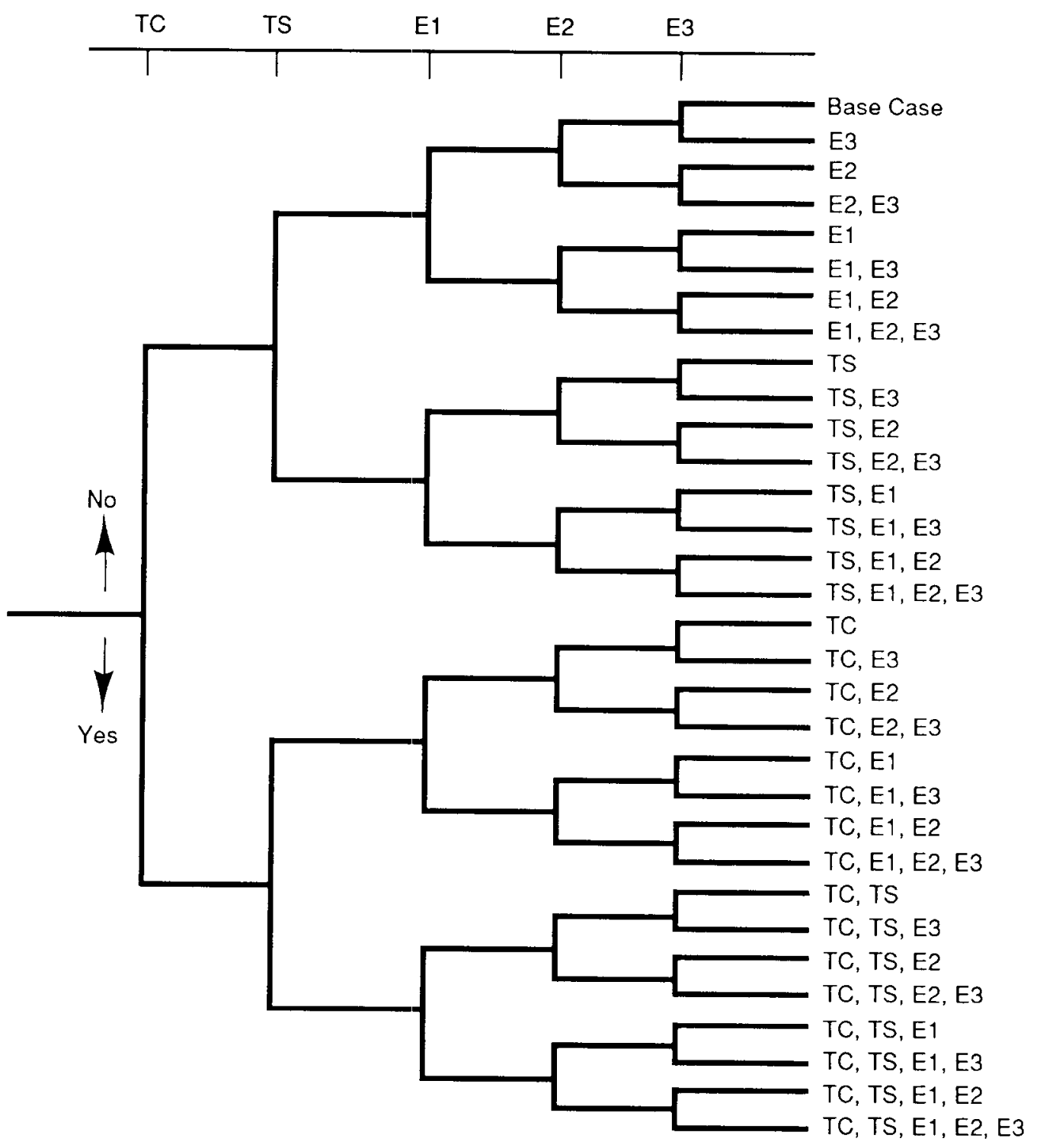

TC - Climatic Change

TS - Subsidence Resulting from Solution Mining of Potash

E1 - Drilling through Room and Brine Pocket

E2 - Drilling through or into a Room

E3 - Drilling Downgradient from Repository

TRI-6342-11.0

Figure 4-2. Potential Scenarios for the WIPP Disposal System. 
1 One of the products of a logic diagram is a "base-case" scenario (Figure 4-2).

2 This scenario consists of the repository in the geologic and hydrologic

3 systems and all events and processes that are certain to occur in all

4 scenarios. The parameters that define these events and processes have ranges

5 of values that may be the result of parameter uncertainty caused by natural

6 variability, experimental design, or limited understanding of the processes

7 involved, and their interaction. All other scenarios are imposed on these

8 base-case conditions. By imposing a disruptive scenario upon the base-case

9 scenario, the parameter values of the base-case scenario are replaced by the

10 corresponding values in the disruptive scenario. Parameters unaffected by the

11 disruptive scenario retain their base-case values. The probability of

12 occurrence of this scenario must be less than 1 , because this probability is

13 the product of the "no" legs along its path in the logic diagram.

14

For this scenario development methodology to be successfully applied to a specific location, the retained radionuclide migration and transport phenomena must be carefully selected according to the definitions required for the construction of a logic diagram. Some of the events and processes retained (Table 4-1) for WIPP must be redefined so that each branch point in the diagram is clearly a yes/no decision for which probabilities of occurrence (and non-occurrence) can be estimated. Phenomena such as groundwater flow, seal performance, leaching, and probably climate change are necessary parts of the analysis of each scenario, and are not branch points in the logic diagram.

\section{APPLICATION OF SCENARIO DEVELOPMENT AND SCREENING TO THE WIPP}

The following discussion on scenarios for the WIPP is only a preliminary, incomplete analysis. This is because the screening of individual events and processes and subsequent scenarios is based primarily on physical

reasonableness and arguments of physical reasonableness usually can be reduced to low probability. Because probabilities of occurrence of the scenarios are critical for screening and for constructing the CCDF, a formal process for estimating probabilities, with complete documentation, is required. For this reason, probabilities are not used to screen out events or processes, except where the probabilities are not specific to the WIPP disposal system and are 
well established in the literature. Consequence, either as effect on the system or as integrated release, has not been used, because the modeling capability for disposal system evaluation is still under development.

For preliminary analysis, a modified list of potentially disruptive events and processes from Table 4-1 is used. Groundwater flow, seal performance, leaching, waste/rock interaction, and waste effects are all part of the base case scenario (Figure 4-2). Effects of these processes are included through parameter variations in the uncertainty analysis of every scenario. Nuclear criticality is presumed to be a low probability event that will be screened separately. For preliminary analyses, climatic change is interpreted to mean unlikely climatic change (TC), such as pluvial periods, and not to mean natural climate variability, which would be part of the base case scenario. Whether such events must be considered in scenario development for constructing the final CCDF will be the subject of a separate scenarioscreening task. Included in this task would be "effects of mining for resources" because subsidence (TS) could enhance recharge in combination with an unlikely climatic event that results in increased recharge. Mining for resources need not be considered within the controlled area. Exploratory drilling must be considered. The remaining events to be included in preliminary scenario definitions are drilling into the waste-filled room (E2) and drilling through the room into a pressurized brine occurrence (E1). A withdrawal well downgradient (Lappin et al., 1989) could possibly pump radionuclide-bearing brine to the surface. Such withdrawal wells are included in preliminary scenario construction.

Figure 4-2 is the logic diagram for constructing all of the possible combinations of the five events and processes that survive the screening process. The next step in the procedure is to screen the scenarios. Two criteria can be used to quickly screen out some scenarios:

TC, TS, E3, TCE3, TCTS, and TCTSE3 - none contains a radionuclide-release mechanism (i.e., E1 or E2).

TS without TC - TS provides areas for additional recharge to occur, but TC is needed to provide significantly more precipitation. 
1 One of the requirements of a scenario is that each event and process within

2 the scenario must contribute to the migration or transport of radionuclides.

3 Figure 4-3 indicates which scenarios are retained after this preliminary

4 screening. The base case (UND) represents the UNDisturbed scenario (Bertram-

5 Howery and Hunter, 1989a). The next six scenarios, from the HUMan INTrusion

6 (HUMINT) group (Bertram-Howery and Hunter, 1989a), do not include TC. The

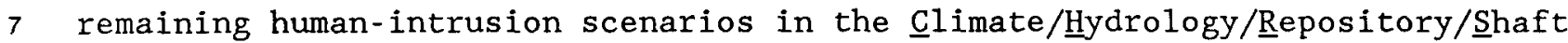

8 (CHRS) scenario group (Bertram-Howery and Hunter, 1989a) do include TC (and

9 TS). A methodology demonstration (Marietta et al., 1989) has provided

10 preliminary analyses of UND and HUMINT (i.e., seven scenarios). The CHRS

11 group will be screened using consequence as the criterion. If the preliminary

12 consequence analysis indicates that TC should be included in the base case

13 and, therefore, in all scenarios, the logic diagram (Figure 4-3) would be

14 decreased by the deletion of the first branch point.

15

The CHRS group includes human intrusion events, E1, E2, and E3, because significant release does not occur without E1 or E2 (Lappin et al., 1989). Preliminary analyses have not included the complete set of scenarios for the WIPP performance assessment. The addition of other events or processes may enlarge the set. Screening out some scenarios by low probability or consequence may reduce the set. The process of identifying and screening events and processes, constructing and screening scenarios, and assigning probabilities to final scenarios is a continuing process that occurs along with consequence modeling. Because the WIPP compliance assessment will be the first time that the performance assessment methodology has been applied to a real disposal system, the procedures for scenario development and probability assignment have not been tested before. Scenario (event/process) screening and probability assignment will always be based, in part, on incomplete data and models because "unlikely" events will be poorly understood. Alternate procedures for developing final scenarios and assigning probabilities to them will always exist. Credibility of whatever procedures are used often will depend on the subjective judgment of appropriate experts for each event or process. Expert judgment will be relied upon in selecting the procedure for WIPP scenario development, screening, and probability assignment. 


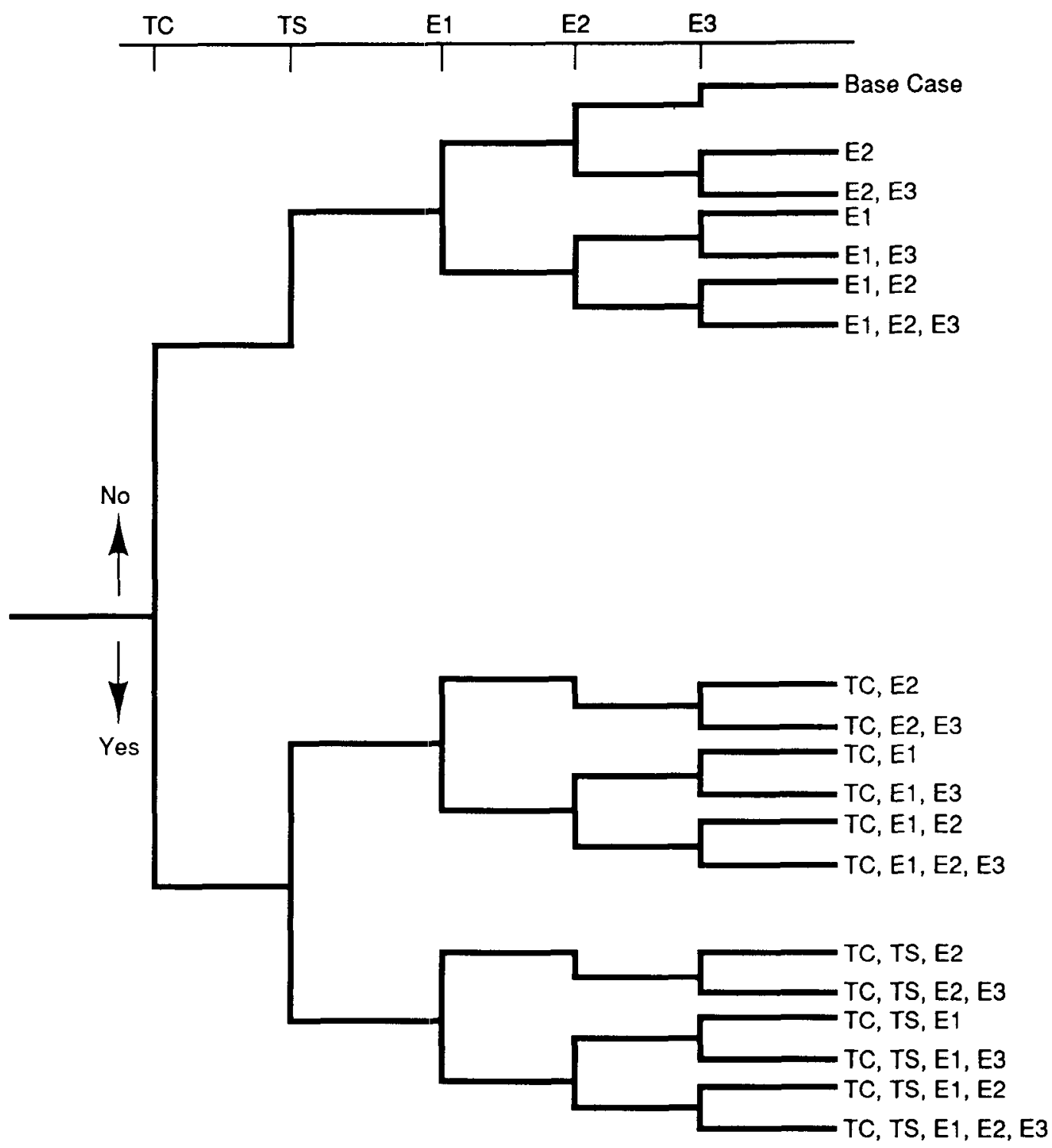

TC - Climatic Change

TS - Subsidence Resulting from Solution Mining of Potash

E1 - Drilling through Room and Brine Pocket

E2 - Drilling through or into a Room

E3 - Drilling Downgradient from Repository

TR1-6342-13-0

Figure 4-3. Preliminary Set of Scenarios for the WIPP Disposal System. 
The WIPP compliance assessment system contains the procedures and modeling tools necessary to perform consequence modeling and parameter uncertainty and sensitivity analyses. Radionuclide migration from the repository is estimated by applying a collection of techniques and computer codes in the methodology. This section describes conceptual models and computer codes that comprise the modules of the system used for consequence modeling and the statistical techniques used for uncertainty and sensitivity analyses. The components of the compliance assessment system are shown in Figure 3-2. These components are described in more detail in the following sections.

Characterization of the hydrology and geology above the Salado Formation is nearly complete. No plans exist to collect significantly more data on these formations except possibly for radionuclide retardations. The present thought to be adequate for supporting performance assessment. Therefore, discussions under Hydrogeology of the Northern Delaware Basin, Calibration of Groundwater Models, and Radionuclide Transport below, as well as their supporting documentation, are not expected to change significantly. Similarly, the computer software for controlling the repetitive calculations of uncertainty and sensitivity analyses is nearly complete, although some development and verification work is continuing. The discussions of CAMCON: Controller for Compliance Calculations and Parameter Uncertainty and Sensitivity Analyses, which describe this software, are not expected to change much either.

However, some of the discussion in the sections describing the repository and shaft subsystems is speculative, because data and understanding have not advanced far enough to confirm hypothesized behavior and to test component designs. Extensive work (Bertram-Howery and Hunter, 1989a) is continuing, so discussions of this work and their supporting documentation are expected to change significantly before the final Comparison is prepared. 


\section{A SUMMARY OF THE HYDROGEOLOGY OF THE NORTHERN DELAWARE BASIN}

An understanding of the hydrogeology of the Study Area is fundamental to Performance Assessment. Evaluation of travel time, possible flow paths, and radionuclide retardation depends on the regional geology and hydrology. The stratigraphy and hydrostratigraphic units important to modeling regional groundwater flow in the northern Delaware Basin are summarized in this section (Brinster, 1989).

The Los Medaños Study Area is in the north-central part of the Delaware Basin, which is in the southern part of the Pecos Valley of the Great Plains physiographic province. This province is between the high plains of west Texas and the Guadalupe and Sacramento Mountains of southeastern New Mexico. The Study Area is 40 by $40 \mathrm{~km}$ ( 25 by $25 \mathrm{mi}$ ) and extends from the Pecos River in southern Eddy County eastward into Lea County and southward from just inside the Delaware Basin to about $20 \mathrm{~km}$ (12 mi) north of the New Mexico-Texas state line (Figure 4-4). The Study Area includes two prominent surface features, Nash Draw, and The Dunes (Los Medaños).

Nash Draw, in the western part of the Study Area, is a broad shallow topographic depression with no external surface drainage. Nash Draw extencls almost $35 \mathrm{~km}$ (22 $\mathrm{mi}$ ) from the Pecos River east of Malaga, New Mexico, almost due north to the Maroon Cliffs area. This feature is bounded on the east by Livingston Ridge and on the west by Quahada Ridge.

The Dunes is a region of gently rolling hills that slopes upward to the northeast from Livingston Ridge on the eastern boundary of Nash Draw to a low ridge called "The Divide". The elevation of the Study Area ranges from $900 \mathrm{~m}$ $(2,900 \mathrm{ft})$ at Malaga Bend to $1,100 \mathrm{~m}(3,600 \mathrm{ft})$ near the Eddy-Lea County line. The WIPP is located in The Dunes.

\section{Hydrogeology of the Bell Canyon Formation}

The lowest hydrostratigraphic unit of interest to performance assessment in the Delaware Basin is the Bell Canyon Formation (Figure 4-5). The Bell 


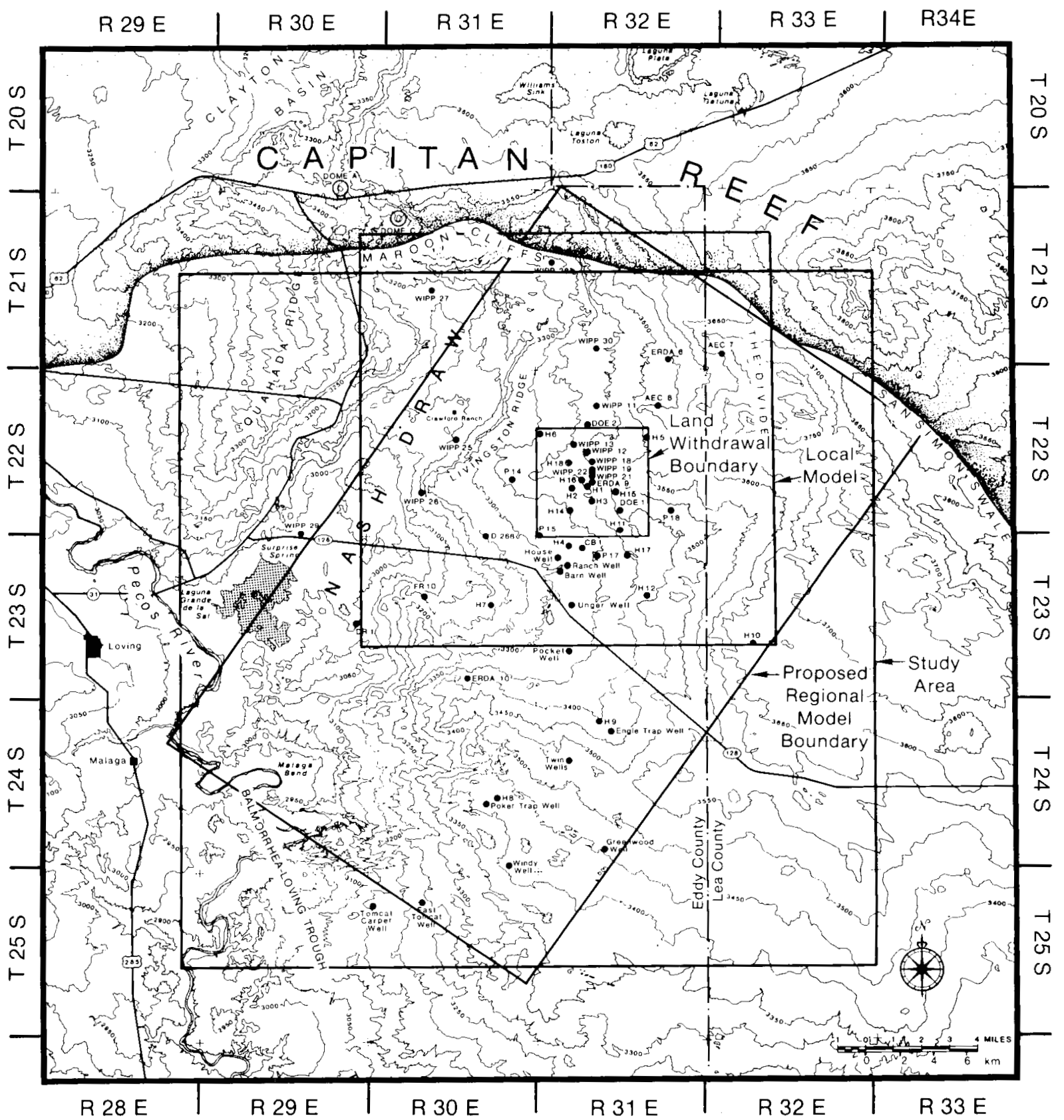

TRi-6342-144-0

Figure 4-4. Map of the Los Medaños Study Area Showing the Boundaries of the Los Medaños Mode1 (Brinster, 1989), the Local Model (LaVenue, et a1., 1988), the Proposed Land Withdrawal and the Observation Wel1 Network (Haug et al., 1987). 


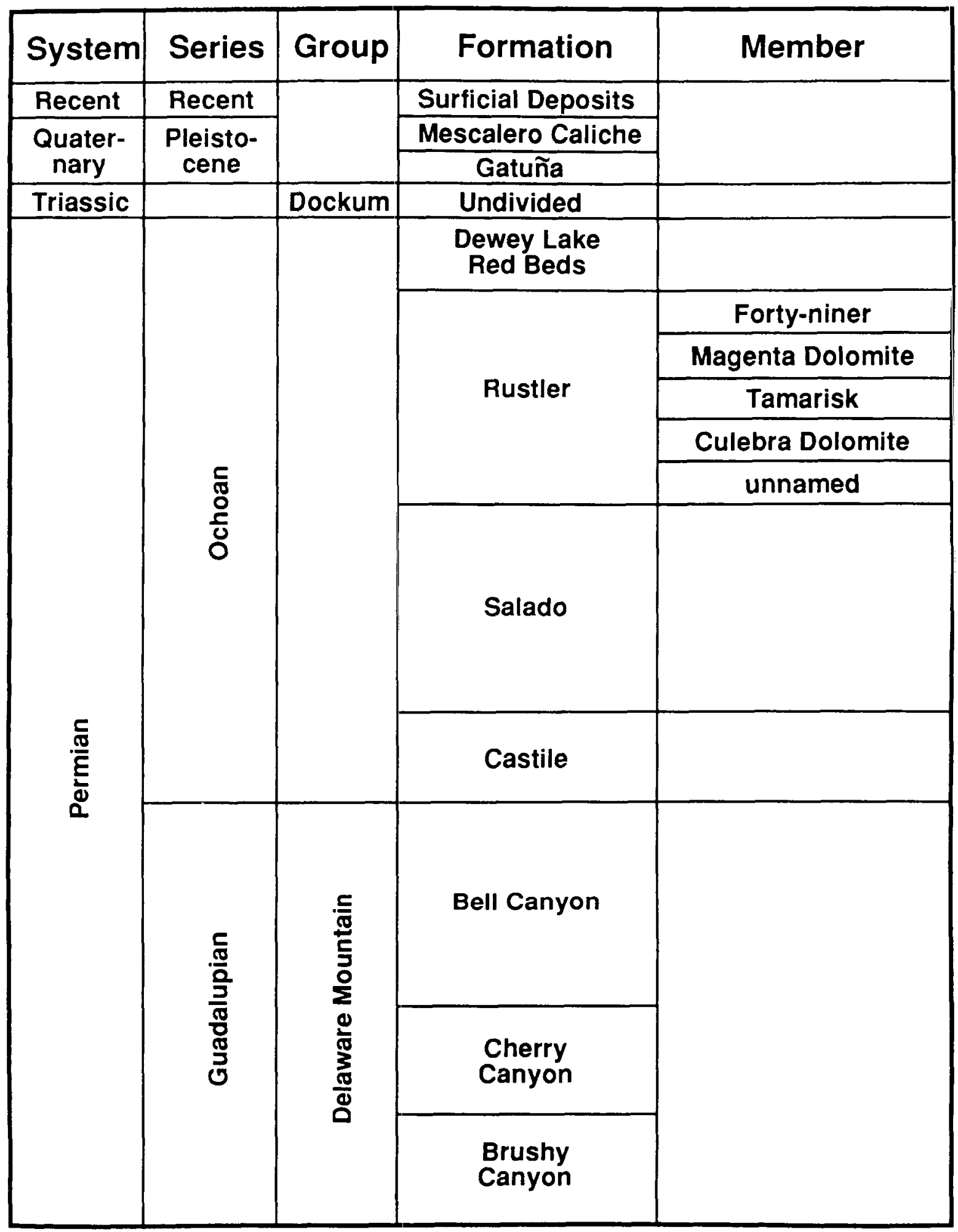

TRI-6330-16-0

Figure 4-5. Generalized Stratigraphic Column of the Delaware Mountain Group and Younger Sedimentary Rocks of and near the WIPP Disposal System (Beauheim, 1.987). 
Chapter IV: Containment Requirements

Canyon Formation is the fore-reef equivalent of the Capitan Reef Limestone. These units interfinger with the Capitan at the basin margins and are contained completely within the reef margins (Hayes, 1964; Mercer, 1983; Lambert, 1983). On a regional scale, the Bell Canyon Formation dips eastward at about 1 degree. On a more local scale, the nose of a southerly plunging asymmetrical syncline extends from Lea County into Texas. The formation occurs at a depth of about $1,200 \mathrm{~m}(3,900 \mathrm{ft})$ in the vicinity of the WIPP. The Bell Canyon Formation is also the oldest formation to crop out in the Delaware Basin. These outcrops are in topographically low areas west and south of the Study Area.

The upper part of the Bell Canyon Formation consists of sandstone and shale members that are composed of sandstone, siltstone, shale, and, locally, limestone. In ascending order, these informally named members are the Hays sandstone, the Olds sandstone, the Ford shale, the Ramsey sandstone, and the Lamar limestone. The siltstones and shales in the upper part of the Bell Canyon Formation contain elongated sandstone stringers about 0.5 to $8 \mathrm{~km}(0.3$ to $5 \mathrm{mi}$ ) wide, 1 to $35 \mathrm{~m}$ ( 3 to $115 \mathrm{ft}$ ) thick, extending basinward up to $70 \mathrm{~km}$ $(-44 \mathrm{mi})$ in a southwesterly direction (Figure 4-6). These isolated stringers were deposited by density currents moving basinward (Williamson, 1978; Hiss, 1976).

Groundwater occurs in the upper portion of the unit that consists of poorly cemented sandstone stringers. The vertical potential of the fresh-waterequivalent heads of this unit is upwards. This has led to the speculation that the Bell Canyon Formation waters have contributed to dissolution of the Castile Formation causing collapse features that can be seen at the surface (Anderson et al., 1978; Anderson, 1981), the implication being that dissolution beneath the repository could breach it. If a source of fluid for dissolution does originate in the Bell Canyon Formation, the mechanism involved must consist of several parts: a source of unsaturated brine, a path upward, a path downward for the dense fluid, and a path to carry away the newly formed denser brine. The Anderson model does not contain these four essential parts. The Castile Formation does not have an extensive fracture network to provide pathways upward to the halites and back down to the Bell Canyon Formation (Lambert, 1983; Mercer, 1983). 


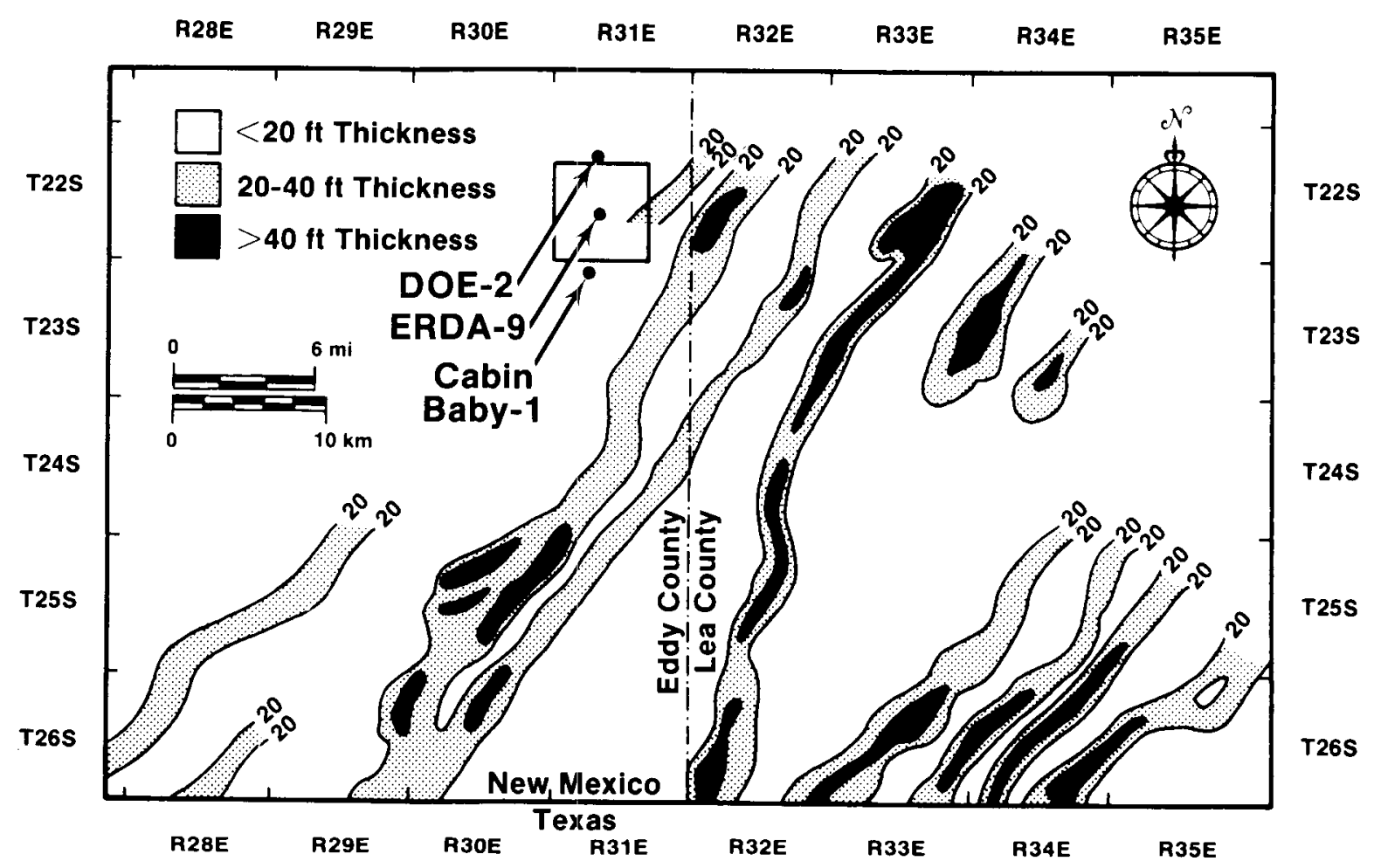

TRI-6334-65-0

Figure 4-6. Map Showing the Orientation of the Upper Bell Canyon Sandstone Stringers in the Vicinity of the WIPP (Lappin, 1988). 
No flow route exists for the brines once the saturated fluid returns to the

Bell Canyon Formation. Examination of the freshwater potentiometric surface map (Mercer, 1983) suggests that groundwater movement in the Bell Canyon is to the northeast, but no apparent movement occurs either vertically or laterally. The geology, groundwater chemistry, and head relationships of the Bell Canyon Formation and the upper hydrostratigraphic units are evidence that the Bell Canyon flow system is stagnant. Gas wells producing from the same horizon of the Bell Canyon Formation have no apparent effect on each other (Lambert, 1983), thereby indicating that production is from separate units. Groundwater chemistry of the Bell Canyon Formation indicates no connection between sandstone stringers, no connection with the Capitan aquifer, and no recharge from precipitation (Lambert, 1983). Examination and comparison of the hydraulic heads of the Bell Canyon Formation and upper units (Lappin, 1988) showed that it is erroneous to just consider the freshwater heads and to conclude that the potential for flow is upward. The natural densities of the fluid, which must be considered when determining vertical potentials, show that the potential for flow is downward. Also, drilling in an open hole will increase fluid density, effectively lowering the hydraulic head and inhibiting upward flow.

The Bel1 Canyon Formation will not be included in performance assessment modeling because of the poor hydraulic connection to the upper hydrostratigraphic units; furthermore, any radionuclides reaching the Bell Canyon Formation will not be transported laterally with significant velocity.

\section{Hydrogeology of the Castile and Salado Formations}

The Castile Formation conformably overlies the Bell Canyon Formation. The contact is transitional within a $1-\mathrm{m}$ ( $3-\mathrm{ft}$ ) zone (Cys, 1978). The Castile is contained completely within the Delaware Basin in New Mexico and is bounded on al1 sides by the contemporaneous Capitan Limestone (Figure 4-7). Near the end of Bel1 Canyon Formation deposition, circulation within the Delaware Basin became more constricted. This condition resulted in the formation of a sequence of organically derived layers alternating with siltstone laminations. The sequence changes rapidly in character upward from layered calcite to calcite-layered anhydrite to anhydrite. This sequence forms the lower 


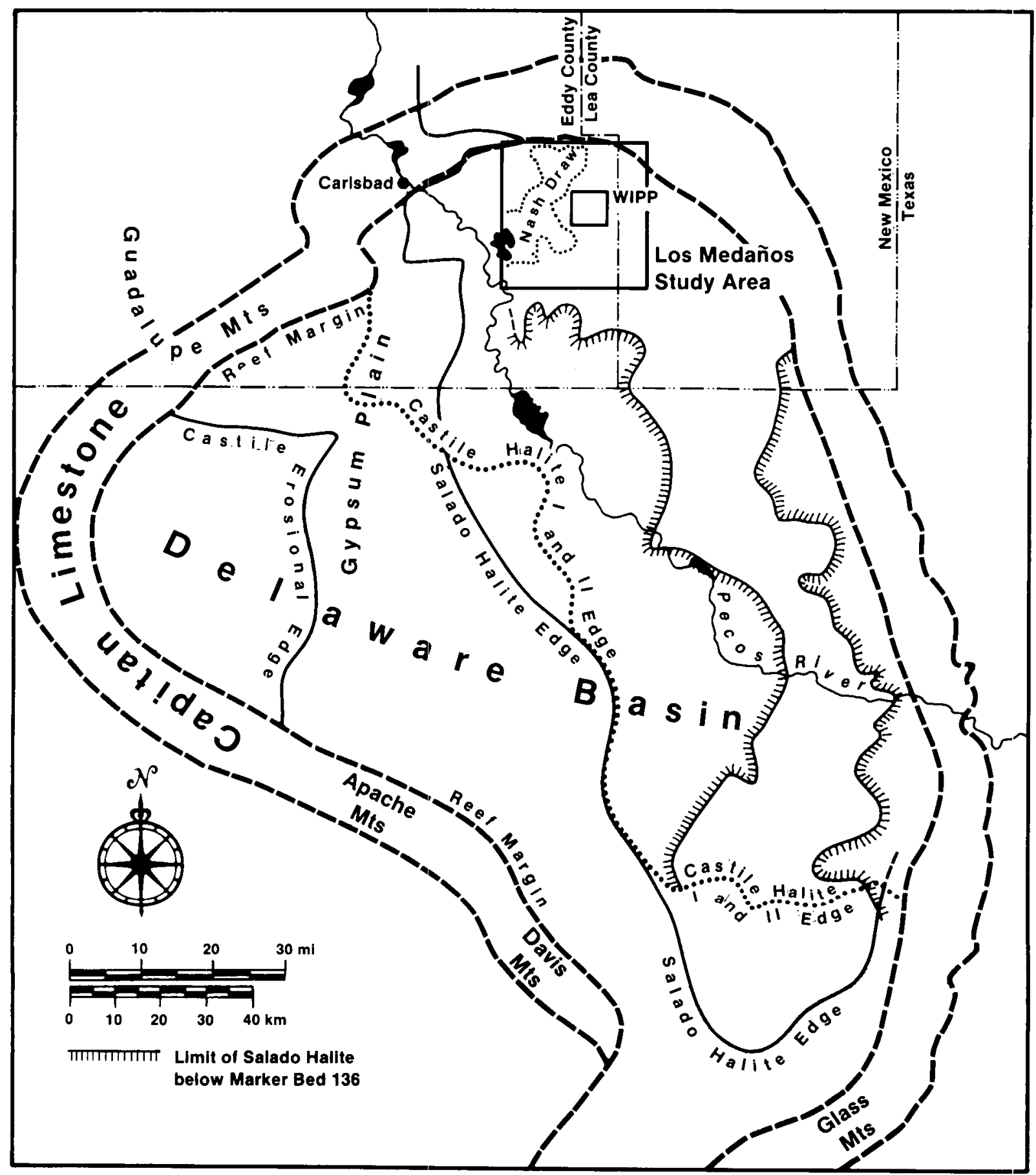

TRI-6342-237-0

Figure 4-7. Map Showing the Outline of the Delaware Basin and the Generalized Locations of the Castile and Salado Formations (modified from Lappin, 1988). 
Castile, which grades into the anhydrite-layered halite of the upper Castile. The transition continues into thick halite of the Salado Formation (Anderson et al., 1972). The Castile Formation consists of seven lithologic members that include four anhydrite members intercalated with three halite members. The formation is present throughout the Study Area but is eroded away southwest of the Study Area (Figure 4-7). In Loving County, Texas, where the Castile section is complete, the unit is $640 \mathrm{~m}(\sim 2,100 \mathrm{ft})$ thick. North of the WIPP, the Castile is about $360 \mathrm{~m}(\sim 1,200 \mathrm{ft})$ thick and thickens southward. At the WIPP, it is about $470 \mathrm{~m}(\sim 1,500 \mathrm{ft})$ thick. At the southern edge of the Study Area the Castile is about $500 \mathrm{~m}(-1,600 \mathrm{ft})$ thick.

As originally defined, the Castile Formation included a halite-rich upper section and an anhydrite-rich lower section (Richardson, 1904 in Mercer, 1983). That formation was later divided into two formations, the lower, called the Castile Formation and the upper salt section, called the Salado Formation (Lang, 1938). The Salado Formation is of particular interest, because it is the host rock for the WIPP. The Salado in the northern Delaware Basin conformably overlies and interfingers with the Castile (Bachman, 1981). Some earlier workers had concluded that the contact was an angular unconformity (Adams, 1944).

Little hydrologic data exists for the Castile Formation. The only data are from the locally pressurized brine encountered in fractured anhydrite during exploratory drilling at ERDA- 6 and WIPP-12 by the DOE and at 13 of about 100 petroleum exploratory wells in the vicinity. Hydrologic and geochemical data indicate these pressurized brine occurrences are isolated hydraulically and contain stagnant pockets of fluid (Lambert, 1978; Lappin, 1988). Water with high amounts of dissolved solids also occurs in the fractured, weathered portions of the Castile Formation at the western margins of the Delaware Basin, far outside of the Los Medaños Study Area. In the Study Area, the Castile Formation is intact, and no regional flow occurs.

Drill-stem tests (DST's) of the Castile Formation have shown permeability to be less than the measurement capability of the testing apparatus (Mercer and Orr, 1979; Mercer, 1983; Mercer, 1987). A conservative estimate (Mercer, 1983) of the permeability of the Castile Formation, based on the capability of 
the testing instruments, would be about one nanodarcy (which yields a hydraulic conductivity of $\left.1.0 \times 10^{-14} \mathrm{~m} / \mathrm{s}\left(-1 \times 10^{-14} \mathrm{ft} / \mathrm{s}\right)\right)$. Permeability for anhydrite is estimated to be less than 0.1 microdarcy $\left(1.0 \times 10^{-12} \mathrm{~m} / \mathrm{s}(\sim 1\right.$ $x 10^{-12} \mathrm{ft} / \mathrm{s}$ ) with porosity of 0.001 (Mercer, 1987).

The Salado Formation underlies the entire Los Medaños Study Area but is absent a few $\mathrm{km}$ west of the Pecos River, which is west of the Study Area (Figure 4-7). Because of its extreme solubility, the Salado does not crop out at the surface. Throughout the Study Area, the Salado Formation consists of about $600 \mathrm{~m}(-2,000 \mathrm{ft})$ of thick, bedded salt rhythmically interbedded with anhydrite, polyhalite, glauberite, and some thin mudstones (Jones, 1973, 1975; Borns and Shaffer, 1985; Bachman, 1981; Mercer, 1983, 1987). The Salado Formation was divided into three informal members on the basis of their economic importance, even though the 1ithologies are similiar (Jones, 1975 ).

The structural features recognized in the Salado Formation consist of a series of small anticlines and shallow synclines with axes dipping southeastward. In the northeastern part of the Study Area, the Salado surface dips steeply northeastward. Unlike the Castile Formation, the Salado Formation overlaps the reef structure and is present outside of the reef area, extending eastward for many kilometers into West Texas and the Texas panhandle region.

As in the Castile Formation, groundwater occurrence in the Salado Formation is restricted to areas in the Delaware Basin where extensive dissolution of the halite has occurred and only a breccia remains. In the Study Area, where the Salado Formation is intact, circulation of groundwater is almost zero because although porous, the Salado Formation lacks open fractures (Mercer, 1983). Permeability of the Salado Formation is very low but measurable (Mercer, 1983, 1986; Powers et a1., 1978; Bredehoeft, 1988). The average permeability of rock salt at lithostatic pressure is 0.05 microdarcies (Powers et al., 1978). Drill stem tests in seven wells in the Salado Formation (Mercer, 1987) and in the walls of the WIPP (Stormont et a1., 1987) also indicate that permeability is measurable in this formation. Drill stem tests in the extremely lowpermeability Salado Formation are similar to conventional DST's used in the petroleum industry but for one significant difference, the addition of an 
Chapter IV: Containment Requirements

1 extra set of packers above and below the original packers forming a "guard2 zone" (Peterson et al., 1985). The guarded system allows for measurement of 3 gas that flows past the first set of packers. Other problems in testing low 4 permeability rocks are the result of the time it takes for proper setting of 5 the packers and the time it takes to examine flow beyond the disturbed zone.

6 Tables of the DST's (Mercer et al., 1987; Mercer, 1987) show a range of

7 permeabilities from 9 nanodarcies to 25 microdarcies throughout the Salado

8 Formation. A porosity of 0.001 was assumed in all of the tests.

9

Shut-in pressures of wells completed in the Salado Formation vary but, in some wells, the hydraulic heads are higher than heads in aquifers in the overlying Rustler. No measurable buildup of pressure has been observed at we1ls DOE-2 and AEC-7 although pressure was found at some potash wells and at Cabin Baby1, WIPP-12, and WIPP-13 (Mercer, 1987). Cabin Baby-1, WIPP-12, and WIPP-13 had formation pressures between lithostatic and hydrostatic; however, these rapidly declined with little fluid production.

The WIPP repository provides access to in situ salt of the Salado Formation. A permeability of 1 to 10 nanodarcies was determined from gas flow measurements in the wall of the repository (Stormont et al., 1987). The higher permeabilities (in the microdarcy range) are the result of disturbance of the salt, whereas the lower measurements are probably more representative of the undisturbed salt and anhydrites. A fluid porosity of 0.001 was assumed.

The Salado Formation is not "dry", but is presupposed to be saturated medium with low permeability; hence after the repository is decommissioned, brine will flow in at a rate of $0.01 \mathrm{l} /$ day/m of tunnel (Bredehoeft, 1988; see also Lappin et al., 1989, section 3.2). This conclusion was drawn from numerical predictions of Darcian flow in the salt based on the following observations. Experimental heater holes and fifty-four vertical boreholes in the repository produce fluids. Completed boreholes in the evaporites produce brine and salt efflorescences occur throughout the facility. Permeability is measureable in the Salado Formation. 
In summary, the Castile and Salado Formations have low permeabilities and effective (connected) porosities. Permeabilities vary from the nanodarcy range to 25 microdarcies and porosity is on the order of 0.001 (Mercer, 1987; Peterson et al., 1987). Formation pressures are seen to vary from hydrostatic to somewhat less than lithostatic ( 8.3 to $10.3 \mathrm{MPA}$ ). The formation appears to be saturated, but the low effective porosity (.001) allows little groundwater movement.

\section{Hydrogeology of the Rustler Formation}

The Salado Formation is conformably overlain by the Rustler Formation, which is the youngest unit of the Ochoan evaporite series (Figure 4-8). The Rustler Formation is of particular interest because it contains water-bearing units that may provide potential pathways for radionuclides to reach the accessible environment.

The composition of the Rustler Formation is about 0.40 anhydrite, 0.30 halite, 0.20 siltstone and sandstone, and 0.10 anhydritic dolomite (Lambert, 1983). The Rustler was divided into four formally named members and a lower unnamed member on the basis of the lithologies of units that crop out along Nash Draw west of the WIPP (Vine, 1963). The five units (Vine, 1963; Mercer, 1983) are, in ascending order, the lower unnamed member (oldest), the Culebra Dolomite Member, the Tamarisk Member, the Magenta Dolomite Member, and the Forty-niner Member (youngest).

Groundwater in the Rustler originally was thought to be restricted to the residuum between the Rustler and Salado Formations (termed the Rustler-Salado Residuum) and the two dolomite members: the Culebra and Magenta (Vine, 1963; Mercer, 1983). At present, evidence of flow occurs in a siltstone unit of the unnamed lower member, and in claystones of the Tamarisk and Forty-niner Members (Beauheim, 1987a; Holt et al., 1989). Claystone in the Tamarisk Member is separated from dolomite in the Culebra and Magenta Members by anhydrite layers. The claystone in the Forty-niner Member is likewise isolated from the Magenta Dolomite and the overlying Dewey Lake Red Beds by anhydrite. Data on the unnamed lower member, the Tamarisk Member, and the Forty-niner Member, are from two wells: H-14 and H-16 (discussed below). The 

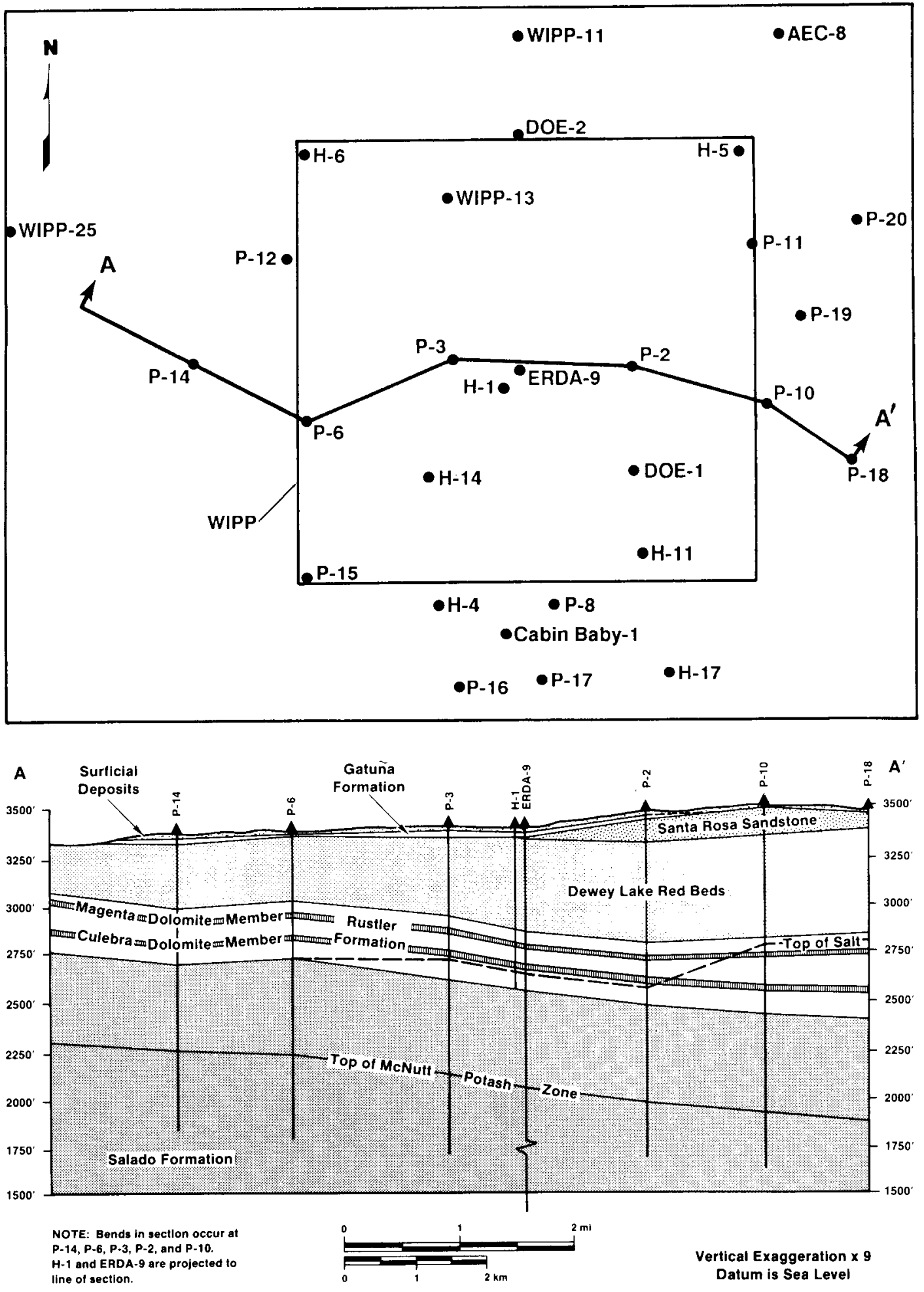

TRI-6342-227-0

Figure 4-8. Geologic Cross-Section Across the WIPP Disposal System (Mercer, 1983). 
first part of the review of the Rustler Formation geohydrology will concentrate on aquitards and the second part will discuss the geohydrology of the hydrostratigraphic units.

\section{Hydrogeology of the Rustler Aquitards}

The lower unnamed member has a mean thickness of $40 \mathrm{~m}(-131 \mathrm{ft})$ and is about $36 \mathrm{~m}(-118 \mathrm{ft})$ thick at the WIPP. The unit thickens slightly eastward across the Study Area (Figure 4-8). The unit is composed mostly of fine-grained silty sandstones and siltstones interbedded with anhydrite (converted to gypsum at Nash Draw) in the western part of the Study Area with increasing amounts of halite present in the eastern part of the Study Area. Halite in the unnamed lower member is present over the WIPP (Figure 4-8) but north and south of the WIPP at the so-called "Nash Draw Reentrants", halite is absent.

The only DST of the unnamed lower member to date was at H-16. Transmissivities of $2.9 \times 10^{-10} \mathrm{~m}^{2} / \mathrm{s}\left(2.7 \times 10^{-4} \mathrm{ft}^{2} / \mathrm{d}\right)$ and $2.4 \times 10^{-10} \mathrm{~m}^{2} / \mathrm{s}(2.2 \mathrm{x}$ $10^{-4} \mathrm{ft}^{2} / \mathrm{d}$ ) were calculated for the first and second buildup periods of the DST (Beauheim 1987). Simulations of a single porosity medium using the first transmissivity and a skin factor of -0.4 and assuming a porosity of 0.3 , a system compressibility of $1.0 \times 10^{-5} \mathrm{~Pa}^{-1}$, and a viscosity of $1.0 \mathrm{cp}$ showed an excellent fit to the data curve for the first buildup, indicating a static formation pressure of $1.47 \mathrm{MPa}$. A second simulation requiring a slightly lower transmissivity indicating we1l damage yielded a pressure of $1.44 \mathrm{MPa}$. From these results, pressure for the claystone unit tested was estimated at $1.58 \mathrm{MPa}$ for an elevation of $793 \mathrm{~m}(2,600 \mathrm{ft}$ ) (Beauheim, 1987).

The Tamarisk Member ranges in thickness from 21 to $75 \mathrm{~m}$ (69 to $246 \mathrm{ft}$ ) in southeastern New Mexico. It has a mean thickness of $21 \mathrm{~m}$ (69 ft) in the study Area and is about $36 \mathrm{~m}$ thick at the WIPP. The Tamarisk consists of mostly anhydrite interbedded with thin layers of claystone and siltstone. The Tamarisk Member outcrops along the southwestern part of Nash Draw. The surface structure of the Tamarisk Member is similar to that of the lower units . 
Unsuccessful attempts were made in two wells, $\mathrm{H}-14$ and $\mathrm{H}-16$, to test a $2.4 \mathrm{~m}$ (7.9 ft) sequence of the Tamarisk Member that consists of claystone/mudstone/ siltstone overlain and underlain by anhydrite. The permeability of the Tamarisk Member was too low to yield transmissivity values in both wells, but Beauheim (1987) estimates the transmissivity of the claystone sequence to be about two orders of magnitude less than the values for the unnamed lower member.

The uppermost member of the Rustler Formation, the Forty-niner Member, consists of anhydrite interbedded with a layer of siltstone. The unit ranges in thickness from 7 to $26 \mathrm{~m}$ (23 to $85 \mathrm{ft}$ ) and has a mean thickness of $21 \mathrm{~m}$ (69 $\mathrm{ft}$ ). At the WIPP, the unit is about $20 \mathrm{~m}$ (66 ft) thick, has a uniform thickness throughout the Study Area, and has a structure similar to that of the lower units. Tests were conducted also on a claystone in the Forty-niner Member in well H-14 and on a clay unit in wel1 H-16 (Beauheim, 1987). The tests on the claystone in we11 H-14 yielded a hydraulic conductivity of about $5 \times 10^{-9} \mathrm{~m} / \mathrm{s}\left(\sim 2 \times 10^{-8} \mathrm{ft} / \mathrm{s}\right)$ and the tests on the clay in well $\mathrm{H}-16$ yielded a hydraulic conductivity of $5 \times 10^{-10} \mathrm{~m} / \mathrm{s}\left(2 \times 10^{-9} \mathrm{ft} / \mathrm{s}\right)$.

To summarize the properties of the aquitard units: the unnamed lower member, the Tamarisk Member, and the Forty-niner Member are considered to be isotropic and homogeneous aquitards of very low permeability throughout the Study Area. The presence of the halite is correlated to a decrease in permeability in the dolomitic members in the eastern part of the Study Area and will be discussed in the hydrology section. Halite is present in the Tamarisk and Forty-niner members to the east but does not extend westward over the WIPP. The estimated hydraulic conductivities of the three hydraulically tight units are, in ascending stratigraphic order, $1 \times 10^{-10} \mathrm{~m} / \mathrm{s}\left(-1 \times 10^{-10} \mathrm{ft} / \mathrm{s}\right), 1 \times 10^{-12} \mathrm{~m} / \mathrm{s}$ $\left(-1 \times 10^{-12} \mathrm{ft} / \mathrm{s}\right)$, and $1 \times 10^{-9} \mathrm{~m} / \mathrm{s}\left(-1 \times 10^{-9} \mathrm{ft} / \mathrm{s}\right)$. The Tamarisk was too tight to test, so the value of $10^{-12} \mathrm{~m} / \mathrm{s}\left(-10^{-12} \mathrm{ft} / \mathrm{s}\right)$ is only an estimate. For transport simulations, the porosity of the aquitards is considered to be 0.3 . 
Rustler-Salado Residuum Hydrostratigraphic Unit

In the vicinity of Nash Draw the Rustler-Salado residuum (from dissolution of the salt at the base of the lower unnamed member) overlies the halite of the Salado Formation. The residuum is known as the "brine aquifer." The unit is made up of a distinctive gray residue of gypsum, clay, and sandstone that grades eastward, intertonguing with the clayey halite of the lower unnamed member. This residuum ranges in thickness in the vicinity of Nash Draw from $3 \mathrm{~m}(10 \mathrm{ft}$ ) to about $20 \mathrm{~m}(66 \mathrm{ft}$ ) and averages about $8 \mathrm{~m}$ (26 ft) (Robinson and Lang, 1938; Mercer and Orr, 1977; Mercer, 1983). Lang (1938, in Robinson and Lang, 1938) noted that "...the structural conditions that caused the development of Nash Draw might also control the position of a body of salt water beneath it in the basal Rustler." Subsequent drilling and testing has confirmed this conjecture to some extent, but evidence from wells P-14 and H-7 indicates that the brine aquifer extends farther east than first reported (Mercer, 1983). It is estimated that the elongated aquifer thickens northward and has a range of thickness from 3 to $30 \mathrm{~m}$ (10 to $100 \mathrm{ft}$ ) and a mean thickness of about $8 \mathrm{~m}$ (26 ft) (Robinson and Lang, 1938). More recent information (Mercer, 1983) shows a range of $2.4 \mathrm{~m}(7.9 \mathrm{ft}$ ) in test hole P-14 to $33 \mathrm{~m}$ (108 $\mathrm{ft})$ in test hole WIPP-29.

Hydraulic conductivity data for the brine aquifer in the study Area are concentrated in and around the WIPP with the exception of a few data points near Malaga Bend. The hydraulic conductivity ranges from $10^{-6}$ to $10^{-12} \mathrm{~m} / \mathrm{s}$ with a mean of $\log$ values of -9.4 . The hydraulic conductivities at Nash Draw are higher by several orders of magnitude than the values east of the draw, ranging from $10^{-8}$ to $10^{-6} \mathrm{~m} / \mathrm{s}$. Eastward, the range is from $10^{-12}$ to $10^{-9} \mathrm{~m} / \mathrm{s}$ (Figure 4-9). Near Malaga Bend, hydraulic conductivities were reported to be around $10^{-3} \mathrm{~m} / \mathrm{s}$ (Hale et al., 1954; Havens and Wilkins, 1979). A contour plot of the negative-log hydraulic conductivities measured in the brine aquifer indicates that two distinct zones of hydraulic conductivity occur with the aquifer becoming tighter east of Nash Draw (Figure 4-9).

Effective porosity estimates for the brine aquifer range from 0.15 to 0.33 (Hale and Clebsch, 1958; Robinson and Lang, 1938; Geohydrology Associates, Inc., 1979; and Mercer, 1983). An average effective porosity of 0.2 has been assumed in previous work (Hale and Clebsch, 1958 and Mercer, 1983). 

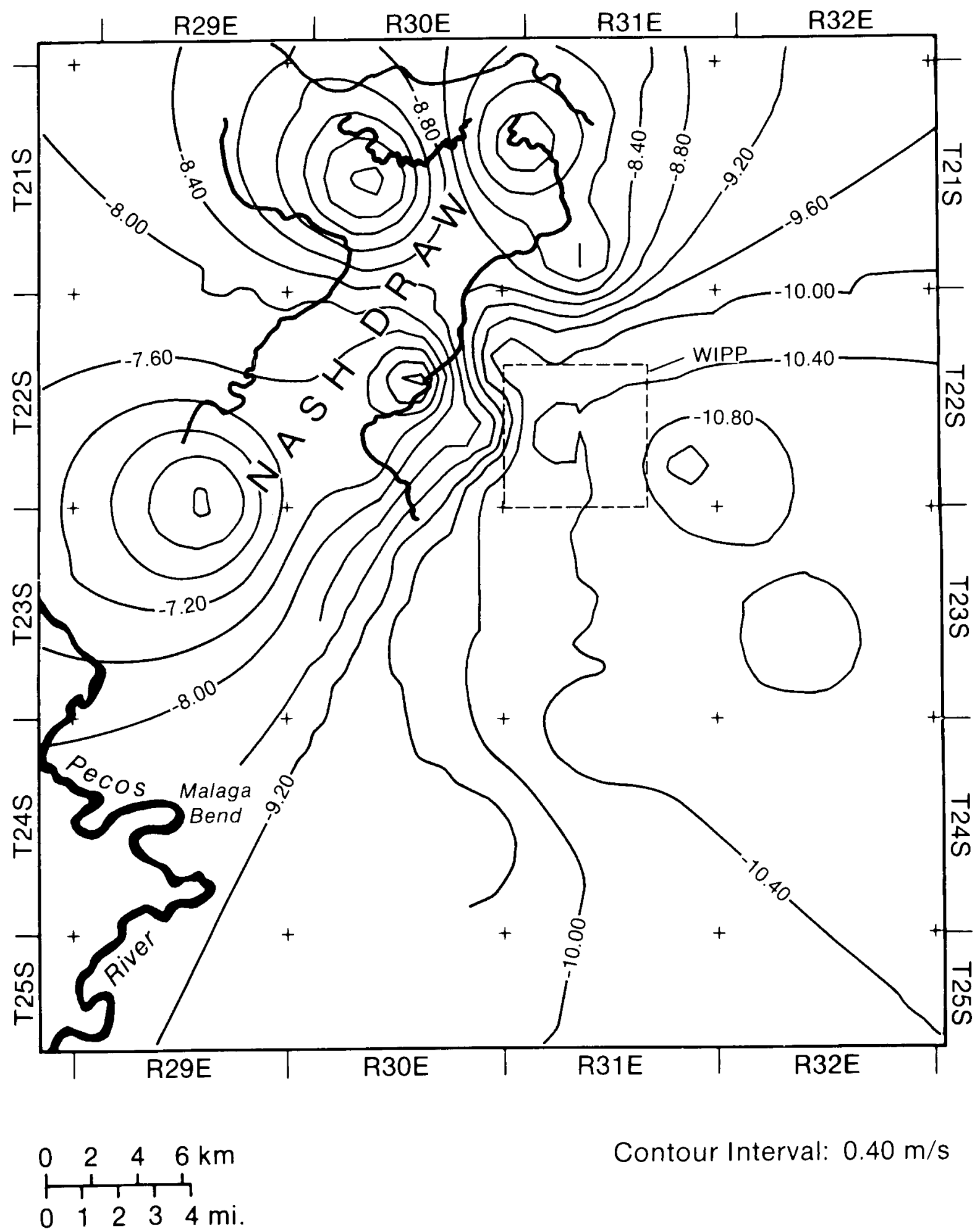

Contour Interval: $0.40 \mathrm{~m} / \mathrm{s}$

TRI-6342-152-0

Figure 4-9. Negative Log Hydraulic Conductivities (m/s) of the RustlerSalado Residuum of the Rustler Formation in the Los Medaños Area (Brinster, 1989). 
A contour map of the potentiometric surface adjusted to freshwater density illustrates the decrease in hydraulic conductivity east of Nash Draw (Figure 4-10). At the WIPP, where the hydraulic conductivity is low, the potentiometric surface is steep and west of the WIPP where the hydraulic conductivity is several orders of magnitude higher, the surface is flatter. The hydraulic gradient in Nash Draw is 0.002 . At the WIPP, the hydraulic gradient is 0.007 .

The waters from the Rustler-Salado residuum are brines consisting mostly of: sulfates and chlorides of calcium, magnesium, sodium, and potassium with sodium and chloride the major constituents (Mercer, 1983). These waters have the highest concentrations of dissolved solids in the WIPP area. The lowest observed density water $\left(1.048 \mathrm{~g} / \mathrm{cm}^{3}\right)$ is at well $\mathrm{H}-7 \mathrm{c}$ and has a concentration of dissolved solids of $79,800 \mathrm{mg} / \ell$. The highest observed density water ( 1.24 $\mathrm{g} / \mathrm{cm}^{3}$ ) has a concentration in excess of $450,000 \mathrm{mg} / \mathrm{l}$ and is at test hole $\mathrm{H}-4 \mathrm{c}$ (Figure 4-11).

Recharge to and discharge from the brine aquifer to Laguna Grande de la Sal (Figure 4-4) and the relationship of Surprise Spring to the lake was first investigated by Robinson and Lang (1938) and later by Hale et al. (1954) and Mercer (1983). The lake is not thought to be connected hydraulically to the brine aquifer, because waters from wells in units under the lake have a lower chloride content than the lake water and near the lake wells, which penetrate lower units, flow (Robinson and Lang, 1938; Mercer, 1983). These observations do not necessarily mean, however, that no connection to lower aquifers exist. If the lake is a discharge area for the lower units, the low chloride content and different water chemistry would be masked by the influx of surface runoff or near-surface flow from gypsiferous members of the Rustler. The largest spring in the area, Surprise Spring, probably gets its water from the Tamarisk and discharges into the northern end of the lake (Mercer, 1983).

Conclusions that the underlying units are confined in lower Nash Draw assume horizontal flow in the Culebra Dolomite Member and the brine aquifer. Horizontal flow in confined aquifers means that flow lines are normal to 

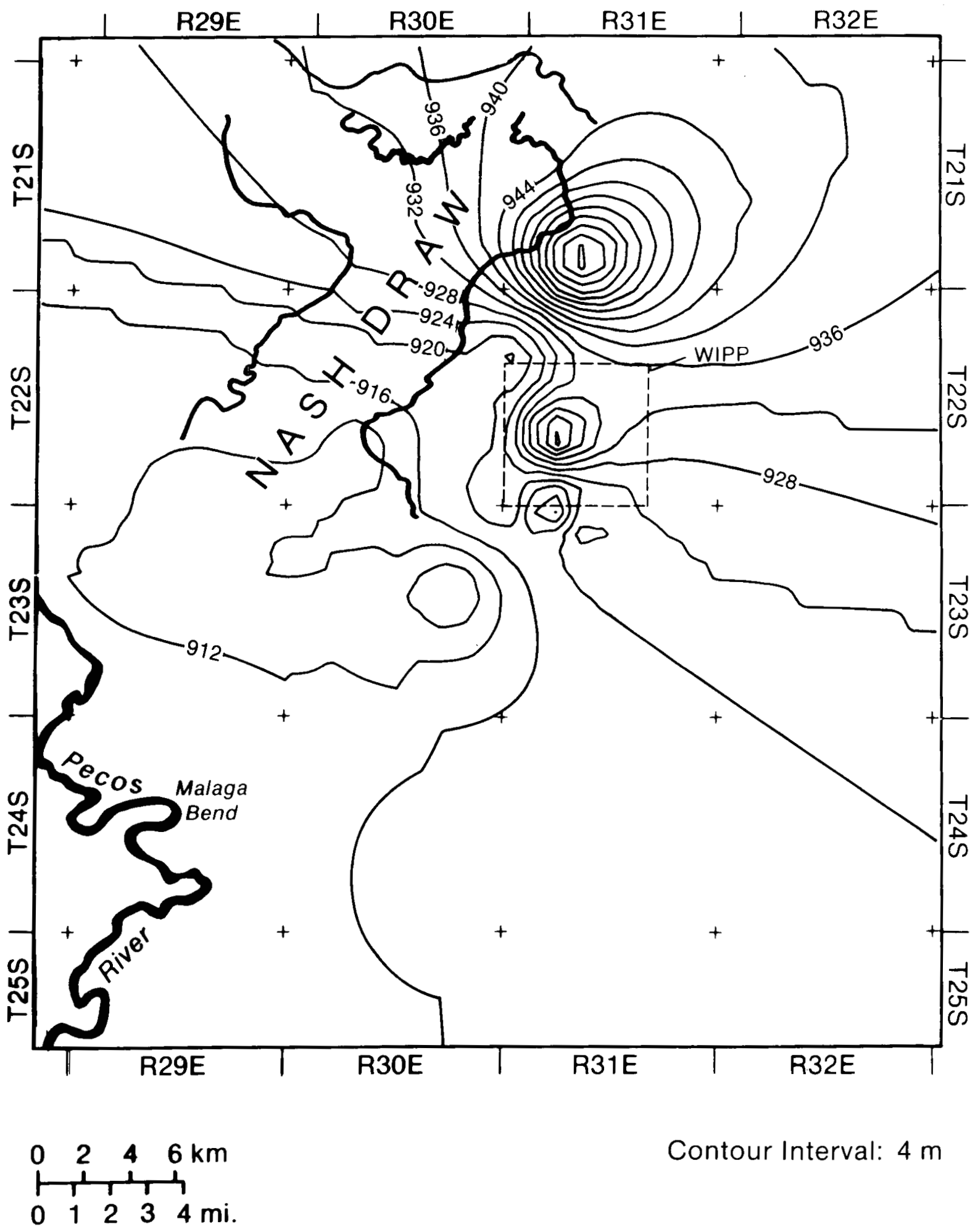

Contour Interval: $4 \mathrm{~m}$

TRI-6342-151-0

Figure 4-10. Adjusted Potentiometric Surface of the Rustler-Salado Residuum in the Los Medaños Area (Brinster, 1989). 

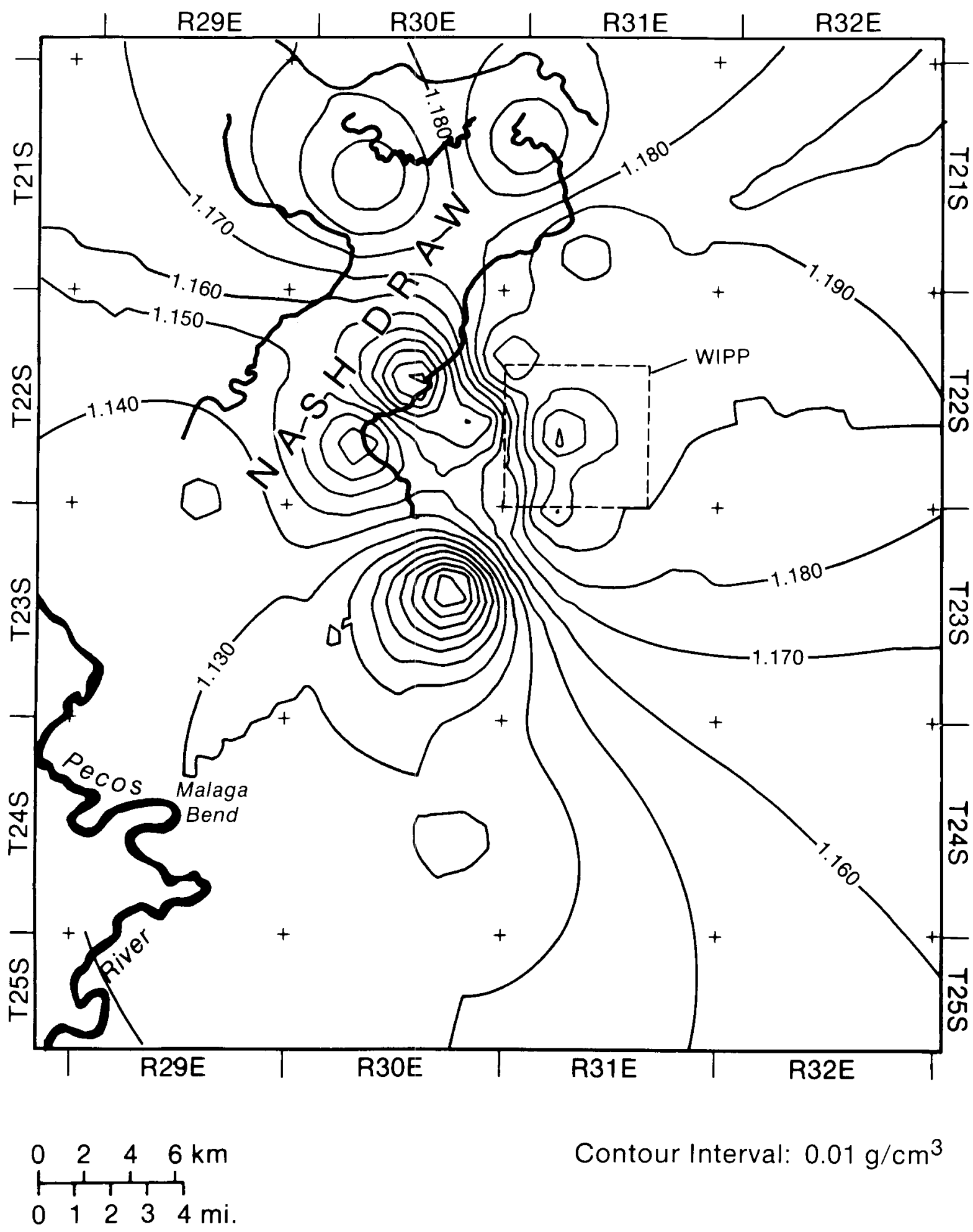

Contour Interval: $0.01 \mathrm{~g} / \mathrm{cm}^{3}$

TRI-6342-147-0

Figure 4-11. Brine Densities of Water from the Rustler-Salado Residuum in the Los Medaños Area (Brinster, 1989). 
vertical equipotential lines when viewed in cross section. In regions where aquifers intersect the water table (such as southern Nash Draw), recharge and discharge result in equipotential lines that are not necessarily vertical but parallel to the recharge and discharge surfaces. Flowing wells in the region near Malaga Bend do not necessarily mean that the water-bearing unit is confined (Brinster, 1989).

The potentiometric-surface map of the freshwater-equivalent hydraulic heads (Figure 4-10) indicates recharge east of the WIPP and discharge southsouthwest to the river. The gradient of the potentiometric surface of the brine aquifer is southerly, thus indicating recharge from the north, near Bear Grass Draw (T. 18 S., R. 30 E.) (Robinson and Lang, 1938; Lang, 1938). Recharge occurs at Clayton Basin (Figure 4-4) and upper Nash Draw (Mercer, 1983). The higher potentiometric surface of the brine aquifer shown east of the WIPP on the potentiometric-surface map indicates recharge may be occurring in the eastern part of the Study Area. Insufficient data exists to indicate if indeed recharge is occurring in this region. A possible source of recharge may be from the upper dolomitic units: the Culebra Dolomite Member and the Magenta Dolomite Member (Mercer, 1983). Some local recharge occurs in the brine aquifer in the vicinity of Malaga Bend. An almost immediate water level rise was reported in a brine-aquifer observation well after a heavy rainstorm (Hale et a1., 1954). A good hydraulic connection, possibly a sinkhole, from the surface through the Rustler Formation to the brine aquifer, was inferred to exist in the vicinity of Malaga Bend with local recharge occurring only under exceptional conditions (Hale et al., 1954). The brine aquifer discharges at the southern end of Nash Draw into the Pecos River at Malaga Bend (Hale et al., 1954).

\section{The Culebra Dolomite Hydrostratigraphic Unit}

The Culebra Dolomite Member of the Rustler Formation is microcrystalline, grayish dolomite or dolomitic limestone with solution cavities (Vine, 1963). The Culebra Dolomite, where present, ranges in thickness from 4 to $11.6 \mathrm{~m}$ (13 to $38.3 \mathrm{ft})$ and has a mean thickness of about $7 \mathrm{~m}(-23 \mathrm{ft})$. In the Study Area the Culebra has a uniform thickness of about $8 \mathrm{~m}(-26 \mathrm{ft})$. The Culebra 
1 Dolomite has a shallow regional dip of less than $.001 \mathrm{~m} / \mathrm{m}$ to the southeast but 2 in the vicinity of the WIPP it dips fairly steeply to the northeast. Outcrops 3 of the Culebra Dolomite occur in the southern part of Nash Draw and along the 4 Pecos River.

5 7

\section{Hydrologic Properties of the Culebra Dolomite Hydrostratigraphic Unit}

More is known about the hydrologic properties of the Culebra Dolomite Member than any other unit in the Study Area (Mercer and Orr, 1977; Mercer and Orr, 1979; Mercer, 1983; Mercer et al., 1987; Beauheim, 1987; LaVenue et al., 1988; and Davies, 1989). A comprehensive data base has been computed (LaVenue et al., 1988). Transmissivity data exists (Figure 4-12) for 20 1ocations around the WIPP (Mercer, 1983). Eighteen new locations have been tested since 1983, and new transmissivities have been estimated for seven previously tested locations (DOE-2, H-11, and WIPP-13) (Beauheim, 1987; Beauheim, 1986; Saulnier, 1987). Most of the data collected are from we1ls (30 of 38) within six miles of the center of the WIPP and 25 of the wells are within the proposed WIPP land withdrawal boundary.

A contour map of the negative-log hydraulic conductivities (Figure 4-13) shows the variation in the hydraulic conductivities in the Study Area. The $\log$ hydraulic conductivities were determined from the mean transmissivities at each hydropad (well cluster) (LaVenue et al., 1988) and divided by the mean Culebra Dolomite Member thickness at each hydropad. The log transmissivities range from -8.7 to $-2.7 \mathrm{~m}^{2} / \mathrm{s}$ with a mean of $-5.5 \mathrm{~m}^{2} / \mathrm{s}$ in the vicinity of the WIPP. The $\log$ hydraulic conductivities range from -9.7 to $-3.7 \mathrm{~m} / \mathrm{s}$ with a mean of $-6.4 \mathrm{~m} / \mathrm{s}$.

Variation in transmissivities is observed throughout the Study Area. This variation resulted from fracturing of the Culebra Dolomite due to subsidence associated with post-depositional dissolution of salt in the Rustler Formation (Snyder, 1985), or from removal of overburden (Holt and Powers, 1988), or possibly from a combination of both processes. It has been noted by several workers (Jones, 1973; Mercer, 1983; Mercer and Orr, 1977) that the Rustler 


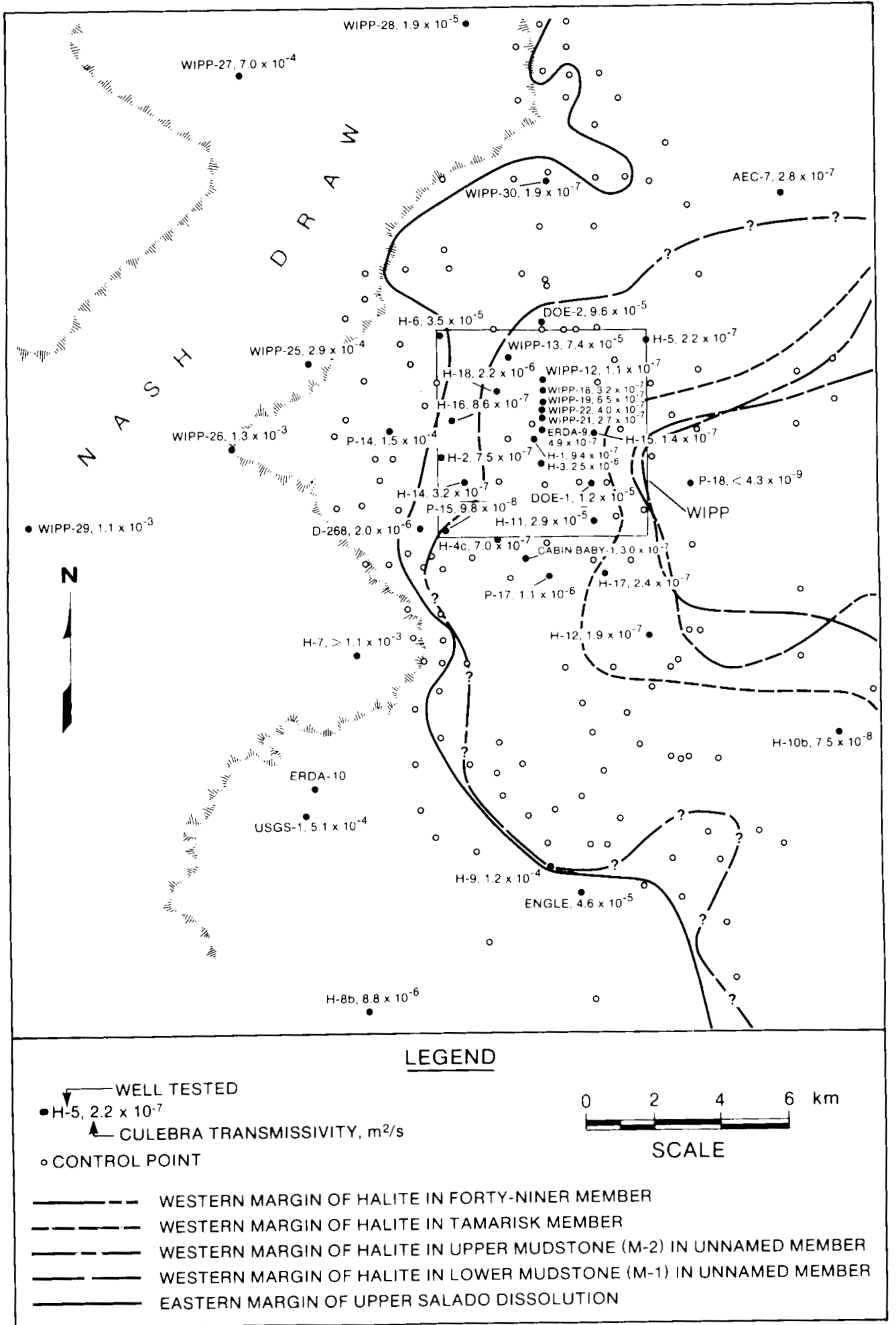

TRI-6342-221-0

Figure 4-12. Rustler Formation Halite and Culebra Dolomite Transmissivity around the WIPP (Lappin et a1., 1989). 

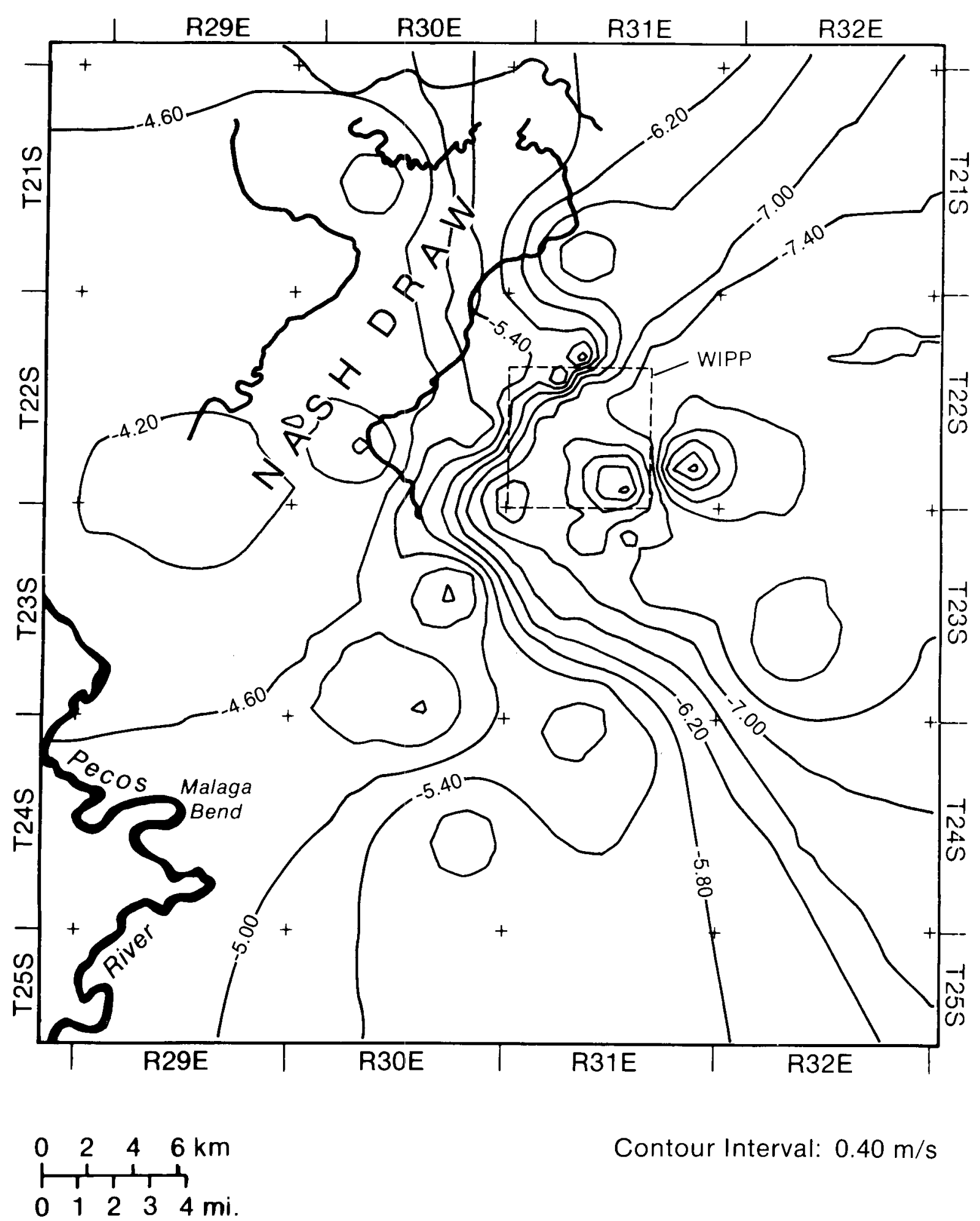

Contour Interval: $0.40 \mathrm{~m} / \mathrm{s}$

TRI-6342-148-0

Figure 4-13. Negative-Log Hydraulic Conductivities of the Culebra Dolomite Member of the Rustler Formation in the Los Medaños Area (Brinster, 1989). 
thickens eastward from Nash Draw as the amount of halite increases in the nondolomitic members. Drill cores collected from east and south of the WIPP where the Rustler is thicker do not show evidence of dissolution such as that seen west of the WIPP towards Nash Draw where the Rustler is thinner (Mercer, 1983; Snyder, 1985). The thickness variation is somewhat erratic in the vicinity of the WIPP (Figure 4-12), although a "smooth" transition of the solution front from west to east has been reported (Beauheim, 1987).

A comparison of the Snyder model and the Holt-Powers model (Beauheim, 1987) shows that well $\mathrm{H}-18$, east of the halite boundary, has a low transmissivity (consistent with the Snyder mode1) but WIPP-30, which has no halite, also has a low transmissivity. In addition, DOE- 1 and $H-11$, east of $H-18$, have relatively high transmissivities. The low transmissivity of the Culebra Dolomite at WIPP-30 is supported by the Holt-Powers model, but this model cannot explain the high transmissivities of DOE-1 and H-11.

A value of 0.20 for the single porosity conceptualization and for the matrix porosity of the dual porosity conceptualization of the Culebra has been used (Haug et al., 1987) as representative of porosities ranging from 0.07 to 0.30 , which were obtained from laboratory analyses of $2.54-\mathrm{cm}$ ( 1 -in) plugs taken from core samples. Two dolomite blocks taken from depths of $154 \mathrm{~m}$ and $157 \mathrm{~m}$ during the access shaft excavation for the Gnome Project revealed total porosities of 0.144 and 0.137 and effective porosities of 0.078 and 0.111 (Cooper and Glanzman, 1971).

An adjusted potentiometric surface map of the Culebra Dolomite Member (Figure 4-14) (Mercer, 1983) will be used in the preliminary modeling effort. Flow west of the WIPP is from north to south, and the flow lines are roughly parallel to the Pecos River. Northeast and east of the WIPP, data are insufficient to determine flow direction and inference of a potentiometric surface is difficult. A few data points exist south of the WIPP and flow is inferred to be toward the Pecos River. Flow in the Culebra Dolomite probably follows Nash Draw because of the higher transmissivity of dolomite in this area. The gradient in the upper Nash Draw area (0.003) is steeper where the Culebra Dolomite has more overburden. In the lower Nash Draw area near Malaga Bend, where the Culebra Dolomite is near the surface, the gradient is flatter 

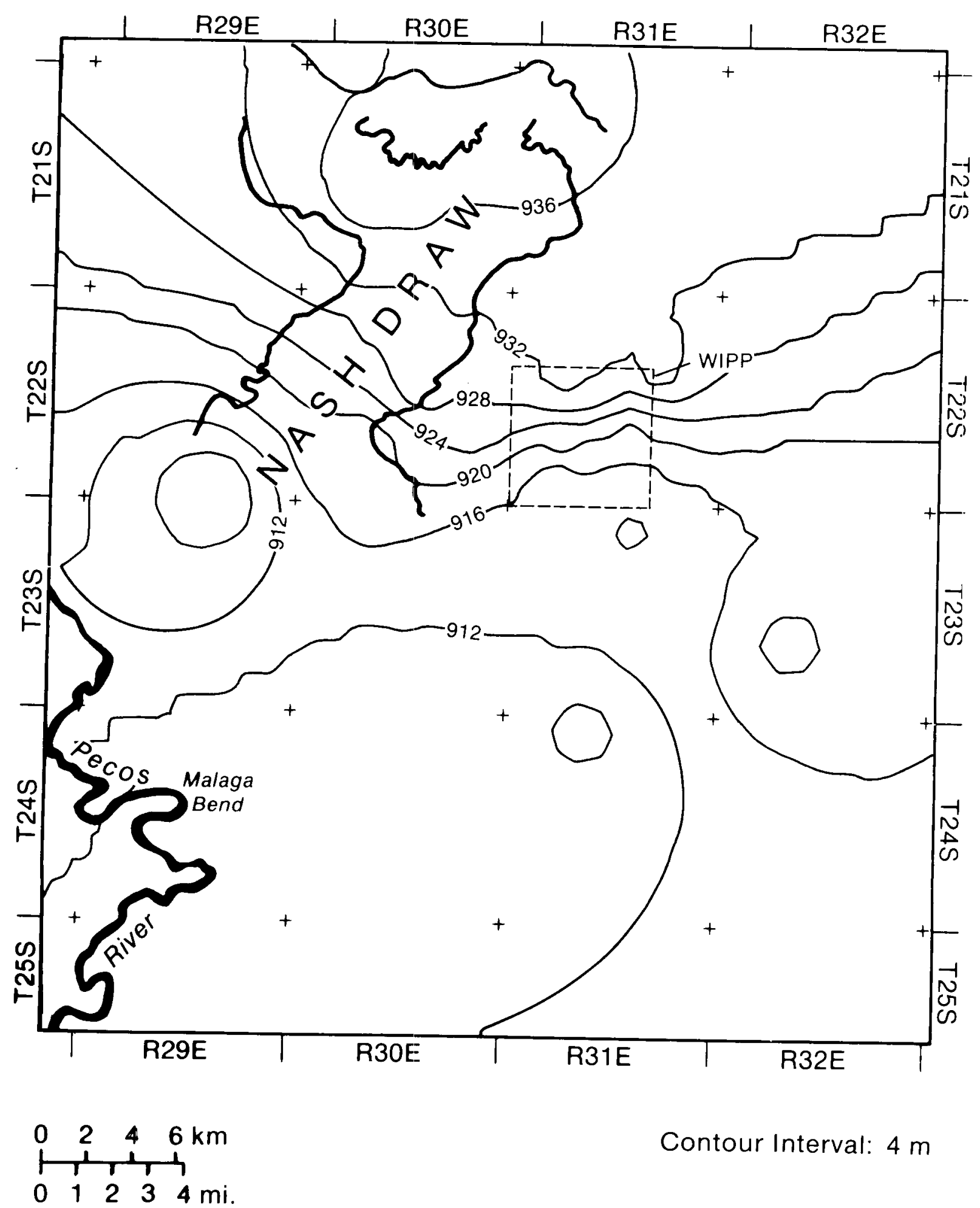

Contour Interval: $4 \mathrm{~m}$

TRI-6342-158-0

Figure 4-14. Adjusted Potentiometric Surface of the Culebra Dolomite Member of the Rustler Formation in the Los Medaños Area (Brinster, 1989). 
$1(0.001 \mathrm{~m} / \mathrm{m})$. The potentiometric surface map indicates recharge from the 2 north, possibly at Bear Grass Draw where the Rustler Formation is near the surface and farther south at Clayton Basin (Figure 4-4) where karst activity has disrupted the Culebra Dolomite Member (Mercer, 1983). Geochemical data suggest an alternative hypothesis for direction of recharge. Uranium 6 concentrations and $234 \mathrm{U} / 238 \mathrm{U}$ activity ratios show that originally flow may 7 have been from west to east (Lambert and Carter, 1987). Activity ratios 8 increase from Nash Draw eastward, which would be typical of flow in that 9 direction in a reducing environment. This is at variance with present day flow. Rustler Formation groundwater is draining from high potentiometric level, low-permeability areas near the WIPP, without appreciable recharge (Lambert and Carter, 1987). This means that the Rustler Formation is not at steady-state and that recharge occurred at Nash Draw 10,000 to 30,000 years ago under much wetter conditions (Lambert and Carter, 1987; Lambert and Harvey, 1987; Lambert, 1987).

Recharge from infiltration of precipitation through the overburden seems unlikely under present day conditions. Comparisons of recharge data from two modern basins similar to the Delaware Basin led to the conclusion that definitive values for recharge to the confined Rustler Formation probably cannot be determined (Lambert and Harvey, 1987).

Discharge from the Culebra Dolomite Member in the Study Area is to the westsouthwest either into the Pecos River at Malaga Bend or into the BalmorrheaLoving Trough or both (Figure 4-4). Salinity of the Pecos River increases at Malaga Bend, which has been described as a discharge area for the region (Hale et a1., 1954; Hale and Clebsch, 1958; Havens and Wilkins, 1979; Mercer, 1983). The increase in salinity could be from brine aquifer's local discharge instead of regional conditions. Culebra Dolomite might be discharging toward the Balmorrhea-Loving Trough. At this time, rates of discharge from the region can only be estimated.

The quality of water from the Culebra Dolomite Member is marginal; this water 34 is used locally for livestock watering. Total dissolved solids range from 353,200 to $420,000 \mathrm{mg} / \ell$ at test holes $\mathrm{H}-8 \mathrm{~b}$ and $\mathrm{P}-18$, respectively. The density 36 of Culebra Dolomite waters increases eastward from the WIPP (Figure 4-15). 

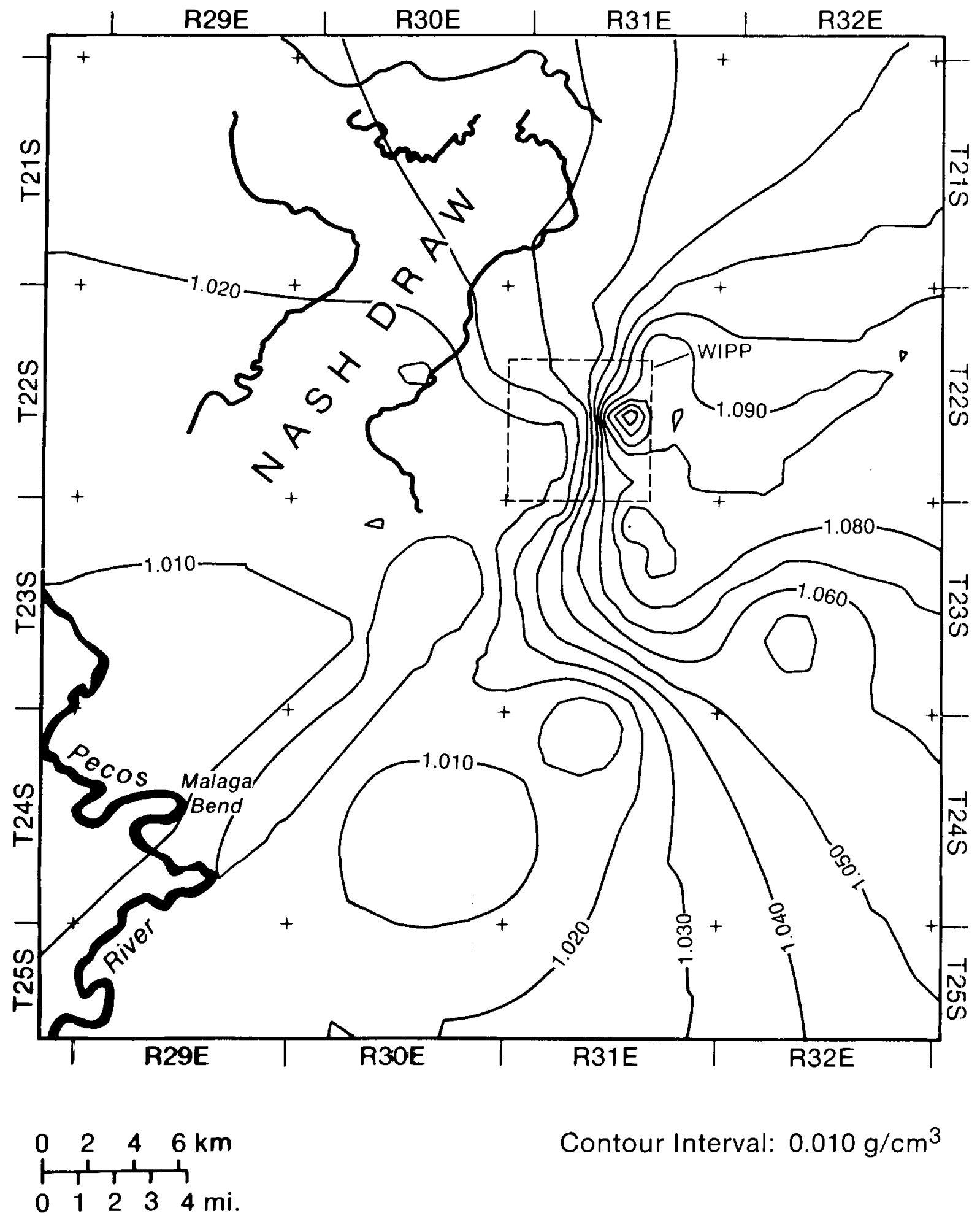

Contour Interval: $0.010 \mathrm{~g} / \mathrm{cm}^{3}$

TRI-6342-153-0

Figure 4-15. Brine Densities of Water from the Culebra Dolomite Member of the Rustler Formation in the Los Medaños Area (Brinster, 1989). 
1 A series of analyses of groundwater flow in the vicinity of the WIPP examined the effects of density-related, flow-driving forces and the effects of boundary conditions (Davies, 1989). Two dimensional model simulation showed that density-related effects were unimportant at the WIPP and west of the WIPP but were important north, northeast, and south of the WIPP. Boundary effects simulations showed that if the Culebra Dolomite Member is relatively impermeable east and northeast of the WIPP, the western part, including the WIPP, is not affected by conditions on the boundary. These analyses also showed that if the Culebra Dolomite is assumed to be confined throughout the region, a change in the Pecos River elevation will eventually affect the Culebra Dolomite at the WIPP.

\section{Hydrogeology of the Magenta Dolomite Hydrostratigraphic Unit}

The Magenta Dolomite Member of the Rustler Formation is a fine grained, greenish-gray dolomite with reddish-purple layers. This member ranges in thickness from 4 to $8 \mathrm{~m}(-13$ to $-26 \mathrm{ft})$ and has a mean thickness of $6 \mathrm{~m}(-19$ $\mathrm{ft})$. The Magenta is about $6 \mathrm{~m}(-19 \mathrm{ft})$ thick at the WIPP. The unit thickens slightly in the central part of the Study Area and thins to the southeast. The Magenta crops out along most of Nash Draw and has a structure similar to the underlying units. Groundwater yield is low, and consequently there has been little interest in the member. The amount of data available reflects this limited interest. Fourteen wells have been tested and reported (Mercer, 1983; Beauheim, 1987).

Hydrologic Properties of the Magenta Dolomite Hydrostratigraphic Unit

The Magenta Dolomite Member is unsaturated at outcrops along Nash Draw. Spring deposits along the eastern rim of the Draw are thought to have been formed when precipitation drained from the surface into fractures of the Rustler Formation, dissolved soluble layers, and emerged at the edge of the Draw where the water evaporated (Bachman, 1981). At Nash Draw, the Magenta Dolomite is almost in contact with the Culebra Dolomite, separated only by a few meters of dissolution residue. 
8

Only 14 values of transmissivity have been measured from the Magenta Dolornite Member, ranging over five orders of magnitude from $4.0 \times 10^{-9}$ to $4 \times 10^{-4} \mathrm{~m}^{2} / \mathrm{s}$ $\left(-4.0 \times 10^{-8}\right.$ to $\left.\sim 4.0 \times 10^{-3} \mathrm{ft}^{2} / \mathrm{s}\right)$ with a mean $\log$ transmissivity of $-7.0 \mathrm{~m}^{2} / \mathrm{s}$. The $\log$ hydraulic conductivity for the Magenta ranges from -9.3 to $-4.3 \mathrm{~m} / \mathrm{s}(-3.7 \mathrm{ft} / \mathrm{s})$, with a mean $\log$ hydraulic conductivity of $-7.8 \mathrm{~m} / \mathrm{s}$ $(-8.7 \mathrm{ft} / \mathrm{s})$. The largest transmissivity tested $\left(4.0 \times 10^{-4} \mathrm{~m}^{2} / \mathrm{s}\right.$ $\left[\sim 4 \times 10^{-3} \mathrm{ft}^{2} / \mathrm{s}\right]$ ) was at WIPP-25 (at the edge of Nash Draw west of the WIPP). The lowest transmissivity tested $\left(6.0 \times 10^{-9} \mathrm{~m}^{2} / \mathrm{s}\left[6 \times 10^{-8} \mathrm{ft}^{2} / \mathrm{s}\right]\right)$ was at test hole H-8. Test holes $\mathrm{H}-7 a$ and WIPP-28 were drilled in an unsaturated part of the Magenta Dolomite Member. Examination of a core of WIPP-28 revealed bedding plane partings and fractures filled with gypsum (Mercer, 1983).

A contour map of log hydraulic conductivities of the Magenta Dolomite Member (Figure 4-16) shows a decrease in conductivity from west to east with slight indentations of the contours north and south of the WIPP that correspond to inlets observable at the surface. A preliminary statistical analysis of the correlation of overburden thickness to hydraulic conductivity shows a poor correlation $(r=-5.0)$. The poor correlation may result from the way the material surrounding the Magenta Dolomite Member has been dissolved and from the subsequent deposition of gypsum in parting planes and fractures.

No porosity measurements have been made on the Magenta Dolomite Member, but: a porosity of 0.20 was assumed (Beauheim, 1987). This is slightly high for intact dolomite but may be close to an average porosity for dolomite that has undergone some karstification.

Contours of the potentiometric-surface map (Figure 4-17) representing freshwater-equivalent heads indicate a southwestward flow in the northeastern part of Nash Draw and a gradient of 0.003 . Flow is almost westward across the WIPP with a gradient of 0.004 . The Magenta Dolomite is absent in the southwestern part of the Draw and, because no springs issue along the rim of the Draw, the groundwater is assumed to flow into lower units through fractures.

The potentiometric map indicates recharge to the Magenta Dolomite Member probably occurs to the north, possibly in Clayton Basin (Figure 4-4) or 

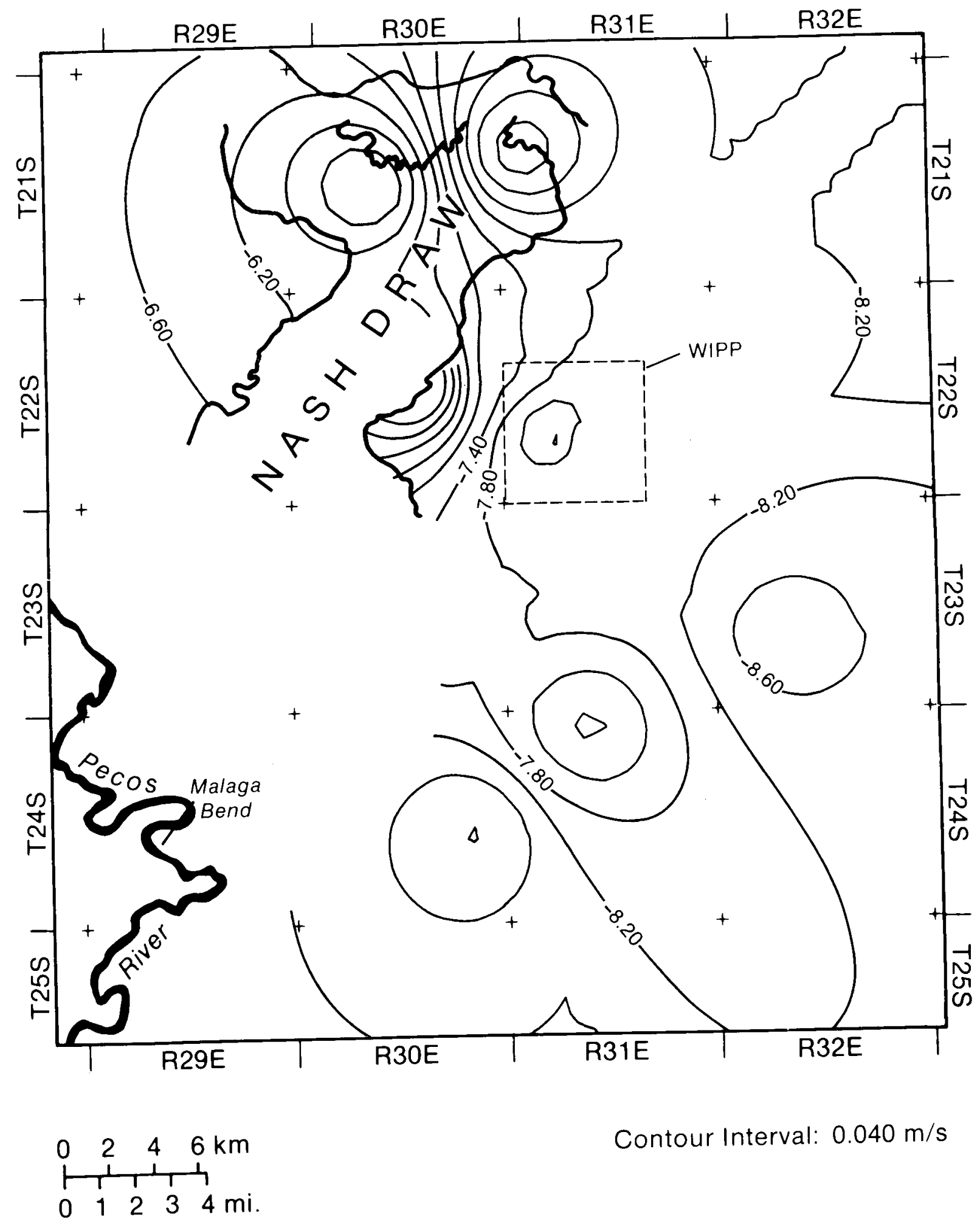

Contour Interval: $0.040 \mathrm{~m} / \mathrm{s}$

TRI-6342-162-0

Figure 4-16. Negative Log Hydraulic Conductivities of the Magenta Dolomite Member of the Rustler Formation in the Los Medaños Area. 

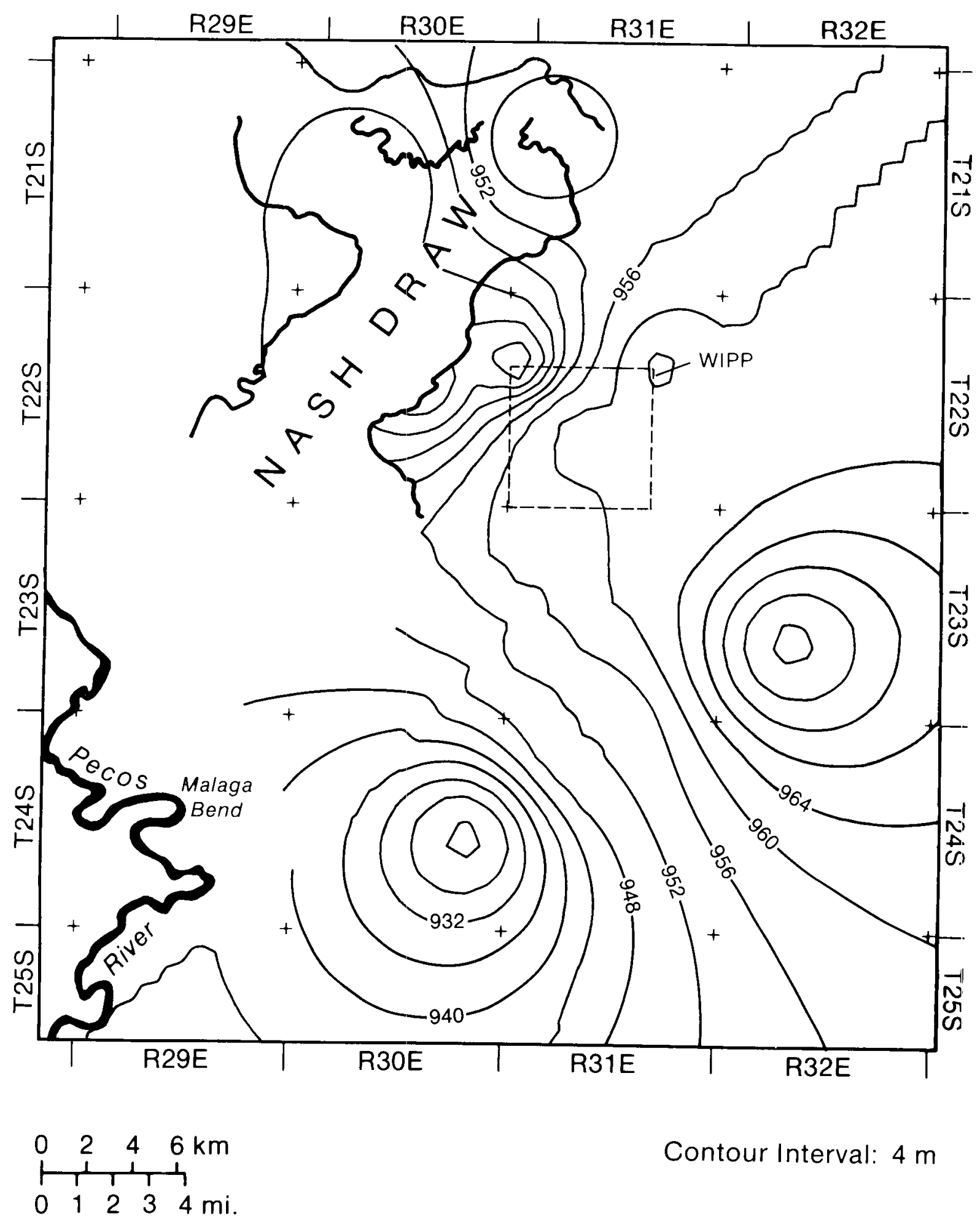

Contour Interval: $4 \mathrm{~m}$

TRI-6342-161-0

Figure 4-17. Adjusted Potentiometric Surface of the Magenta Dolomite Member of the Rustler Formation in the Los Medaños Area. 
1 farther north at Bear Grass Draw where the Rustler crops out (Mercer, 1983).

Apparent recharge to the east of the WIPP may be an artifact of variable water quality corrections and density effects on the static-head estimate (Mercer, 1983). Discharge is probably into the lower units (Tamarisk Member and Culebra Dolomite Member).

Water density varies from $1.004 \mathrm{~g} / \mathrm{cm}^{3}$ (only slightly saline) at test hole $\mathrm{H}-9 \mathrm{a}$ in the southern part of the Study Area to $1.171 \mathrm{~g} / \mathrm{cm}^{3}$ at test hole $\mathrm{H}-10$ southeast of the WIPP (Figure 4-18). The Magenta Dolomite water-quality distribution is not as well defined as the Culebra Dolomite water-quality distribution but is, nevertheless, distinguishable and reflects the degree of dissolution of underlying halite (Mercer, 1983).

\section{Hydrogeology of the Supra-Rustler Rocks}

Several rock units younger than the Ochoan Rustler are present in the Study Area. These are of little hydrologic importance because they are not aquifers and, indeed, are dry throughout most of the Study Area (Lappin et a1., 1989). However, the units should be considered because saturation could occur in the upper units as a result of climatic changes or from a breach of a pressurized brine reservoix. The Permian Dewey Lake Beds and the overlying Mesozoic, Cenozoic, and Holocene material are lumped as one hydrologic unit for regional modeling purposes and more detailed discussion of these units can be found in references cited.

Conformably overlying the Rustler Formation are the youngest Ochoan rocks, the Dewey Lake Red Beds (Pierce Canyon red beds in Vine, 1963), consisting of reddish-brown alternating fine-grained sandstones and siltstones cemented with calcite and gypsum. Bedding may be structureless or cross-laminated, and ripple marks and mud cracks may be present. In the Study Area, the Dewey Lake Red Beds are absent in Nash Draw, are as much as $60 \mathrm{~m}$ (196 ft) thick where present west of the WIPP, and may be over $200 \mathrm{~m}$ (656 ft) thick east of the WIPP. The Dewey Lake Red Beds are unconformably overlain by Mesozoic rocks that consist of the Triassic Dockum Group and Cretaceous sediments. These rocks and sediments are mostly absent west of Nash Draw; the thickness ranges to over $100 \mathrm{~m}(328 \mathrm{ft}$ ) in western Lea County. Overlying the Mesozoic are 

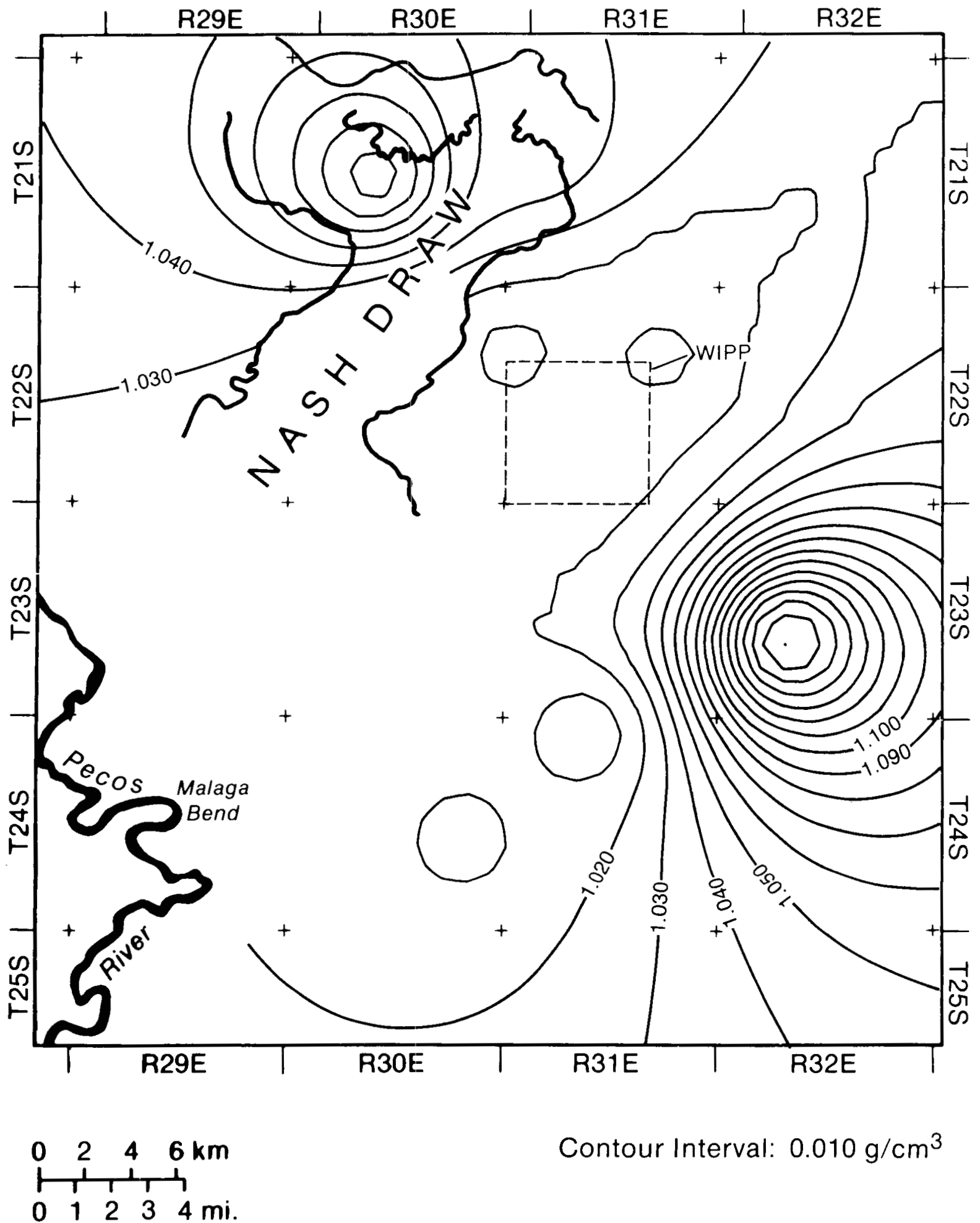

Contour Interval: $0.010 \mathrm{~g} / \mathrm{cm}^{3}$

TRI-6342-164-0

Figure 4-18. Brine Densities of Water from the Magenta Dolomite Member of the Rustler Formation in the Los Medaños Area. 
Cenozoic materials consisting of the Pliocene Ogallala Limestone on the extreme eastern part of the Study Area. Overlying these units unconformably are the Quaternary Gatuña and the informally named Mescalero caliche.

Drilling in the Dewey Lake Red Beds has not identified any continuous saturated zone. Some localized zones of relatively high permeability were identified by loss of drilling fluids at DOE-2 and H-3d (Mercer, 1983; Beauheim, 1987). Some thin, lenticular, saturated, perched, and semiperched sands were identified in the upper Dewey Lake Red Beds at wells $\mathrm{H}-1, \mathrm{H}-2$, and H-3 (Mercer and Orr, 1979; Mercer, 1983). The only wells producing water from the Dewey Lake Red Beds in quantities sufficient to water livestock are the James Ranch wells, Fairview we11, and Pocket well.

Preliminary hydrologic properties of supra-Rustler rocks are difficult to determine because of the lack of long-term pump tests and lab tests. The hydraulic conductivity of these rocks, assuming saturation, is estimated to be $1 \times 10^{-11} \mathrm{~m} / \mathrm{s}\left(\sim 1 \times 10^{-11} \mathrm{ft} / \mathrm{s}\right)$, similiar to the hydraulic conductivity of the Forty-niner Member. The porosity is assumed to be 0.20 , which is representative of fine-grained sandstone: Storativity (storage coefficient) is assumed to be $10^{-4}$. Water density is assumed to be similar to that of the water in the Magenta Dolomite Member.

The supra-Rustler units are recharged locally by water percolating downward through fractures to bedding planes and fine-grained lenticular sandstones; the units discharge to lower zones (Mercer, 1983). Lateral movement of groundwater is restricted by the lenticular nature of the sands.

\section{Surface Water}

The Pecos River drainage system, the principal surface-water feature in southeastern New Mexico, is part of the Rio Grande drainage basin and flows southeastward in New Mexico approximately parallel to the axis of the Delaware 


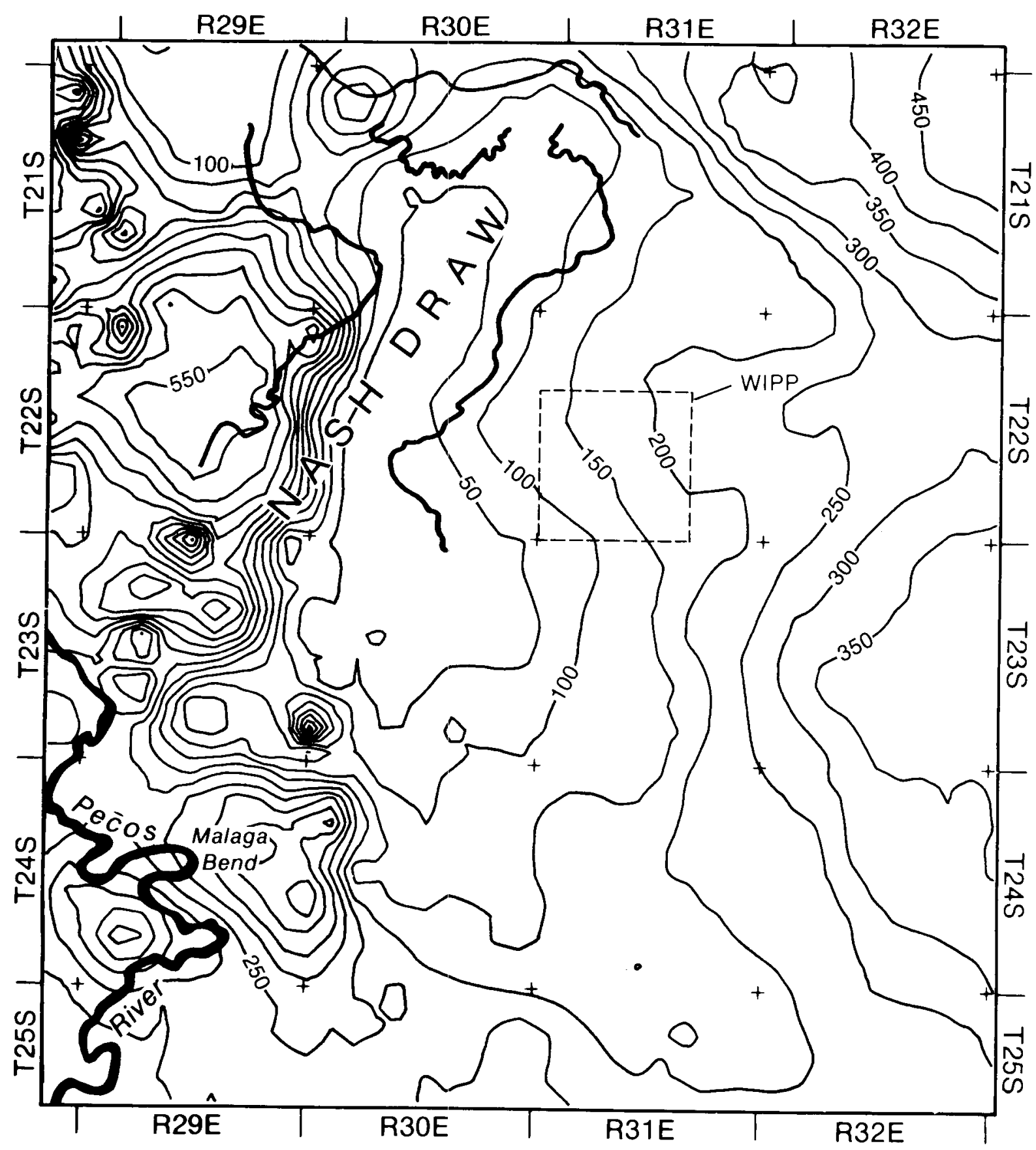

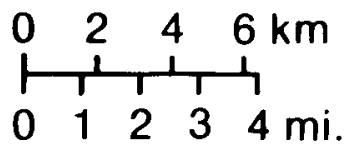

Contour Interval: $50 \mathrm{~m}$

TRI-6342-150-0

Figure 4-19. Isopach Map of the Supra-Rustler Rocks in the Los Medaños Area. 
Basin in Eddy County, draining into the Rio Grande in western Texas. In the vicinity of the WIPP, the drainage system consists of small ephemeral creeks and draws in addition to the Pecos River with a drainage area of about 50,000 $\mathrm{km}^{2}$. The Pecos River, which is about $20 \mathrm{~km}(12 \mathrm{mi})$ southwest of the WIPP, flows diagonally across the southwestern corner of the Los Medaños Study Area and has the lowest surface elevation of the Study Area.

Several broad shallow lakes in Nash Draw that cover an area of about $16 \mathrm{~km}^{2}$ $\left(\sim 6 \mathrm{mi}^{2}\right)$ lie north of Malaga Bend and southwest of the WIPP. The largest lake, Laguna Grande de la Sal, has existed for many years. Since 1942, effluent from potash mining and oil-well development in the area has formed smaller, intermittent lakes in closed depressions north of Laguna Grande de la Sal (Hunter, 1985). The effluent has enlarged Laguna Grande de la Sal. The lakes also collect precipitation, surface drainage, and groundwater discharge from springs and seeps. The rate of discharge from the groundwater to the lakes in the area is estimated to be $0.67 \mathrm{~m}^{3} / \mathrm{s}\left(-24 \mathrm{ft}^{3} / \mathrm{s}\right)$ (Hunter, 1985). Very little, if any, of the water from these lakes reaches the Pecos river (Robinson and Lang, 1938; Lambert, 1983).

The only spring of importance in the Study Area is Surprise Spring at the northern edge of Laguna de 1a Sal. In 1942, the spring discharged at a rate of less than $0.01 \mathrm{~m}^{3} / \mathrm{s}$ ( $1 \mathrm{ft}^{3} /$ day) and this rate has since declined (Lambert and Harvey, 1987; Hunter, 1985).

\section{Summary}

The important hydrostratigraphic units for regional groundwater flow in the vicinity of the WIPP are, in ascending order, the Rustler-Salado residuum and the Culebra and Magenta Dolomite Members of the Rustler Formation.

The Rustler-Salado residuum is the first hydrostratigraphic unit above the Salado Formation and consists of residue from dissolution of upper Salado and lower Rustler Formation halite. The log hydraulic conductivity ranges within an order of magnitude from $-12.0 \mathrm{~m} / \mathrm{s}$ in the vicinity of the WIPP to $-6 \mathrm{~m} / \mathrm{s}$ in Nash Draw. The mean effective porosity of the unit is about 0.20. The unit is under confined conditions over most of the area but under water table 
conditions in the vicinity of Malaga Bend in the southwestern corner of the Study Area. The residuum recharges north of the WIPP and discharges to the southwest.

The Culebra Dolomite Member of the Rustler Formation is a microcrystalline dolomite that is of relatively consistent thickness, around $8 \mathrm{~m}(26 \mathrm{ft})$, and is present throughout the Study Area. The Culebra is under confined conditions in the vicinity of the WIPP and under water table conditions near Malaga Bend at the lower end of Nash Draw. The log hydraulic conductivity ranges within an order of magnitude from $-10 \mathrm{~m} / \mathrm{s}$ in the eastern part of the Study Area to $-4 \mathrm{~m} / \mathrm{s}$ in the western part of the Study Area in Nash Draw and near Malaga Bend. The average porosity of the unit is about 0.20. The Culebra recharges from the north and east and discharges to the southwest.

The Magenta Dolomite Member of the Rustler Formation is similar in composition and thickness to the Culebra Dolomite Member but is not present in the western part of the Study Area in Nash Draw. Log-hydraulic conductivity ranges within an order of magnitude from about $-9 \mathrm{~m} / \mathrm{s}$ to $-4 \mathrm{~m} / \mathrm{s}$. Effective porosity of the Magenta is about 0.20. The Magenta recharges from the north and possibly east and discharges through fractures into the Tamarisk and Culebra Dolomite Members.

The units above the Rustler are considered as one hydrostratigraphic unit with a composite hydraulic conductivity based on the values for all the overlying units. The unit is unsaturated except for some locally perched sands that may provide water for a few livestock wells. Recharge to the supra-Rustler units is probably from precipitation. A $3-\mathrm{m}(10-\mathrm{ft})$ thick unit of caliche that is present throughout the area allows very little recharge to the Rustler Formation.

\section{CALIBRATION OF GROUNDWATER MODELS}

Groundwater flow models must be calibrated using available data. Calibration provides initial fluid fields and material property fields for long time-scale simulations, and benchmarks for judging model performance. 
1 There are two transients with documented time scales. A short time scale on 2 the order of decades (Lappin, 1988), reflects a perturbation because of potash mining and local pumping such as for WIPP data acquisition. The longer time scale reflects residual transiency from the last glacial age (Lappin, 1988; Lambert, 1988). How this longer time scale affects 10,000-year predictions for WIPP compliance assessment is still unknown. Transient model predictions must confirm intuitive assessments of the effects on transport of these two transients in the present groundwater flow over the time interval for each significant scenario. Calibrated models provide initial fluid fields and material property fields for these simulations. Preliminary modeling of the Los Medaños groundwater flow system used the Sandia Waste-Isolation Flow and Transport code (SWIFT II), a transient, three-dimensional finite-difference code that solves the fully coupled equations for flow and transport in porous media (Reeves et al., 1986).

Calibrating models is a tuning procedure that attempts to reproduce observed information within some acceptable range of an appropriate measure. For the WIPP site characterization, calibration focused first on reproducing approximate steady-state head conditions and simulating the $\mathrm{H}-3$ and WIPP-13 multipad-scale interference tests. Transient head distributions, including hydraulic stresses resulting from construction of the Air-Intake Shaft and from the H-11 multipad-tracer test were simulated to complete the calibration efforts.

Successful calibration means that the observed groundwater flow was simulated adequately over the time period of the hydropad tests using a numerical model. Calibration over a time period using a dynamical model is more than just interpolation of observed field data; the subjective combination of filling interpolated and predicted fields to observed time series of data at isolated points is a "dynamical interpolation". The time records are short (on the order of years) compared to relevant groundwater time scales so the dynamical interpolation is a snapshot in time compared to a prediction. Therefore, calibration is not model validation for performance assessment. Calibration provides initial fluid fields and a conceptual model for material property fields. The former are not important for long-term prediction, but the latter are very important because stationarity (in time) is inherently assumed for uncertainty analyses.

IV -52 
REPOSITORY/SHAFT SYSTEM OVERVIEW

The repository/shaft module of the compliance assessment system includes flow and transport within the underground workings at the repository horizon and within various shafts and boreholes that connect the underground workings with overlying formations. Figure 4-20 shows the repository design in a plan view. The waste-disposal rooms occupy the southern end of the mined horizon. A.11 rooms, drifts, and shafts will be backfilled when the repository is closed.

A model of this complex repository/shaft system must be included as a modvie in the compliance assessment methodology (i.e., in CAMCON) for performing uncertainty and sensitivity analyses. This model includes the source term and all important processes that bear upon transport of radionuclides from the storage rooms. For the UND scenario, the modeling problem is to predict transport of radionuclides from the rooms through the entire repository/shaft system to overlying fluid-bearing zones, such as the Culebra Dolomite Member of the Rustler. A source within the hydrology model for this member can be specified and a coupled fluid-flow/transport simulation continued to the boundary between the controlled area and the accessible environment. A similar separation can be performed for the CHRS scenario group and the HUMINT scenario group.

An intrusion borehole that penetrates a storage room serves as a possible flow connection with overlying or underlying formations. Flow and transport through this connection can be described, and sources characterized within fluid-bearing zones that are appropriate for each human-intrusion scenario. In this case, the repository/shaft module impacts the analysis only through the waste-storage room of the system model. The degree of consolidation of the room and its contents at the time of intrusion help define the source term for the simulation.

CAMCON provides an efficient, readily available tool for modularizing components within the respository/shaft system. The design of the repository and shafts divides into components that are connected but can be treated separately. Each component includes the various processes determined to be 


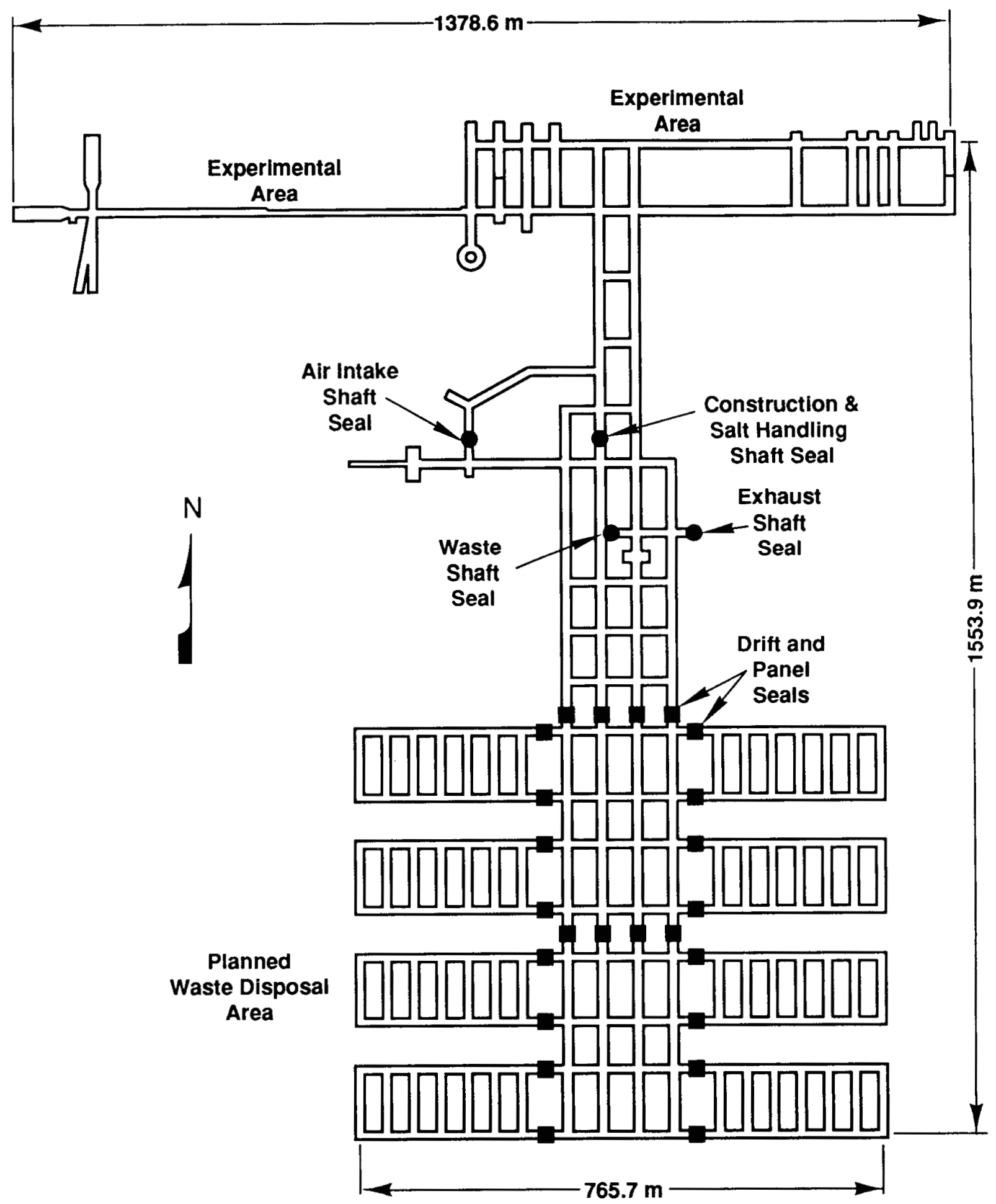

TRI-6342-222-0

Figure 4-20. Plan View of Storage Horizon Showing Shaft, Drift and Panel Seal Locations (after Stormont, 1988). 
important for the transport problem. These processes and important parameters are selected on the basis of sensitivity analyses performed on the repository/shaft systems model.

Construction of a repository/shaft systems model is complicated because of the wide range of model types used to analyze different processes that influence repository design. Many of these models are also important for consequence modeling, and would normally be used during compliance assessment. However, models used for design may be simple analytical models or complex finiteelement models. A reasonable match of component models and data is required for systems studies. Construction of a compliance assessment module provides a mechanism for feedback to the designers through sensitivity analyses that are used to match modeling components and data. The repository/shaft systems model for compliance assessment is RESYSM (REpository-Shaft SYStem/Source-term Mode1).

The component of RESYSM that represents a single room incorporates many phenomena. Predicting the final state of the room is the main objective, but predicting impacts of human intrusion is also important. To predict the room's final state, many factors must be considered during model development, even though some of them may not be important or even appear in the final RESYSM (Table 4-3).

TABLE 4-3. FACTORS POTENTIALLY IMPORTANT FOR MODELING THE ROOM (Tyler et al., 1988; Lappin et al., 1989, Bertram-Howery and Hunter, 1989a).

Creep closure of the salt

Brine inflow from the Salado Formation

Structural response of the backfill mix

Structural response of the waste containers and contents Inventory and waste categories

Room and brine chemistry

Gases generated by microbiological, radiolytic, and corrosive decomposition of waste materials

Brine and gas interactions with the backfill mix Gas interactions with the Salado Formation Brine and gas interaction with MB139 Radionuclide solubilities in the room environment Effect of intruding drilling fluids Effect of injected pressurized brines 
For the HUMINT scenario group, the room is directly connected to overlying fluid-bearing zones by intrusion boreholes. Concentrations of radionuclides in the room as a function of time following these intrusions must be estimated to describe the rate of radionuclide migration (source) to overlying water bearing units. Preliminary calculations (Lappin et al., 1989; Marietta et a1., 1989) use solubility-limited source terms that include the volume of an entire panel. Sensitivity analyses (Marietta et al., 1989, Appendix A;

Rechard et al., 1989) are assessing this assumption to refine the volume of waste accessible to an intrusion borehole and to account for brine flow rate through the waste panel. Those estimates primarily use the room component of RESYSM. For other scenarios, transport through panel seals (Figure 4-20) and the MB139 seal (Figure 4-21) must be modeled (Table 4-4).

TABLE 4-4. FACTORS TO BE CONSIDERED IN THE PANEL-SEAL COMPONENT OF RESYSM (Tyler et al., 1988; Lappin et al., 1989, Bertram-Howery and Hunter, 1989a).

Consolidation of seal materials

Saturation effects on consolidation

Gas effects on seal consolidation and saturation

Pressure effects on seal materials after pressurized brine injection

Pressure driven flow and transport through seals, along seal/host rock interface, and through disturbed rock zone

Radionuclide retardation in brine-saturated seals and host rock in the saturated brine environment

The features of a single panel seal are considered during sensitivity studies and seal design. The eventual module for RESYSM must account for the system of panel seals and backfilled drifts. The room/panel seal connection will be integrated and scaled into a network that combines the effect of many rooms, drifts, and seals into one module for systems simulations. This network represents everything to the south of the northernmost panel seals (Figure $4-20)$.

MB139 is an important parallel path for radionuclide transport to the shafts. MB139 will be sealed under all panel seals. Portions of MB139 under the backfilled drifts also will be included in RESYSM (Figure 4-21). 


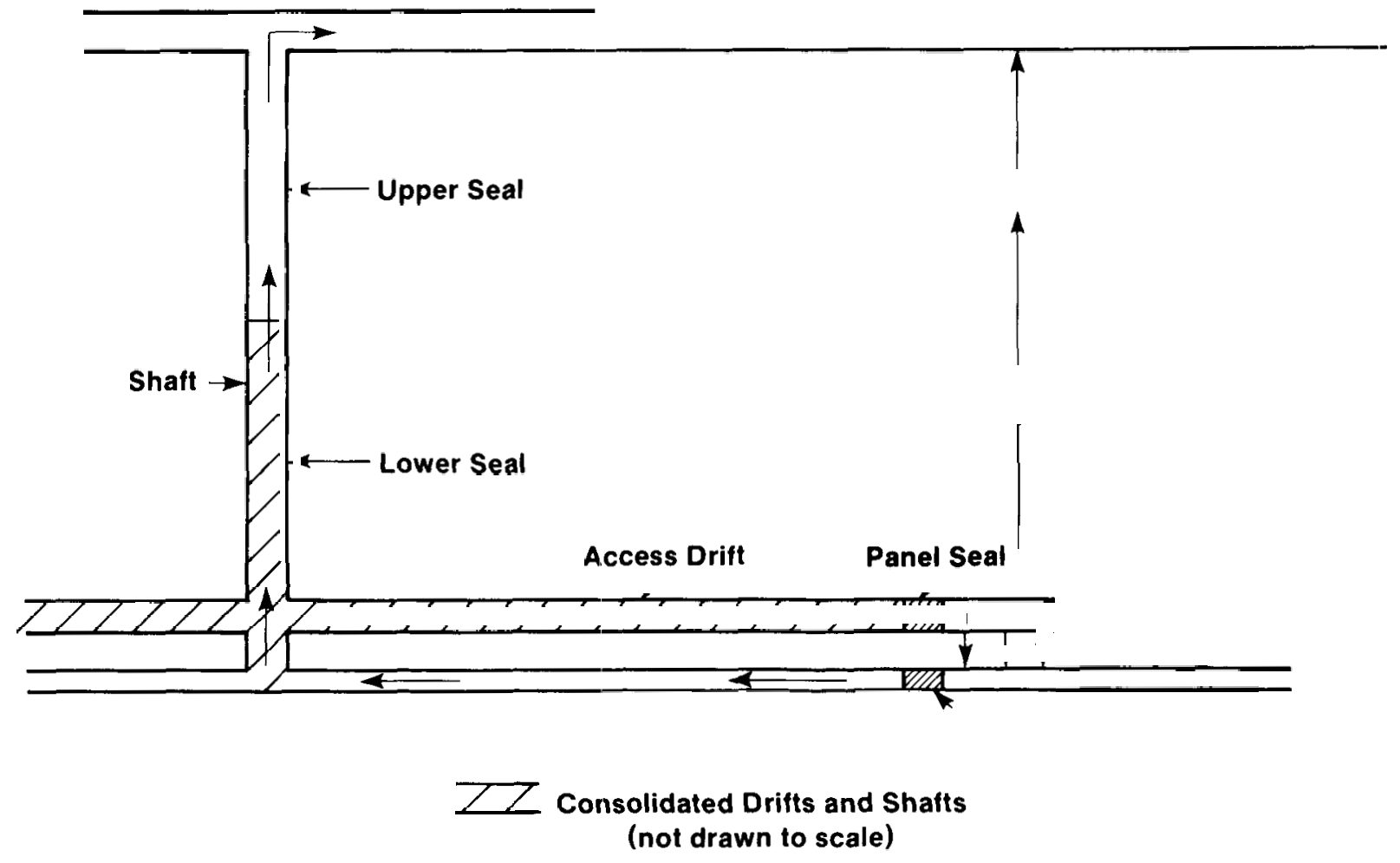

TRI-6342-200-10

Figure 4-21. Conceptual Model Used in Simulating Undisturbed Performance (Lappin et al., 1989). 
1 The system of drifts from the northernmost panel seals to the bottoms of the

2 various shafts (Figure 4-20) and MB139 form the drift component of RESYSM.

3 The features of this component that must be considered in developing a systems

4 module are similar to features of the panel-seals module except that there is

5 no over-excavation of the drift and stiff members are not present. Backfill

6 material in this part of the drifts may be identical to panel-seal material

7 (i.e., salt blocks), but crushed salt probably will be used in the drifts.

8
TABLE 4-5. FACTORS TO BE CONSIDERED IN THE DRIFT/MB139 COMPONENT OF RESYSM (Tyler et al., 1988; Lappin et al., 1989, Bertram-Howery and Hunter, 1989a).

Backfill consolidation

Reconsolidation of disturbed rock zone

Saturation effects on consolidation

Radionuclide retardation in host rock and backfill materials

Brine and gas interaction with host rock and backfill materials

Brine and gas interaction with MB139

Radionuclide retardation in MB139 and backfill materials

The shaft/seal component of RESYSM is another separate system of seals with stiff structural members that maintain seal-material integrity during consolidation. This component is represented by a single module. The seal material in the lower seal system was selected to reproduce the desirable natural-barrier features of the Salado Formation. The seal material and design in the upper seal system was selected to prevent fluid seepage from overlying fluid-bearing zones. Material for stiff members was selected to maintain system integrity until final consolidation, which will occur by lateral rather than vertical salt creep, is complete.

Two fluid-flow applications of the shaft/seal component are necessary for compliance assessment. First, upward transport through the seal system to overlying water bearing units must be considered for undisturbed performance analyses. Second, fluid seepage downward represents a possible mechanism for repository saturation and should be simulated as part of design sensitivity analyses. Modeling of both flow directions is required to analyze CHRS scenarios. 
2

TABLE 4-6. FACTORS TO BE CONSIDERED FOR THE SHAFT/SEAL COMPONENT OF RESYSM (Tyler et al., 1988; Lappin et al., 1989, Bertram-Howery and Hunter, 1989a).

\section{Consolidation of seal materials}

Saturation of the shaft/seal system from host rock, overlying water-bearing units, or pressurized Castile Formation brine

Radionuclide retardation by host rock and seal materials

Flow and transport through seal materials, along the host rock/shaft interface, and through the disturbed rock zone

The bottom of the shaft is separated from the drift by a concrete seal that: is included in the shaft/seal system. Stiff-member materials like this concrete layer at the bottom of the shaft are not designed to survive in the brine environment beyond a hundred years after repository closure. Therefore, the connection between the drift and shaft modules for RESYSM is only a transition from drift backfill to shaft-seal material. A sensitivity analysis to assess the importance of drift backfill materials within the overall system will guide materials selection. Similarly, the shaft seal system above the repository horizon can be modeled as a seal consisting only of consolidated salt because degradation time for the stiff member is short compared to the 10,000-year Containment Requirements.

The assembly of these RESYSM components into a systems model requires individual component and system sensitivity analyses to identify important parameters and processes. Detailed complex models such as finite-element structural-analysis codes are used where data are extensive (e.g., room closure). Simplified analytical or even network flow models may be used where data are sparse (e.g., transport through shaft seals). Even though highly detailed, finite-element and finite-difference fluid-flow codes are availabile, mode1 selection must be commensurate with supporting data and module importance to the performance measure.

Many of the important phenomena must be considered in a coupled mode. Consolidation with back-pressure response of interstitial brines and simultaneous gas generation is one example. The room module will be a set of simplified empirical calculations using data derived from complex-model simulations, analytical solutions, and measurements. Empirical data fitting; must be based on a systematic sensitivity analysis of the overall system. 
Chapter IV: Containment Requirements

\section{ROOM MODEL}

The disposal-room characterization program studies the interaction of TRU waste and backfill mixtures in a waste room during and after consolidation by creep deformation of the surrounding salt. Brine inflow and gas generated by waste decomposition will influence room closure. The interaction of waste and containers, backfill mixtures, brine, gases, and closure are studied through laboratory tests, small- and large-scale field experiments for different engineered modifications and sensitivity analyses to assess performance and safety. A major aspect of room modeling will be coupling individual components into a model that allows room conditions to be estimated as a function of time. For WIPP performance assessment, it is important to know not only the state of the room when an intrusion event occurs but also the transient response following that event so that migration of radionuclides away from the room can be predicted.

The room model will be developed from the studies of room processes that are currently underway. Any discussion of the model and the radionuclide source term would be highly speculative at this time. Therefore, this material will be added in the future.

\section{PANEL-SEAL MODELING}

Panel seals isolate disposal rooms from the remainder of the repository (Figure 4-20). A number of diverse activities must be integrated to complete the conceptual-seal design (Figure 4-22). Analyses of brine inflow from the host rock, consolidation of seal materials, creep closure of the host rock, disturbed zone formation and closure, and stress must be applied to panel-seal design and modeling. Structural analysis and fluid-flow codes developed for room design can be used to analyze performance of seal components.

Various empirical, analytical, or numerical codes must be merged and may be simplified for use as a module within RESYSM. Significant differences exist in model setup. Seal geometry requires different meshes to represent seal shape and material differences. Analysis of seal performance requires simulating three possible flow paths: flow through seal materials, flow along 


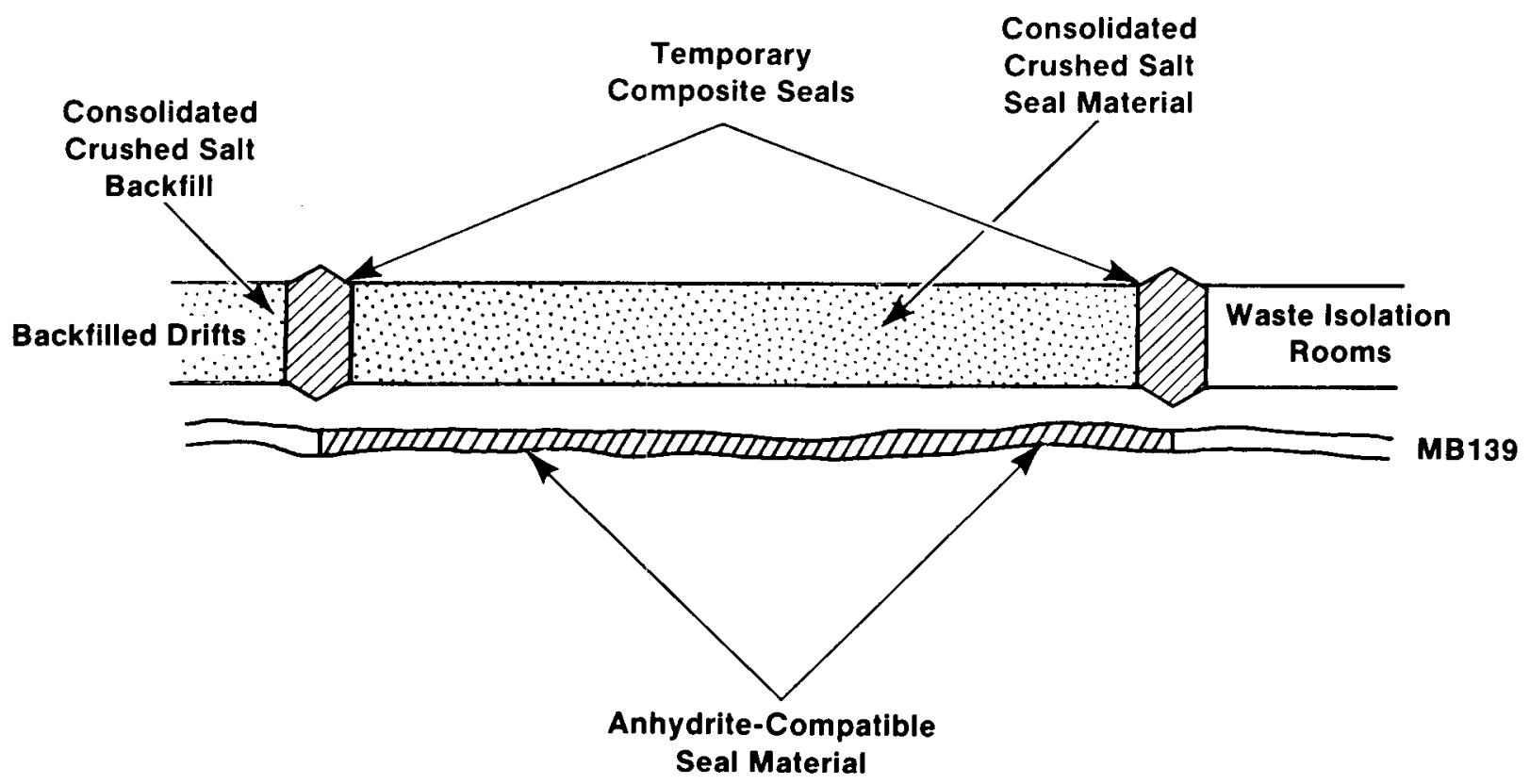

TRI-6342-224-0

Figure 4-22. Schematic Design of a WIPP Panel Seal (Lappin et al., 1989). 
the interface between seal materials and the host rock, and flow through the host rock including the disturbed rock zone. Panel-seal models must simulate flow and transport along these three pathways. If a pathway is determined to be unimportant during sensitivity studies, it will not be included in RESYSM. Final modules for room/panel seals must account for the full assemblage of rooms and seals (Figure 4-22), so a network modeling approach may be the most reasonable choice. The network model will require that individual components of the system be fully modeled. 9

Studies to develop process models for panel-seal design and RESYSM-module development are a subset of the room-model studies with different geometry and materials.

\section{Seal-Material-Consolidation Modeling}

These studies use the same models for constitutive and structural analyses that are used in modeling backfill-mix consolidation and closure for the room. Crushed and block salt without additives must be analysed to determine the final degree of consolidation of the system. The sensitivity of consolidation of crushed-salt seal components to brine inflow, creep closure, initial density, and other parameters (Nowak and Stormont, 1987), has been determined. Seals include layers, probably consisting of bentonite and concrete, that resist creep closure. Layering must be included in structural analyses. Seal designs include over-excavation of the drift, which develops stress concentrations at corners and causes the host rock to fracture. These effects must be modeled using variable mesh generation and fracture models.

\section{Brine-Inflow Modeling}

Consideration of brine inflow is important in assessing panel-seal performance during consolidation, because brine may create a backpressure that retards closure. Predicting the final degree to which panel seals consolidate requires coupling saturation and creep-closure models. If bentonite is a seal material, its structural response to swelling must also be included. Again, the models (e.g., Nowak et al., 1988) applied to the room can be applied to different materials and geometries of panel seals. 
Disturbed Rock Zone Modeling

Modeling flow through the DRZ is particularly important for panel seals and shaft seals. Flow and transport through fractures of the DRZ could possibly circumvent seal materials. The fracture pattern around panel seals will probably be complex and anisotropic due to overexcavation of the drift. This possible pathway can be assessed by simulating pressure-driven flow through the DRZ. A pressure gradient may exist across panel seals in the final consolidation state. As discussed in the human-intrusion scenario, injection of Castile Formation brines into the room could also result in such a pressure gradient. Seal performance under such hypothetical conditions must be assessed.

Tracer-gas studies (Stormont et al., 1987; Peterson et al., 1987b) have been conducted to estimate fracture continuity and apertures in MB139. These studies indicated connection between the excavations and MB139 through the fractured salt. Further studies are underway to analyze the effects of the DRZ (i.e., its fracture-induced porosity) on hydrologic properties. Simulating fracture flow and transport through the host rock requires a flow code with a fracture model. First, formation of the DRZ in response to the excavations of the drifts, rooms, and seals must be described. A concept of processes that form the DRZ and how it will respond during closure (e.g., to what extent the fractures will heal) can be developed by integrating various fracture data. A predictive capability for simulating fracturing and fracture closure can be developed from this conceptual model. A fracture model can serve as a constitutive model and be included as part of the computational scheme within structural analysis codes. If the fracture pattern is fixed, it can be included in flow codes. Dtherwise, the fracture model must be coupled with a deformation code so the changing fracture pattern can be predicted. Then fluid flow and its backpressure effects can be included. The pore space within the DRZ is now unsaturated (Borns and Stormont, 1988; 1989) due to microfracturing and mine ventilation. Because of this increased pore volume, the DRZ's ability to accept fluids, both brine and gas, is enhanced. Codes for modeling such coupled processes do not exist; although, in principle, they can be assembled. For developing a RESYSM module commensurate with the relative importance of panel seals within the repository/shaft system, a 
fairly simple network model relying on dual porosity approximations is a reasonable first step.

\section{Flow and Transport Modeling}

The undisturbed-scenario analysis requires simulations of flow and transport through the repository/shaft system to overlying water-bearing units (e.g., the Culebra Dolomite Member). Human-intrusion scenarios include transient, pressure-driven flow away from the borehole into the Culebra Dolomite. This transient flow could result from injection into the repository of pressurized brine from the Castile Formation. The transient could be extended by flow into the borehole from the host rock if fluid pressure in the rock is greater than hydrostatic pressure. For other scenarios, the primary mechanism for transport through the saturated repository and shafts is pressure-driven flow. Room consolidation or gas generation could cause pressure within the disposal room to exceed hydrostatic pressure. Transport through, along, and/or around panel-seal materials must be modeled. Capability for handing all scenarios requires solving equations (including retardation and fracture flow) for radionuclide transport along the three flow pathways. Because network models only solve one-dimensional equations along preassigned pathways for fixedfluid fields, more detailed, multi-dimensional modeling may be required to justify the use of these simplified models in the uncertainty analyses.

\section{Panel Seal and Room Assemblage}

Once transport past a single panel seal from a single room can be adequately estimated by room-performance and panel-seal modules, the effect of all storage rooms and drifts behind the northernmost pane1 seals can be estimated by assembling individual component networks into a multicomponent network. Diffusive and perhaps advective fluxes of radionuclides across the northern panel seals are required for interfacing with the next RESYSM module. A multipath, network model could be used although the results would be limited by all the disadvantages of using oversimplified numerics and physics. The network code applied would require careful benchmarking against more complete, verified, dynamical codes on test problems designed for WIPP repository geometry. 


\section{DRIFT MODELING}

A module within RESYSM will simulate flow and transport from the northernmost panel seals to the concrete bases of the shafts (Figure 4-23). Flow and transport through the underlying MB139 will be included. Drifts may contain backfill consisting of salt or salt mixed with other materials. Final selection of backfill for these drifts depends on their importance within the overal1 CAMCON system. Development of a drift module for RESYSM is another application of the creep closure, brine inflow, flow, and transport codes used for the room/panel-seal modules. Geometry and materials may be a little different. Output of the drift module is radionuclide flux into the bottom of the shaft seal material. Because concrete is not designed to last beyond a hundred years, the drift backfill (if any) will be directly connected to shaft-seal material when final consolidation has been achieved.

\section{SHAFT SEAL SYSTEM}

Seal components are divided into two categories according to function and time scale. Temporary seal components protect the integrity of the seal system during consolidation. They will be constructed of concrete bulkheads and bentonite-containing materials. They must protect the seal system from intrusion of Rustler Formation brines from above and repository gas from below. Long-term seal components are constructed from blocks of reconsolidated, crushed salt and crushed salt-based grouts. Crushed salt will consolidate in response to creep closure of the host rock. Grout is used to seal interbeds. These seal components are the primary barrier to radionuclide migration. Candidate seal materials are WIPP crushed salt, bentonite and bentonite-salt mixtures, concrete, and crushed salt-based grout. Both laboratory and modeling studies are being conducted to evaluate these materials.

The four shafts (Figure 4-20) will have multi-component seals extending from the drift upward to the surface. Each shaft-seal system (Figure 4-23) will. consist of an upper seal and a lower seal. 


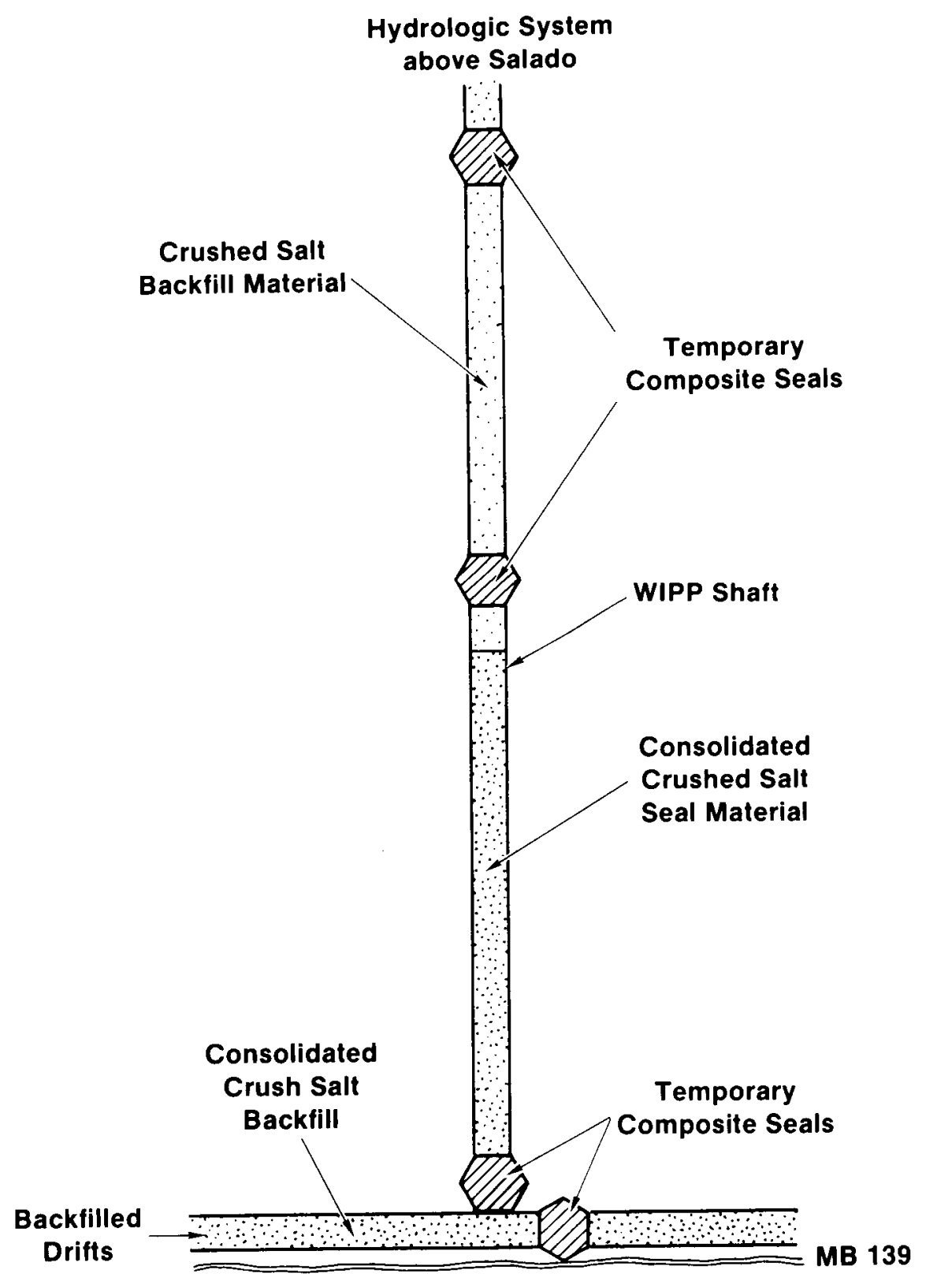

TRI-6342-225-0

Figure 4-23. Schematic Design of a WIPP Lower Shaft Seal System (Lappin et al., 1989). 
The upper seal is designed to limit seepage of Rustler Formation brine into the lower system so that interstitial brine will not interfere with consolidation of the lower seal. Consolidation should occur at a rate similar to that of the storage panels beginning from the drifts upward. Crushed salt will be placed in the upper seal system, but consolidation will be slower so these seals are not considered a primary barrier to radionuclide transport. Therefore, the upper seal has only a temporary function, and is expected to degrade to a hydraulic state similar to silty sand (Stormont and Arguello, 1988).

Lower seals contain crushed salt that will consolidate to nearly 0.95 intactsalt density (Nowak and Stormont, 1987) as the host rock creeps laterally into the shaft. The lower seal's integrity is maintained by concrete bulkheads emplaced at the bottom of the shaft and at the bottom of the upper seal. Additional bulkheads will be placed in the drifts adjacent to the shafts to protect the lower seals from possible degradation by waste-generated gases. Once these lower seals consolidate, they will form the barrier (in the absence of intrusion) to brine migration and radionuclide transport upward from the repository.

\section{Seal-Material-Consolidation Modeling}

These studies use the same set of constitutive and structural-analysis models that are used for modeling backfill-mix consolidation and closure for the room, panel seals, and drifts. Consolidation will be most rapid near the bottom of the shaft so estimates of closure rates along the shaft are important to ensure that temporary seal components provide sufficient protection.

\section{Brine-Inflow Modeling}

Brine inflow is important for assessing shaft-seal performance during consolidation, because brine may create a backpressure that retards closure. Predicting the final degree of consolidation of shaft seals requires couplirg resaturation and creep-closure models. In addition, models must include brine seepage from above. Bentonite is a seal material only for temporary 
components so its structural response (i.e., swelling) is not important for long-term seal behavior. The same models applied to the panel seals can be used for process studies to evaluate different materials and designs.

\section{Disturbed Rock Zone Modeling}

Modeling flow through the DRZ is particularly important for shaft seals. Flow and transport through fractures of the DRZ could possibly circumvent seal materials. Simulating flow through the DRZ is necessary to assess this possible pathway. Rustler brines conceivably could leak through the DRZ and saturate the lower seal system. To ensure the integrity of the lower seal system, sensitivity studies of the upper seal system will be performed to evaluate performance. These studies include the DRZ. Simulating fractured flow and transport through the host rock requires a flow code with a fracture model. The codes used for similar studies of panel seals and panels (rooms) can be used for shaft seals when the codes are available.

\section{Flow and Transport Modeling}

The undisturbed-scenario analysis requires simulating flow and transport through the repository/shaft system to overlying water-bearing units (e.g., the Culebra Dolomite Member). For human-intrusion scenarios, the primary concern is transport through a plugged intrusion borehole and not through consolidated drifts and shafts, although these pathways should be considered in defining room conditions. Transport through, along, and around shaft-seal materials must be modeled for the undisturbed scenario to determine repository conditions, especially for transient brine and gas flow and closure effects. Capability for handling all scenarios requires solving equations including retardation and fractures for radionuclide transport along the three transport pathways. Because network models solve only one-dimensional equations along preassigned pathways for fixed fluid fields, more detailed, multi-dimensional modeling may be required to justify the use of these simplified network models in the uncertainty analyses. 


\section{Shaft-Seal System in RESYSM}

The interface with the next CAMCON module is lateral fluxes of radionuclicles in brines into water-bearing units that overlie the Salado Formation. The network code applied would require benchmarking against more complete and verified dynamical codes on idealized test problems designed for WIPP facility geometry. However, a network model can be formulated to include flow through seal materials, along the seal/host-rock interface, and through the DRZ. In the absence of data, however, calculations are not reliable. The importance of these seals in the overall RESYSM system must be evaluated by sensitivity analysis to determine if increased understanding of flow and transport is required. Preliminary calculations indicate that the undisturbed-performance scenario is not a significant contributor to the release of radionuclides, whereas human intrusion scenarios may be significant (Lappin et al., 1989). Shaft seals are not important in human-intrusion scenarios.

\section{RADIONUCLIDE TRANSPORT}

The Culebra Dolomite Member of the Rustler Formation is the first significant, laterally continuous, water-bearing unit above the WIPP repository. It has been identified in the site characterization as one of the most important paths for radionuclides to be transported from the repository to the accessible environment. Before transport of radionuclides in the Culebra Dolomite can be modeled, the dominant physical/chemical processes during transport must be identified and simulated.

The characteristics of the Culebra Dolomite Member are described in A Summary of the Hydrogeology of the Northern Delaware Basin. The significance for transport of fractures in the Culebra Dolomite Member has been examined with two hydropad tracer tests, $\mathrm{H}-3$ and $\mathrm{H}-4$, near the WIPP (Kelley and Pickens, 1986).

The SWIFT II code was used to simulate tracer breakthrough times at $\mathrm{H}-3$ and H-4. The main objective of the analysis was to conceptualize the governing. 
physical processes for solute transport in the Culebra Dolomite Member. Given the fractured nature of the Culebra Dolomite, three conceptual mode1s are possible: (1) a discrete-fracture model, (2) a porous-flow model, and (3) a dual-porosity model. Comparisons of the single- and double-porosity assumptions in SWIFT II with observed breakthrough curves indicate that the double-porosity calibration is more consistent with the observations.

For the H-4 tracer test, in addition to single- and dual-porosity models, a layered, porous-medium model was also included. From the SWIFT II simulations, the observed tracer-breakthrough curves were concluded to be best simulated by representing the Culebra Dolomite Member with a layered system consisting of alternating high-and low-permeability zones. The best fit was obtained for five or six high-permeability zones, although none of the fits were satisfactory, especially at longer times. This result indicates that sensitivity analyses are needed to assess how vertical resolution within important water-bearing units affects the results of transport simulations.

\section{Regional-Scale Contaminant Transport Calculations in the Culebra Dolomite Member}

Detailed field testing and interpretation of conservative-tracer testing at the $\mathrm{H}-3$ hydropad indicate that fracturing and dual-porosity behavior can play a major role in transport of contaminants in the Culebra Dolomite at the hydropad scale $(30 \mathrm{~m})(98 \mathrm{ft})$. The ultimate goal of the WIPP performance assessment, however, is to estimate the amount and rate of release of radionuclides from the disposal system to the accessible environment. Thus, it is necessary to determine whether the governing transport behavior at the hydropad scale is still valid at the regional scale.

The regional-scale contaminant transport within the Culebra Dolomite Member under undisturbed head-distribution conditions has been investigated (Reeves et al., 1987). Three transport mechanisms compared were discrete-fracture, dual porosity, and equivalent porous medium. From the SWIFT II simulations, the "effective" transport behavior of the Culebra Dolomite Member between any point directly above the site and the $5-\mathrm{km}$ ( $3 \mathrm{mi}$ ) boundary was concluded to be adequately represented by an equivalent porous medium having a porosity equal 
1 to the sum of matrix and fracture porosities. Inclusion of the dual-porosity

2 formalism at this scale apparently would not change expected travel times by

3 more than 0.10 .

Validity of the results is contingent on assumptions concerning base-case transport parameters. In the event of intrusion into pressurized Castile Formation brine, the volume and pressure of brine injected into the Culebra Dolomite Member might be sufficient to increase the hydraulic gradient. Under this condition, the velocity of groundwater in fractures might be greatly enhanced, making the characteristic diffusion time into the matrix much longer than the characteristic transport time in the fracture. In this case, the equivalent-porous-medium approximation would not be valid.

\section{Transport Models}

Numerous groundwater flow and transport models are available. They range from simple, one-dimensional analytical solutions to sophisticated, threedimensional numerical models. Most of these models are for flow and transport in porous media. In the numerical models, spatial and temporal variation of system properties such as hydraulic conductivity, porosity, and dispersivity can be included as required for different scenario analyses.

"Network" models represent a different approach to discretizing flow and transport for efficient computation but with less accuracy and realism. Instead of solving the governing differential equation for solute transport, solute concentrations in these codes are determined by calculating the motion of a large number of discrete particles in a network of known flowpaths.

Both inorganic and organic chemical reactions may occur during the transport: process. Most of what is known about the chemical behavior of contaminants in groundwater pertains to inorganic contaminants. Two approaches are used for: the prediction of the chemical behavior of inorganic contaminants in groundwater. The first approach involves use of distribution coefficients in describing the sorption behavior. The second approach makes use of thermodynamically based chemical-equilibrium models. Field experiments have shown that for trace-level inorganic contaminants controlled by adsorption, 
such as cationic radionuclides, the retardation relation provided estimates of relative velocity within a factor of about 5 or better (Cherry et al., 1984).

Dissolved organic contaminants in groundwater can be influenced not only by adsorption, oxidation, and hydrolysis, but also by microbiological degradation. Trace organics, especially those that are nonpolar and relatively insoluble, tend to be sorbed by sediments and soils. Sorption of many trace organic compounds has been shown to follow a linear isotherm. Therefore, retardation factors may be used to describe their transport. The more hydrophobic a compound is, the more retarded it is (Roberts et a1., 1980; Schwarzenbach and Westa11, 1981; Mackay et al., 1985). Good evidence exists that certain organic groundwater contaminants can be biologically transformed by microorganisms attached to solid surfaces within the aquifer (McCarty et al., 1984). However, because the understanding of biotransformation processes is limited, organic contaminants should be assumed to persist indefinitely, particularly in the absence of evidence to the contrary.

Simulating transport of contaminants in fractured media may depend largely on assumptions that can be made about the density and size of fractures and the extent of dead-end pore volume intersecting fractures. If the medium is densely fractured, with small apertures and high connectivity, and with relatively little mobile fluid, a porous flow model may suffice. If the medium is coarsely fractured with tight matrix adjacent to the fractures, flow and transport probably takes place only in fractures. For media that fall between these two cases, a dual-porosity model may be necessary. In a dualporosity concept, the advective transport takes place in the fractures with molecular diffusion into the matrix. Many transport models with different capabilities are available, and some (SWIFT II, NEFTRAN, SUTRA, REMTRAN, TAKRAT) are already included in CAMCON. Final compliance analysis may use several of these transport codes because the choice of code may differ among scenarios.

\section{CAMCON: CONTROLLER FOR COMPLIANCE ASSESSMENT SYSTEM}

The complex disposal system at the WIPP requires that computer codes in the compliance assessment system be controlled by a computerized executive 
1 program. CAMCON is the controller for the system (Rechard, 1989; Rechard et

2 al., 1989). An executive program to control consequence calculations must

3 meet several requirements. These requirements can be grouped into two

4 categories: built-in flexibility and built-in quality assurance (QA). An

5 executive program must link several distinct model components with little

6 analyst intervention, trace calculations so that they can be repeated, track

7 parameter uncertainty using Monte Carlo techniques, and identify calculations

8 to avoid misinterpretation. The controller should also provide easy

9 examination of intermediate and final results, interpolation between modeling

10 scales, and iteration between computer modules. Easy replacement of computer

11 modules within the executive program is also necessary for scenario screening,

12 model/model comparisons, sensitivity analysis, and fine-tuning of the system

13 for final compliance assessment. CAMCON modularizes tasks so computer codes

14 for a particular module are interchangeable.

Compliance evaluation quality depends on data quality. Data bases have been grouped into three categories: primary, secondary, and computational.

Primary Data Base

The primary data base contains measured field and laboratory data gathered during the disposal-system and regional characterization. The important requirements of the primary data base are: (1) data quality must be good, because the analysis can be no better than these data, (2) the data base must contain all necessary data for the compliance assessment and repository design and (3) data should have as little subjective interpretation as possible. Data base structure must be flexible to accommodate different organizations and unforeseen types of data. Practical experience suggests that a relational data base is best (Rautman, 1988).

\section{Secondary Data Base}

The secondary data base contains interpreted data, usually interpolated onto a regular grid, and is a collection of information that comprises the conceptual model of the disposal system. Levels of interpretation can vary from objective interpolation of data combined with subjective judgments (possibly 
reproducible by others) to totally subjective extrapolations of data (not reproducible by others unless documented in reports). Data from literature or

\section{Computational Data Base}

The computational data base is named CAMDAT for Compliance Assessment Methodology DATa. CAMDAT uses a neutral-file format (Figure 4-24) so that a series of codes can be linked by a "zig-zag" connection rather than the usual serial connection. This format has the following advantages: (1) only one plotting program, which reads the computational data base, is needed to display any intermediate or final results from the many codes linked together; (2) codes are easily changed; (3) iterative calculations during calibration or convergence studies on multiple computational domains or grids are readily controlled; (4) a controller that automates compliance assessment is easier to design if information is stored in one file format. The file format chosen for CAMDAT was based on GENESIS (Taylor et al., 1987) and EXODUS and their associated data manipulation and plotting programs (Gilkey, 1986a and b, 1988b; Gilkey and Flanagan, 1987).

\section{Code-Linkage and Data-Flow Controller}

Code linkage and data flow through CAMDAT is controlled by CAMCON. Computer programs that make up the CAMCON system are major program modules, minor program modules, and translators. Major program modules refer to programs that represent major tasks of the consequence modeling. Minor program modules refer to programs such as interpolators, that are necessary to facilitate use of major program modules. Translator program modules refer to programs that translate data either into or out of the computational data base. Major program modules for consequence modeling are the mesh-generation, Monte Carlo sampling, regional-hydrology, local-hydrology, repository-shaft-source, transport-hydrology, biological-pathways, human-dose, and human-response modules. Minor program modules interpolate boundary conditions between 


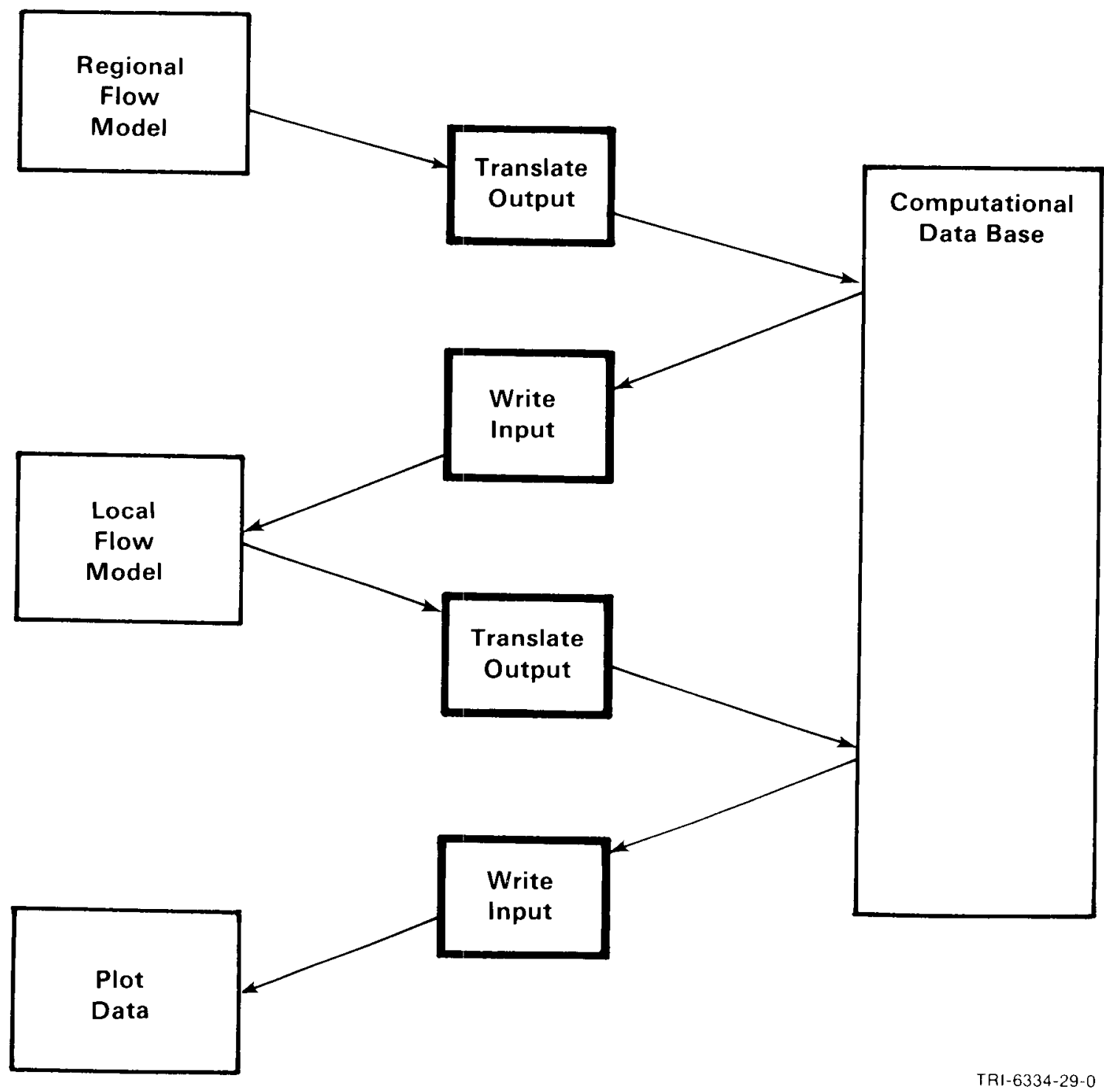

Figure 4-24. Coupling Through a Computational Data Base using a "Neutral File" (Rechard, 1989). 
models, track particles though simulated flow fields, generate various diagnostics and plot results. Translators communicate between codes and the secondary and computational data bases. The algorithm for controlling a 4 simple analysis using CAMCON is complex (Figure 4-25), but the advantages of 5 rapid problem set up and execution with built-in quality assurance makes a 6 logical data flow and execution program necessary.

7

9

\section{Parameter Uncertainty and Sensitivity Analyses}

Computer models that will be used for the WIPP performance assessment are complex. Parameters for these models are not precise because (1) measurement techniques may be either incorrect or misapplied, (2) parameter values are based on statistical reductions of measured data, (3) variable parameters are replaced with lumped parameters, (4) random variations are replaced with deterministic parameters, (5) data are misinterpreted (Cranwell and Bonano, 1987); there are also natural variations in the system.

A parameter uncertainty analysis determines the amount of variability in the results of a model that can be attributed to uncertainty in the input data. A sensitivity analysis identifies the main contributors to the observed variation in the results. Some techniques used to quantify and/or reduce parameter uncertainty are: (1) differential-analysis techniques, (2) statistical methods, and (3) stochastic modeling (Cranwell and Bonano, 1987). In the differential-analysis technique, a first order Taylor series expansion is used as an approximation of the model, and partial derivatives must be calculated. For an uncertainty analysis, the series approximation used with Monte Carlo simulations produces distribution functions for the performance measure.

Statistical methods are based either on experimental design/response-surface procedures or sampling/Monte Carlo methods. In the experimental design/response-surface procedures, an experimental design is used to select values of parameters for calculations using computer models. A least-squares method is used to determine a fitted response surface to match the data. The fitted response surface can be used to assess both parameter uncertainty and parameter sensitivity. In the sampling/Monte Carlo methods, the input 


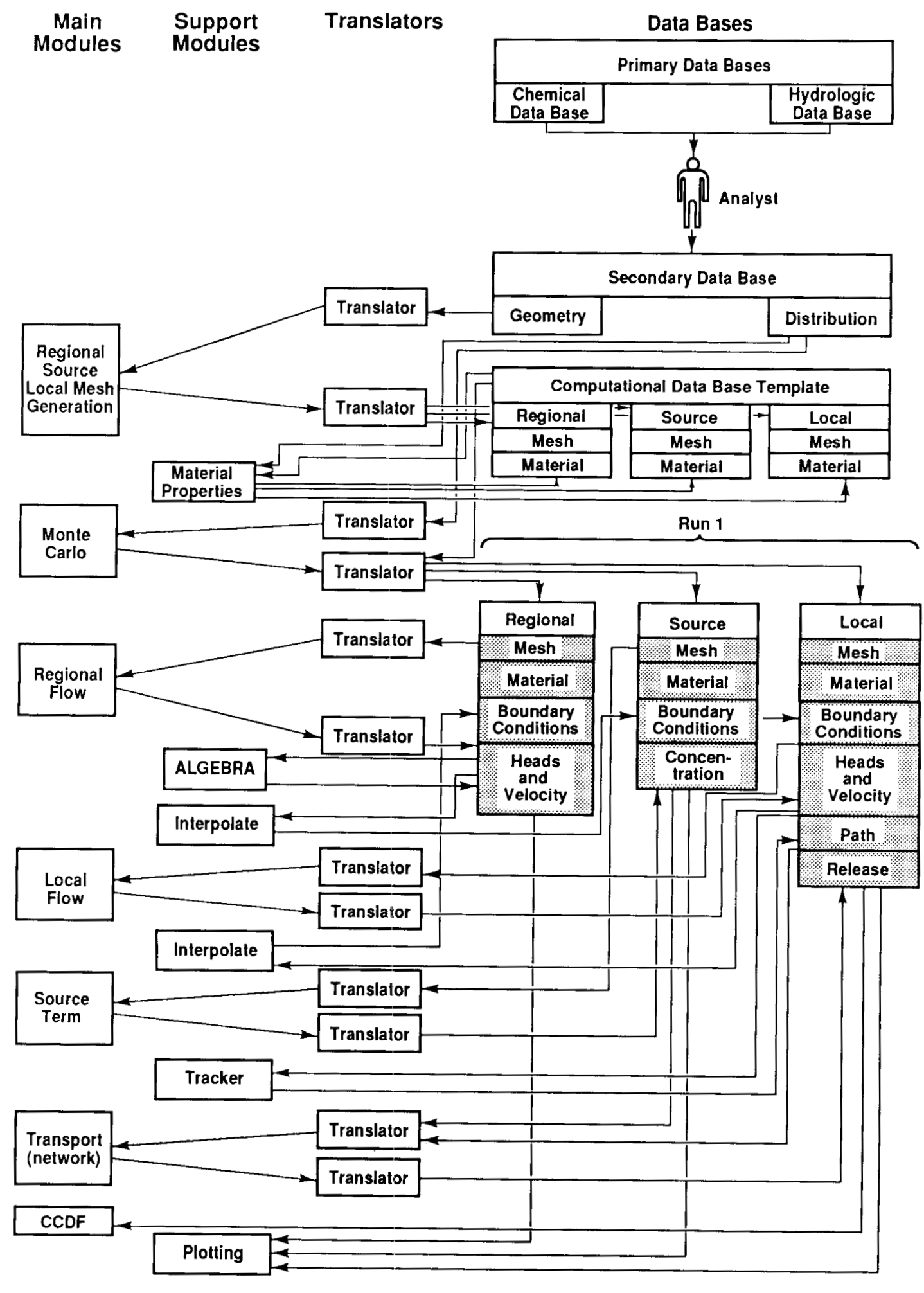

TRI-6342-102-0

Figure 4-25. Algorithm for Logical Data Flow During Compliance Assessment (Rechard, 1989). 
Chapter IV: Containment Requirements

parameters are considered to be random variables with probability distributions. Statistical-sampling techniques are used to select input parameters for the model. Repeated runs of the model produce a distribution of the results. Stochastic models incorporate information on the correlation between parameters directly into the model. One set of equations is solved for the mean behavior of the dependent variables, and another set is solved for the variance about the mean.

A comparison study of several widely used uncertainty and sensitivity analysis techniques was performed on three models having large uncertainties and varying degrees of complexity. The technique using LHS and regression analysis gave the best overall results (Iman and Helton, 1985). Therefore, the WIPP performance assessment has adopted the LHS sampling approach. LHS is a modified Monte Carlo technique for obtaining sets of parameters for computer models (McKay, Conover, and Bechman, 1979). The technique has been used at SNL for performance assessment of hypothetical disposal systems in bedded salt (Cranwell et al., 1987) and basalt sites (Bonano et al., 1988). A brief description of the LHS technique is presented below (Iman et al., 1980).

To obtain $n$ different values from each of $K$ variables $x_{1}$. . $x_{K}$, an LHS sample is obtained by first dividing the range of each variable into $n$ nonoverlapping intervals on the basis of equal probability (Figure 4-26). One point value from each interval is selected at random with respect to the probability density in the interval. The $\mathrm{n}$ values thus obtained for $\mathrm{x}_{1}$ are paired in a random fashion with $n$ values of $x_{2}$. These $n$ pairs are combined in a random manner with the $n$ values of $x_{3}$, and so on, until a set of $n_{K}$-tuples is formed.

Due to the random pairing of input values in LHS, undesired correlations may be induced among some of the variables. Such unwanted correlations can be avoided by a technique that restricts the possible pairings (Iman and Conover, 1982b; Iman and Shortencarier, 1984). In addition, if a known correlation exists between variables (an example would be hydraulic conductivity and porosity), LHS allows the pairings to produce the desired correlation (Iman et a1., 1980). This feature ensures that unbiased estimates of the output are obtained. 

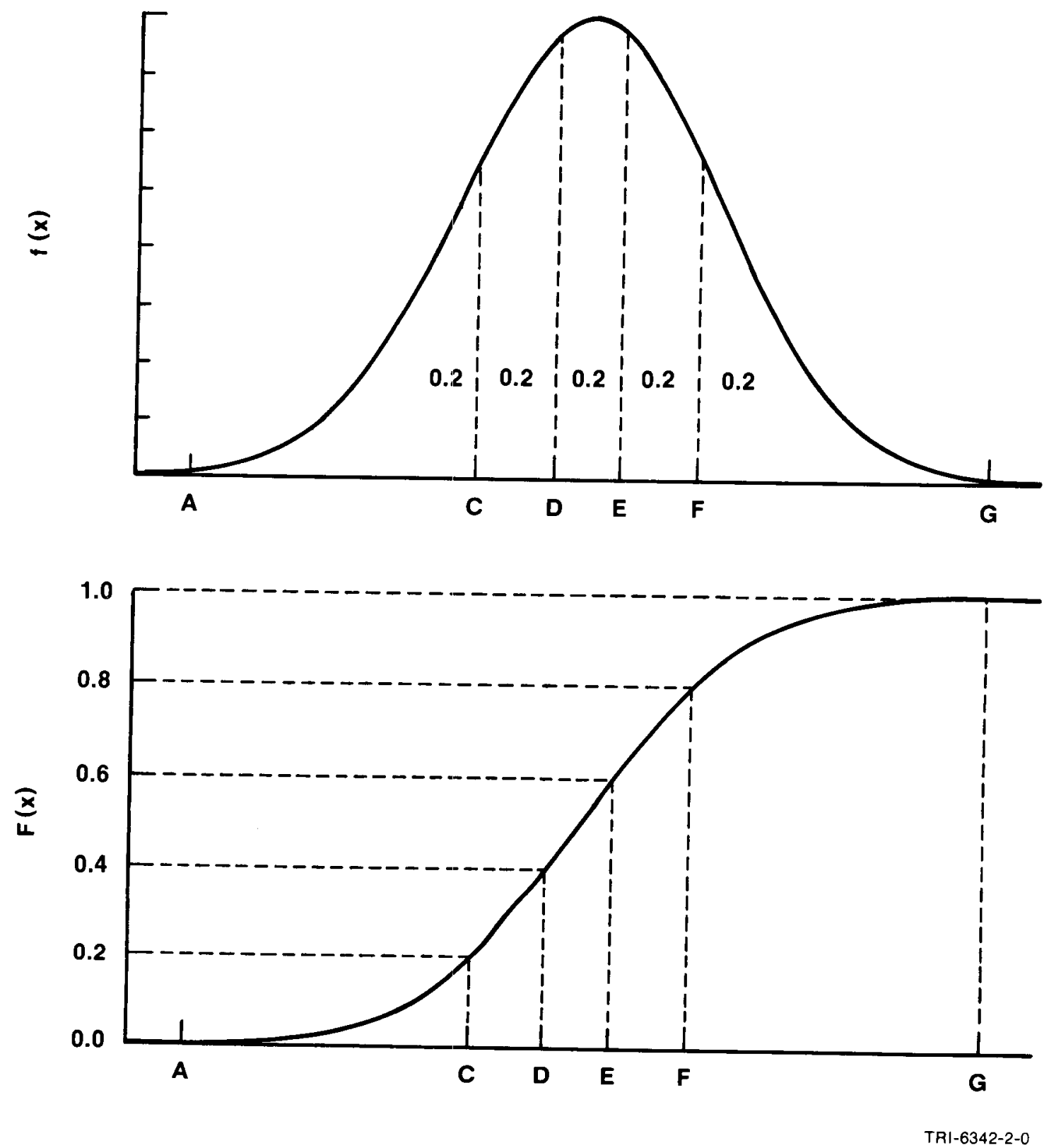

Figure 4-26. Intervals Used with a Latin Hypercube Sample of Size $n=5$ in Terms of the Density Function and Cumulative Distribution Function for a Normal Random Variable (Iman and Shortencarier, 1984). 
1 The choice of sample size $\mathrm{n}$ for LHS depends mainly on the time required to analyze all the samples and the number of input variables $K$. A rule of thumb is $\mathrm{n} \geq(4 / 3) \mathrm{K}$ (Iman and Helton, 1985). It is also important to note that the

Sensitivity analyses identify important input parameters by quantitatively estimating the amount of variation in the output that results from a particular variation in the input parameter. Results of a sensitivity analysis can aid in reducing uncertainty by directing research efforts towards understanding the relationship between relevant parameters and reduction of the ranges of the values of these parameters, if possible.

Two approaches to performing sensitivity analyses are (1) statistical sampling of input parameters followed by stepwise regression analysis of the results as a function of the input value, and (2) the differential or deterministic approach where explicit relationships between input and output are described in a computer code, and important parameters are identified by using a direct method such as the adjoint method. For preliminary WIPP performance assessment, statistical sampling using LHS, followed by stepwise regression analysis (Draper and Smith, 1981) will be used for the parameter sensitivity analysis. Other techniques will be used when necessary for specific studies.

In LHS, if all input variables are varied simultaneously, the sensitivity of the output relative to an individual input variable may be difficult to determine. Calculating the partial correlation coefficient is a technique that can quantify such sensitivity. However, this technique will not provide a reliable measure of sensitivity if extreme values of input variables are present. The partial rank correlation coefficient technique (Iman and Helton, 1985) is used to avoid this problem. Here, variable data and results are replaced by their corresponding ranks from 1 to $n$, and all the necessary calculations in determining the partial correlation coefficients are done on these ranks.

For the WIPP performance assessment, different sensitivity analysis techniques will be compared to ensure that the best technique will be used. 


\section{INDIVIDUAL PROTECTION REQUIREMENTS}

\section{COMPLIANCE ASSESSMENT APPROACH}

The Standard contains Individual Protection Requirements:

"Disposal systems for transuranic wastes shall be designed to provide a reasonable expectation that for 1000 years after disposal, undisturbed performance of the disposal system shall not cause the annual dose equivalent from the disposal system to any member of the public in the accessible environment to exceed $25 \mathrm{mrem}$ to the whole body and $75 \mathrm{mrem}$ to any critical organ." ( $§ 191.15)$

Two previous studies (U.S. DOE, 1980a; Lappin et al., 1989) reported doses to humans resulting from hypothetical releases from WIPP for selected scenarios. Although these studies employed deterministic calculations and were not concerned with assessing compliance with $\S 191.15$, they have an important bearing on the design of probability-based dose calculations. The approach in the WIPP Final Environmental Impact Statement (U.S. DOE, 1980a) for analyzing the effects of release of radioactivity from WIPP was to estimate the consequences of five different hypothetical scenarios that might move radionuclides to the biosphere. The analyses of these scenarios proceeded from radionuclide movement through the geosphere to transport through the biosphere after discharge into the Pecos River at Malaga Bend, and finally, predicted radiation doses received by people. The human dose estimates were based on the "Report of ICRP Committee II on Permissible Dose for Internal Radiation, International Commission on Radiological Protection, Publication. 2" (ICRP, 1959), and is usually referred to as ICRP 2. The travel times for radionuclides arriving at Malaga Bend were on the order of a million years, but this study predates the Standard, which specifies a time scale of one thousand years for individual protection.

The second study (Lappin et al., 1989), performed as a basis for the WIPP Draft Supplemental Environmental Impact Statement (U.S. DOE, 1989e), analyzed the effects of release of radioactivity from WIPP by estimating the consequences of two different hypothetical cases. Human dose estimates wera based on the new ICRP philosophy as described in ICRP Publications 26 (ICRP, 1977) and ICRP 30 (ICRP, 1979), respectively. 
The Standard requires that an uncertainty analysis of undisturbed conditions be performed to assess compliance with $\S 191.15$. In this case, the performance measure is dose to humans. However, the recent study (Lappin et al., 1989) indicated that, in the absence of human intrusion, releases resulting in doses via a route through the Culebra Dolomite Member to a livestock well will not occur in the 1,000-year time scale of $\$ 191.15$. Repeating that study to include uncertainty analyses is unlikely to provide any parameter selection that results in doses in a 1,000-year time scale. This hypothesis has been verified for saturated repository conditions without gas generation (Marietta et a1., 1989) and it is unlikely that gas generation can affect radionuclide migration within 1,000 years.

Therefore, dose calculations are not expected to be a part of the WIPP assessment of compliance with 40 CFR Part 191. However, Subpart B is in remand. The outcome of the remand may require dose calculations over longer times. This discussion presents the WIPP performance assessment approach for calculating human doses if required. Dose analyses for purposes other than comparison to $\S 191.15$ also can be done using this methodology.

\section{UNDISTURBED PERFORMANCE}

\section{RELEASE AT A LIVESTOCK POND}

This scenario is the undisturbed disposal-system scenario used in analyses for the Containment Requirements. Livestock wells are assumed to be located downgradient from the repository. This scenario was selected for earlier analyses (Lappin et al., 1989) because it was believed to be the only realistic scenario that could result in transport of radionuclides to the surface under undisturbed conditions.

Radioactive material is assumed to be carried by Salado brine fluids from the storage panels into MB139. It seeps through and around grouted seals in the marker bed, and migrates through the part of MB139 that underlies drift excavations to the bottom of the sealed shafts. Radioactive material is then assumed to continue to migrate up through the lower seal system due to the pressure gradient between the repository and the Culebra Dolomite Member. 
Material is then introduced into the Culebra Dolomite and entrained in the groundwater flow. In order to provide a route to man, it is assumed that an active livestock well penetrates the Culebra Dolomite downgradient from the sealed shafts. Radioactive material migrates through the Culebra layer to the livestock well where it is pumped to the surface and cattle drink the contaminated water. This is the beginning of the biological pathway to hurnans via a beef ingestion route (Lappin et al., 1989). Other possible pathways exist and will be considered, but for undisturbed conditions, any possibilj.ty requires a pumping well route to the surface. Because this route is not completed in 1,000 years, no need exists to consider other possible pathways for $\S 191.15$ at this time, although the response to the remand may change this position.

The procedure used to perform these analyses is to define a conceptual model of the system based on present understanding (Lappin et a1., 1989), and to use numerical models to calculate groundwater flow, radionuclide transport to humans, and human dosimetry and response.

\section{CONCEPTUAL MODEL OF THE SYSTEM TO BE ANALYZED}

In the initial system conceptual model, panels are filled with waste and backfill and no free water is present. MB139 is fractured as a result of excavation of the drifts and panels, and in response to later salt creep into these excavations. These new fractures occur directly under all excavations, but not under the intact salt pillars. Grout seals are in place in MB139 directly under panel seals. All access drifts and the experimental area are backfilled and the shafts are sealed (Lappin et al., 1989).

Microbiological degradation of organic material in waste containers begins when the containers are filled and continues in the repository. As salt creep closes rooms and drifts, waste containers rupture and gas enters voids in the rooms and drifts. Gas migrates into MB139 through the marker bed seals and eventually fills the fracture volume. Gas pressure rises, slowing room closure and brine inflow, and maintaining open fractures in MB139. As gas generation slows, brine begins to resaturate the repository and MB139. The balance of creep closure, gas generation and dispersion, and resaturation with 
1 host rock brines is complex and highly dependent on room chemistry and waste

2 types. If the waste panels partially or fully saturate, transport can occur

3 by diffusion and advection in pressure-driven brine, provided a pressure

4 gradient exists (Lappin et al., 1989).

5

Available codes assume Darcy flow along each leg of the transport path and transport calculations must assume saturated media along the flowpaths. Multiphase codes are being evaluated, and the assumptions of saturation and incompressible Darcy flow will be assessed through sensitivity analyses. Radionuclides are assumed available for dissolution in the brine according to their solubility limits. Parameter uncertainty will be reflected in the analysis. Parameter distributions for uncertainty analysis describe the room's moisture content (saturation). If sampled parameter values indicate room saturation, transport can occur because Darcy flow applies and the calculation proceeds for that Monte Carlo input vector. If sampled parameter values indicate the room is not saturated, transport cannot occur and the calculation is terminated with a zero consequence for that vector (Lappin et al., 1989). The importance for performance assessment of modeling transport in partially saturated waste within the repository and Salado will be assessed through sensitivity analyses.

In the conceptual model of the repository system (Figure 4-22), the preferred transport path is assumed to be from the waste panels into MB139, through the grout seal, along fractures in MB139 to the base of the shafts, and through the lower and upper shaft seals to the Culebra Dolomite Member. The lower shaft seal is assumed to be well consolidated whereas the upper seal is less consolidated. Flow is driven by a pressure gradient between waste panels and the Culebra Dolomite Member. Transport continues through the Culebra Dolomite to the livestock well (Lappin et a1., 1989).

Flow through MB139 and up the shafts is more 1ikely because each leg has a higher permeability than the host rock. An alternate flow path from the waste panels through the intact Salado and Rustler Formations to the Culebra Dolomite Member also must be considered because of the large cross-sectional area of the waste panels. Darcy flow must be assumed for the Salado Formation if available codes are used (Lappin et al., 1989). 
Another alternate path to be considered is the route through MB139 to ERDA.-9 and up to the Culebra Dolomite Member. This path requires migration of brine and radionuclides through a fully consolidated part of the marker bed within the host rock. The shortest distance from an excavated drift is only about: $100 \mathrm{~m}$ (300 ft), which may be important for transport on a 10,000-year time scale, but not a 1,000-year time scale.

\section{COMPLIANCE ASSESSMENT SYSTEM}

To evaluate compliance with the Individual Protection Requirements ( $\$ 191.15$ ), radionuclide concentrations as a function of space and time must be calculated. Undisturbed conditions are used for these calculations. Evaluating compliance with $\S 191.15$ requires that the analyst replace the CCDF module with the biotransport and dosimetry modules (Figure 3-1). The performance measure becomes dose to humans instead of a CCDF. Extra modules must be included in CAMCON so that input-parameter uncertainty can be considered. The calculation results in a probability distribution function for human-exposure. Additional modules are: (1) biological-pathways, (2) human-dosimetry, and (3) dose-response modules.

\section{EXPOSURE PATHWAYS IDENTIFICATION}

An "exposure pathway" is a potential route through which humans may be exposed to radionuclides or radiation. General pathway categories are external exposure, inhalation, and ingestion. A specific pathway describes the route of exposure within these categories such as a contaminated-water-to-beef-toman ingestion pathway. Release points to the biosphere must be considered when defining these biological pathways. WIPP scenarios (see Chapter IV) include direct release to the surface through cuttings and eroded particles or withdrawal wells. Only pathways that arise from withdrawal wells will be considered for compliance with $\S 191.15$; therefore, withdrawal wells are included within the definition of undisturbed conditions. Withdrawal wells will be assumed to provide water for livestock in tanks or ponds, irrigation, and general domestic purposes for local ranches. Livestock ponds will dry after they are abandoned, and provide a starting point for airborne releases. Exposure pathways will include external pathways due to the rancher's exposure 
to withdrawal well fluids, inhalation pathways due to airborne particulates arising from a dry livestock pond, ingestion pathways arising from consumption of food products grown in soil contaminated by airborne particulates from a dry livestock pond, ingestion pathways arising from consumption of food products grown with irrigation water from a contaminated withdrawal we1l, and ingestion pathways arising from the consumption of meat and milk products processed from livestock that was watered at ponds or holding tanks contaminated through withdrawal wells.

\section{COMPUTER MODELS AND DATA}

Many pathways and dose models exist as well-developed, quality-assured, userfriendly codes (Moore et a1., 1979; Till et a1., 1987; Napier et al, 1988) and as developmental research codes (Gallegos et al., 1980; Gallegos and Wenzel, 1984; Wenzel and Gallegos, 1985). These codes can be applied to the WIPP data base, but any set of dosimetry/effects codes is very dependent upon the selection of input data.

Input data for dose calculations will be taken from several readily available sources (transfer factors from Baes et al,, 1984 and Till and Meyer, 1983; ingestion rates from NCRP, 1984 and Till and Meyer, 1983; Committed Effective Dose Equivalents (CEDE) from U.S. DOE, 1988b, which has replaced U.S. DOE, 1985). The CEDE factors will be taken from U.S. DOE, 1988b, because that document is intended to be used as the primary reference by the DOE and its contractors for calculating dose equivalents for the public resulting from the ingestion or inhalation of radionuclides. Wide variability exists in published parameter values within these references. Calculated 50-year CEDEs can differ by a factor of 10 because of this variability between literature sources (Lappin et al., 1989). No obvious reason is known for preferentially selecting transfer factors or ingestion rates from one specific reference. For example, ingestion rates for beef consumption range from $86 \mathrm{~g} / \mathrm{d}$ (NCRP, 1984) to $206 \mathrm{~g} / \mathrm{d}$ (Till and Meyer, 1983). The beef consumption rate of $86 \mathrm{~g} / \mathrm{d}$ assumes that other meats are eaten as well. If human dose calculations are required, the uncertainty in these input parameters will have to be included. 


\section{ASSURANCE REQUIREMENTS PLAN}

As prescribed in the Second Modification to the Consultation and Cooperation Agreement, the WIPP Project has prepared a plan for implementing the Assurance Requirements (U.S. DOE, 1987). That plan is briefly summarized here. The plan is preliminary, because better methods and technologies could evolve over the operational time period. In accordance with the Project's interpretation of the EPA's intention, the Project will select assurance measures based on the uncertainties in the final performance assessment. This discussion will be updated as the operating contractor (see Chapter I) updates the implementation plans. The current plan includes definitions and clarifications of the Standard as it applies to the WIPP, the implementation objective for each requirement, an outline of the implementation steps for each requirement, and a schedule of activities leading to final compliance. The implementation objective for each requirement follows.

\section{ACTIVE INSTITUTIONAL CONTROLS}

Active institutional controls are expected to include post-operational monitoring, decontamination and decommissioning, land reclamation, evaluation of land use in the area, maintaining fences and buildings, and guarding the facility. The objectives of these activities are to restore the land surface to its original condition to avoid future preferential selection of the area for incompatible uses, to provide a facility and presence at the site during active cleanup, and to monitor the disposal system.

\section{DISPOSAL SYSTEM MONITORING}

Monitoring is required if the monitoring program will be useful for evaluating uncertainties associated with the long-term performance predictions and if the time period over which data can be collected is realistic for exercising active control over the site. The objective would be to detect substantial and detrimental deviation from the expected performance of the disposal system. Monitoring activities will be identified during the course of the performance assessment. 
2

\section{PASSIVE INSTITUTIONAL CONTROLS}

The Project will implement passive institutional controls over the entire controlled area, including markers, records, and federal ownership. The DOE or some successor agency will retain ownership and administrative control over the land in accordance with Appendix B of the Standard. The federal agency responsible for the land will institute regulations that appropriately restrict land use and development. Markers will include on-site structures engineered and constructed to survive for at least 5,000 years as a means of preserving knowledge of the location of TRU radioactive wastes. The objectives are to restore the disposal site to nearly original condition, to preserve a record of the disposal site and its contents in perpetuity, and to warn those in the vicinity of the disposal site of the hazards associated with subsurface development activities.

\section{MULTIPLE BARRIERS}

The Standard requires that both natural and engineered barriers be used as part of the isolation system. At the WIPP, natural barriers include both the salt formation, with its favorable characteristics, and the geohydrologic setting. Engineered barriers include the repository, backfills, and plugs and seals that isolate volumes of wastes. The effectiveness of these barriers is being modeled for the performance assessment. The objective is to provide a disposal system that isolates the radioactive wastes to the levels required in the Standard.

\section{NATURAL RESOURCES}

The Standard requires that locations containing recoverable resources not be used unless it can be shown that the favorable characteristics of a location compensate for the greater likelihood of being disturbed in the future. The WIPP Project met this requirement when the site was selected, and the Project will issue a finding to that effect. 


\section{WASTE REMOVAL}

2

3 The Standard requires that it be technologically feasible to locate and

4 recover the waste for a reasonable period of time after disposal. In

5 promulgating the Standard, the EPA stated that "any current concept for a.

6 mined geologic repository meets this requirement without any additional

7 procedures or design features" (U.S. EPA, 1985, p. 38082). Thus, the WIFP

8 satisfies this requirement. 


\section{RESULTS}

3

4

5

\section{6}

7

9

10

\section{CONTAINMENT (PERFORMANCE ASSESSMENT)}

\section{SCENARIO RELEASE ANALYSES}

This section will summarize the scenario-by-scenario consequences and probabilities that must be used to construct the CCDF.

\section{COMPLEMENTARY CUMULATIVE DISTRIBUTION FUNCTION (CCDF)}

This section will describe the step-by-step construction of the CCDF and the actual curve superimposed on the regulatory curve (Figure 2-2). A discussion of important scenarios, important parameters, and important radionuclides will be included.

The final steps to assess regulatory compliance with $\S 191.13$ are to calculate an EPA sum for each scenario, generate the CCDF, and compare with the release limits of the containment section.

\section{INDIVIDUAL PROTECTION}

\section{RELEASES}

This section will present radionuclide releases to the biosphere, along biological transport pathways, and external/internal human exposures.

Compliance with $\S 191.15$ will be demonstrated by calculating doses to humans: resulting from releases to the biosphere for the undisturbed-performance scenario only. For extremely conservative assumptions, no releases occur in 10,000 years (Lappin et al., 1989). The present regulatory time scale is 1,000 years for individual protection. No releases that will require dose calculations to show compliance are expected to occur within 1,000 years. To 
demonstrate that dose calculations are not required, transport calculations through 10,000 years will be reported, as will results of deterministic transport calculations (Lappin et al., 1989). Uncertainty analysis of the undisturbed scenario is required by $\S 191.15$. Parameter uncertainty will be included as described by $\$ 191.13$. If releases actually occur, the appropriate performance measure should be dose, and uncertainty in dose values should be reported as a probability distribution function. Because no releases are expected, this performance measure is not meaningful, and others should be reported. Only arrival times at major nodes within the system are reported (e.g., the bottom of the lower shaft-seal system, the top of the lower shaft-seal system, or the Culebra Dolomite Member of the Rustler Formation) (Lappin et al., 1989). Extending these calculations to include parameter uncertainty will provide a probability distribution function for these arrival times. In addition, integrated flux of radionuclides across the same nodes provides a measure of the state of transport at 10,000 years and the uncertainty in that state. Both arrival times and integrated flux will be reported at important nodes in the system.

DOSES

This section will report the predicted doses including critical pathways, critical radionuclides, critical organs, and total body dose.

This section is included only to describe how doses would be reported if releases occur. Such dose calculations may be required if the response to the remand of Subpart B results in an extension of time scale and an inclusion of human intrusion within the Individual Protection Requirements.

Compliance with $\S 191.15$ requires that uncertainty be considered when comparing to the regulation. The methodology is the same as used for comparison with Containment Requirements, but the performance measure is dose to humans instead of integrated discharge to the accessible environment. Parameter uncertainty is included through Monte Carlo techniques using CAMCON. The results are frequency distributions for dose to the whole body and critical organs of maximally-exposed individuals. Following the same frequentist approach described for generating the CCDF, plots of probability 
versus dose will be produced to compare with the regulatory limits of 25 and 75 mrem to critical organs and whole body respectively. Because $\S 191.15$ only requires analysis of the undisturbed performance scenario, unlikely events and scenario probabilities are not considered. Because final uncertainty analyses will probably rely on beta distributions for sampled input parameters, the calculated probability distributions for doses will be truncated at the extreme or conservative end of the range, i.e., the integral of the probability distribution function is arbitrarily close to but not equal to one.

Dose measures that could be reported are maximum individual; peak annual; whole body; and critical organ doses including critical pathways and radionuclides, average individual dose in the critical population, 50-yeardose commitment including critical pathways and radionuclides, integrated average individual dose in the same critical population over 50 - or 70 -year time periods including age and sex subgroups in the tracked cohort.

\section{ASSURANCE PLANS}

Changes to the plans that will be required to support predictions of compliance with the Containment Requirements predictions will be described in this section. Such changes could include establishing criteria and specifications for passive markers to minimize the probability of inadvertent intrusion through exploratory drilling. Another possible change is specifying techniques for borehole plugging; such techniques might be incorporated into the legal records along with the description and location of the disposal system. The records might also contain a warning about the potential effects of drilling through the repository and into pressurized brine in the Castile Formation. 
4 This chapter will compare the final compliance assessment to subpart B of the 5 Standard.

6

7 CONTAINMENT REQUIREMENTS

8

9

10

ASSURANCE REQUIREMENTS

INDIVIDUAL PROTECTION REQUIREMENTS

GROUNDWATER PROTECTION REQUIREMENTS 


\section{RECOMMENDATIONS}

2

3 


\section{REFERENCES}

Adams, J.E., 1944. "Upper Permian Ochoa Series of Delaware Basin, West Texas and Southeastern New Mexico", Am Assn Pet Geol Bul1 28:1596-1625.

Anderson, R.Y., 1981. Deep-Seated Salt Dissolution in the Delaware Basin, Texas and New Mexico, NM Geol Soc, Special Publication No. 10, pp 133-145.

Anderson, R.Y., W.E. Dean, Jr., D.W. Kirkland, and H.I. Snider, 1972. "Permian Castile Varved Evaporite Sequence, West Texas and New Mexico", GSA Bull $83: 59-86$.

Anderson, R.Y., K.K. Kietzke, and D.J. Rhodes, 1978. "Development of Dissolution Breccias, Northern Delaware Basin, New Mexico and Texas", in Geology and Mineral Deposits of Ochoan Rocks in Delaware Basin and Adjacent Areas, NM Bur of Mines and Mineral Resources Circular 159, pp 47-52.

Anderson, R.Y., and D.W. Powers, 1978. "Salt Anticlines in Castile-Salado Evaporite Sequence, Northern Delaware Basin," in Geol and Mineral Deposits of Ochoan Rocks in Delaware Basin and Adjacent Areas, NM Bur of Mines and Mineral Resources Circular 159, pp 79-84.

Bachman, G.O., 1981. Geology of Nash Draw, Eddy County, New Mexico, USGS OpenFile Rpt 81-31.

Baes, C.F., III, R.D. Sharp, A.I. Sjoreen, and R.W. Shor, 1984. A Review and Analysis of Parameters for Assessing Transport of Environmentally Released Radionuclides through Agriculture, ORNL-5786. Oak Ridge National Laboratory, Oak Ridge, TN.

Beauheim, R.L., 1986. Hydraulic-Test Results for Well DOE-2 at the Waste Isolation Pilot Plant (WIPP) Site, SAND86-1364. Sandia National Laboratories, Albuquerque, NM.

Beauheim, R.L., 1987. Interpretations of Single-Well Hydraulic Tests Conducted At and Near the Waste Isolation Pilot Plant (WIPP) Site, 1983-1987, SAND87-0039. Sandia National Laboratories, Albuquerque, NM.

Bertram-Howery, S.G. and R.L. Hunter, Eds., 1989a. Preliminary Plan for Disposal-System Characterization and Long-Term Performance Evaluation of the Waste Isolation Pilot Plant, SAND89-0178. Sandia National Laboratories, Albuquerque, NM.

Bertram-Howery, S.G., and R.L. Hunter, 1989b. Plans for Evaluation of the Waste Isolation Pilot Plant's Compliance with EPA Standards for Radioactive Waste Management and Disposal, SAND88-2871. Sandia National Laboratories, Albuquerque, NM.

Bingham, F.W., and G.E. Barr, 1979. Scenarios for Long-Term Release of Radionuclides From a Nuclear-Waste Repository in the Los Medanos Region of New Mexico, SAND78-1730. Sandia National Laboratories, Albuquerque, NM. 
References

1 Bonano, E.J., P.A. Davis, L.R. Shipers, K.F. Brinster, W.E. Beyeler, C.D.

Updegraff, E.R. Shepherd, L.M. Tilton, and K.K. Wahi, 1988. Demonstration of a

Performance Assessment Methodology for High-Level Radioactive Waste Disposal

in Basalt Formations, SAND86-2325 (NUREG/CR-4759). Sandia National

Laboratories, Albuquerque, NM.

Borns, D.J., and S.E. Shaffer, 1985. Regional Well-Log Correlation in the New Mexico Portion of the Delaware Basin, SAND83-1798. Sandia National

Laboratories, Albuquerque, NM.

Borns, D.J., and J.C. Stormont, 1988. An Interim Report on Excavation Effect Studies at the Waste Isolation Pilot Plant: The Delineation of the Disturbed Rock Zone, SAND87-1375. Sandia National Laboratories, Albuquerque, NM.

Borns, D.J., and J.C. Stormont, 1989. "The Delineation of the Disturbed Rock Zone Surrounding Excavations in Salt," Proc. 30th University S. Rock Mechanics Symp. at the U. West Virginia, June 19-22, 1989, pub. by A.A. Balkema, Rotterdam, Netherlands.

Bredehoeft, J.D., 1988. "Will Salt Repositories Be Dry?," EOS, Amer. Geophys. Union $69(9)$.

Brinster, K.F., 1989 (in preparation). Geology and Hydrology of the Los Medanos Region, Southeastern New Mexico; A Preliminary Conceptual Model for Compliance Assessment of the Waste Isolation Pilot Plant (WIPP), SAND89-7147. Sandia National Laboratories, Albuquerque, NM.

Campbe11, J.E. and Cranwe11, R.M., 1988. "Performance Assessment of Radioactive Waste Repositories." Science 239, pp 1389-1392.

Cherry, J.A., R.W. Gillham, and J.F. Barker, 1984. "Contaminants in Groundwater: Chemical Processes," in Groundwater Contamination, National Academy Press.

Claiborne, H.C., and F. Gera, 1974. Potential Containment Failure Mechanisms and Their Consequences at a Radioactive Waste Repository in Bedded Salt in New Mexico, ORNL-TM-4639. Oak Ridge National Laboratory, Oak Ridge, TN.

Cooper, J.B., and V.M. Glanzman, 1971. "Geohydrology of Project GNOME Site, Eddy County, New Mexico," in Hydrology of Nuclear Test Sites, USGS Prof Paper $712-\mathrm{A}$.

Cranwel1, R.M. and E.J. Bonano, 1987. "Sources/Treatment of Uncertainties in the Performance Assessment of Geologic Radioactive Waste Repositories" in Proceedings of a Nuclear Energy Agency Workshop on Uncertainty Analysis of Performance Assessments of Radioactive Waste Disposal Systems, pp 53-68. Seattle, WA, February 24-26, 1987. NEA, Paris.

Cranwe11, R.M., R.V. Guzowski, J.E. Campbel1, and N.R. Ortiz, 1989, in preparation. Risk Methodology for Geologic Disposal of Radioactive Waste: Scenario Selection Procedure, SAND80-1429 (NUREG/CR-1667). Sandia National Laboratories, Albuquerque, NM. 
1 Cranwel1, R.M., and J.C. Helton, 1981. Uncertainty Analysis for Geologic

2 Disposal of Radioactive Waste, in D. C. Kocher, ed., Proceedings of the

3 Symposium on Uncertainties Associated with the Regulation of the Geologic

4 Disposal of High-Level Radioactive Waste, Gatlinburg, TN, March 9-13, 1981.

Cranwe11, R.M., and J.C. Helton, 1980. "Uncertainty Analys is Associated with Radioactive Waste Disposal, a Discussion Paper," in Proceedings of the DOE Statistical Symposium, October 29-31, 1980, Berkeley, CA. Published in 1981.

Cranwe11, R.M., J.E. Campbe11, J.C. He1ton, R.L. Iman, D.E. Longsine, N.R. Ortiz, G.E. Runkle, and M.J. Shortencarier, 1987. Risk Methodology for Geologic Disposal of Radioactive Waste: Final Report, SAND81-2573 (NUREG/CR2452). Sandia National Laboratories, Albuquerque, NM.

Cranwel1, R.M., R.V. Guzowski, J.E. Campbe11, and N.E. Ortiz, 1982, Risk Methodology for Geologic Disposal of Radioactive Waste: Scenario Selection Procedure, SAND80-1429, NUREG/CR-1667. Sandia National Laboratories, Albuquerque, NM. (Draft copy available from U.S. Nuclear Regulatory Commission Public Document Room).

Cys, J.M., 1978. "Transitional Nature and Significance of the Castile-Bell Canyon Contact," in Geology and Mineral Deposits of Ochoan Rocks in Delaware Bas in and Adjacent Areas, NM Bur of Mines and Mineral Resources Circular 159, pp 53-56.

Davies, P.B., 1989. Variable-Density Ground-Water Flow and Paleohydrology in the Region Surrounding the Waste Isolation Pilot Plant (WIPP), Southeastern New Mexico, U.S. Geological Survey Open-File Report 88-490, U.S. Geological Survey, Albuquerque, NM.

Draper, N.R., and H. Smith, 1981. Applied Regression Analysis, John Wiley \& Sons, Inc., New York.

Environmental Evaluation Group, 1980. Geotechnical Considerations for Radiological Hazard Assessment of WIPP, A Report of a Meeting Held on January 17-18, 1980, EEG-6, Environmental Evaluation Group, Environmental Improvement Division, State of New Mexico, Santa Fe, NM.

Gallegos, A.F., B.J. Garcia, and C.M. Sutton, 1980. Documentation of TRU Biological Transport Mode1 (BIOTRAN), LA-8213-MS. Los Alamos National Laboratory, Los Alamos, NM 87545.

Gallegos, A.F., and W.J. Wenzel, 1984. HUMTRN: Documentation and Verification for an ICRP-Based Age- and Sex-Specific Human Simulation Model for Radionuclide Dose Assessment. LA-9994-MS. Los Alamos National Laboratory, Los Alamos, NM 87545 .

Geohydrology Associates, Inc., 1979. Water-Resources Study of the Carlsbad Potash Area, New Mexico, Consultant Report for the U.S. BLM. Contract No. YAS12-CT8-195, pp 92 . 
Gilkey, A.P., 1988a. ALGEBRA - A Program that Algebraically Manipulates the Output of a Finite Element Analysis (EXODUS Version), SAND88-1431. Sandia Nationa1 Laboratories, Albuquerque, NM.

Gilkey, A.P., 1988b. BLOT-A Mesh and Curve Plot Program for the Output of a Finite Element Analysis, SAND88-1432. Sandia National Laboratories, Albuquerque, NM.

Gilkey, A.P., 1986a. SPLOT-A Distance-Versus-Variable Plot Program for the Output of a Finite Element Analysis, SAND86-0882. Sandia National Laboratories, Albuquerque, NM.

Gilkey, A.P., 1986b. TPLOT-A Time History or X-Y Plot Program for the Output of a Finite Element Analysis, SAND86-0882. Sandia National Laboratories, Albuquerque, NM.

Gilkey, A.P., and D.P. Flanagan, 1987. DETOUR-A Deformed Mesh/Contour Plot Program, SAND86-0914. Sandia National Laboratories, Albuquerque, NM.

Hale, W.E., and A. Clebsch, Jr., 1958. Preliminary Appraisal of Groundwater Conditions in Southeastern Eddy County and Southwestern Lea County, New Mexico. U.S. Geological Survey Trace Element Memorandum Report 1045, pp 23.

Hale, W.E., L.S. Hughes, and E.R. Cox, 1954. Possible Improvement of Quality of Water of the Pecos River by Diversion of Brine at Malaga Bend, Eddy County, New Mexico, Pecos River commission, New Mexico and Texas, in cooperation with USGS Water Resources Division, Carlsbad, NM.

Haug, A., V.A. Kelly, A.M. LaVenue, and J.F. Pickens, 1987. Modeling of Groundwater Flow in the Culebra Dolomite at the Waste Isolation Pilot Plant (WIPP) Site: Interim Report, SAND86-7167. Sandia National Laboratories, Albuquerque, NM.

Havens, J.S., and D.W. Wilkins, 1979. Experimental salinity alleviation at Malaga Bend of the Pecos River, Eddy County, New Mexico. U.S. Geological Survey Water-Resources Investigations 80-4, $65 \mathrm{pp}$.

Hayes, P.T., 1964. Geology of the Guadalupe Mountains, New Mexico, USGS Prof Paper 446 .

Helton, J.C., and P.C. Kaestner, 1981. Risk Methodology for Geologic Disposal of Radioactive Waste: Model Description and User Manual for Pathways Model, SAND78-1711 (NUREG/CR-1636, Vol. 1). Sandia National Laboratories, Albuquerque, NM.

Hiss, W.L., 1976. Stratigraphy and Ground-Water Hydrology of the Capitan Aquifer, Southeastern New Mexico and West Texas, Ph.D. Dissertation. U. of Colorado, Boulder, CO, pp 336.

Holt, R.M. and D.W. Powers, 1988. Facies Variability and Post-Depositional Alteration Within the Rustler Formation in the Vicinity of the Waste Isolation Pilot Plant, Southeastern New Mexico, DOE/WIPP-88-004. U.S. Department of Energy, Carlsbad, NM. 
Holt, R.M., D.W. Powers, R.L. Beauheim, and M.E. Crawley, 1989. Conceptual Hydrogeological Model of the Rustler Formation in the Vicinity of the Waste Isolation Pilot Plant Site, Southeastern New Mexico, SAND89-0862. Sandia National Laboratories, Albuquerque, NM.

Hunter, R.L., 1989. Events and Processes for Constructing Scenarios for the Release of Transuranic Waste From the Waste Isolation Pilot Plant, Southeastern New Mexico, SAND89-2546, Sandia National Laboratories, Albuquerque, NM.

Hunter, R.L., 1985. A Regional Water Balance for the Waste Isolation Pilot Plant (WIPP) Site and Surrounding Area, SAND84-2233. Sandia National Laboratories, Albuquerque, NM.

Hunter, R.L., 1983. Preliminary Scenarios for the Release of Radioactive Waste From a Hypothetical Repository in Basalt of the Columbia Plateau, SAND83-1342 (NUREG/CR-3353). Sandia National Laboratories, Albuquerque, NM.

Hunter, R.L., G.E. Barr, and F.W. Bingham, 1983. Scenarios for Consequence Assessments of Radioactive-Waste Repositories at Yucca Mountain, Nevada Test Site, SAND82-1277. Sandia National Laboratories, Albuquerque, NM.

Hunter, R.L., G.E. Barr, and F.W. Bingham, 1982. Preliminary Scenarios for Consequence Assessments of Radioactive-Waste Repositories at the Nevada Test Site, SAND82-0426. Sandia National Laboratories, Albuquerque, NM.

Hunter, R.L., R.M. Cranwe11, and M.S.Y. Chu, 1986. Assessing Compliance with the EPA High-Level Waste Standard: An Overview, SAND86-0121 (NUREG/CR-4510). Sandia National Laboratories, Albuquerque, NM.

International Commission on Radiological Protection, 1979. Annals of the ICRP, ICRP Publication 30, Limits for Intake of Radionuclides by Workers, Pergamon Press.

International Commission on Radiological Protection, 1977. Annals of the ICRP, ICRP Publication 26, Recommendations of the International Commission on Radiological Protection, Pergamon Press.

International Commission on Radiological Protection, 1959. Report of the ICRP Committee II on Permissible Dose for Internal Radiation, International Commission on Radiological Protection, ICRP Publication 2, Pergamon Press.

Iman, R.L., and W.J. Conover, 1982a. Sensitivity Analysis Techniques: SelfTeaching Curriculum, SAND81-1978 (NUREG/CR-2350). Sandia National Laboratories, Albuquerque, NM.

Iman, R.L., and W.J. Conover, 1982b. "A Distribution-Free Approach to Inducing Rank Correlation Among Input Variables," Comm. in Statistics B11(3), pp $311-334$.

Iman, R.L., J.M. Davenport, and D.K. Zeigler, 1980. Latin Hypercube Sampling (Program User's Guide), SAND79-1473. Sandia National Laboratories, Albuquerque, NM. 
References

1 Iman, R.L., J.M. Davenport, E.L. Frost, and M.J. Shortencarier, 1980. Stepwise

2 Regression with PRESS and Rank Regression (Program User's Guide), SAND79-1472.

3 Sandia National Laboratories, Albuquerque, NM.

4

Iman, R.L., and J.C. Helton, 1985, A Comparison of Uncertainty and Sensitivity Analysis Techniques for Computer Models, SAND84-1461 (NUREG/CR-3904). Sandia National Laboratories, Albuquerque, NM.

Iman, R.L., and M.J. Shortencarier, 1984. A FORTRAN 77 Program and User's Guide for the Generation of Latin Hypercube and Random Samples for Use with Computer Mode1s, SAND83-2365 (NUREG/CR-3624). Sandia National Laboratories, Albuquerque, NM.

Jones, C.L., 1975. Potash resources in part of Los Medanos area of Eddy and Lea Counties, New Mexico: U.S. Geological Survey Open-File Report 75-407, pp 37.

Jones, C.L., 1973. Salt deposits of Los Medanos area, Eddy and Lea Counties, New Mexico, with sections on Groundwater Hydrology by M.E. Cooley, and Surficial geology by G.O. Bachman: U.S. Geological Survey Open-File Report 73-135, pp 67.

Kelley, V.A. and J.F. Pickens, 1986. Interpretation of the Convergent-Flow Tracer Tests Conducted in the Culebra Dolomite at the H-3 and $\mathrm{H}-4$ Hydropads at the Waste Isolation Pilot Plant (WIPP) Site, SAND86-7161. Sandia Nationa1 Laboratories, Albuquerque, NM.

Lambert, S.J., 1988. "Isotopic Constraints on the Rustler and Dewey Lake Groundwater Systems". M.D. Siege1, S.J. Lambert, and K.L. Robinson, eds., Hydrogeochemical Studies of the Rustler Formation and Related Rocks in the WIPP Area, Southeastern New Mexico, SAND88-0196. Sandia National Laboratories, Albuquerque, NM.

Lambert, S.J., 1987. "Stable-Isotope Studies of Groundwaters in Southeastern New Mexico," SAND85-1978C, Sandia National Laboratories, Albuquerque, NM. In Chaturvedi, L., ed., The Rustler Formation at the WIPP Site, EEG-34. New Mexico Envir. Eval. Group, Santa Fe, NM.

Lambert, S.J., 1983. Dissolution of Evaporites in and around the Delaware Basin, Southeastern New Mexico and West Texas, SAND82-0461. Sandia National Laboratories, Albuquerque, NM.

Lambert, S.J., 1978. "Geochemistry of Delaware Basin Groundwaters," in Geology and Mineral Deposits of Ochoan Rocks in Delaware Basin and Adjacent Areas, NM Bur of Mines and Mineral Resources Circular 159, pp 33-38.

Lambert, S.J., and J.A. Carter, 1987. Uranium-Isotope Systematics in Groundwaters of the Rustler Formation, Northern Delaware Basin, Southeastern New Mexico, SAND87-0388, Sandia National Laboratories, Albuquerque, NM.

Lambert, S.J., and D.M. Harvey, 1987. Stable-Isotope Geochemistry of Groundwater in the Delaware Basin of Southeastern New Mexico, SAND87-0138. Sandia National Laboratories, Albuquerque, NM. 
Lang, W.B., 1938. "Geology of the Pecos River between Laguna Grande de la Sal and Pierce Canyon," in 12 th and 13 th biennial reports, New Mexico State Engineer, pp 80-86.

Lappin, A.R., 1988. Summary of Site-Characterization Studies Conducted from 1983 through 1987 at the Waste Isolation Pilot Plant (WIPP) Site, Southeastern New Mexico, SAND88-0157. Sandia National Laboratories, Albuquerque, NM.

Lappin, A.R., R.L. Hunter, D.P. Garber, P.B. Davies, R.L. Beauheim, D.J . Borns, L.H. Brush, B.M. Butcher, T. Cauffman, M.S.Y. Chu, L.S. Gomez, R.V. Guzowski, H.J. Iuzzolino, V. Kelley, S.J. Lambert, M.G. Marietta, J.W. Mercer, E.J. Nowak, J. Pickens, R.P. Rechard, M. Reeves, K.L. Robinson, and M.D. Siegel, 1989. Systems Analysis, Long-Term Radionuclide Transport, and Dose Assessments, Waste Isolation Pilot Plant (WIPP), Southeastern New Mexico; March 1989, SAND89-0462. Sandia National Laboratories, Albuquerque, NM.

LaVenue, A.M., A. Haug, and V.A. Kelley, 1988. Numerical Simulation of Groundwater Flow in the Culebra Dolomite at the Waste Isolation Pilot Plant (WIPP) Site; Second Interim Report, SAND88-7002. Sandia National Laboratories, Albuquerque, NM.

Mackay, D.M., J.A. Cherry, D.L. Freyberg, G.D. Hopkins, P.L. McCarty, M. Reinhard, and P.V. Roberts, 1985. "Implementation of a Field Experiment on Groundwater Transport of Organic Solutes," in Proceedings of a National Conference on Environmental Engineering, ASCE, U. Colorado, Boulder, CO.

Mackay, M.D., W.J. Conover, and R.J. Beckman, 1979. "A Comparison of Three Methods for Selecting Values of Input Variables in the Analysis of Output From a Computer Code," Technometrics 12(3), pp 591-612.

Marietta, M.G., S.G. Bertram-Howery, D.R. Anderson, K. Brinster, R. Guzowski, H. Iuzzolino, and R.P. Rechard, 1989. Performance Assessment Methodology Demonstration: Methodology Development for Purposes of Evaluating Compliance with EPA 40 CFR Part 191, Subpart B, for the Waste Isolation Pilot Plant, SAND89-2027; Sandia National Laboratories, Albuquerque, NM.

McCarty, P.L., B.E. Rittman, and E.J. Bouwer, 1984. In Groundwater Pollution Microbiology, eds. G. Bitton and C.P. Gerba, Wiley Pub., New York, NY, PP 90-115.

McCormick, N.J., 1981. Reliability and Risk Analysis - Methods and Nuclear Power Applications: Academic Press, New York.

Mercer, J.W., 1987. Compilation of Hydrologic Data from Drilling the Salado and Castile Formations Near the WIPP Site, Southeastern New Mexico, SAND86-0954. Sandia National Laboratories, Albuquerque, NM.

Mercer, J.W., 1983. Geohydrology of the Proposed Waste Isolation Pilot Plant Site, Los Medanos Area, Southeastern New Mexico, U.S. Geological Survey, Water-Resources Investigations Report 83-4016. U.S. Geological Survey, Albuquerque, NM. 
Mercer, J.W., R.L. Beauheim, R.P. Snyder, and G.M. Fairer, 1987. Basic Data Report for Drilling and Hydrologic Testing of Drillhole DOE-2 at the Waste Isolation Pilot Plant (WIPP) Site, SAND86-0611. Sandia National Laboratories, Albuquerque, NM.

Mercer, J.W. and B.R. Orr, 1979. Interim Data Report on Geohydrology of the Proposed Waste Isolation Pilot Plant, Southeast New Mexico, USGS Water Resources Investigation 79-98.

Mercer, J.W. and B.R. Orr, 1977. Review and Analysis of Hydrogeologic Conditions Near the Site of a Potential Nuclear-Waste Repository, Eddy and Lea Counties, New Mexico, USGS Open-File Rpt 77-123.

Moore, R.E., C.F. Baes, L.M. McDowe11-Boyer, A.P. Watson, F.0. Hoffman, J.C. Pleasant, and C.W. Miller, 1979. AIRDOS-EPA: A Computerized Methodology for Estimating Environmental Concentrations and Dose to Man from Airborne Releases of Radionuclides, EPA 520/1-79-009. Reprint of ORNL-5532. Oak Ridge National Laboratories, Oak Ridge, TN.

Napier, B.A., R.A. Peloquin, D.L. Strenge, and J.V. Ramsde11, 1988. GENII The Hanford Environmental Radiation Dosimetry Software System, Volume 1: Conceptual Representation and Volume 2: User's Manual, PNL-6584. Pacific Northwest Laboratory, Richland, WA.

NCRP, 1984. Radiological Assessment: Predicting the Transport, Bioaccumulation, and Uptake by Man of Radionuclides Released to the Environment, National Council on Radiation Protection and Measurements, NCRP Report No. 76. Bethesda, MD.

NEA, 1988. Feasibility of Disposal of High-Level Radioactive Wastes into the Seabed, Volumes 1 - 8, Nuclear Energy Agency of the Organization for Economic and Cooperative Development, Paris.

Nowak, E.J., D.F. McTigue, and R. Beraun, 1988. Brine Inflow to WIPP Disposal Rooms: Data, Modeling, and Assessment, SAND88-0112. Sandia National Laboratories, Albuquerque, NM.

Nowak, E.J., and J.C. Stormont, 1987. Scoping Mode1 Calculations of the Reconsolidation of Crushed Salt in WIPP Shafts, SAND87-0879. Sandia National Laboratories, Albuquerque, NM.

Peterson, E.W., P.L. Lagus, and K. Lie, 1987. Fluid Flow Measurements of Test Series $A$ and $B$ for the Small Scale Seal Performance Tests, SAND87-7041. Sandia National Laboratories, Albuquerque, NM.

Peterson, E.W., P.L. Lagus, J. Brown, and K. Lie, 1985. WIPP Horizon In Situ Permeability Measurements, SAND85-7166. Sandia National Laboratories, Albuquerque, NM.

Pepping, R.E., M.S.Y. Chu, and M.D. Siegel, 1983. "A simplified analysis of a hypothetical repitory in a basalt formation, Volume 2," in Technical

Assistance for Regulatory Development: Review and Evaluation of the Draft EPA Standard 40 CFR 191 for Disposal of High-Level Waste, SAND82-1557, NUREG/CR3235, Sandia National Laboratories, Albuquerque, NM.

$\mathrm{R}-8$ 
Powers, D.W., S.J. Lambert, S.E. Shaffer, L.R. Hill, and W.D. Weart, ed, 1978. Geological Characterization Report, Waste Isolation Pilot Plant (WIPP) Site, Southeastern New Mexico, SAND78-1596 Vol 1 and 2. Sandia National Laboratories, Albuquerque, NM.

Public Law 96-164, 1979, Department of Energy National Security and Military Applications of Nuclear Energy Authorization Act of 1980.

Rautman, C., 1988. Technical Data Base Planning Strategy for the NNWSI Site \& Engineering Properties Data Base, SLTR87-5003. Sandia National Laboratories, Albuquerque, NM.

Rechard, R.P., 1989. Review and Discussion of Code Linkage and Data Flow ir: Nuclear Waste Compliance Assessments, SAND87-2833. Sandia National Laboratories, Albuquerque, NM.

Rechard, R.P., H.J. Iuzzolino, J.S. Rath, R.D. McCurley, and D.K. Rudeen, 1989. User's Manual for CAMCON: Compliance Assessment Methodology Controller, SAND88-1496. Sandia National Laboratories, Albuquerque, NM.

Reeves, M., V.A. Kelley, and J.F. Pickens, 1987. Regional Double-Porosity Solute Transport in the Culebra Dolomite: An Analysis of Parameter Sensitivity and Importance at the Waste Isolation Pilot Plant (WIPP) Site, SAND87-7105. Sandia National Laboratories, Albuquerque, NM.

Reeves, M., D.S. Ward, N.D. Johns, and R.M. Cranwe11, 1986. Theory and Implementataion for SWIFT II, the Sandia Waste-Isolation Flow and Transport Model for Fractured Media, Release 4.84, SAND83-1159 (NUREG/CR-3328). Sandia National Laboratories, Albuquerque, NM.

Roberts, P.V., P.L. McCarty, M. Reinhard, and J. Schreiner, 1980. "Organic Contaminant Behavior During Groundwater Recharge," J. Water Pollution Control, pp $161-172$.

Robinson, T.W., and W.B. Lang, 1938. Geology and Groundwater Conditions of the Pecos River Valley in the Vicinity of Laguna Grande de la Sal, New Mexico, With Special Reference to the Salt Content of the River Water, New Mexico State Engineer 12th-13th Biennial Rpts 1934-1938, pp 77-100.

Sandia National Laboratories, 1988. Sandia National Laboratories Waste Management Technology Department Waste Isolation Pilot Plant Quality Assurance Program Plan, Revision M, WIPP QAPP. Sandia National Laboratories, Albuquerque, NM.

Saulnier, G.J. Jr., 1987. Analysis of Pumping Tests of the Culebra Dolomite Conducted at the H-11 Hydropad at the Waste Isolation Pilot Plant (WIPP) Site, SAND87-7124. Sandia National Laboratories, Albuquerque, NM.

Schwarzenbach, R.P. and J. Westa11, 1981. "Transport of Nonpolar Organic Compounds From Surface Water to Ground Water, Laboratory Sorption Studies," Environmental Science Technology, 15, pp 1360-1367. 
1 Snyder, R.P., 1985. Dissolution of Halite and Gypsum, and Hydration of Anydrite to Gypsum, Rustler Formation, in the Vicinity of the Waste Isolation Pilot Plant, Southeastern New Mexico, Open-File Report 85-229, U.S. Geol. Survey, Denver, CO.

Spiegler, P., 1982. Analysis of the Potential Formation of a Breccia Chimney Beneath the WIPP Repository EEG-13. Environmental Evaluation Group, Environmental Improvement Division, State of New Mexico, Santa Fe, NM.

Stormont, J.C., 1988. Preliminary Seal Design Evaluation for the Waste Isolation Pilot Plant, SAND87-3083. Sandia National Laboratories, Albuquerque, NM.

Stormont, J.C., and J.G. Argue1lo, 1988. Mode1 Calculations of Flow through Shaft Seals in the Rustler Formation, SAND87-2859. Sandia National Laboratories, Albuquerque, NM.

Stormont, J.C., E.W. Peterson, and P.L. Lagus, 1987. Summary of and Observations about WIPP Facility Horizon Flow Measurements through 1986, SAND87-0176. Sandia National Laboratories, Albuquerque, NM.

Taylor, L.M., D.P. Flanagan, and W.C. Mills-Curran, 1987. The GENESIS Finite Element Mesh File Format, SAND86-0910. Sandia National Laboratories, Albuquerque, NM.

Till, J.E. and H.R. Meyer, 1983. Radiological Assessment: A Textbook on Environmental Dose Analysis. NUREG/CR-3332. U.S. Nuclear Regulatory Commission, Washington D.C.

Ti11, J.E., H.R. Meyer, and R.E. Moore, 1987. MICROAIRDOS: User's Manual and Documentation, Radiological Assessment's Corporation, Route 2, Box 122, Neeses, SC.

Tyler, L.D., R.V. Matalucci, M.A. Molecke, D.E. Munson, E.J. Nowak, and J.C. Stormont, 1988. Summary Report for the WIPP Technology Development Program for Isolation of Radioactive Waste, SAND88-0844. Sandia National Laboratories, Albuquerque, NM.

U.S. Department of Energy, 1989a. Draft Plan for the Waste Isolation Pilot Plant Test Phase: Performance Assessment and Operations Demonstration, DOE/WIPP 89-011. Carlsbad, NM.

U.S. Department of Energy, 1989b. Waste Isolation Pilot Plant Compliance Strategy for 40 CFR Part 191, WIPP-DOE-86-013. U.S. Department of Energy, Carlsbad, NM.

U.S. Department of Energy, 1989c. Final WIPP Safety Analysis Report, Waste Isolation Pilot Plant, U.S. Department of Energy, Carlsbad, NM (in preparation).

U.S. Department of Energy, 1989d. Internal Dose Conversion Factors for Calculation of Dose to the Public, DOE/EH-0071. U.S. Department of Energy, Washington D.C. 
U.S. Department of Energy, 1989e. Draft Supplemental Environmental Impact Statement, Waste Isolation Pilot Plant, DOE/EIS-0026-DS, Volume 1 of 2. U.S. Department of Energy, Washington, DC.

U.S. Department of Energy, 1988. Internal Dose Conversion Factors for Calculation of Dose to the Public, DOE/EH-0071. U.S. Department of Energy, Washington, DC.

U.S. Department of Energy, 1987. A Plan for the Implementation of Assurance Requirements in Compliance with 40 CFR Part 191.14 at the Waste Isolation Pilot Plant, DOE/WIPP 87-016. U.S. Department of Energy, Carlsbad, NM.

U.S. Department of Energy, 1985. "Committed Dose Equivalent Tables for the U.S." in Population Dose Calculations, ed. J.P. Corley, Pacific Northwest Laboratory, U.S. Department of Energy/EH, Washington, D.C.

U.S. Department of Energy and State of New Mexico, 1981, as modified. "Agreement for Consultation and Cooperation" on WIPP by the State of New Mexico and U.S. Department of Energy, modified 11/30/84 and 8/4/87.

U.S. Department of Energy, 1980a. Final Environmental Impact Statement: Waste Isolation Pilot Plant, DOE/EIS-0026. U.S. Department of Energy, October 1980.

U.S. Department of Energy, 1980b. WIPP Safety Analysis Report, Waste Isolation Pilot Plant. U.S. Department of Energy, Carlsbad, NM.

U.S. Department of Energy, 1980c. Subject: Radioactive Waste Management. DOE Order 5820.2A, dated September 26, 1988.

U.S. Environmental Protection Agency, 1985. Environmental Standards for the Management and Disposal of Spent Nuclear Fuel, High-Level and Transuranic Radioactive Waste; Final Rule, 40 CFR Part 191, Federal Register, vol. 50, p. $38066-38089$.

U.S. Nuclear Regulatory Commission, 1975. Reactor Safety Study - An Assessment of Accident Risks in U.S. Commercial Nuclear Power Plants: U.S. Nuclear Regulatory Commission Rept. WASH-1400 (NUREG-75/014). Washington D.C.

Vine, J.D., 1963. "Surface Geology of the Nash Draw Quadrangle, Eddy County, New Mexico," USGS Bull 1141-B.

Waste Management Technology Department, 1987. The Scientific Program at the Waste Isolation Pilot Plant, SAND85-1699. Sandia National Laboratories, Albuquerque, NM.

Wenzel, W.J., and A.F. Gallegos, 1985. EFFECTS: Documentation and Verification for a BEIR III Cancer Risk Model Based on Age, Sex, and Population Dynamics for BIOTRAN, LA-10371-MS. Los Alamos National Laboratory, Los Alamos, NM 87545 . 
References

1 Westinghouse Electric Corp., 1989. TRU Waste Acceptance Criteria for the Waste 2 Isolation Pilot Plant. WIPP-DOE-069-Rev.3. Westinghouse Electric Corporation, 3 Carlsbad, NM.

4

5 Williamson, C.R., 1978. Depositional Processes, Diagenesis and Reservoir 6 Properties of Permian Deep-Sea Sandstone, Bell canyon Formation, Ph.D.

7 Dissertation. U. of Texas, Austin, TX. 


\section{GLOSSARY}

Actinide - Any element in the actinium series of elements of increasing atomic numbers beginning with actinium (89) and ending with Lawrencium (103).

Advection - The process of transport of an aqueous property by mass motion.

Alpha Particle - A positively charged particle emitted in the radioactive decay of certain nuclides. Made up of two protons and two neutrons bound together, it is identical to the nucleus of a helium atom. It is the least penetrating of the three common types of radiation - - alpha, beta, and gamma . Anhydrite - A mineral consisting of anhydrous calcium sulfate $\left(\mathrm{CaSO}_{4}\right)$. It is gypsum without water, and is denser, harder, and less soluble.

Anisotropic - Variation in hydraulic conductivity with direction.

Anticline - A fold of rocks, generally convex upward, whose core contains stratigraphically older rocks.

Aperture - The open space along a fracture in rock.

Aquifer - A body of rock that is sufficiently permeable to conduct groundwater and to yield significant quantities of groundwater to wells and springs. The opposite of an aquiclude.

Aquitard - A confining bed that retards but does not prevent the flow of water to or from an adjacent aquifer.

Backfill - Material placed around the waste containers, filling the open space in the room.

Backpressure - Pressure caused by a force operating in a direction opposite to that being considered, such as that of a pore fluid pressure on matrix. 
Glossary

Be11 Canyon Formation - A sequence of rock strata that form the topmost

2 formation of the Delaware Mountain Group.

3

4

5

6

7

8

9

10

Benchmark - To compare predictions made with one code with those obtained with other codes or with analytical solutions. Benchmarking is a part of verification.

Bentonite - A commercial term applied to clay materials containing montmorillonite (smectite) as the essential mineral.

Biodegradable - Possessing the ability of being broken down by microorganisms.

Blosphere - The lift zone of the earth, including the lower part of the atmosphere, the hydrosphere, soil, and the lithosphere to a depth of about 2 $\mathrm{km}(1 \mathrm{mi})$.

Biotransformation - The transformation of chemical compounds within a living system.

Biotransport - Transport of radionuclides over biological pathways, such as through the food chain.

Borehole - (1) A manmade hole in the wall, floor, or ceiling of a subsurface room used for verifying the geology, observation, or the emplacement of waste canisters. The horizontal wall holes are used for remote-handled (RH-TRU) waste. (2) A hole drilled from the surface for purposes of geologic or hydrologic testing, or to explore for resources; sometimes referred to as a drillhole.

Breccia - A rock consisting of very angular, coarse fragments held together by a mineral cement or a fine-grained matrix (as sand or clay).

Brine Aquifer - The Rustler-Salado Residuum; a zone of residual material at the interface of the Rustler and Salado Formations left after dissolution of the original salt. It is highly permeable and contains much brine. 
Brine Inclusion - A small opening in a rock mass (salt) containing brine; also, the brine included in such an opening. Some gas is often present.

Calibrate - To fit and/or tune computational models to simulate observed data.

Caliche - A calcareous material commonly found in layers on or within the surface of stony soils of arid or semi-arid regions. It occurs as gravels, sands, silts, and clays cemented together by calcium carbonate (lime) or as crusts at the surface of the soil.

Canister - A container, usually cylindrical, for remotely handled waste, spent fuel, or high-level waste; affords physical containment but not radiation shielding. Waste remains in its canister during and after burial.

Capitan Reef - A fossilized limestone reef of Permian age that surrounds most of the Delaware Basin.

Cask - A radiation shielded shipping container.

Castile Formation - A formation of evaporite rocks (interbedded halite and anhydrite) of Permian age that immediately underlies the Salado Formation (in which the WIPP disposal level is being built).

C\&C Agreement (Consultation and Cooperation Agreement) - An agreement that affirms the intent of the Secretary of Energy to consult and cooperate with the State of New Mexico with respect to State public health and safety concerns. It is an appendix to a July 1981 agreement (the Stipulated Agreement) made with the State and approved by the District court when that court stayed the proceedings of a lawsuit against the DOE by the State. The C\&C agreement identifies a number of "key events" and "milestones" in the construction and operation of the WIPP that must be reviewed by the state before they are started. The C\&C agreement has been updated and extended as recently as March 1988.

Cenozoic - An era of geologic time from the beginning of the Tertiary period ( -65 million years ago) to the present. 
Glossary

1 CH-TRU Waste - Contact-ㅌandled IRansuranic waste is packaged TRU waste whose

2 external surface dose rate does not exceed 200 mrem per hour.

3

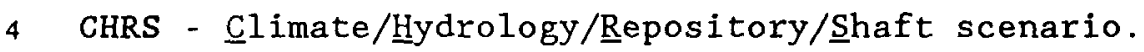

5

Consolidation - Process by which backfill and waste mass loses pore space in response to the increasing weight of overlying material.

Creep - A usually very slow deformation of solid rock resulting from constant stress; refers to the geologic phenomenon experienced as the gradual flow of salt under high compressive loading.

Creep closure - Closure of underground openings, especially openings in salt, by plastic flow of the surrounding rock under pressure. 
1 Cretaceous - Latest period of the Mesozoic Era, between -144 and -65 million

2 years ago.

3

4 Criticality - The state of a mass of fissionable material when it is

5 sustaining a chain reaction.

6

7 Culebra Dolomite Member - The lower of two layers of dolomite within the

8 Rustler Formation that are locally water bearing.

9

Curie - A unit quantity of any radionuclide in which $3.7 \times 10^{10}$

12

Cuttings - Rock chips cut by a bit in the process of drilling a borehole or 14 well.

Delaware Basin - The part of the Permian Basin in southeastern New Mexico and adjacent parts of Texas where a sea deposited large thicknesses of evaporites some 200 million years ago. It is partially surrounded by the Capitan Reef.

Delaware Mountain Group - A set of three formations of Permian age that underlie the Castile Formation at the Los Medaños site.

Depositional - Pertaining to the process of deposition.

Deterministic - Pertaining to an exact mathematical relationship between the dependent and independent variables in a system. 


$$
2
$$

Dewey Lake Red Beds - A formation that overlies the Rustler Formation and is composed of reddish brown marine mudstones and siltstones interbedded with finegrained sandstone.

Diapirism - The process of piercing or rupturing of domed or uplifted rocks by mobile core material by the effect of geostatic load in sedimentary rocks.

Diffusive - Characterized by the transfer of chemical components from a region of higher to one of lower concentration.

Disposal - Emplacement of waste in a manner that assures isolation from the biosphere with no intent of retrieval and that requires deliberate action to regain access to the waste.

Dockum Group - A geologic sedimentary sequence that overlies the Dewey Lake Red Beds over part of the Los Medaños area.

DOE - The U.S. Department of Energy, established in 1978 as a successor to ERDA and the AEC.

Dolomitic - Dolomite-bearing or containing dolomite (usually 5 to 50 percent of the mineral dolomite).

Dose - A general term indicating the amount of energy absorbed per unit mass from incident radiation.

Dose Equivalent - The product of absorbed dose and modifying factors that take into account the biological effect of the absorbed dose. While dose includes only physical factors, dose equivalent includes both physical and biological factors and provides a radiation-protection scale applicable to all types of radiation. Units are rem for individual and person-rem for a population group.

Dosimetry - The measurement of radiation doses.

Drift - A horizontal passageway in a mine. 
Dynamical - A family of solutions to an ordinary differential equation.

2

4

5

6

7

8

9

10

EEG - The Environmental Evaluation Group, an agency of the State of New Mexico

that reviews the safety of the WIPP.

Emplacement - At WIPP, the placing of radioactive wastes within the waste rooms.

EPA - Environmental Protection Agency of the U.S. Government.

Equipotential - Lines connecting points of same potential.

Evaporite - A sedimentary rock composed primarily of minerals produced by precipitation from a solution that has become concentrated by the evaporation of a solvent, especially salts deposited from a restricted or enclosed body of seawater or from the water of a salt lake. In addition to halite ( $\mathrm{NaCl}$ ) these salts include potassium, calcium, and magnesium chlorides and sulfates.

Fissile - Capable of being split along closely spaced planes.

Flowpath - The path traveled by a neutral particle released into a groundwater flow field.

Frequentist - Based on the patterns of recurrence of events or processes exhibited over a period of time.

Geochemical - Pertaining to the study of the distribution and amounts of the chemical elements in minerals, ores, rocks, soils, water, and the atmosphese.

Geology - The study of the earth, the materials of which it is made, the processes that act on these materials, the products formed, and the history of the planet and its life forms since its origin.

Geosphere - The solid portion of the earth as compared to the atmosphere and the hydrosphere. 
Glossary

1 Geohydrology - Referring to the hydrologic or flow characteristics of

2 subsurface waters.

3

Glaciation - The formation, movement, and recession of glaciers or ice sheets.

5

6 Glauberite - A brittle, light-colored, monoclinic mineral: $\mathrm{Na}_{2} \mathrm{Ca}\left(\mathrm{SO}_{4}\right) 2$. It

7 has a vitreous luster and saline taste and occurs in saline residues.

8

9 Grout - A cement slurry of high water content.

10

Halite - A dominant mineral in evaporites; salt, $\mathrm{NaCl}$.

14

Halogenated - Atoms from the halogen family of elements combined with other atoms such as carbon.

HEPA Filter - A $\underline{H} i g h$ Efficiency Particulate Air filter usually capable of $99.97 \%$ efficiency as measured by a standard photometric test using a $0.3 \mu \mathrm{m}$ droplets (aerodynamic equivalent diameter) of DOP.

Holocene - An epoch of the Quaternary period from the end of the Pleistocene epoch $(-8,000$ years ago $)$ to the present.

Horizon (geol) - An interface indicative of a particular position in a stratigraphic sequence. An underground level; for instance, the wasteemplacement horizon at the WIPP is the level about $650 \mathrm{~m}(2,150 \mathrm{ft})$ deep in the Salado Formation where openings are mined for waste disposal.

Hot Cell - A heavily shielded compartment in which highly radioactive material can be handled, generally by remote control.

HUMINT - HUMan INTrusion scenario.

Hydraulic - Pertaining to a fluid in motion. 
Hydraulic Gradient - A quantity defined in the study of groundwater hydraulics that describes the rate of change of total head per unit distance of flow in a given direction.

Hydrogeology - The science dealing with subsurface waters and with related geologic aspects of surface waters.

Hydrology - The science that deals with global water, its properties, circulation, and distribution.

Hydropad - A complex of hydro-wells closely spaced in order to perform tests on hydrostratigraphic units.

Hydrophobic - Lacking an affinity for, repelling, or failing to adsorb or absorb water.

Hydrostratigraphic - Pertaining to a body of rock having considerable lateral extent and composing a geologic framework for a reasonably distinct hydrologic system.

In situ - In the natural or original position; used to distinguish in-place experiments, rock properties, and so on, from those in the laboratory.

Interbedded - Pertaining to sedimentary beds lying between or alternating with other beds with different characteristics.

Interfinger - The disappearance of sedimentary bodies in laterally adjacent masses owing to splitting into many thin layers, each reaching an independent pinch out.

Interpolators - Computer codes used to estimate an intermediate value of one (dependent) variable which is a function of a second variable.

Intracrystalline - Pertaining to something within a mineral crystal. 
Glossary

$$
3
$$

Isopach - A line drawn on a map through points of equal true thickness of a designated stratigraphic unit or group of stratigraphic units.

Isotherm - A line on a map connecting points of equal temperature.

Isotope - A species of atom characterized by the number of protons and the number of neutrons in its nucleus. In most instances an element can exist as any of several isotopes, differing in the number of neutrons, but not the number of protons, in their nuclei. Isotopes can be either stable isotopes or radioactive isotopes (also called radioisotopes or radionuclides).

Isotropic - Hydraulic conductivities of a porous media independent of direction of measurement.

Iterative - A computational procedure in which replication of a cycle of operations produces results which approximate the desired result more and more closely.

Karst - A topography formed over limestone, dolomite, or gypsum; characterized by sinkholes, caves, and underground drainage.

Karstification - The formation of karst features by the solutional and mechanical action of water.

Lenticular - Resembling in shape the cross-section of a lens, esp. of a double-convex lens. The term may be applied to a body of rock or a sedimentary structure.

Lithologic - Pertaining to the description of rocks.

Lithosphere - The solid portion of the earth as opposed to the atmosphere and the hydrosphere. Same as geosphere.

Lithostatic Pressure - Subsurface pressure caused by the weight of overlying rock or soil. 
Los Medaños - Literally "the dunes." The area in which the WIPP is located.

Mesozoic - The era of geologic time from 245 million years ago to -65 million years ago.

Meta - A prefix for benzene-ring compounds when two side chains are connected to carbon atoms with an unsubstituted carbon atom between them.

Microbiology - A branch of biology dealing especially with microscopic forms of life.

Microcrystalline - Crystals too small to see with the naked eye.

Microdarcy - A unit of permeability $\left(1,000,000^{\text {th }}\right.$ of a Darcy).

Microfracturing - The formation of fractures that cannot be detected with the unaided eye.

Microwave - A comparatively short electromagnetic wave between 100 centimeters and 1 centimeter in wavelength.

Modular - Constructed with standardized units or dimensions for flexibility and variety in use.

Monte Carlo Sampling - A random sampling technique using computer simulation to obtain approximate solutions to mathematical or physical problems, especially in terms of a range of values each of which has a calculated probability of being the solution.

Mrem - Millirem.

Multipad - See hydropad.

Multipath - The propagation phenomenon that results in signals reaching a radio receiving antenna by two or more paths, causing distortion in radio and ghost images in television. 
Glossary

1 Nash Draw - A shallow 5-mile-wide valley open to the southwest located to the

2 west of the WIPP site.

3

NRC - Nuclear Regulatory Commission of the U.S. Government.

Neoprene - A synthetic rubber made by the polymerization of chloroprene.

Noncombustibles - Materials that will not burn.

Nonpolar - Not having or requiring the presence of electrical poles.

Nuclide - A species of atom characterized by the construction of its nucleus.

Organics - Compounds containing carbon.

Overexcavation - Excavation of the disturbed rock zone prior to emplacement of a seal.

Overpack (waste) - A container put around another container. In the WIPP, overpacks would be used on damaged or otherwise contaminated drums, boxes, and canisters that it would not be practical to decontaminate.

Particulate - of or relating to minute separate particles.

Pecos River - Major surface hydrological feature in eastern New Mexico.

Pennsylvanian - Second to the last Paleozoic period ( -320 million to $\sim 280$ million years ago).

Performance Assessment - An analysis that identifies the processes and events that might affect the disposal system; examines the effects of these processes and events on the performance of the disposal system; and estimates the cumulative releases of radionuclides, considering the associated uncertainties caused by all significant procedures and events. 
1 Permeability - A measurement of the ability of a rock or soil to transmit

2 fluid under hydraulic gradient.

3

4

5

6

7

Pillar - Rock left in place after mining to provide underground vertical

support.

Pintle - A cylindrical flanged device on the end of an RH-TRU waste canister used for grasping and lifting the canister.

Plutonium - A reactive metallic element, symbol $\mathrm{Pu}$, atomic number 94, in the transuranium series of elements; used as a nuclear fuel, to produce radioactive nuclides for research, and as a fissile agent in nuclear weapons.

Pluvial - Of a geologic episode, change, deposit, process, or feature resulting from the action or effects of rain.

Polyethylene - Various partially crystalline lightweight thermo-plastics made from ethylene.

Polyhalite - An evaporite mineral: $\mathrm{K}_{2} \mathrm{MgCa}_{2}\left(\mathrm{SO}_{4}\right)_{4} \cdot 2 \mathrm{H}_{2} \mathrm{O}$; a hard, poorly soluble mineral.

Polypropylene - A plastic made from propylene.

Polyvinyl - A plastic made from vinyl chloride.

Potash - Specifically $\mathrm{K}_{2} \mathrm{CO}_{3}$. Also loosely used for many potassium compounds, especially as used in agriculture or industry.

Potential - A function or set of functions of position in space, from whose first derivatives a vector can be formed, such as that of a static field intensity.

Potentiometric Surface - An imaginary surface representing the total head of groundwater and defined by the level to which water will rise in a well. 
Glossary

16

Predictive - Estimates of future states of a system.

Probabilistic - Using the probability of a given set of events from a family of outcomes.

Quality Assurance - All those planned and systematic actions necessary to provide adequate confidence that a structure, system, or component will perform satisfactorily in service.

Quaternary - The second period of the Cenozoic era, following the Tertiary, starting 1.6 million years ago and continuing to the present; the corresponding system of rocks.

Radioactivity - The emission of energetic particles and/or radiation during radioactive decay.

Radioactive Waste - Solid, liquid, or gaseous material of negligible economic value that contains radionuclides in excess of threshold quantities.

Radiological - Pertaining to nuclear radiation and radioactivity.

Radiolysis - The damage to a material caused by radiation.

Radionuclide - A radioactive nuclide.

Reentrants - A prominent, generally angular indentation in a land form.

Rem - Roentgen Equivalent Man.

RH-TRU Waste - Remote-Handled TRansUranic waste. Packaged TRU waste whose external surface dose rate exceeds 200 mrem per hour, but not greater than 1,000 rem per hour.

Rustler Formation - A sequence of upper Permian age elastic and evaporite sedimentary rocks that contains two dolomite marker beds, and overlies the Salado Formation. 
1 Salado Formation - A sequence of -200-million yr old salt with minot amounts 2 of clay and anhydrite. Location of the WIPP repository.

3$$
4
$$

Scenario - A combination of events and processes that represents a possible

future state of the repository, geologic, and groundwater systems.

Sealing - Formation of barriers within man-made penetrations (shafts, drillholes, tunnels, drifts).

Sedimentation - The action or process of forming or depositing sediment.

Shaft - A man-made hole, either vertical or steeply inclined, that connects the surface with the underground workings of a mine.

Sinkhole - A hollow in a limestone region that communicates with a cavern or passage.

Sludge - A muddy or slushy mass, deposit, or sediment.

Solute - The material dissolved in a solvent.

Sorb - To take up and hold by either adsorption or absorption.

Source term - The kinds and amounts of radionuclides that make up the source of a potential release of radioactivity. For the performance assessment, the source term is defined as the sum of the quantities of the important radionuclides in the WIPP inventory that will be mobilized for possible transport to the accessible environment, and the rates at which these radionuclides will be mobilized.

Standard - 40 CFR Part 191

Stationarity - A stochastic process is said to be stationary if its set of associated pdfs are invariant under arbitrary time translators. 
Glossary

1 Stochastic Process - Involving a random variable or random vector synonymous

2 with random function or random process.

3

4 Storativity - The volume of water released by an aquifer per unit surface area

5 per unit drop in hydrologic head.

6

Surfactant - A surface active substance.

Syncline - A fold having stratigraphically younger rock material in its core; it is usually concave upward.

Thermodynamic - Pertaining to the relation of heat to mechanical and other forms of energy.

Topographic - Pertaining to the configuration of a land surface, including its relief and the position of its natural and man-made features.

Transiency - Ability to affect something or produce results beyond itself.

Translator - A code that translates output from one code to input for another code. Also referred to as pre- and post-processors.

Transmissivity - The rate at which water of the prevailing kinematic viscosity is transmitted through a unit width of the aquifer under a unit hydraulic gradient.

Triassic - The first period of the Mesozoic era, lying above the Permian and below Jurassic, -208 to -245 million years ago. 
1 TRU Waste - TRansUranic Waste. Without regard to source or form, waste that

2 is contaminated with alpha-emitting transuranium radionuclides with half-1ives

3 greater than 20 years and concentrations greater than $100 \mathrm{nCi} / \mathrm{g}$ at the time of

4 assay. Heads of field organizations can determine that other alpha

5 contaminated wastes, peculiar to a specific site, must be managed as TRU

6 waste.

7

8 Unconformably - Not conformable, i.e., a break in deposition of sedimentary

9 material.

10

11 UND - UNDisturbed scenario.

Unsaturated - A11 the pores in rock or soil are not full of water.

15 Validate - To establish confidence that the model (and the associated computer 16 code) correctly simulates the appropriate physical and chemical phenomena.

17 Validation is accomplished through either laboratory or in situ experiments, 18 as appropriate.

Verification - The process of assuring that a computer code (computational model) correctly performs the operation specified in a numerical model. Each computational model must be verified and the verification documented.

24 Benchmarking is a verification method that compares the results produced by one computational model against results produced by other computational models that solve similar problems. 


\section{APPENDIX A: \\ TITLE 40, CODE OF FEDERAL REGULATIONS, SUBCHAPTER F, PART 191}




\section{APPENDIX A}

\section{TITLE 40, CODE OF FEDERAL REGULATIONS SUBCHAPTER F-RADIATION PROTECTION PROGRAMS \\ PART 191-ENVIRONMENTAL RADIATION PROTECTION STANDARDS FOR MANAGEMENT AND DISPOSAL OF SPENT NUCLEAR FUEL, HIGH-LEVEL AND TRANSURANIC RADIOACTIVE WASTES}

Subpart A-Environmental Standajds for Management and Storage

Sec.

191.01 Applicability.

191.02 Definitions.

191.03 Standards.

191.04 Alternative standards.

191.05 Effective date.

Subpart B-Environmental Standards for Disposal

191.11 App1icability.

191.12 Definitions.

191.13 Containment requirements.

191.14 Assurance requirements.

191.15 Individual protection requirements.

191.16 Ground water protection requirements.

191.17 Alternative provisions for disposal.

191.18 Effective date.

Appendix A Table for Subpart B

Appendix B Guidance for Implementation of Subpart B

Authority: The Atomic Energy Act of 1954, as amended; Reorganization Plan No. 3 of 1970; and the Nuclear Waste Policy Act of 1982.

Subpart A-Environmental Standards for Management and Storage

\section{$\S 191.01$ Applicability.}

This Subpart applies to:

(a) Radiation doses received by members of the public as a result of the management (except for transportation) and storage of spent nuclear fuel or high-level or transuranic radioactive wastes at any facility regulated by the Nuclear Regulatory Commission or by Agreement States, to the extent that such management and storage operations are not subject to the provisions of Part 190 of title 40; and

(b) Radiation doses received by members of the public as a result of the management and storage of spent nuclear fuel or high-level or transuranic wastes at any disposal facility that is operated by the Department of Energy and that is not regulated by the Commission or by Agreement States. 


\section{$\S 191.02$ Definitions.}

Unless otherwise indicated in this Subpart, all terms shall have the same meaning as in Subpart A of Part 190.

(a) "Agency" means the Environmental Protection Agency.

(b) "Administrator" means the Administrator of the Environmental Protection Agency.

(c) "Commission" means the Nuclear Regulatory Commission.

(d) "Department" means the Department of Energy.

(e) "NWPA" means the Nuclear Waste Policy Act of 1982 (Pub. L. 97-425).

(f) "Agreement State" means any State with which the Commission or the Atomic Energy Commission has entered into an effective agreement under subsection 274b of the Atomic Energy Act of 1954, as amended (68 Stat. 919).

(g) "Spent nuclear fuel" means fuel that has been withdrawn from a nuclear reactor following irradiation, the constituent elements of which have not been separated by reprocessing.

(h) "High-level radioactive waste," as used in this Part, means highlevel radioactive waste as defined in the Nuclear Waste Policy Act of 1982 (Pub. L. 97-425).

(i) "Transuranic radioactive waste," as used in this Part, means waste containing more than 100 nanocuries of alpha-emitting transuranic isotopes, with half-lives greater than twenty years, per gram of waste, except for: (1) High-level radioactive wastes; (2) wastes that the Department has determined, with the concurrence of the Administrator, do not need the degree of isolation required by this Part; or (3) wastes that the Commission has approved for disposal on a case-by-case basis in accordance with $10 \mathrm{CFR}$ Part 61 .

(j) "Radioactive waste," as used in this Part, means the high-level and transuranic radioactive waste covered by this Part.

(k) "Storage" means retention of spent nuclear fuel or radioactive wastes with the intent and capability to readily retrieve such fuel or waste for subsequent use, processing, or disposal.

(1) "Disposal" means permanent isolation of spent nuclear fuel or radioactive wastes from the accessible environment with no intent of recovery, whether or not such isolation permits the recovery of such fuel or waste. For example, disposal of waste in a mined geologic repository occurs when all of the shafts to the repository are backfilled and sealed.

(m) "Management" means any activity, operation, or process (except for transportation) conducted to prepare spent nuclear fuel or radioactive waste for storage or disposal, or the activities associated with placing such fuel or waste in a disposal system. 
(n) "Site" means an area contained within the boundary of a location under the effective control of persons possessing or using spent nuclear fuel or radioactive waste that are involved in any activity, operation, or process covered by this Subpart.

(o) "General environment" means the total terrestrial, atmospheric, and aquatic environments outside sites within which any activity, operation, or: process associated with the management and storage of spent nuclear fuel or: radioactive waste is conducted.

(p) "Member of the public" means any individual except during the time when that individual is a worker engaged in any activity, operation, or process that is covered by the Atomic Energy Act of 1954, as amended.

(q) "Critical organ" means the most exposed human organ or tissue exclusive of the integumentary system (skin) and the cornea.

\section{$\S 191.03$ Standards.}

(a) Management and storage of spent nuclear fuel or high-level or transuranic radioactive wastes at all facilities regulated by the Commissicn or by Agreement States shall be conducted in such a manner as to provide reasonable assurance that the combined annual dose equivalent to any member: of the public in the general environment resulting from: (1) Discharges of radioactive material and direct radiation from such management and storage and (2) all operations covered by Part 190; shall not exceed 25 millirems to the whole body, 75 millirems to the thyroid, and 25 millirems to any other critical organ.

(b) Management and storage of spent nuclear fuel or high-level or transuranic radioactive wastes at all facilities for the disposal of such fuel or waste that are operated by the Department and that are not regulated by the Commission or Agreement States shall be conducted in such a manner as to provide reasonable assurance that the combined annual dose equivalent to any member of the public in the general environment resulting from discharges of radioactive material and direct radiation from such management and storage shall not exceed 25 millirems to the whole body and 75 millirems to any critical organ.

\section{$\S 191.04$ Alternative standards.}

(a) The Administrator may issue alternative standards from those standards established in 191.03 (b) for waste management and storage activities at facilities that are not regulated by the Commission or Agreement States if, upon review of an application for such alternative standards :

(1) The Administrator determines that such alternative standards will prevent any member of the public from receiving a continuous exposure of more than 100 millirems per year dose equivalent and an infrequent exposure of more than 500 millirems dose equivalent in a year from all sources, excluding natural background and medical procedures; and 
(2) The Administrator promptly makes a matter of public record the degree to which continued operation of the facility is expected to result in levels in excess of the standards specified in 191.03(b).

(b) An application for alternative standards shall be submitted as soon as possible after the Department determines that continued operation of a facility will exceed the levels specified in 191.03 (b) and shall include all information necessary for the Administrator to make the determinations called for in 191.04(a).

(c) Requests for alternative standards shall be submitted to the Administrator, U.S. Environmental Protection Agency, 401 M Street, SW., Washington, DC 20460.

\section{$\S 191.05$ Effective date.}

The standards in this Subpart shall be effective on November 18, 1985.

\section{Subpart B-Environmental Standards for Disposal}

\section{$\S 191.11$ App1icability.}

(a) This Subpart applies to:

(1) Radioactive materials released into the accessible environment as a result of the disposal of spent nuclear fuel or high-level or transuranic radioactive wastes;

(2) Radiation doses received by members of the public as a result of such disposal; and

(3) Radioactive contamination of certain sources of ground water in the vicinity of disposal systems for such fuel or wastes.

(b) However, this Subpart does not apply to disposal directly into the oceans or ocean sediments. This Subpart also does not apply to wastes disposed of before the effective date of this rule.

\section{$\S 191.12$ Definitions.}

Unless otherwise indicated in this Subpart, all terms shall have the same meaning as in Subpart $A$ of this Part.

(a) "Disposal system" means any combination of engineered and natural barriers that isolate spent nuclear fuel or radioactive waste after disposal.

(b) "Waste," as used in this Subpart, means any spent nuclear fuel or radioactive waste isolated in a disposal system.

(c) "Waste form" means the materials comprising the radioactive components of waste and any encapsulating or stabilizing matrix.

(d) "Barrier" means any material or structure that prevents or substantially delays movement of water or radionuclides toward the accessible environment. For example, a barrier may be a geologic structure, 
a canister, a waste form with physical and chemical characteristics that significantly decrease the mobility of radionuclides, or a material placed over and around waste, provided that the material or structure substantially delays movement of water or radionuclides.

(e) "Passive institutional control" means: (1) Permanent markers placed at a disposal site, (2) public records and archives, (3) government ownership and regulations regarding land or resource use, and (4) other methods of preserving knowledge about the location, design, and contents of a disposal system.

(f) "Active institutional control" means: (1) Controlling access to a disposal site by any means other than passive institutional controls; (2) performing maintenance operations or remedial actions at a site, (3) controlling or cleaning up releases from a site, or (4) monitoring parameters related to disposal system performance.

(g) "Controlled area" means: (1) A surface location, to be identified by passive institutional controls, that encompasses no more than 100 square kilometers and extends horizontally no more than five kilometers in any direction from the outer boundary of the original location of the radioactive wastes in a disposal system; and (2) the subsurface underlying such a surface location.

(h) "Ground water" means water below the land surface in a zone of saturation.

(i) "Aquifer" means an underground geological formation, group of formations, or part of a formation that is capable of yielding a significant amount of water to a well or spring.

(j) "Lithosphere" means the solid part of the Earth below the surface, including any ground water contained within it.

(k) "Accessible environment" means: (1) The atmosphere; (2) 1and surfaces: (3) surface waters; (4) oceans; and (5) all of the lithosphere that is beyond the controlled area.

(1) "Transmissivity" means the hydraulic conductivity integrated over the saturated thickness of an underground formation. The transmissivity of a series of formations is the sum of the individual transmissivities of each formation comprising the series.

(m) "Community water system" means a system for the provision to the public of piped water for human consumption, if such system has at least 15 service connections used by year-round residents or regularly serves at least 25 year-round residents.

(n) "Significant source of ground water," as used in this Part, means: (1) An aquifer that: (i) Is saturated with water having less than 10,000 milligrams per liter of total dissolved solids; (ii) is within 2,500 feet of the land surface; (iii) has a transmissivity greater than 200 gallons per day per foot, provided that any formation or part of a formation included within the source of ground water has a hydraulic conductivity greater than 
2 gallons per day per square foot; and (iv) is capable of continuously yielding at least 10,000 gallons per day to a pumped or flowing well for a period of at least a year; or (2) an aquifer that provides the primary source of water for a community water system as of the effective date of this Subpart.

(o) "Special source of ground water," as used in this Part, means those Class I ground waters identified in accordance with the Agency's GroundWater Protection Strategy published in August 1984 that: (1) Are within the controlled area encompassing a disposal system or are less than five kilometers beyond the controlled area; (2) are supplying drinking water for thousands of persons as of the date that the Department chooses a location within that area for detailed characterization as a potential site for a disposal system (e.g., in accordance with Section $112(\mathrm{~b})(1)(B)$ of the NWPA); and (3) are irreplaceable in that no reasonable alternative source of drinking water is available to that population.

(p) "Undisturbed performance" means the predicted behavior of a disposal system, including consideration of the uncertainties in predicted behavior, if the disposal system is not disrupted by human intrusion or the occurrence of unlikely natural events.

(q) "Performance assessment" means an analysis that: (1) Identifies the processes and events that might affect the disposal system; (2) examines the effects of these processes and events on the performance of the disposal system; and ( 3 ) estimates the cumulative releases of radionuclides, considering the associated uncertainties, caused by all significant processes and events. These estimates shall be incorporated into an overall probability distribution of cumulative release to the extent practicable.

(r) "Heavy metal" means all uranium, plutonium, or thorium placed into a nuclear reactor.

(s) "Implementing agency," as used in this Subpart, means the Commission for spent nuclear fuel or high-level or transuranic wastes to be disposed of in facilities licensed by the commission in accordance with the Energy Reorganization Act of 1974 and the Nuclear Waste Policy Act of 1982, and it means the Department for all other radioactive wastes covered by this Part.

\section{$\S 191.13$ Containment requirements.}

(a) Disposal systems for spent nuclear fuel or high-level or transuranic radioactive wastes shall be designed to provide a reasonable expectation, based upon performance assessments, that cumulative releases of radionuclides to the accessible environment for 10,000 years after disposal from all significant processes and events that may affect the disposal system shall:

(1) Have a likelihood of less than one chance in 10 of exceeding the quantities calculated according to Table 1 (Appendix A); and

(2) Have a likelihood of less than one chance in 1,000 of exceeding ten times the quantities calculated according to Table 1 (Appendix A). 
(b) Performance assessments need not provide complete assurance that the requirements of 191.13(a) will be met. Because of the long time period involved and the nature of the events and processes of interest, there will inevitably be substantial uncertainties in projecting disposal system performance. Proof of the future performance of a disposal system is not to be had in the ordinary sense of the word in situations that deal with much shorter time frames. Instead, what is required is a reasonable expectation, on the basis of the record before the implementing agency, that compliance with 191.13(a) will be achieved.

\section{$\S 191.14$ Assurance requirements.}

To provide the confidence needed for long-term compliance with the requirements of 191.13, disposal of spent nuclear fuel or high-level or transuranic wastes shall be conducted in accordance with the following provisions, except that these provisions do not apply to facilities regulated by the Commission (see 10 CFR Part 60 for comparable provisions applicable to facilities regulated by the Commission):

(a) Active institutional controls over disposal sites should be maintained for as long a period of time as is practicable after disposal; however, performance assessments that assess isolation of the wastes from the accessible environment shall. not consider any contributions from active institutional controls for more than 100 years after disposal.

(b) Disposal systems shall be monitored after disposal to detect substantial and detrimental deviations from expected performance. This monitoring shall be done with techniques that do not jeopardize the isolation of the wastes and shall be conducted until there are no significant concerns to be addressed by further monitoring.

(c) Disposal sites shall be designated by the most permanent markers, records, and other passive institutional controls practicable to indicate the dangers of the wastes and their location.

(d) Disposal systems shall use different types of barriers to isolate the wastes from the accessible environment. Both engineered and natural barriers shall be included.

(e) Places where there has been mining for resources, or where there is a reasonable expectation of exploration for scarce or easily accessible resources, or where there is a significant concentration of any material that is not widely available from other sources, should be avoided in selecting disposal sites. Resources to be considered shall include minerals, petroleum or natural gas, valuable geologic formations, and ground waters that are either irreplaceable because there is no reasonable alternative source of drinking water available for substantial populations or that are vital to the preservation of unique and sensitive ecosystems. Such places shall not be used for disposal of the wastes covered by this Part unless the favorable characteristics of such places compensate for their greater likelihood of being disturbed in the future.

(f) Disposal systems shall be selected so that removal of most of the wastes is not precluded for a reasonable period of time after disposal. 


\section{$\S 191.15$ Individual protection requirements.}

Disposal systems for spent nuclear fuel or high-level or transuranic radioactive wastes shall be designed to provide a reasonable expectation that, for 1,000 years after disposal, undisturbed performance of the disposal system shall not cause the annual dose equivalent from the disposal system to any member of the public in the accessible environment to exceed 25 millirems to the whole body or 75 millirems to any critical organ. All potential pathways (associated with undisturbed performance) from the disposal system to people shall be considered, including the assumption that individuals consume 2 liters per day of drinking water from any significant source of ground water outside of the controlled area.

\section{$\S 191.16$ Ground water protection requirements .}

(a) Disposal systems for spent nuclear fuel or high-level or transuranic radioactive wastes shall be designed to provide a reasonable expectation that, for 1,000 years after disposal, undisturbed performance of the disposal system shall not cause the radionuclide concentrations averaged over any year in water withdrawn from any portion of a special source of ground water to exceed:

(1) 5 picocuries per 1 iter of radium-226 and radium-228;

(2) 15 picocuries per liter of alpha-emitting radionuclides (including radium-226 and radium-228 but excluding radon); or

(3) The combined concentrations of radionuclides that emit either beta or gamma radiation that would produce an annual dose equivalent to the total body or any internal organ greater than 4 millirems per year if an individual consumed 2 liters per day of drinking water from such a source of ground water.

(b) If any of the average annual radionuclide concentrations existing in a special source of ground water before construction of the disposal system already exceed the limits in 191.16(a), the disposal system shall be designed to provide a reasonable expectation that, for 1,000 years after disposal, undisturbed performance of the disposal system shall not increase the existing average annual radionuclide concentrations in water withdrawn from that special source of ground water by more than the limits established in $191.16(\mathrm{a})$.

\section{$\S 191.17$ Alternative provisions for disposal.}

The Administrator may, by rule, substitute for any of the provisions of Subpart $B$ alternative provisions chosen after:

(a) The alternative provisions have been proposed for public comment in the Federal Register together with information describing the costs, risks, and benefits of disposal in accordance with the alternative provisions and the reasons why compliance with the existing provisions of subpart $B$ appears inappropriate;

(b) A public comment period of at least 90 days has been completed, during which an opportunity for public hearings in affected areas of the country has been provided; and 
(c) The public comments received have been fully considered in developing the final version of such alternative provisions.

\section{$\S 191.18$ Effective date.}

The standards in this Subpart shall be effective on November 18, 1985. Appendix A-Table for Subpart B

TABLE 1.-RELEASE LIMITS FOR CONTAINMENT REQUIREMENTS

(Cumulative releases to the accessible environment for 10,000 years after disposal)

\begin{tabular}{|c|c|}
\hline Radionuclide & $\begin{array}{c}\text { Release } \\
\text { limit per } \\
1,000 \\
\text { MTHM or } \\
\text { other unit } \\
\text { of waste } \\
\text { (see } \\
\text { notes) } \\
\text { (curies) }\end{array}$ \\
\hline 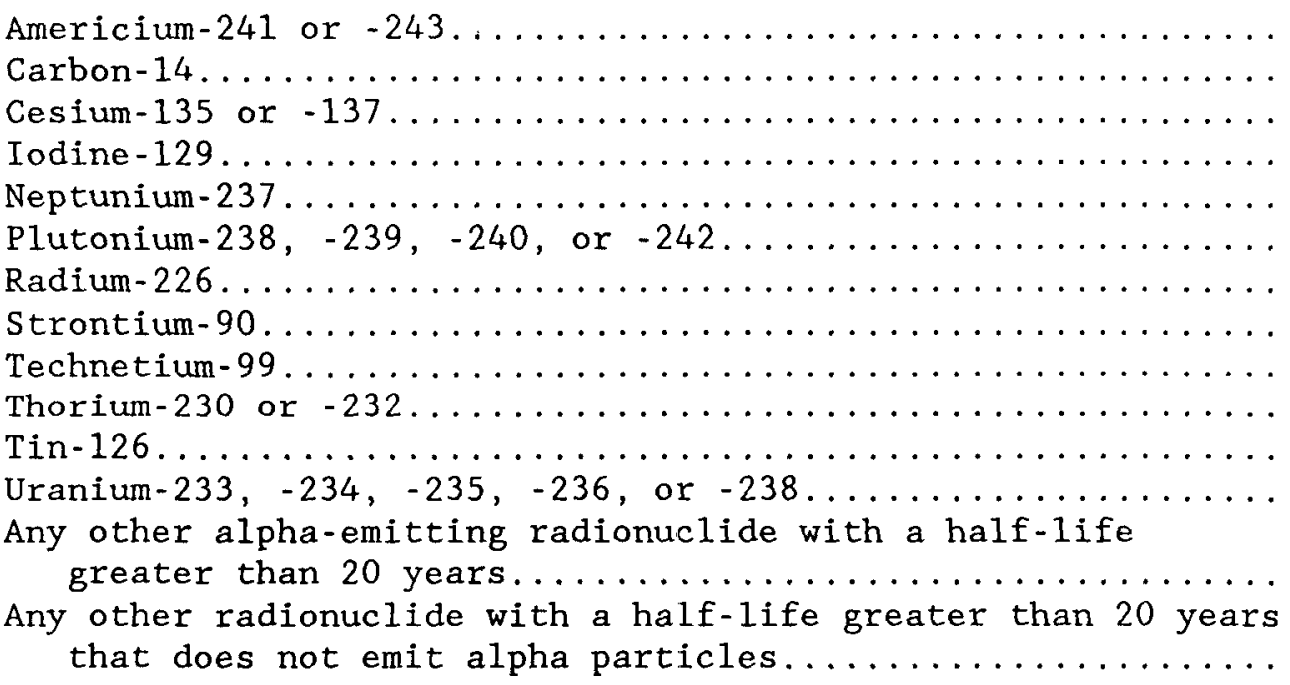 & $\begin{array}{r}100 \\
100 \\
1,000 \\
100 \\
100 \\
100 \\
100 \\
1,000 \\
10,000 \\
10 \\
1,000 \\
100 \\
100 \\
1,000\end{array}$ \\
\hline
\end{tabular}

Application of Table 1

Note 1: Units of Waste. The Release Limits in Table 1 apply to the amount of wastes in any one of the following:

(a) An amount of spent nuclear fuel containing 1,000 metric tons of heavy metal (MTHM) exposed to a burnup between 25,000 megawatt-days per metric ton of heavy metal (MWd/MTHM) and 40,000 MWd/MTHM; 
(b) The high-level radioactive wastes generated from reprocessing each 1,000 MTHM exposed to a burnup between 25,000 MWd/MTHM and 40,000 MWd/MTHM;

(c) Each 100,000,000 curies of gamma or beta-emitting radionuclides with half-lives greater than 20 years but less than 100 years (for use as discussed in Note 5 or with materials that are identified by the Commission as highlevel radioactive waste in accordance with part $B$ of the definition of highlevel waste in the NWPA);

(d) Each 1,000,000 curies of other radionuclides (i.e., gamma or betaemitters with half-lives greater than 100 years or any alpha-emitters with half-lives greater than 20 years) (for use as discussed in Note 5 or with materials that are identified by the Commission as high-level radioactive waste in accordance with part $B$ of the definition of high-level waste in the NWPA); or

(e) An amount of transuranic (TRU) wastes containing one million curies of alpha-emitting transuranic radionuclides with half-lives greater than 20 years.

Note 2: Release Limits for Specific Disposal Systems. To develop Release Limits for a particular disposal system, the quantities in Table 1 shall be adjusted for the amount of waste included in the disposal system compared to the various units of waste defined in Note 1 . For example:

(a) If a particular disposal system contained the high-level wastes from 50,000 MTHM, the Release Limits for that system would be the quantities in Table 1 multiplied by 50 (50,000 MTHM divided by 1,000 MTHM).

(b) If a particular disposal system contained three million curies of alpha-emitting transuranic wastes, the Release Limits for that system would be the quantities in Table 1 multiplied by three (three million curies divided by one million curies).

(c) If a particular disposal system contained both the high-level wastes from 50,000 MTHM and 5 million curies of alpha-emitting transuranic wastes, the Release Limits for that system would be the quantities in Table 1 multiplied by 55 :

$$
\frac{50,000 \text { MTHM }}{1,000 \text { MTHM }}+\frac{5,000,000 \text { curies TRU }}{1,000,000 \text { curies TRU }}=55
$$

Note 3: Adjustments for Reactor Fuels with Different Burnup. For disposal systems containing reactor fuels (or the high-level wastes from reactor fuels) exposed to an average burnup of less than 25,000 MWd/MTHM or greater than 40,000 MWd/MTHM, the units of waste defined in (a) and (b) of Note 1 shall be adjusted. The unit shall be multiplied by the ratio of $30,000 \mathrm{MWd} / \mathrm{MTHM}$ divided by the fuel's actual average burnup, except that a value of 5,000 MWd/MTHM may be used when the average fuel burnup is below 5,000 MWd/MTHM and a value of $100,000 \mathrm{MWd} / \mathrm{MTHM}$ shall be used when the average fuel burnup is above 100,000 MWd/MTHM. This adjusted unit of waste shall then be used in determining the Release Limits for the disposal system. 
For example, if a particular disposal system contained only high-level wastes with an average burnup of 3,000 MWd/MTHM, the unit of waste for that disposal system would be:

$$
1,000 \mathrm{MTHM} \times \frac{(30,000)}{(5,000)}=6,000 \mathrm{MTHM}
$$

If that disposal system contained the high-level wastes from 60,000 MTHM (with an average burnup of 3,000 MWd/MTHM), then the Release Limits for that system would be the quantities in Table 1 multiplied by ten:

$$
\frac{60,000 \mathrm{MTHM}}{6,000 \mathrm{MTHM}}=10
$$

which is the same as:

$$
\frac{60,000 \mathrm{MTHM}}{1,000 \mathrm{MTHM}} \times \frac{(5,000 \mathrm{MWd} / \mathrm{MTHM})}{(30,000 \mathrm{MWd} / \mathrm{MTHM})}=10
$$

Note 4: Treatment of Fractionated High-Level Wastes. In some cases, a highlevel waste stream from reprocessing spent nuclear fuel may have been (or will be) separated into two or more high-level waste components destined for different disposal systems. In such cases, the implementing agency may allocate the Release Limit multiplier (based upon the original MTHM and the average fuel burnup of the high-level waste stream) among the various disposal systems as it chooses, provided that the total Release Limit multiplier used for that waste stream at all of its disposal systems may not exceed the Release Limit multiplier that would be used if the entire waste stream were disposed of in one disposal system.

Note 5: Treatment of Wastes with Poorly Known Burnups or Original MTHM. In some cases, the records associated with particular high-level waste streams may not be adequate to accurately determine the original metric tons of heavy metal in the reactor fuel that created the waste, or to determine the average burnup that the fuel was exposed to. If the uncertainties are such that the original amount of heavy metal or the average fuel burnup for particular highlevel waste streams cannot be quantified, the units of waste derived from (a) and (b) of Note 1 shall no longer be used. Instead, the units of waste defined in (c) and (d) of Note 1 shall be used for such high-level waste streams. If the uncertainties in such information allow a range of values to be associated with the original amount of heavy metal or the average fuel burnup, then the calculations described in previous Notes will be conducted using the values that result in the smallest Release Limits, except that the Release Limits need not be smaller than those that would be calculated using the units of waste defined in (c) and (d) of Note 1.

Note 6: Uses of Release Limits to Determine Compliance with 191.13. Once release limits for a particular disposal system have been determined in accordance with Notes 1 through 5 , these release 1 imits shall be used to determine compliance with the requirements of 191.13 as follows. In cases where a mixture of radionuclides is projected to be released to the accessible environment, the limiting values shall be determined as follows: For each radionuclide in the mixture, determine the ratio between the cumulative release quantity projected over 10,000 years and the limit for that 
radionuclide as determined from Table 1 and Notes 1 through 5 . The sum of such ratios for all the radionuclides in the mixture may not exceed one with regard to $191.13(a)(1)$ and may not exceed ten with regard to $191.13(a)(2)$.

For example, if radionuclides $A, B$, and $C$ are projected to be released in amounts $Q_{a}, Q_{b}$, and $Q_{c}$, and if the applicable Release Limits are $R L_{a}, R L_{b}$, $R L_{c}$, then the cumulative releases over 10,000 years shall be limited so that the following relationship exists:

$$
\frac{\mathrm{Q}_{a}}{\mathrm{RL}_{\mathrm{a}}}+\frac{\mathrm{Q}_{\mathrm{b}}}{\mathrm{RL}_{\mathrm{b}}}+\frac{\mathrm{Q}_{\mathrm{c}}}{\mathrm{RL}_{\mathrm{c}}}<1
$$

\section{Appendix B-Guldance for Implementation of Subpart B}

[Note: The supplemental information in this appendix is not an integral part of $40 \mathrm{CFR}$ Part 191. Therefore, the implementing agencies are not bound to follow this guidance. However, it is included because it describes the Agency's assumptions regarding the implementation of Subpart B. This appendix will appear in the Code of Federal Regulations.]

The Agency believes that the implementing agencies must determine compliance with $\S \S 191.13,191.15$, and 191.16 of Subpart B by evaluating long-term predictions of disposal system performance. Determining compliance with $\S$ 191.13 will also involve predicting the likelihood of events and processes that may disturb the disposal system. In making these various predictions, it will be appropriate for the implementing agencies to make use of rather complex computational models, analytical theories, and prevalent expert judgment relevant to the numerical predictions. Substantial uncertainties are likely to be encountered in making these predictions. In fact, sole reliance on these numerical predictions to determine compliance may not be appropriate; the implementing agencies may choose to supplement such predictions with qualitative judgments as well. Because the procedures for determining compliance with Subpart B have not been formulated and tested yet, this appendix to the rule indicates the Agency's assumptions regarding certain issues that may arise when implementing $\S \S 191.13,191.15$, and 191.16. Most of this guidance applies to any type of disposal system for the wastes covered by this rule. However, several sections apply only to disposal in mined geologic repositories and would be inappropriate for other types of disposal systems.

Consideration of Total Disposal System. When predicting disposal system performance, the Agency assumes that reasonable projections of the protection expected from all of the engineered and natural barriers of a disposal system will be considered. Portions of the disposal system should not be disregarded, even if projected performance is uncertain, except for portions of the system that make negligible contributions to the overall isolation provided by the disposal system.

Scope of Performance Assessments. Section 191.13 requires the implementing agencies to evaluate compliance through performance assessments as defined in $\S 191.12(q)$. The Agency assumes that such performance assessments need not consider categories of events or processes that are estimated to have less than one chance in 10,000 of occurring over 10,000 years. Furthermore, the 
performance assessments need not evaluate in detail the releases from all events and processes estimated to have a greater likelihood of occurrence. Some of these events and processes may be omitted from the performance assessments if there is a reasonable expectation that the remaining probability distribution of cumulative releases would not be significantly changed by such omissions.

Compliance with Section 191.13. The Agency assumes that, whenever practicable, the implementing agency will assemble all of the results of the performance assessments to determine compliance with $\S 191.13$ into a "complementary cumulative distribution function" that indicates the probability of exceeding various levels of cumulative release. When the uncertainties in parameters are considered in a performance assessment, the effects of the uncertainties considered can be incorporated into a single such distribution function for each disposal system considered. The Agency assumes that a disposal system can be considered to be in compliance with $\S 191.13$ if this single distribution function meets the requirements of $\S 191.13(a)$.

Compliance with Sections 191.15 and 191.16. When the uncertainties in undisturbed performance of a disposal system are considered, the implementing agencies need not require that a very large percentage of the range of estimated radiation exposures or radionuclide concentrations fall below limits established in $\S \S 191.15$ and 191.16, respectively. The Agency assumes that compliance can be determined based upon "best estimate" predictions (e.g., the mean or the median of the appropriate distribution, whichever is higher).

Institutional Controls. To comply with $\S 191.14(\mathrm{a})$, the implementing agency will assume that none of the active institutional controls prevent or reduce radionuclide releases for more than 100 years after disposal. However, the Federal Government is committed to retaining ownership of all disposal sites for spent nuclear fuel and high-level and transuranic radioactive wastes and will establish appropriate markers and records, consistent with $\S 191.14(\mathrm{c})$. The Agency assumes that, as long as such passive institutional controls endure and are understood, they: (1) can be effective in deterring systematic or persistent exploitation of these disposal sites; and (2) can reduce the likelihood of inadvertent, intermittent human intrusion to a degree to be determined by the implementing agency. However, the Agency believes that passive institutional controls can never be assumed to eliminate the chance of inadvertent and intermittent human intrusion into these disposal sites.

Consideration of Inadvertent Human Intrusion into Geologic Repositories. The most speculative potential disruptions of a mined geologic repository are those associated with inadvertent human intrusion. Some types of intrusion would have virtually no effect on a repository's containment of waste. On the other hand, it is possible to conceive of intrusions (involving widespread societal loss of knowledge regarding radioactive wastes) that could result in major disruptions that no reasonable repository selection or design precautions could alleviate. The Agency believes that the most productive consideration of inadvertent intrusion concerns those realistic possibilities that may be usefully mitigated by repository design, site selection, or use of passive controls (although passive institutional controls should not be assumed to completely rule out the possibility of intrusion). Therefore, 
inadvertent and intermittent intrusion by exploratory drilling for resources (other than any provided by the disposal system itself) can be the most severe intrusion scenario assumed by the implementing agencies. Furthermore, the implementing agencies can assume that passive institutional controls or the intruders' own exploratory procedures are adequate for the intruders to soon detect, or be warned of, the incompatibility of the area with their activities.

Frequency and Severity of Inadvertent Human Intrusion into Geologic Repositories. The implementing agencies should consider the effects of each particular disposal system's site, design, and passive institutional controls in judging the likelihood and consequences of such inadvertent exploratory drilling. However, the Agency assumes that the likelihood of such inadvertent and intermittent drilling need not be taken to be greater than 30 boreholes per square kilometer of repository area per 10,000 years for geologic repositories in proximity to sedimentary rock formations, or more than 3 boreholes per square kilometer per 10,000 years for repositories in other geologic formations. Furthermore, the Agency assumes that the consequences of such inadvertent drilling need not be assumed to be more severe than: Direct release to the land surface of all the ground water in the repository horizon that would promptly flow through the newly created borehole to the surface due to natural lithostatic pressure-or (if pumping would be required to raise water to the surface) release of 200 cubic meters of ground water pumped to the surface if that much water is readily available to be pumped; and (2) creation of ground water flow path with a permeability typical of a borehole filled by the soil or gravel that would normally settle into an open hole over time-not the permeability of a carefully sealed borehole. 
APPENDIX B:

REFERENCE DATA BASE 


\section{APPENDIX C: \\ RESPONSE TO REVIEW COMMENTS}




\section{DISTRIBUTION LIST}

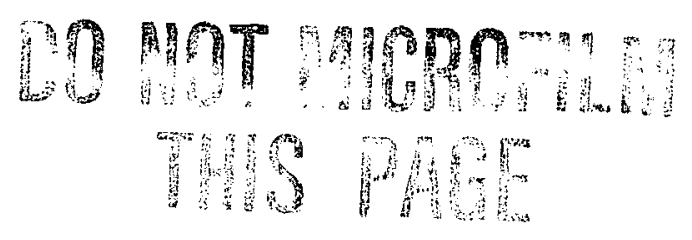


U. S. Department of Energy (5)

Office of Defense Waste and

Transportation Management

Attn: J. E. Lytle -.... DP-10

L. D. Tyler ..... DP-10

T. B. Hindman -... DP -12

M. Duff ….... DP -123

A. Follett ..... DP -122

C. H. George ..... DP-124

J. Mathur …... DP-123

Forrestal Bldg.

1000 Independence Ave.

Washington, DC 20545

U. S. Department of Energy (8)

Albuquerque Operations Office

Attn: Bruce G. Twining

J. E. Bickel

R. Marquez

K. A. Griffith

M. Wilson

D. Krenz

G. Runkle

C. Soden

P.O. Box 5400

Albuquerque, NM 87185-5400

U. S. Department of Energy (12)

WIPP Project Office (Carlsbad)

Attn: J. Arthur (4)

A. Hunt

T. Lukow (2)

V. Daub

$K$. Hunter

M. McFadden

P. O. Box 3090

Carlsbad, NM 88221-3090

U.S. Department of Energy (2)

Deputy Assistant Secretary for

Environment, EH-20

Attn: Raymond P. Berube John Tseng

1000 Independence Ave. SW

Washington, D.C. 20585
U. S. Department of Energy, (5)

Office of Civilian Radioactive Waste Management

Attn: Deputy Director, RW-2

Associate Director, RW-10

Office of Program

Administration and

Resources Management

Associate Director, RW-20

office of Facilities

Siting and

Development

Associate Director, RW-30

office of Systems

Integration and

Regulations

Associate Director, RW-40

Office of External

Relations and Policy

Office of Geologic Repositories

Forrestal Building

Washington, DC 20585

U. S. Department of Energy

Attn: National Atomic Museum Library Albuquerque Operations office

P. 0. Box 5400

Albuquerque, NM 87185

U. S. Department of Energy

Research \& Waste Management Division

Attn: W. R. Bibb, Director

P. O. Box E

Oak Ridge, TN 37831

U. S. Department of Energy

Idaho Operations office

Fuel Processing and Waste

Management Division

Attn: J. E. Solecki

785 DOE Place

Idaho Falls, ID 83402

U.S. Department of Energy (3)

Savannah River Operations office

Defense Waste Processing

Facility Project Office

Attn: S. Cowan

W. J. Brumley

M. G. O'Rear

P.O. Box A

Aiken, SC 29802

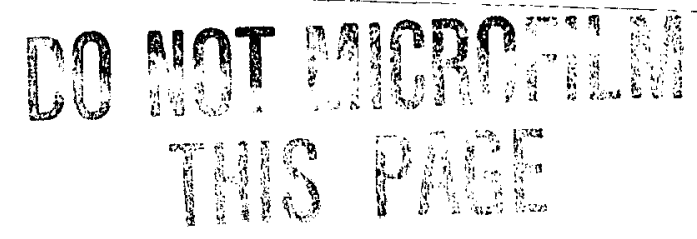


U.S. Department of Energy

Attn: Marvin Furman

R. E. Gerton

Richland Operations office 825 Jadwin Ave.

P.0. Box 550

Richland, WA 99352

U.S. Department of Energy

Nevada Operations office

Attn: J. R. Boland

D. Livingston

P. K. Fitzsimmons

2753 S. Highland Drive

Las Vegas, NV 87183-8518

U.S. Department of Energy (2)

Technical Information Center

P.O. Box 62

Oak Ridge, TN 37831

U.S. Department of Energy (2)

Chicago Operations Office

Attn: J. C. Haugen

David Dashavsky

9800 South Cass Avenue

Argonne, IL 60439

U.S. Department of Energy (2)

Los Alamos Area Office

Attn: J. D. Tillman

528 35th Street

Los Alamos, NM 87544

U.S. Department of Energy (3)

Rocky Flats Area Office

Attn: W. C. Rask

$\mathrm{T}$. Anderson

P.O.Box 928

Golden, CO 80402-0928

U.S. Department of Energy

Dayton Area Office

Attn: R. Grandfield

P.O.Box 66

Maimisburg, OH 45343-0066
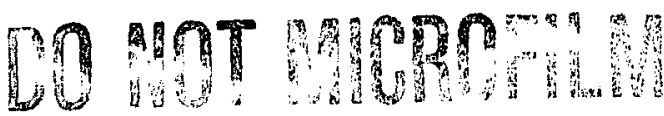

THS PAEE

Dist - 2
Charlie Armstrong, WIPP Panel

Secretary

National Research Council

Board on Radioactive Waste Management

HA462

2101 Constitution Avenue

Washington, DC 20418

U.S. Environmental Protection Agency (5)

Office of Radiation Protection Programs (ANR-460)

Attn: Daniel J. Egan, Jr.

Washington, D.C. 20460

Bureau of Land Management

101 E. Mermod

Carlsbad, NM 88220

Bureau of Land Management

New Mexico State Office

P.O. Box 1449

Santa Fe, NM 87507

U.S. Geological Survey

Branch of Regional Geology

Attn: R. Snyder

MS913, Box 25046

Denver Federal Center

Denver, CO 80225

U.S. Geological Survey

Conservation Division

Attn: W. Melton

P.O. Box 1857

Roswe11, NM 88201

U.S. Geological Survey (2)

Water Resources Division

Attn: Cathy Peters

Suite 200

4501 Indian School, NE

Albuquerque, NM 87110

U.S. Nuclear Regulatory Commission (4)

Division of Waste Management

Attn: Michael Bell

Hubart Miller

Jacob Philip

NRC Library

Mail Stop 623SS

Washington, DC 20555 
Distribution (Continued):

Environmental Evaluation Group (5)

Attn: Robert Neill

Suite F-2

7007 Wyoming Blvd., N.E.

Albuquerque, NM 87109

New Mexico Bureau of Mines

and Mineral Resources (2)

Attn: F. E. Kottolowski, Director

J. Hawley

Socorro, NM 87801

NM Department of Energy \& Minerals Attn: Kasey LaPlante, Librarian

P.O. Box 2770

Santa Fe, NM 87501

Bob Forrest

Mayor, City of Carlsbad

P.O. Box 1569

Carlsbad, NM 88221

Chuck Bernard

Executive Director

Carlsbad Department of Development

P.O. Box 1090

Carlsbad, NM 88221

Tom Bahr (2)

Chairman, Radioactive Waste Consultation Task Force

408 Galisteo

Santa Fe, NM 87503

Robert M. Hawk (2)

Chairman, Hazardous and Radioactive Materials Committee

Room 334

State Capitol

Sante Fe, NM 87503

Kirkland Jones (2)

Department Director

New Mexico Environmental Improvement Division

P.O. Box 968

1190 St. Francis Drive

Santa Fe, NM 87503-0968
Battelle Pacific Northwest

Laboratories (6)

Attn: D. J. Bradley

J. Relyea

R. E. Westerman

S. Bates

H. C. Burkholder

L. Pederson

Battelle Boulevard

Richland, WA 99352

Savannah River Laboratory (6)

Attn: N. Bibler

E. L. Albenisius

M. J. Plodinec

G. G. Wicks

C. Jantzen

J. A. Stone

Aiken, SC 29801

Savannah River Plant (2)

Attn: Richard G. Baxter

Building 704-S

K. W. Wierzbicki

Building 703-H

Aiken, SC 29808-0001

Los Alamos National Laboratory (2)

Attn: B. Erdal, CNC-11

Attn: J. L. Warren, HSE - 7, MS-ES16

P.O. Box 1663

Los Alamos, NM 87545

Los Alamos National Laboratories (3)

HSE - 8

Attn: M. Enoris

L. Soholt

J. Wenze1

P.O. Box 1663

Los Alamos, NM 87544

Oak Ridge National Laboratory (4)

Attn: R. E. Blanko

E. Bondietti

C. Claiborne

G. H. Jenks

Box Y

Oak Ridge, TN 37830

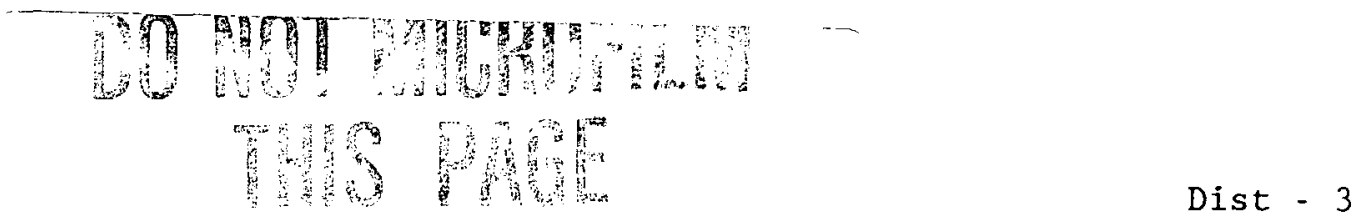


Distribution (Continued):

Lawrence Livermore National Laboratory

Attn: G. Mackanic

P.0. Box 808, MS L-192

Livermore, CA 94550

Martin Marietta Systems, Inc.

Oak Ridge National Labs

Attn: J. Setaro

P.O. Box 2008, B1dg. 3047

Oak Ridge, TN 37831-6019

Argonne National Labs

Attn: A. Smith

9700 South Cass, Bldg. 201

Argonne, IL 60439

INTERA Technologies, Inc. (4)

Attn: G. E. Grisak

J. F. Pickens

A. Haug

A. M. LeVenue

Suite \#300

6850 Austin Center Blvd.

Austin, TX 78731

INTERA Technologies, Inc.

Attn: Wayne Stensrud

P.O. Box 2123

Carlsbad, NM 88221

IT Corporation

Attn: R. F. McKinney (2)

Regional office - Suite 700

5301 Central Avenue, NE

Albuquerque, NM 87108

IT Corporation

R. J . Eastmond

$825 \mathrm{Jadwin}$ Ave.

Richland, WA 99352

IT Corporation

Attn: D. E. Dea1

P.O. Box 2078

Carlsbad, NM 88221

RE/SPEC, Inc. (2)

Attn: W. Coons

P. F. Gnirk

P.O. Box 14984

Albuquerque NM 87191

Dist - 4
RE/SPEC, Inc. (7)

Attn: L. L. Van Sambeek

D. B. Blankenship

G. Callahan

T. Pfeifle

J. L. Ratigan

P. O. Box 725

Rapid City, SD 57709

Reynolds Elect/Engr. Co., Inc. Building 790, Warehouse Row

Attn: E. W. Kendall

P.O. Box 98521

Las Vegas, NV 89193-8521

Rockwell International (2)

Attn: C. E. Wickland

D. Reinhart

Rocky Flats Plant

Golden, CO 80401

Rockwe11 International (3)

Atomics International Division

Rockwell Hanford Operations

Attn: J. Nelson (HWVP)

P. Salter

W. W. Schultz

P.O. Box 800

Richland, WA 99352

Science Applications

International Corporation

Attn: Howard R. Pratt, Senior Vice President

10260 Campus Point Drive

San Diego, CA 92121

Science Applications

International Corporation

Attn: Michael B. Gross Ass't. Vice President

Suite 1250

160 Spear Street

San Francisco, CA 94105

Science Applications

International Corporation

George Dymme1

101 Convention Center Dr.

Las Vegas, NV 89109
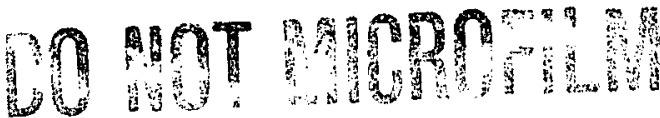

THS PHE 
Distribution (Continued):

Science Applications

International Corporation

Attn: J. Sandha

W. Beyeler

J. Schreiber

2109 Air Park Road, SE

Albuquerque, NM 87106

Systems, Science, and Software (2)

Attn: E. Peterson

$P$. Lagus

Box 1620

La Jolla, CA 92038

Westinghouse Electric Corporation (9)

Attn: Library

L. Trega

W. P. Poirer

W. R. Chiquelin

V. F. Likar

D. J. Moak

R. F. Kehrman

T. Campbe11

T. Miller

T. Halverson

P. O. Box 2078

Carlsbad, NM 88221

$E G \& G$ Idaho (3)

1955 Fremont Street

Attn: C. Atwood

C. Hertzler

T. I. Clements

Idaho Falls, ID 83415

New Mexico Engineering Research

Institute (6)

Attn: J. Bean
A. Schreyer
R. McCurley
D. Morrison
J. Rath
D. Rudeen

P.O. Box 25

University Station

Albuquerque, New Mexico 87131

Geo-Centers, Inc.

Attn: H. J. Iuzzolino

2201 Buena Vista Dr., SE

Suite 300

Albuquerque, New Mexico 87106
Charles R. Hadlock

Arthur D. Little, Inc.

Acorn Park

Cambridge, MA 02140-2390

Kathleen Hain

BDM Corporation

7519 Jones Branch Drive

McLean, VA 22101

Bill Kennedy

Pacific Northwest Laboratory

Batte1le Blvd.

P.O. Box 999

Richland, WA 99352

Don Wood

Westinghouse Hanford Company

P.0. Box 1970

Richland, WA 99352

K. Owens

Westinghouse/Hanford

2401 Stevens Road

Richland, WA 99352

R. Blauvelt

Monsanto Research Corp.

Mound Road

Miamisburg, OH 45432

University of Arizona

Attn: J. G. McCray

Department of Nuclear Engineering

Tucson, AZ 85721

University of New Mexico (2)

Geology Department

Attn: D. G. Brookins

Library

Albuquerque, NM 87131

Pennsylvania State University

Materials Research Laboratory

Attn: Della Roy

University Park, PA 16802

Texas A\&M University

Center of Tectonophysics

College Station, TX 77840 
Distribution (Continued):

Mechanical, Aerospace, and

Nuclear Engineering Department (2)

Attn: W. Kastenberg

D. Browne

5532 Boelter Hall

University of California

Los Angeles, CA 90024

Thomas Brannigan Library

Attn: Don Dresp, Head Librarian

$106 \mathrm{~W}$. Hadley St.

Las Cruces, NM 88001

Hobbs Public Library

Attn: Marcia Lewis, Librarian

509 N. Ship Street

Hobbs, NM 88248

New Mexico State Library

Attn: Ingrid Vollenhofer

P.0. Box 1629

Santa Fe, NM 87503

New Mexico Tech

Martin Speere Memorial Library

Campus Street

Socorro, NM 87810

Pannel1 Library

Attn: Ruth Hill

New Mexico Junior College

Lovington Highway

Hobbs, NM 88240

Roswell Public Library

Attn: Nancy Langston

301 N. Pennsylvania Avenue

Roswe11, NM 88201

WIPP Public Reading Room

Attn: Lee Hubbard, Head Librarian

Carlsbad Municipal Library

$101 \mathrm{~S}$. Halagueno St.

Carlsbad, NM 88220

Government Publications Department

General Library

University of New Mexico

Albuquerque, NM 87131
Charles Fairhurst, Chairman

Department of Civil and

Mineral Engineering

University of Minnesota

500 Pillsbury Dr. SE

Minneapolis, MN 55455

John 0. Blomeke

Route 3

Sandy Shore Drive

Lenoir City, TN 37771

John D. Bredehoeft

Western Region Hydrologist

Water Resources Division

U.S. Geological Survey (M/S 439)

345 Middlefield Road

Menlo Park, CA 94025

Kar1 P. Cohen

928 N. California Avenue

Palo Alto, CA 94303

Fred M. Ernsberger

250 01d Mill Road

Pittsburgh, PA 15238

Rodney C. Ewing

Department of Geology

University of New Mexico

200 Yale, NE

Albuquerque, NM 87131

George M. Hornberger

Department of Environmental Science

Clark Hall

University of Virginia

Charlottesville, VA 22903

Frank L. Parker

Department of Environmental

Engineering

Vanderbilt University

Nashville, TN 37235

D'Arcy A. Shock

233 Virginia

Ponca City, OK 74601

Dist - 6

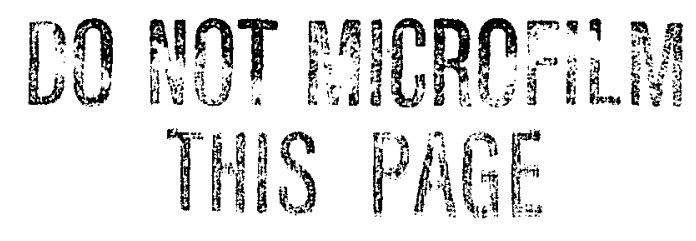


Distribution (Continued):

Peter B. Myers, Staff

Director (3)

National Research Council

Committee on Radioactive

Waste Management

2101 Constitution Avenue

Washington, DC 20418

Ina Alterman

Board on Radioactive Waste Management

GF462

2101 Constitution Avenue

Washington, D. C. 20418

G. Ross Heath

College of Ocean

and Fishery Sciences

University of Washington

Seattle, WA 98195

Thomas H. Pigford

Department of Nuclear Engineering

4153 Etcheverry Hall

University of California

Berkeley, CA 94270

Patrick A. Domenico

Geology Department

Texas A \& M

College Station, TX 77843-3115

Neville Cook

Rock Mechanics Engineering

Mine Engineering Dept.

University of California

Berkeley, CA 94270

Thomas A. Cotton

4429 Butterworth Place, NW

Washington, DC 20016

Robert J. Budnitz

President, Future Resources

Associates Inc.

2000 Center Street

Suite 418

Berkeley, CA 94704
C. John Mann

Department of Geology

245 Natural History Bldg.

1301 West Green Street

University of Illinois

Urbana, IL 61801

Charles D. Hollister

Dean for Studies

Woods Hole Oceanographic

Institute

Woods Hole, MA 02543

Benjamin Ross

Disposal Safety, Inc.

Suite 600

1629 K Street NW

Washington, D.C. 20006

Christopher Wipple

Electric Power Research Institute

3412 Hillview Avenue

Palo Alto, CA 94303

Tech. Reps., Inc. (2)

5000 Marble NE

Suite 222

Albuquerque, NM 87110

Attn: D. Medina

J. Stikar

Studiecentrum Voor Kernenergie (1)

Centre D'Energie Nucleaire

Attn: A. Bonne

SCK/CEN

Boeretang 200

B-2400 Mol

BELGIUM

Atomic Energy of Canada, Ltd.

Whiteshell Research Estab.

Attn: Peter Haywood

John Tait

Pinewa, Manitoba, CANADA

ROE 1LO

D. K. Mukerjee

Ontario Hydro Research Lab

800 Kipling Avenue

Toronto, Ontario, CANADA

M8Z 554 
Distribution (Continued):

Jean-Pierre Olivier

OECD Nuclear Energy Agency

Division of Radiation Protection and Waste Management

38, Boulevard Suchet

75016 Paris, FRANCE

Claude Sombret

Centre D'Etudes Nucleaires

De La Vallee Rhone

CEN/VALRHO

S.D.H.A. BP 171

30205 Bagnols-Sur-Ceze

FRANCE

Bundesministerium fur Forschung und Technologie

Postfach 200706

5300 Bonn 2

FEDERAL REPUBLIC OF GERMANY

Bundesanstalt fur Geowissenschaften und Rohstoffe

Attn: Michae1 Langer

Postfach 510153

3000 Hannover 51

FEDERAL REPUBLIC OF GERMANY

Hahn-Mietner-Institut fur

Kernforschung (1)

Attn: Werner Lutze

Glienicker Strasse 100

100 Berlin 39

FEDERAL REPUBLIC OF GERMANY

Institut fur Tieflagerung (4)

Attn: K. Kuhn

Theodor-Heuss-Strasse 4

D-3300 Braunschweig

FEDERAL REPUPLIC OF GERMANY

Kernforschug Karlsruhe (1)

Attn: K. D. Closs

Postfach 3640

7500 Karlsruhe

FEDERAL REPUBLIC OF GERMANY

Physikalisch-Technische Bundesanstalt

Attn: Peter Brenneke

Postfach 3345

D-3300 Braunschweig

FEDERAL REPUBLIC OF GERMANY
D. R. Knowles

British Nuclear Fuels, plc

Risley, Warrington, Cheshire WA3 6AS

1002607 GREAT BRITAIN

Shingo Tashiro

Japan Atomic Energy Research

Institute

Tokai-Mura, Ibaraki-Ken

319-11 JAPAN

Netherlands Energy Research

Foundation

ECN (2)

Attn: Tuen Deboer, Mgr.

L. H. Vons

3 Westerduinweg

P.0. Box 1

1755 ZG Petten, THE NETHERLANDS

Svensk Karnbransleforsorjning $A B$

Attn: Fred Karlsson

Project KBS

Karnbrans lesakerhet

Box 5864

10248 Stockholm, SWEDEN 
Internal Distribution:

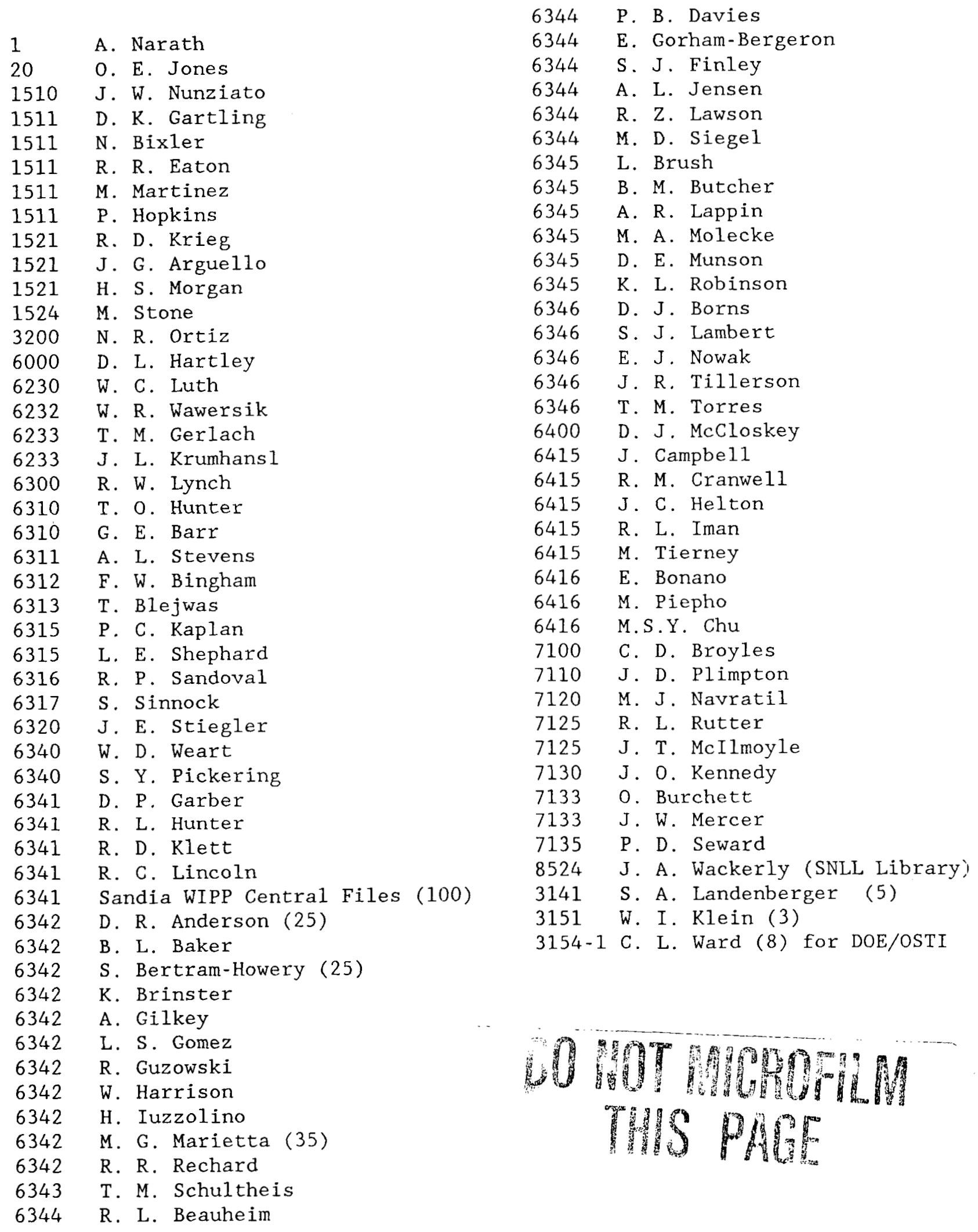

